\title{
ROBOTIC COMPANIONSHIP
}

\author{
THE MAKING OF ANTHROPOMATIC KITCHEN ROBOTS \\ IN QUEER FEMINIST TECHNOSCIENCE PERSPECTIVE
}

\author{
Pat Treusch
}

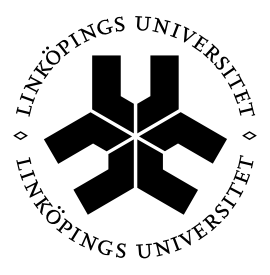

\section{Linköping University}

Linköping Studies in Arts and Science No. 649

Linköping University, Department of Thematic Studies - Gender Studies Linköping 2015 
At the Faculty of Arts and Science at Linköping University, research and doctoral studies are carried out within broad problem areas. Research is organized in interdisciplinary research environments and doctoral studies mainly in graduate schools. Jointly, they publish the series Linköping Studies in Arts and Science. This binational thesis comes from Tema Genus - the Department of Thematic Studies - Gender Studies and the ZIFG - Center for Interdisciplinary Women's and Gender Studies - Technical University Berlin.

Distributed by:

TEMA - the Department of Thematic Studies

Linköpings universitet

58183 Linköping

Sweden

Pat Treusch

Robotic Companionship: The Making of Anthropomatic Kitchen Robots in Queer Feminist Technoscience Perspective

Coinciding with Dissertation manuscript submitted to Berlin, Technical University (TU Berlin), 2014, with the title Making Robots Domestic. A Queer Feminist Cartography of Anthropomatic Kitchen Robotics

Published in accordance with the Cotutelle Agreement between TU Berlin and Linköping University.

Edition 1:1

ISBN 978-91-7519-039-6

ISSN 0282-9800

(C) Pat Treusch

TEMA - the Department of Thematic Studies and ZIFG - Center for

Interdisciplinary Women's and Gender Studies, 2015

Printed by LiU-Tryck, Linköping, 2015

Cover design by Pat Treusch and Rainer Hänsel 




\section{Contents}

Acknowledgements ....................................................................................................

1. Robot Companions: Machines to Work and Live with?.................................13

1.1. Introduction: Toward an Inventory of the Robot Companion

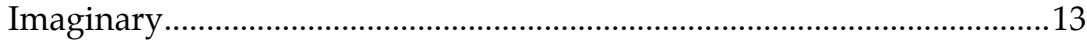

1.2. Aim and Research Questions..................................................................17

1.3. Methodology: A Methodological-Theoretical Framework ......................23

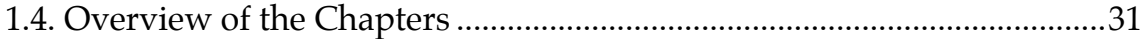

2. Historical Dimensions of Modern Automation Technologies......................35

2.1. Automata in the Household: The Coming of the Machine in

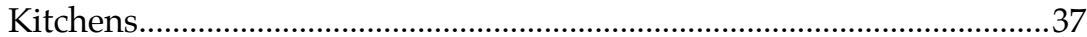

2.2. Configurations of Early AI: Primacy of Cognition ..................................47

2.3. Human-Machine Interfaces - A Historical Framework ..........................57

3. The Anthropoid in Public: Introducing Human-Machine Relations

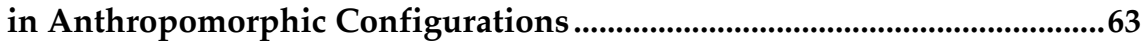

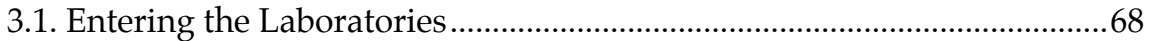

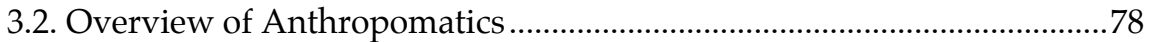

3.3. Human-Machine in the Loop: Configuring Anthropomorphism ........... 90

3.4. Conclusions: Human-Machine Relations of Anthropo-Alikeness ........100

\section{Mapping Human-Machine Relations during Demonstrations:}

Performing the Kitchen in the Robotic Laboratory.

4.1. Demonstrations: The Theatre of Use and Theatre of Proof of Armar .109

4.2. A Selection of Interactional Sequences: Anthropoid-Human Bodies-in-Interaction

4.3. Conclusions: Demonstrations as Performing the Kitchen 
5. Body Modeling in the Anthropomatic Kitchen .......................................149

5.1. The Active Head - Modeling Human-like Vision ...................................152

5.2. Modeling the Upper Body of the Human-like Robot .............................160

5.3. The 'Whole-Body Model' - Patterns of Modeling the

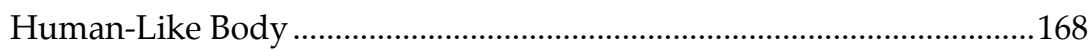

5.4. Conclusions: Modeling the Robot Companion - Configuring the Human-Like Body in Parts in the Kitchen.............................................175

6. Bringing Bodies into Motion in the Anthropomatic Kitchen ....................179

6.1. Current Embodiments of the Enabled Anthropoid................................183

6.2. Equipping the Robot with Vision as a Means of Enablement ...............194

6.3. Armar III - The Kitchen Boy ...................................................................202

6.4. Conclusions: Configuring the Humanoid Kitchen Service Robot ........211

7. Conclusions: Robot Companions - Machines to Become with? ...............217

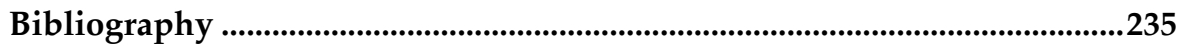

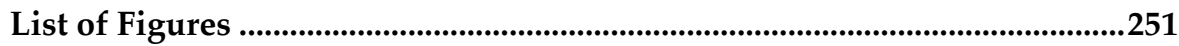




\section{Acknowledgements}

Questions around categorical belongings in their inclusive and exclusive operations and the very idea of belonging that is stipulated by sorting into identity categories have troubled my being and thinking for almost two decades now. In particular, the thought of bodies as something that 'are' and that at the same time are constantly being 're-made' fascinates me on the intertwined levels of personal and academic interests. These interests constantly motivate me to learn more about the changing conditions and circumstances of embodying individuality and sociality in present-day societies.

Right from the beginning when I read for the first time about robots that are not only modeled on the human but are also intended to be human-like companions in our everyday lives, especially in the realm of care work and reproductive services, this technological development caught my full attention. It reverberates strongly with my interests in understanding how proper bodies come to matter; more specifically, I became interested in understanding how an example of a model of robotic bodies comes to matter as a replication of the 'organic original' and in relations of caring for and accompanying humans. The goal of designing such inorganic, but nevertheless humanoid, bodies of robot companions forces us to develop an understanding of bodies that emerges through sorting into the categories of the proper human and the human-like. I immediately associated this with the possibility of decoupling bodily materialities from their essentialist connotations. Detailing these concerns with the bodily materialities emerging at the robot companion-human interface, I underscore the chances of, and even the need for, interdisciplinary research across robotics and social sciences, more specifically feminist and queer thinking as it emphasizes the more-than-human and material agencies in the signification and mattering of bodies and categories of social ordering. Pivotal points for my study thus became questions of what I can learn from the making of this robot about the co-production of bodies, proper categories, and relations of social meaningfulness as well as how I could contribute to the making of robot companions.

Throughout my doctoral studies, I was in the fortunate position of finding several spaces that allowed me to conduct my research and thus equally 
supported me in finding answers to the questions raised above, as much financially as through committed discussions, lively instructions and plenty of motivation. In detail, these spaces are the Center for Interdisciplinary Women's and Gender Studies (ZIFG), at the Technical University Berlin, the PhD training school "Gender as a Category of Knowledge", at the HumboldtUniversität zu Berlin, funded by the German Research Foundation (DFG), and Tema Genus, at Linköping University and, last but not least, the Institute for Anthropomatics and Robotics at the Karlsruhe Institute of Technology. I have met a lot of inspiring people at all four places who were involved in conducting my research and in discussing the writing of this thesis - which is indeed a true co-production - and I am sure there are many more people who helped me and were involved in this than I am able to name here.

I am more than happy that Mike Laufenberg told me - only shortly after we met each other - to 'Go and do this research!' Thus, it really is true that this project would not have been possible without Mike's initial empowerment and his generous friendship throughout the years. After deciding that this really was the case; that I wanted to research the topic of the 'inorganic other' and of seemingly cold metal made into caring machines, I was also lucky to find my supervisor, Sabine Hark. I am grateful for the opportunity to have conducted my study under Sabine's supervision, as well as to have had the privilege of her full support in finding a doctoral scholarship plus a finalizing grant and, later on, in the decision to pursue a binational doctorate. Sabine furthermore provided me with a great mixture of freedom regarding my research design and at the same time guidance in making my academic passions work with my studies throughout my doctoral research. I also appreciate Monika Schweichler's knowledge, calmness and endurance in setting up and proceeding with the cotutelle agreement between Technical University Berlin and Linköping University.

When I started working on possible outlines for my research, I immediately became fascinated by one robot model because it was being built in a kitchen setting; a setting that I regard as iconic for new dimensions of the humanrobot imaginary. I was in the fortunate position of being able to conduct my research in this context of contemporary robotics. Thus, I would like to especially thank Tamim Asfour and his team at the Institute for Anthropomatics and Robotics at the Karlsruhe Institute of Technology, who 
welcomed me and invited me as a social researcher to participate in the dayto-day work of the IAR as well as the cooperating sub-institutes that are involved in the development of the robot model upon which this study centrally draws: Armar. I would like to express my appreciation for these invitations, which became the foundations of this research, as well as for the openness of Tamim and his team. This included supporting me in my research 'across disciplines' and engaging in many rich conversations about developments in robotic technology at the IAR as well as transversal dialogues about each other's research. It was Tamim and his team, along with the cooperating institutes, who made it possible for me to come to grips with aspects of contemporary robotics and to gain a huge amount of robotics knowledge pertinent to the envisioned interdisciplinary scope of my thesis.

Petra Lucht's 'Forschungswerkstatt' at the ZIFG provided an ideal context for me to develop my dissertation project, as did the overall context of the ZIFG, which then also helped me in working on and finalizing this thesis. Here I am thinking especially of the weekly colloquium with Sabine Hark and my doctoral colleagues at the ZIFG, especially Käthe von Bose, Mike Laufenberg, Aline Oloff and Inka Greusing. I would also like to express my appreciation for financial support in the form of a finalizing grant for my thesis writing for the first half of 2014, funded by the "Program to Promote Gender Equality of Women in Research and Teaching in Berlin at the TU Berlin". In addition, I thank Hanna Meißner for our collaborative work, for example, when she joined me in organizing the workshop "Biotechnoethics: Mapping prospective bodily landscapes" at Humboldt-Universität in 2013. I would also like to thank Gabriele Jähnert, Center for Transdisciplinary Gender Studies $(\mathrm{ZtG})$ at Humboldt-Universität, who had the initial idea for such a workshop, which enabled a discussion of the importance of bringing together strands of bio- and techno-ethics. Gabriele also supported me on many other occasions.

The PhD training school "Gender as a Category of Knowledge" also provided me with an important context for developing my research with an emphasis on conducting interdisciplinary research across different realms of the humanities as well as across the social and natural sciences. Here I am thinking particularly of the generous mentorship that Corinna Bath offered me right at the beginning of my scholarship and has ever since continued to 
sustain on different occasions, for example as my opponent at the 'Final Seminar' at Tema Genus in September 2014. The weekly colloquium at Humboldt-Universität also shaped my thinking and writing. I would particularly like to thank my colleagues Katrin Köppert, Lisa Malich, Kirstin Mertlitsch, Käthe von Bose, Ulrike Klöppel and Aline Oloff. Aline in particular helped me with many struggles around getting this project started and finding my way into doing this research. I am also grateful for Beate Binder's interest and her support of my dissertation research and thesis writing throughout the time of my scholarship and beyond, especially in her function as an assessor of my thesis in the cotutelle procedure.

Moreover, Tema Genus and in particular the Posthumanities Hub has become of major importance for my dissertation research. I would like to warmly thank my supervisor Cecilia Åsberg for her constant empowerment, her generous support, the inspiring discussions and her thought-provoking readings of my chapters. I am also grateful to her not only for supervising my dissertation, but also for her work on making the cotutelle procedure between TU Berlin and LiU possible and the huge amount of hours and energy dedicated to this. Beyond this, I would like to thank Cecilia, Magdalena Górska, Nina Lykke, Margrit Shildrick and Redi Koobak for creating a welcoming environment during every stay at Tema Genus, but especially during my first stay as visiting scholar at the Posthumanities Hub, as well as the encouraging discussions about my research throughout the years. During that first stay, in November 2011, I also enjoyed meeting the then 'new PhD' candidates who immediately accepted me as a member of their circle and whom I consider great colleagues: Marie-Louise Holm, Tara Mehrabi, Line Henriksen, Helga Sadowski, Desireé Ljungcrantz and Marietta Radomska.

In addition, I met Lissa Holloway-Attaway, who was also a visiting scholar at the Posthumanities Hub in November 2011, and with whom I had the pleasure to share a flat during this time. I would like to thank Lissa for the great time during my first stay in Linköping and for her support of my thesis, especially in her function as an assessor in the cotutelle procedure. In addition, during this first stay at Tema Genus, I also had the opportunity to participate in the InterGender Course "Introducing Feminist Materialisms" with Stacy Alaimo, Nina Lykke and Cecilia Åsberg, which became a great influence in my thinking and writing. I thank Stacey Alaimo for the feedback 
she provided to me during this course as well as during the following year. Moreover, I would like to especially thank my committee for the 'Final seminar' at Tema Genus in September 2014 that shaped the finalization of my thesis in many ways: Dag Balkmar, Myra Hird and Nina Lykke. Furthermore, I thank Berit Starkman and Björn Pernrud for their kind and thorough assistance with administrative questions of all kinds.

Shortly after I started my PhD research, I also joined AtGender, the European Association for Gender Research, Education and Documentation, and was elected a board member for the period between April 2011 and June 2014. I thank my colleagues on the AtGender board for this time with its many learning experiences and challenging new tasks as well as their guidance and support in mastering these: Berteke Waaldijk, Sveva Magaraggia, Edyta Just, Aino-Maija Hultunen, Iris van der Tuin, Mia Liinason, Paulina Bolek, Nadya Alexandrova, Andrea Pető, Barbara Bagilhole and Tilly Vriend. I learned a lot from these colleagues and I am grateful that I was able to work with all of them on the project of creating and maintaining a strong network of European Gender Studies in all of its facets. AtGender also became a context for finding a network of individuals throughout Europe who are concerned with feminist materialisms and research across feminist (post)humanities and the natural sciences, and through this I met some amazing scholars: Peta Hinton, Iris van der Tuin, Dagmar Lorenz-Meyer, Sigrid Schmitz, Kathrin Thiele. I would like to especially thank Iris for her encouraging and generous words whenever we met and her support for my academic life on different levels. Moreover, from this context emerged the anthology "Teaching with Feminist Materialisms" and I especially thank my co-editor Peta for her work on this book project. Beyond this, I appreciate our friendship and I thank Peta particularly for proofreading the first draft of my thesis as well as for sharing insights on 'life after the PhD'. I thank Simran Sodhi for her patient work on improving my English, and finally Liz Sourbut for copy-editing this version of my thesis in such a careful and enriching manner.

In addition, I would like to further express my gratitude toward the many people I met throughout my dissertation project who have become more than colleagues. It was Magdalena Górska who introduced me to Cecilia Åsberg and the Posthumanities Hub. Surely, this dissertation would not have 
materialized in the way it did without Magdalena's generosity, interest and, importantly, the friendship that accompanied this project. Moreover, Katrin Köppert enriched my intellectual and personal life tremendously through committed discussions and shared visions, especially during our time as scholars at the PhD training school "Gender as a Category of Knowledge". I thank my colleague - also from Humboldt-Universität - Jens Borcherding for his support of my research and his help with the graphics, but even more importantly for becoming a friend whom I would not want to lose from my life. Marie-Louise Holm, whom I met in Linköping, has equally become a friend who shares my excitement for theorizing bodies in a way that moves us. Finally, I would like to particularly thank Käthe von Bose for the last few years of going through the joys and sufferings of finalizing an article together and then also a doctoral thesis around the same time. I am very glad that I had the chance to get to know you as such an empathetic friend in all of our inspiring discussions, experiencing similiar anxieties and also through a shared passion: radical crafting. I am looking forward to future collaborative work in the realm of academia as well as that of our shared passions with all of you!

I would like to dedicate the last words of these acknowledgements to my family - my chosen as well as my biological family. I thank Anne KleinTreusch for her constant financial and emotional support over the last 13 years of my academic education, even though at times she has not been able to recognize the purpose of all this time and money invested in pursuing this education. AK OK Kleinlein made me believe in this project at moments when I felt as though I could not cope with the task of organizing my thoughts in the process of learning to communicate what I wanted to say and thus, even more importantly, I thank AK OK for teaching me some lessons in 'acquiring a voice'. Last but not least, I thank Rainer Hänsel with all my heart for encountering me with love throughout the last three years and more, including my most horrible moods. Here, I particularly appreciate Rainer's persistence and ongoing motivation in teaching me more than one lesson on finding a work-life balance. Of course, I am equally grateful for Rainer's endurance and insights in discussing this thesis.

Berlin, April 2015

Pat Treusch 


\section{Robot Companions: Machines to Work and Live with?}

\subsection{Introduction: Toward an Inventory of the Robot Companion Imaginary}

At the heart of this thesis is an exploration of developments in contemporary robotics technology. It examines engineering process of relating humans and machines, as well as the ways in which this development implements 'human-likeness'. In the face of what have been postulated as the great challenges for societies in the 21st century, such as ageing populations, more stressful and work-saturated everyday lives and fewer middle-class women readying themselves for domestic duty, engineered solutions like humanoid household robots have entered 'our' present imaginary with great force. As I will argue throughout this introduction, such robots have become vital constituents of a socio-technical vision of future societies in which work is redelegated between humans and humanoid robots, including in the domestic sphere, involving both assistive tasks and care work.

During the process of writing this interdisciplinary dissertation, I had the opportunity to closely follow the development of one of these robots intended for domestic service at the Karlsruhe Institute of Technology (KIT). The actual robot, "Armar", which is being developed at the KIT, is modeled on the human and its design reflects the intention of making it a machine that people can live and work with in every sphere of human existence. Therefore, one focus of my study is the peculiar interrelation between making robots fit into everyday lives, for example in the household, and equipping them with a human-like appearance and concomitant human-like qualities of serving, helping and assisting in multiple fields of operation. More precisely, I collected qualitative data on the processes of designing and building, and the experimental use, of this specific robot model, Armar, at its location, the KIT. Drawing on the wider fields of feminist technoscience studies, queer theorizing and science and technology studies, I grapple with this specific version of a human-robot interface as equally produced by and a producer of the contemporary robotic socio-technical imaginary.

When I started to collect data about Armar at the very beginning of my thesis work, the webpage "robotcompanions" caught my attention with the following statement: "Human society faces a critical challenge: how to increase and maintain our quality of life in the future. Robot Companions - as 
a new class of technology - will offer a variety of roles to assist facing this challenge."1 At the beginning of the second decade of the third millennium, the European research network "robotcompanions" describes a critical challenge for human society: How to increase or maintain what has become our somewhat homogenized Western-European standard for quality of life. The robot to live and work with is introduced as a robot companion, "a new class of technology", which seems to offer help in facing the postulated critical challenges. Thus, the notion of the companion here designates this emerging class of technology, which is seen as a promising solution to the problem of how to design and build technologies that will increase and maintain "our quality of life in the future". Academic robotics institutes from 25 countries, mostly European, are members of the 'Robot Companions for Citizens' network, including the Institute for Anthropomatics and Robotics [IAR], KIT, on which my dissertation project focuses.

I draw on the concept of the socio-technical imaginary of contemporary robotics to examine the technological development and the surrounding engineering of human-robot relations in their promises of societal benefit. One example is the promise of increasing quality of life through future robotic automation at home. The term social or cultural imaginary has become established in feminist studies that investigate different bio-technology-driven visions of societal futures and how these imaginings implement and negotiate understandings of subjectivity and sociality in regard to the realms of the present and the future (Franklin et al. 2000; Braidotti 2006; Lykke 2008). Examples are work on the "genetic imaginary" (Franklin 2000), the "Viagra imaginary" (Åsberg and Johnson 2009) and "national sociotechnical imaginaries" (Jasanoff and Kim 2009). These assembled accounts have in common that they map the "fantasy landscape" (Stacey 2008, 96) in which specific bio-technological developments are embedded.

In addition, the term socio-technical has been used in strands of science and technology studies, which take into account the fact that technological development is a construction process constituted by the social, while the evolving technologies and artifacts shape how humans relate to each other, and therefore are constitutive of society (MacKenzie and Wajcman 1999, 3)

\footnotetext{
${ }^{1}$ www.robotcompanions.eu. Robot companions is a European "flagship project" and research network, working on 'Robot Companions for Citizens', that was active from April 2012 until April 2013.
} 
Thus, I grapple with the co-constitutions of the social and the technical as always entangled; as the socio-technical. I use this approach in my study in order to research socio-technical entanglements in making robots the prospective social agents for improving 'human efficiency' and increasing the Western-European standard for quality of life.

\section{The Robotic Imaginary - Robot Companions in the Media}

The kind of automaton that is envisioned, the domestic robot, is becoming an increasingly ubiquitous object of public attention. In what follows, I briefly discuss collected headlines from reports in the media on contemporary robotics as illustrative examples of the dimensions of the robotic imaginary. According to such reports, contemporary robotics fosters the automation of mass production as well as services within new dimensions. Imaginings of a robotic future accumulate in postulations of "the age of robots" (Ichbiah 2005, 31). At the heart of this is the coming of the fourth industrial revolution on the factory floors of the third millennium, and, importantly, also in spheres previously thought of as intrinsically external to factories, namely the domestic sphere.

Reports refer to humanoid robots as "creatures" (DB mobil, April 2010, translation: PT), which will be "Always at Your Service: In laboratories, a new generation of artificial creatures is growing. [...]. Some of these intelligent helpers will soon make themselves helpful in our households" (ibid.). The idea of such a new generation of robots evokes associations between technological development in robotics and natural processes when robots are designated as growing creatures. The image of robots as growing creatures primarily naturalizes the design of these machines and the engineering of service work, assistance and care, but also their capacity for relating as human-like. Achieved is this picture of the prospective domestic robot with the intention of "Making Robots Human" (National Geographic August 2011). This design strategy promises to make robots suitable and useful for human everyday lives by designing them to be human-like. Associated with this is the image of "Robots Get Real" (ibid.). Robots that are made humanlike are becoming real and, thus, can be helpful in the domestic sphere as "they can now serve drinks, act as companions, and look like us" (Caroll and Aguilera-Hellweg, in: ibid.). The robot companion is an iconic figure in the 
fantasy landscape of the contemporary robotic imaginary. Moreover, this robot is a machine that carries the promise of relieving humans from work in the domestic sphere, as it becomes an artificial creature that embodies humanlikeness in its appearance and capacities.

Other headlines strengthen these imaginings and the concomitant promises of technological development in robotics by announcing that "The Robots Are Coming. In industry, care facilities and on the streets mobile 'Iron Colleagues' (Blechkollegen) are forcing their way into our everyday lives [...]" (Strassmann, 2012, translation: PT). Framing the robot as forcing its way into 'our everyday lives', however, this headline fuels promises as well as the concerns raised about the postulated coming age of robots, while other reports welcome a robotic takeover: “The Robots Take Over. They're coming for your job. And you'll be glad they did" (Wired, January 2013). Such a picture of a redelegation of duties centrally involves imagining new human-robot interfaces. I will be interested in mapping how these are engineered through the example of one particular model of robot companion throughout my thesis.

The future robot functions as a companion that no longer operates solely as a fast and strong machine; for example, manipulating heavy car parts in factories, but becomes the kind of machine that people can live and work with. In addition, I read the headlines of reports in the media as examples of imagining possibilities for a re-delegation of responsibilities in worksaturated everyday lives between humans and robots. They illustrate that this means both making robots more capable of assisting in human everyday lives, and establishing new modes of relating between humans and robots that even encompass affective and caring relations. As I will continue to argue, introducing the humanoid care and domestic worker simultaneously invokes possible relations between human and machine, society and technology, with which we are already familiar and those with which we are not familiar, yet. To map how the familiar and the new come together is a crucial dimension of studying the socio-technical imaginary of contemporary robotics as it is articulated in my centralized example.

These collected headlines depict one way in which the new and the familiar are woven together. Making the companion robot also means making this new human-robot interface public. Thus, the headlines are clear examples of 
the inseparability between the sciences and engineering on the one hand and the public on the other that I am interested in throughout this dissertation. The companion robot is made public through reports in papers, but also through reports on television. My attention was first drawn to the robot model Armar as it is being developed at the KIT through a popular science documentary series called "Inside Science - Wissenschaft Live", screened on German television in December 2009. Part two of this documentary series was an episode on "Robots - the 'Manmachine",", which portrayed current developments in robotics in Germany. As the title "Inside Science" already implies, the reporter guided me through this episode by "looking over the scientists' shoulders" (ibid.; translation: PT). The framework of this broadcast evokes the feeling that one is watching 'live' as the scientists work on their projects. The viewers are thus taken into selected robotics laboratories, where it is intended that they will gain insights into the most current state of the art in robotics. The impression of looking over the shoulders of scientists, specifically the robotics engineers with whom this broadcast works, became the point of departure for my own field study. In the tradition of science and technology studies and feminist science of the artificial (Law 2004, 2009; Clarke 2005; Suchman 2007), in this dissertation I follow the negotiations and production of human-likeness as well as companionship and care between humans and robots in designing and realizing the human-Armar interface.

\subsection{Aim and Research Questions}

The aim of this dissertation is to map out and explore the socio-technical imaginary of anthropomatic robotics through local practices of engineering the human-like robot companion in the kitchen. More specifically, I am investigating the making and public testing of a specific robot, Armar, and the associative relationships between robots and conceptualizations of humanness, human-like-ness, care, companionship and care work as linked to those of gender, nation and sexual reproduction. This is done through fieldwork in the form of participatory observation, qualitative interviews, and the analysis of anthropomatic discourses.

\footnotetext{
${ }^{2}$ http: / / www.presseportal.de/pm / 7840 / 1521804 /-inside-science-zdf-begleitetwissenschaft-hautnah (translation: PT).
} 
I regard my thesis as an endeavor to trace labors of companionship and care and to query the familiar and the new in imagining human-machine relations at the robot-human interface. I will study the topics raised here through the making of one centralized figure, namely the anthropoid version of the companion robot in its manifestation as a domestic machine that operates in kitchens. Along these lines, I will analyze this new human-robot interface in the making, and how this making is charged with companionship and care as intrinsically human qualities that, when realized in the robot, are held up as a guarantee for realizing the promises of future robot companions.

\section{The Robot Companion - A Figure of Automating Reproductive Service?}

The humanoid robot is a machine that in its appearance is modeled on the human: a torso, a head, two arms, and two legs. The robot that is being developed at the KIT reflects this design, with the exception of legs, as these are not yet realized in the most prominent generation of Armar. The class of humanoid robots in general, and companion robots as a new class of technology in particular, is publicized as an intelligent, autonomous labor force, that will assist in 'human everyday lives'. This robot is conceptualized as embodying certain capacities for action, which will enable this machine to fit into scenarios of shared workspaces, for example in households. The humanoid robot of the 21st century is not only human-like in its shape, but also in the automation of agency and cognitive behavior at the human-robot interface.

The capacity for action at the human-robot interface is a central part of realizing an automaton that will increase human quality of life, specifically the efficiency of 'human labor' in our everyday lives. The concept of a robot as an autonomous agent makes it a human-like creature, which moves in with its owners and, importantly, supposedly also moves and behaves in a similar way to its owners. Thus, the conceptualizations and the production of agency as well as the capacity for action embodied by the robot are another vital dimension of my study of this technology in the making as they promise technologies of automation that will take over from 'us humans'.

Furthermore, and in line with Suchman, I understand the capacity for action embodied by the human-like machine to carry a peculiar understanding of agency, which speaks to the "modernist, post- 
Enlightenment assumption [...] that autonomous agency is contained within individuals and is a distinguishing capacity of the human" (Suchman 2007, 213). This understanding relates humanness to agency by charging the latter with the idea that agency is a distinctively human characteristic. Thus, its evolving agential properties appear to be what distinguishes this class of robots from other machines, making the contemporary robot a human-like companion that we can live and work with, as it embodies human features as they became apparent to me within one specific context of contemporary humanoid robotics. I will provide a map that pins down aspects of the conceptualizations and production of agency at the robot-human interface that I researched. In this way, I will discuss negotiations and the emergence of embodied capacities for action, especially in regard to the ways in which these employ human-likeness and the possibilities for interaction between human and robot at the robot-human interface, which I regard as one central contribution of my study to feminist sciences of the artificial.

Contemporary robotics is one major interdisciplinary field of innovation and research in which the machinelike attributes of humans and the humanlike capacities of machines are negotiated. However, and as I will continue to argue throughout this thesis, science and technology studies and feminist science of the artificial suggest an understanding of agency that contrasts with modernist thinking as outlined above. Such studies underscore the distinctively non-human forms of agency and trace them as constitutive of the human, who is thought of as an individual subject embodying agency (Pickering 1995; Law 2007; Suchman 2007; 2011). Against this backdrop, I suggest an understanding of agency in the robotics laboratory that emphasizes that humans and the more-than-human always act in concert. Thus, I am interested in the distribution of agency at the companionrobot/human interface, and how this distribution either supports or limits associations between agency and human-likeness in the robot. In addition, I will bring together empirical research on the entanglements of the social and the technical within one field of technology development, namely anthropomatics, with feminist and queer thinking concerning the very nature of agency. Mapping the socio-technical imaginary of contemporary robotics, I will work throughout this thesis with a fine-grained account of the engineering process of relating humans and machines and the ways in which 
this development implements human-likeness. In short, the term 'finegrained' indicates an analytical sensitization to how the capacity for action emerges through local specificities of producing the interactive machine in their co-constitutions, rather than assuming that either a subject or an object simply contains such a capacity.

Humanoid robots envisioned as interacting with humans in our everyday lives are an iconic image of the fantasy landscape of the 21st century. As robots emerge with a new usability from the factory floors and move into the domestic sphere, the fascination with such machines seems to be growing even faster and wider. Since this robot is growing into such an iconic image, questions concerning the relations between human and machine are also capturing public interest - whether in terms of budgeting for research funding, of reports in the media or of science fictional representations in film and literature. Contemporary imaginations signify a step in the development of automata that serve humans, displaying the most recent state of affairs in robotics: They are made 'more human' and will always be at 'our' service. In this regard, the human-like robot is imagined as a service agent of a redelegation of labor between humans and robots within new dimensions. This re-delegation is of interest for this thesis as it deploys a "politics of value" (Stacey and Suchman 2012,4) of labor through engineering practices (ibid.) that also carries specific imaginings of what a human is, what the human-like is and how they should relate. The practice of contemporary technological development is imbued with the idea of a re-delegation of labor; that is, the powerful project of valuing labor and constantly re-inventing the division between acknowledged and neglected labors. Against this backdrop, I will trace the ways in which the design and realization of the robot model that I am researching is charged with these values connected to humanness, to which a politics of differentiation between human and machine are tied.

Emerging machines are based on the long-standing idea of making them appear to behave in a human-like manner and become self-propelled (automated) in ways that 'we humans' can recognize as meaningful in scenarios of shared, even interactive, spaces. The humanoid robot, in short, seems to figure human-machine relations in which the human self and the machine other are mirroring each other. Against this backdrop, I will map the 
politics of value and the politics of differentiation in making one contemporary robot that will supposedly become a domestic companion.

'Human labor' is delegated amongst modern categories of social ordering that categorize into male and female, Westerners and non-Westerners, human and nonhuman. The sexual and transnational division of labor along "global care chains" (Hochschild 2000), as well as the nuclear family, the pairing into domestic households with its "heterosexual contract" (Hark and Laufenberg 2013, 231, translation: PT) and the attendant forms of heterosexual kinship as the naturalized norm (Butler 2002; 2004) are topics of feminist and queer investigations into taken-for-granted norms that constitutively organize our everyday lives. Thus, I consider the particular form of humanness that is usually assigned to certain forms of labor to complicate the question of a politics of value and, accordingly, the frame of measurement for valuing this labor. Here I am thinking especially of reproductive services in the form of emotional labor of companionship and care in the light of their transitive delegation in relation to modern categories of social ordering.

Some forms of labor are more likely to be delegated to machines, while others remain within the realm of un-delegated 'human labor', which, nevertheless, is a realm with shifting limits. One example is the automation of monotonous, repetitive tasks on factory floors, in contrast to duties that comprise reproductive services such as serving, assisting and caring. As Stacey and Suchman point out, the latter depicts a form of labor that strongly signals humanness as it involves care and emotions (Stacey and Suchman 2012 , 4). Thus, I am interested in the delegation of labors of companionship in their relationship to care, as well as the socio-technical entanglements deployed by the robotic automation of these fields of labor and their possible impact on the societal organization of everyday lives, as well as the very connection between labor and humanness.

The societal organization of responsibilities in the private sphere and the taken-for-granted sexual division of labor in particular are topics of debate and have a long history of struggle - both personal and collective - over the delegation of labor. At the core of these fights is the (not only) queer and feminist issue of the valuing of reproductive duties and care as work in capitalist societies. Care (work) is an abiding issue and a centralized concern of my study. The socio-technical imaginary of the robot companion draws 
centrally upon the idea of propelling the project of automating work that falls under the label of reproductive service involving care and companionship. As Stacey and Suchman note, this project performs a shift "from a focus on manufacture to a preoccupation with forms of labour previously defined as external to industry, whether within the household or in the marketplace" (Stacey and Suchman 2012, 26). Intrinsically understood as external to industry, care is thus a key term in the project of engineering the contemporary robot because it serves as an indicator of the preoccupation with new forms of delegation of labor as well as the attendant signs of humanness in these evolving machines. In particular, this includes mapping the intertwining of the ideas of, firstly, making automata self-standing agents that provide companionship and care and, secondly, of employing humanness in this making and how this is thought of as key in realizing the first idea.

\section{Research Questions}

In what follows I develop the main research questions in relation to the centralized categories of analysis (human, machine and interaction that employs human-like companionship and care), as well as how these link to the aim of this thesis. My argument here is that introducing the humanoid care and domestic worker simultaneously invokes possible relations between human and machine, society and technology, with which we are already familiar and others with which we are not familiar, yet. Thus, it points to forms of the societal organization of labor and the social categories of ordering that are constitutive of our being and knowing, while it also seems to open up new dimensions of relations between human and machine, society and technology within the present realm of experience that also categorize. The machine's role as potentially capable of performing what is considered to be human-like companionship and care depicts a key analytical perspective, from which I develop the issues of concern for this thesis.

Bearing these issues in mind, I developed the central research questions for this thesis. These are:

- What human-machine relations are realized during the process of making this robot model into a domestic companion? And: How are the 
boundaries between human and machine, valued and neglected labors, drawn and re-drawn in anthropomatics?

- How do anthropomatic robotics in the making impact upon our understanding of what it means to be human?

- How can we develop a queer-feminist contribution to imaginings and realizations of future everyday lives with the robot companion that goes beyond only acknowledging either the seemingly distinctive 'human sociality' or the 'humanoid technicality' as a frame of evaluation - and rather proceeds through a posthumanist frame of co-constitutive entanglement?

\subsection{Methodology: A Methodological-Theoretical Framework}

In her most recent work, Jasanoff defines the socio-technical imaginary as:

collectively held, institutionally stabilized, and publicly performed visions of desirable futures, animated by shared understandings of forms of social life and social order attainable through, and supportive of, advances in science and technology. (Jasanoff 2015, 5)

Jasanoff's explanation of what the term socio-technical imaginary captures is particularly helpful in pinning down how the new relates to the existing in processes of producing the robot companion. In order to do so, I suggest analyzing the public performances of a new class of technology that promises societal benefits by asking how this is linked to existing forms of social life, the current social order, and expert collectives and their institutions. I use this insight into the interrelations between public performances, the social, institutions and their expert collectives and new technologies to trace imaginings of human-likeness between humans and robots that are constitutive of and constituted by the emerging human-robot interface in anthropomatic laboratories.

Mapping the socio-technical imaginary of contemporary robotics through the laboratory practices of bringing one robot into experimental use, I draw centrally upon a research methodology that has become established in qualitative social sciences within the field of science and technology studies. More precisely, I emphasize methods of collecting empirical data that have been developed in strands of science and technology studies in the tradition of laboratory studies. At the core of this tradition is the aim, as with Kathrin Amelang puts it, to explore knowledge production "in situ - which means on- 
site, in its 'natural' arena" (Amelang 2012, 148; translation: PT; emphasis in original). Laboratory studies conceive of the laboratory and its "technical content" (Knorr-Cetina 1995, 140) as a central site of socio-technical work, and specifically as a dominant site in the production of facts and artifacts.

Laboratory studies became established in the early 1970s. These early studies were researching the "social construction" (Latour and Woolgar 1979) or "manufacture" (Knorr-Cetina 1981) of knowledge and included detailed descriptions of "experimental practices" (Shapin and Schaffer 1985, 3). Such detailed descriptions, however, can be achieved through different research design strategies. I have chosen to work with a mixed method approach of collecting empirical data that I developed from my engagement with more recent feminist studies of science and technology, or rather technoscience ${ }^{3}$ studies, which centrally re-work the scope of describing laboratory practices. As I will continue to argue throughout this thesis, such a methodologicaltheoretical framework for my study includes applying a posthumanist frame and acknowledging power differentials as constitutive of laboratory practices. Such an approach enables fine-grained descriptions of the socio-technical production of one robot model and takes into account the intertwinements between knowing, being and ethics, as I will continue to elaborate upon.

I use both of the terms 'feminist' and 'queer' as an indicator for, as Haraway describes it, taking on "the job of undoing 'normal' categories" (Haraway 2008, xxiv) in describing laboratory practices. In my take on queerfeminist studies as the project of undoing taken-for-granted norms, in short, the job of queering, I draw on a legacy of critique of "compulsory heterosexuality" (Rich 1980) and "heteronormativity" (Warner 1991), both of which are constitutive of the heterosexist matrix of intelligibility, the binary gender system and the sexed materialization of bodies (Butler 1990, 1993). ${ }^{4}$ However, as Haraway emphasizes, such a "queering [of] specific normalized categories is not for the easy frisson of transgression, but for the hope for livable worlds" (Haraway 1994, 60). Along these lines, I propose a queering

\footnotetext{
${ }^{3}$ Technoscience, as Donna Haraway notes, "extravagantly exceeds the distinction between science and technology as well as those between nature and society, subjects and objects, and the natural and the artifactual that structured the imaginary time called modernity" (Haraway 1997, 3).

${ }^{4}$ The sexing of the body describes only one axis of power for subject formations; for an intersectional account of subjectivation, see for example Nina Lykke, 2010, and for a reworking of intersectionality as assemblage, see for example Jasbir Puar, 2011.
} 
that takes as its pivotal point a study of the contingency and exclusionary operations that are constitutive of the category of the human (Butler 2004, 13; Giffney and Hird 2008). In line with Haraway, "none [of the 'normal categories'] is more critical than the human/nonhuman sorting operation" (Haraway 2008, xxiv). Queering in this sense becomes a research methodology, which emphasizes studying the production of the human-robot interface in terms of the attendant sortings into the 'normal categories' of human, robot and human-like in their relation to labors of companionship and care, as well as to the matrix of sexism, racism and able-bodiedness.

Recent queer and feminist thinking and critiques of contemporary humannonhuman sorting operations, the concomitant production of the category of the human, and suggestions of a queering of taken-for-granted norms inform my approach to the making of Armar through multiple insights and analytical concepts. My selection of feminist and queer thinking and theorizing and how this sits within the realm of science and technology studies will become more palpable in the empirical chapters of this dissertation. Importantly, the methodological-theoretical framework that I assemble in this thesis is not only relevant in terms of describing how I analyze the collected data, but is also equally important for describing how it structured my approach to collecting data in the first place.

\section{Fieldwork in a Robotic Laboratory - A Method-Mix}

Through my suggested theoretical-methodological scope of research, my study of laboratory practices in situ becomes a research endeavor that requires methods of collecting empirical data on different scales. Here, I am thinking, for example, of Haraway's insights into the laboratory as a place of special meaning. As she points out:

[t]he laboratory is a special place [...] because the laboratory is an arrangement and concentration of human and nonhuman actors, action, and results that change entities, meanings, and lives on a global scale. (Haraway 1997, 66)

Therefore, investigating the laboratory requires directing my analytical attention toward the human and nonhuman actors, actions and results in the making of a specific model of the robot companion. Moreover, this theoretical-methodological scope of research reverberates with contemporary strands of "posthumanist feminism" (Åsberg 2010; 2013; 2014) and material feminism (cf. Van der Tuin 2011). Stacy Alaimo determines the core of these 
strands when she emphasizes that what has become popular as "the material turn" (Alaimo and Hekman 2008; Van der Tuin 2011) takes as its pivotal point the need to "account for the ways in which [...] the material world itself signif[ies], act[s] upon, or otherwise affect[s] human bodies, knowledges, and practices" (Alaimo 2010, 7-8). I have chosen to use insights and concepts from posthumanist feminisms and feminist materialisms while developing my research design in order to account for the ways in which the laboratory is a place of actors who act in concert on multiple scales.

In addition, this perspective allows me to conceive of the subjects and objects in the robotic kitchen laboratory as reverberating with Haraway's idea of bodies as "materialsemiotic generative nodes", specifically "a cumbersome entity called a "material-semiotic actor"' (Haraway 1991, 200). She goes on to explain that this includes understanding bodies "as an active, meaninggenerating axis of the apparatus of bodily production, without ever implying immediate presence of such objects" (ibid.). On the one hand, Haraway unsettles the naturalizing idea of bodies as fixed entities by developing the concept of the apparatuses of bodily production, and on the other hand she acknowledges that bodies are themselves generative in this process of production. The term generative troubles our understandings of embodiment as passive and controllable through, for example, human language. As Hinton points out, Haraway's concept of bodies as material-semiotic actors "[shifts] the nature of agency" (Hinton 2014, 106). Thus, to understand bodies as "'agents', rather than resources" (ibid.) speaks to my theoretical framework in different ways. One important aspect that I wish to highlight here is that the idea of bodies as generative nodes helps me in a twofold manner when entering the robotic laboratories, in their negotiations of the human-like always in relation to the human. The acknowledgement that the bodies of everyone participating in this production of the robot function as generative nodes, in addition to the apparatuses that regulate the boundaries of bodies, describes vital insights that guided my research, as will become apparent in the empirical chapters.

Furthermore, to take on the position of a witness to the everyday work in robotics in general, and demonstrations as a form of public testing of this technology in particular, became one key socio-ethnographic strategy of my research. The form of my encounter with the humanoid at the Institute of 
Anthropomatics and Robotics [IAR] has shifted several times, from reading books, articles, and reports, to watching movies and TV series, to standing in the middle of a kitchenette lab. Standing in this laboratory, I faced a multitude of actors working on and with the humanoid, including the arrangements of (parts of) the humanoid in the enactment of interaction in the kitchen setting. The robot is displayed in 'its kitchen' as the new kind of domestic technology to come.

In addition, experiencing how this machine is demonstrated as an interactive humanoid kitchen robot in front of an audience also guided my interest in delving deeper into the organization of knowledge at the IAR and the conceptions of human-like embodiments of interaction on which the realization of this automaton is grounded. Thus I analyze all kinds of materials relating to the production of Armar, including metaphors and narratives as well as instruments and devices. To collect such data, I used the additional key analytical strategy of qualitative research. I conducted 15 "expert interviews" (Meuser and Nagel 2004) with robotics practitioners during the course of my research stays in July 2011 and July 2012 and engaged in informal conversations on a daily basis.

Shortly after my arrival at the IAR in July 2011, the team leader, Prof. Tamim Asfour, who welcomed me to the institute, introduced me to the practitioners working on the current robot model, as well as the next generation, in the main laboratories of the IAR. After this initial contact with the practitioners, I joined them in their daily routines. During our more informal conversations, for example during lunch breaks, the practitioners informed me about the different areas they were working on, like the realization of 'active vision' in the robot. Those informal contacts also served as starting points for more formal interviews about their work.

Moreover, Asfour not only guaranteed that I had access to the IAR, but also introduced me to cooperating institutes like the Institute of Sports Science (KIT) or the Fraunhofer Institute of Optronics, System Technologies, and Image Exploitation. Thus, I also conducted interviews with experts working at these affiliated institutes. Notably, a large majority of the practitioners working on the robot model Armar were male, and the only female interviewee during my research process was the practitioner whom I interviewed at the Institute of Sports Science. Furthermore, the team was 
international and guests from different parts of Europe and also from as far away as Japan, for example, stayed at the institute during my research. Most of the practitioners whom I interviewed were either in the process of completing their dissertation or had already completed it. Their dissertations mainly investigate questions about realizing and improving certain aspects of humanoid robots in general and of Armar III and the following generations in particular. In addition to my field notes and expert interviews, I also collected published papers that were mentioned during interviews and public relations documents relating to the IAR.

A prerequisite for participating in the everyday labors of project work in AI and robotics was to be invited to the institute as a guest. As I quickly noticed during everyday communication, this invitation was to some extent tied to expectations of me as a social scientist. These were primarily articulated as interest in the question of how other disciplines, such as 'the humanities', perceive and evaluate contemporary robotics. I also gained the impression that this was accompanied by an interest in making this specific robot model more public. In this sense, the invitation to conduct my research as a guest at the IAR was charged with addressing me on the one hand as a representative of 'the humanities' and on the other hand as a witness to high-tech, cuttingedge developments in humanoid robotics that also, to some extent, is ascribed to the role of a public relations person.

\section{Becoming a Queering Witness to Anthropomatic Robotics - An Ethico-Onto- Epistemological Methodology}

In order to find my role within the field of robotics as a queer-feminist social scientist, I drew centrally, and continue to draw, upon Haraway's and Barad's work. In short, Haraway suggests approaching fieldwork through engaging with and encountering the field to be researched by creating what she describes as "attachment sites for world making" (Haraway 2008, 36). In line with Haraway, the idea of attachment sites accomplishes both learning to adhere to the "social semiotics" (ibid., 24) of a specific field, collective or institution and therefore also to the conditions and practices of the production of iconic facts and artifacts within this field. Following this suggestion, I will develop an approach to the robotics laboratory through which I engage in creating attachment sites between the robotics experts and me. 
Barad's work is informed by Haraway's account of feminist technoscience studies in many ways. Without delving too deeply into Barad's rich oeuvre, what I want to underscore here is her work on "agential realism" (Barad 2003; 2007) as methodology and "ontology-epistemology" (ibid.). In short, Barad demands that we develop "a deeper understanding of the ontological dimensions of scientific practices" (Barad 2007, 42). She suggests adjusting the analytical lens from finding the right description to represent 'what things are' to building a sensitivity to 'how things become'. Along these lines, Barad advocates an "ethico-onto-epistemology" through which research

questions have to do with responsibility and accountability for the entanglements 'we' help enact and what kinds of commitments 'we' are willing to take on, including commitments to 'ourselves' and who 'we' may become. (Barad ibid., 382)

Furthermore, focusing on the question of how the discursive and material are "conjoined" (Barad 2003, 823), she proposes that "the primary ontological unit is not independent objects with inherent boundaries and properties but rather phenomena" (Barad 2007, 139; emphasis in original). I will use and discuss the benefits and limits of Barad's fine-grained account of actions and actors in the laboratory, namely the ontological unit of phenomena and the attendant concept of agency beyond individual entities, throughout this thesis.

In addition, Barad explores the "nature of touching" (Barad 2012a, 207) in order to develop an account of being 'in touch', creating a close relationality or intimacy between oneself and the field and things under study (ibid.). Barad's account of queer and feminist technoscience studies depicts an "engagement with science" (ibid.), which is "commit[ted] to be in the science [as field of research], not to [...] be above or outside of it" (ibid.). In this regard, she invites me to engage in a close relationality with my field of research, which reverberates with my chosen method-mix of participative observations, expert interviews and anthropomatic discourses that I consider as contributing to an ethico-onto-epistemological methodology.

The concept of "situated knowledges" (Haraway 1991) became crucial in learning to create attachment sites and getting in touch. Appearing most prominently in Haraway's work, the concept of situated knowledges derives from the larger feminist tradition "which is often called the politics of location" (Lykke 2010, 4). I have chosen to work with this tradition in a Harawayan vein in order to grapple with the politics of location when 
entering a robotics laboratory of "sociotechnical production" (Haraway 1997, 7). In short, in opposition to a "positivist epistemology" (Lykke 2010, 4), which neglects the conditions and practices of the making of facts and artifacts, Haraway argues for a "doctrine of embodied objectivity" (Haraway 1991, 188). With this approach, Haraway troubles objectivist science, and suggests that knowledge claims can be situated by embedding these claims within "material-semiotic fields of meaning" (Haraway 1991, 195), and by highlighting that the conditions and practices of production always already contain more than human actors and actions ${ }^{5}$.

As my research is situated within the legacies of queer theory and politics and feminist technoscience studies, the implications of the invitation to research robotics as representing 'the humanities' evoked ambiguous feelings. Surely it felt almost comical to be addressed as representing 'the humanities' as a junior queer and gender studies scholar, who knows very well about the precarity of queer feminist research, both academically and economically. Nevertheless, such an invitation also represents a wonderful opportunity to engage in the creation of attachment sites between contemporary humanoid robotics and queer feminist technoscience studies.

The role of the participating guest who becomes a witness holds a special meaning in to the context of the establishment of modern science as experimental science (Shapin and Schaffer 1985) and queer feminist technoscience studies in general (Haraway 1997; Suchman 2011) as well as the methodological-theoretical framework of this thesis in particular. This role of a witness to everyday laboratory practices is charged with two positions within the field of research. The first is that of the "modest witness" (Haraway 1997, 23; emphasis in original), which is an emblematic figure of objectivist science. As Haraway points out, the modest witness "mirror[s] reality" (ibid.) by becoming "invisible, that is, an inhabitant of the potent 'unmarked category"' (ibid.). Thus, this position carries the idea of what Haraway describes as the "god-trick of seeing everything from nowhere" (Haraway

\footnotetext{
${ }^{5}$ Material-semiotic is a compound term coined by Haraway, which, in short, emphasizes the interweaving of the materiality and meaning of bodies, objects and other things that equip the contemporary socio-technical imaginary. As David Bell points out, when Haraway speaks of entities, "it means to see [these entities] [...] as concrete, or material, or fleshy things, but also as entities that mean things. Hence the material - the thingness of things - is welded to the semiotic (i.e. meaning)" (Bell $2007,121)$.
} 
1991, 189). This god-trick, or powerful "gaze from nowhere" (ibid., 188), "signifies the unmarked positions of Man and White" (ibid.), establishing objectivity as a neutral position of all-pervasive vision. The god-trick enables 'the knower' to speak the truth, while neglecting her/his subjective, embodied worldliness. The epistemological position of the modest witness is based on researching from a distance and neglecting the politics of location.

As the modest witness is entrenched in a positivist epistemology, Haraway proposes to "queer" (ibid., 24) this position. In line with her doctrine of embodied objectivity, she envisions "a more corporeal, inflected, and optically dense, if less elegant, kind of modest witness to matters of fact to emerge in the worlds of technoscience" (ibid.). Thus, I develop an account of the queered modest witness as a research position of corporeal inflection through which I immerse myself in the creation of attachment sites between anthropomatics and queer and feminist technoscience studies. In short, I use the figure of the queered witness to what emerges in the anthropomatic kitchen laboratory as the starting point for a possible queer-feminist contribution to the making domestic of the robot model Armar and the sociotechnical imaginary of contemporary robotics.

\subsection{Overview of the Chapters}

In chapter two, Historical Dimensions of Modern Automation Technologies, I examine a selection of machines that shaped the ways in which we think about human-machine relations. The selection, in this sense, brings together the history of domestic appliances and machines that have been debated as intelligent machines. My argument is that the idea of the contemporary robot that becomes a companion for humans ties in with both of these histories. Therefore, in chapter two I detail aspects of these histories along with selected examples of technological devices. In this way, I intend to develop some important overlaps and paradigms, as well as ruptures and contradictions as they become tangible in how human-machine relations have been crafted in examples drawn from the last 75 years of technological development in connection with what we know so far about the contemporary robot companion for humans. As I read the enumerated examples through a genealogical perspective, I draw on the rich work of feminist science and technology studies to explore the politics of differentiation between human 
and machine, the gendering of the selected machines and the politics of valuing labor in building automata, ranging from machines that cook for us to machines that think for us. However, my emphasis is to avoid either a determinist or an antagonist way of thinking in analyzing the making of these technologies.

In the next chapter, The Anthropoid in Public: Introducing Human-Machine Relations in Anthropomorphic Configurations, I introduce the IAR and the central robot model: Armar III. My focus is on mapping core aspects of the public image of Armar. Furthermore, developing the outlines of a perspective of embodied cognition, I describe how I experienced getting in touch with the field, and then elaborate upon how this machine is imagined, what it should look like and what it should supposedly to be able to do. Here, I bring selfrepresentations together with how I experienced the IAR during my visits. Thus, in chapter three I initially discuss the ways in which anthropomatics deploys human-likeness as a design strategy and methodology in establishing the image of the anthropoid robot as companion in the domestic kitchen.

Chapter four, Mapping Human-Machine Relations during Demonstrations: Performing the Kitchen in the Robotic Laboratory, focuses on the demonstrations of the robot model Armar as they take place in the robotic kitchen laboratory. Here, I map interactions at the human-robot interface in the kitchen during demonstrations. In order to grapple with these interactions as the enactment of human-machine relations, I map the co-production of this robot-human interface in its plethora of conditions, actions and actors that make interaction at this interface efficient. In this way, I will map the apparatuses of this coproduction and will also trace how these re-work seemingly fixed subject and object relations. Finally, I suggest conceptualizing the enactment of interactions in demonstrations through the notion of performing the kitchen.

Through analyzing demonstrations, I also get to know the robot 'in action' and come to understand that it embodies a specific design and capacity for action. The demonstrations, in short, made me curious about the ways in which Armar is envisioned and designed. Thus, in chapters six and seven I delve deeper into selected specificities of the anthropoid's design as it is related to the execution of tasks. Tracing the preconditions on which the performative enactment of the robot is based, I continue to map the "apparatuses of bodily production" (Haraway 1991, 200) as they already 
became tangible during the demonstrations. Beyond this, by drawing on papers published by the IAR as well as on passages from the expert interviews, I intend to bring what appear to be facts together with the situations in which these facts became matters of concern.

In chapter five, Body Modeling in the Anthropomatic Kitchen, I discuss the body model of Armar, which is thought of as making the robot 'more natural' to humans. Next, I zoom in on the design of different body parts of the robot that were of special significance during the demonstrations. In doing so, my emphasis is on patterns of differentiation in their relation to power differentials, such as sex, gender, race and able-bodiedness. At the focus of chapter six, Bringing Bodies into Motion in the Anthropomatic Kitchen, is the cognitive structure, specifically the architecture of Armar. This structure is key to what is conceived of as 'enabling the robot' to interact. Again, I delve into apparatuses of co-production between human and machine as "boundary-making practices" (Barad 2007, 148) that draw and redraw the boundaries between human and machine, active and passive, and subject and object. However, while in chapter five my focus is on the design of the anthropoid's body, in chapter six I shift my perspective slightly by attuning to the practices of synthesizing movements as that which represents human-like liveliness in the machine. Finally, the closing chapter brings together the central insights of this thesis and, in addition, also provides an epilogue that discusses insights beyond this thesis.

\section{Note on My Empirical Data}

Between 2010 and 2012, I stayed at the IAR during several different periods. Initially, I participated at the Inauguration in October 2010. I felt very welcome and it was easy to get in contact with the practitioners who were working with Armar on that day. Accordingly, I decided to stay at the IAR for three weeks in July 2011. Following this initial stay, I was invited by the IAR to visit their booth at the CeBIT ${ }^{6}$ - introducing the mobile kitchenette - in March 2012, and to stay for an additional week at the IAR in July 2012.

\footnotetext{
${ }^{6}$ CeBIT is the acronym for "Centrum für Büroautomation, Informationstechnologie und Technologie" (Center for Office Automation, IT and Technology) and the world's largest (annual) fair on information technologies, which takes place in Hanover, Germany.
} 
During these research stays, I conducted a total of 15 expert interviews with robotics practitioners, primarily researchers and practitioners who were working at the IAR. In addition, I engaged in informal conversations on a daily basis; for example, when joining the practitioners in their daily lunch routines, and participated in five demonstrations of Armar on a variety of occasions, including a video shoot by the public relations department. I documented both through field notes and also took pictures of Armar and the practitioners and shot short video clips during demonstrations.

The final pillar of my corpus of empirical data consists of publications about Armar written by the robotics practitioners, primarily papers developed from presentations given at international robotics conferences and published in either robotics journals or as conference proceedings. I selected publications based on the topics and themes that they touch upon, for example a focus on the robot's head in its activities. In addition, I also received recommendations from the robotics practitioners during expert interviews and informal conversations on what to read if I wanted to gain a fuller understanding of a certain aspect of the engineering of the robot that we had talked about. 


\section{Historical Dimensions of Modern Automation Technologies}

In this chapter, I delve into aspects of historical examples of modern machines, ${ }^{7}$ or rather automata, and ask how these have paved the way for contemporary human-machine interfaces in the light of robot companions to come. More precisely, I deal with two examples; namely, the microwave and the theoretical model of the computer as it has become popular through the work of Alan Turing, the Turing machine. I have chosen to explore these two examples because I think they will enrich my map of the socio-technical imaginary of contemporary robotics in its focus on the making of one specific robot model. I regard them as clear examples of the historical dimensions of how human-machine interfaces have been imagined and realized throughout the history of modern automation technology.

For the purposes of this thesis, I wish both to develop a historical perspective of human-machine interfaces and to demonstrate how this relates to the companion service robot as a currently emerging artifact. My selection of examples is based on two different criteria. Firstly, the selected machines are devices that succeeded in different societal spheres: the market, the military and the sciences. Secondly, this success is also relevant to the establishment of certain imaginings and practices of the relations between human and artifact, society and technology, in the development of machines. Thus, I have chosen the microwave and the Turing machine as examples of socio-technical entanglements through which historically specific humanmachine interfaces become articulated. In this way, I will trace negotiations and practices of imagining and in building and using a certain technology and ask how these furnish a lasting contribution to the socio-technical imaginary.

As I worked through the selected historical data, it became apparent that the idea of a companion service robot as it figures in current robotics research has not appeared from nowhere. Instead, I argue that it is embedded in the historical context of an ongoing co-constitution between technology and society, and between automata and humans, as they develop through the range of successful devices that emerged out of technological development in the West during the 20th century. In short, modern Western technological

\footnotetext{
7 Modernity is a term for the historical period marked primarily by the transformation from feudalism to capitalism, which was propelled by the rapid changes in infrastructure emerging from industrialization.
} 
development shapes the way 'we' live today. This encompasses, for example, how work and social relations are organized on the level of the societal and individual organization of 'human everyday lives'. In turn, the organization of work and established social relations constitute an enormous (consumerist) desire for technology. These desires then propel the development of devices, which in turn shape our everyday lives. Here I am thinking of "ordinary objects" (Bowker and Star 1999, 299) of different dimensions: from the small scale, such as smartphones, MP3 players, and other pocket-sized lifestyle devices of technologically mediated communication and interaction (also with oneself), to larger devices. The latter include objects like domestic appliances, which are thought of, for example, as making labor under the rubric of reproductive service more efficient.

I am interested in the ways in which these automata shape human-machine relations that modern societies, primarily in the Global North, have become familiar with. Notably, the two examples that I explore emerge from the historically shared framework of technoscientific technology development. Technoscience describes the transformation of cultures and practices of science and technology, initiated by the urge to reinvent science in the aftermath of World War II (Bowker 1993). This transformation, as Haraway argues, fostered "technology [as the site] where the social and the technical implode into each other" (Haraway 1992, 299). At the core of technoscientific practices is the convergence between different fields of science, knowledge and engineering, which foster implosions between a variety of human and nonhuman actors, as well as the material and the social. The concept of "implosion" (Haraway 1991; 1997) refers, in short, to practices, imaginings and artifacts as intermingling in a socio-technical, world-building manner.

In this chapter, I juxtapose two technologies spanning approximately the last 80 years of Western automating technological development: household technologies and the example of the microwave and the thinking machine of symbolic Artificial Intelligence [AI]. Both have been extensively analyzed in feminist science and technology studies and I regard these studies as vital foundations for my approach to the making of the robot companion, as I will argue throughout this chapter. Furthermore, this selection is grounded in the nature of the main object of this thesis: the figure of the companion service robot as a contemporary socio-technical iconic image of increasing popularity. 
Along these lines, it is worth paying brief attention to the historical context of the robot within Western technological development, as historians describe it. The term robota emerged in the 1920s, a period that lies between World War I and World War II, as well as the Second Industrial Revolution (1870-1914) and Third Industrial Revolution (until the early 1970s). Furthermore, overlaps between the mechanical age (1623-1945), the electronic age (1945-today), and the age of information and control, or the age of the computer (late 1970stoday) constitute the socio-cultural and historical horizon of the robot of the late 20th and early 21st century. This division into ages, from which specific models of automata arise, is broadly derived from the division into four stages of what Stacey and Suchman describe as the "now-familiar history of automata" (Stacey and Suchman 2012, 9), stages that were most prominently coined by the cyberneticist Norbert Wiener (ibid.). However, the topic of this chapter is not to trace dominant narrations of the history of automata, which seem to lead directly into the stage that is considered to have begun most recently: the age of robots as the beginning of the Fourth Industrial Revolution, in all its teleological detail. Rather, I suggest that this new kind of robot can be categorized into two different classes of automata. Firstly, it seems to be categorized into the class of intelligent machines and, secondly, into the class of domestic appliances. I therefore consider examples from each class of machines in order to provide a historical context for the contemporary robot companion imaginary.

\subsection{Automata in the Household: The Coming of the Machine in Kitchens}

"Usually, when we think of the word industrialization, we think in terms not of homes but of factories and assembly lines and railroads and smokestacks. [...] We are given the impression that industrialization occurred outside the four walls of the home [...] [or even] in opposition to it." Ruth Schwartz Cowan, More work for Mother, 1983

In the quote above, Ruth Schwartz Cowan historically reconstructs the socioculturally established and widespread division between factories and homes, a division that locates the modern process of the coming of the machine, namely, industrialization, in factories rather than homes. She furthermore contests this concept of industrialization by elucidating how it had been occurring, and continued in the late 20th century to occur, on factory floors 
and in households simultaneously, indicating that the separation of these two spaces functions as an ideology (Cowan 1983, 100ff). Historians agree that waves of industrialization in both the Anglo-American and European contexts, which started around the 18th century, came with the invention of standardized technologies and machines that still play a role in shaping how we live today (Mokyr 1998; Cowan 1983). The household in Western industrialized society is constituted by technologies that are dichotomously conceptualized along the division between societal spheres of industrialization: internal (the private sphere) and external (the public sphere) to the household.

Waves of industrialization enabled a certain standard of living, creating the bourgeois household. The need to maintain such a standard, however, caused a "revolution in [the] household" (Cockburn and Ormrod 1993, 129). The modern bourgeois household is equipped with domestic appliances, generally large, stationary machines such as the washing machine, the fridge, and the oven. Stating that "household technology [...] resembles production technology" (Mokyr 1998, 13), Joel Mokyr suggests that the technologies of both spheres, household and industry, appear to advance in step with each other. Foregrounding the interrelation of homes and factories that was brought about by technological development, in this sub-section I explore aspects of the socio-technical production of domestic appliances and the coconstitutive relations between technological innovations, the societal organization of labor, and the division of spheres with which modern technologies are imbued.

My argument is that the societal organization of reproductive service is strongly interwoven with modern automation technologies. The household is thought of as intrinsically external to industry and as the "workaday feminine environment" (Cockburn and Ormrod 1993, 128). Furthermore, Cynthia Cockburn and Susan Ormrod underscore that the household is a societal space, composed of a variety of daily tasks, which are traditionally performed by women (ibid., 132). ${ }^{8}$ Women, they argue, "take responsibility for the daily cycle of cleaning, cooking, washing and caring" (ibid., 132). This tradition

\footnotetext{
${ }^{8}$ Drawing on the terms women/men and feminine/masculine in this subchapter signifies sexed/gendered identities and social positions that are understood to be regulated by the ordering categories of the binary, heteronormative sex-gender system.
} 
draws on the modern gendered division of labor, which aligns the two sexes with the societal organization of labor between households and factories. ${ }^{9}$ Modern production in capitalist societies divides the idealized family into the subject position of the male breadwinner and the female housewife. ${ }^{10}$ The latter is thereby associated with the sphere of the private, the home, and the former with the public sphere (Cowan 1983, 19). ${ }^{11}$ However, as Cowan reminds us, homes are a site of industrialization just as much as factories and assembly lines. Thus, I am interested in the ways in which the domestic kitchen of modern societies, which constitutes the core of the household, has been and continues to be at the center of multiple automation endeavors.

Marxist feminists such as Silvia Federici have analyzed the gendered division of labor and its attendant organization of social relations within the heterosexual nuclear family. Following Federici's line of thought, the interplay between the gendered division of labor and societal spheres describes an "immense circle of households and assembly lines" (Federici 2012, 36; translation: PT). ${ }^{12}$ Drawing on Federici's picture of a circle helps me to grapple with the interdependencies between the success of assembly-line production and women staying at home and taking care of the daily cycles of housework. Moreover, highlighting these interdependencies, she also points out that the connection between market work, housework and technology in

\footnotetext{
${ }^{9}$ During Western industrialization (19th century), the separation of work and home became established. As a consequence of this separation, "novel conditions for the performance of women's traditional work [emerged], and a new word was coined as testimony to the change" (Cowan 1983, 18). This new term is "housework" (ibid.).

10 According to Cowan, the term housewifery was coined in the 13th century, historically a period at the crossover from feudalism to capitalism, in which "some of the women who did [...] chores were given the name, and the very special social status, of 'housewives'” (Cowan 1983, 17).

${ }^{11}$ Key figures of modern production, for example Henry Ford, developed the idea of the automation of production by perfecting assembly-line production in plants built by the Ford automobile industry. The rise of production at assembly plants constituted a complementary model of societal organization, Fordism. This model is based on the pairing of individuals in the bourgeois heterosexual nuclear family: men perform market work at the plant and take on the role of breadwinners, while women are supposed to stay at home and take care of the daily cycles of housework, which are not acknowledged as labor and are thus unpaid (Cowan 1983; Cockburn and Ormrod 1993). However, as historians have made clear, working-class families, in contrast, were always affected by the necessity of the double burden for women: doing the chores and waged work.

${ }^{12}$ Feminist science and technology studies are strongly rooted in Marxism, although formulating an equally strong critique of Marxist blind spots such as the ignorance of how sex and gender matter and of the importance of housework for production in capitalist societies; see for example Haraway 1991; Wajcman 2000; Federici 2012.
} 
capitalist societies has traditionally been neglected until, for example, the rise of the international campaign "wages for housework" during the 1960s and 1970s (ibid., 37). Following Federici's critique, we can see that waged work is valued over housework; the first is acknowledged as work, producing a surplus, while the latter seems solely to serve the renewal of the former without producing a surplus. Reading Cowan and Federici briefly together, I developed an understanding of households as being at the same time the site of industrialization and of unacknowledged work in which the latter is organized as the taken-for-granted responsibility of women providing reproductive service.

Furthermore, this sociocultural ordering of modern societies carries with it a value-giving relation between labor and goods that is established through the division into dichotomous spheres of home and factory. This division of spheres is not only gendered, but also makes the home into a consumerist sphere, in which domestic appliances, including small devices, which are made available through mass production, become desirable goods. Building a tentative connection between domestic appliances in general and the companion service robot in particular, the latter also appears to be imagined as a prospective future consumer product, which fits into the conception of the household as a consumerist sphere.

I think that the interrelation between assembly lines and households, alongside the concomitant valuing of different forms of labor in capitalist societies, is useful for grappling with a politics of value, the linkage between labor and humanness and the modern power differentials that constitute the automation of work, including reproductive service. However, in what follows, I would like to focus more on the human-machine interfaces in the domestic sphere that are enabled by a specific automaton, the microwave, and the accompanying imaginings of human-machine relations. In doing so, I draw on the microwave as a machine that was initially chosen to become a mass-produced cooking device, as discussed by Cockburn and Ormrod (Cockburn and Ormrod 1993). Reading their study in this sub-section, I will develop an understanding of automata that are thought of as increasing efficiency in the household. In this regard, the microwave is a clear example of a machine that enters the domestic sphere and, in doing so, shapes relations within the household as well as the wider circle of households, assembly 
lines, and technoscientific laboratories of technological development. I use the example of the microwave to conceptualize the class of domestic appliances as one of machines that are not only prospective consumer goods that constitute a variety of human-machine interfaces at home, but also powerful agents in the negotiations of how housework, market work, and technological development are related. Finally, I will outline how this is useful to my map of the making of the domestic robot; for example, by asking how the microwave as domestic appliance relates to the claims made about possible future household robots.

\section{The Microwave}

Analyzing the microwave as a simple yet complex technological device of domestic kitchen machinery, Cockburn and Ormrod carve out the interrelations between the network of actors engaged in the development, economic marketing, and bringing into domestic use of this device. They also examine the hierarchical relations of gender and class that constitute categories of social ordering, as well as gender and class identities (Cockburn and Ormrod 1993, 32ff.). Although constituted by a network, "the project itself creates the network" (ibid., 40), becoming "one recent instance within a continuum of technological change in domestic life" (ibid., 129). Hence, the microwave appears to be an ideal device to trace the fantasy landscape of automation that is constitutive of and propelled by the model of the modern household.

As a first step, I briefly describe the workings of this device. The core of it is a magnetron, which converts "household electric current to high frequency (2450MHz) electromagnetic waves" (Cockburn and Ormrod 1993, 17). The magnetron was initially developed in military research for military purposes, but succeeded as a cooking machine (ibid., 18). The goal of using electromagnetic waves for preparing food was, as Cockburn and Ormrod point out, to " produce 'the ultimate cooking machine'" (ibid., 78). Moreover, the authors analyze the success of the microwave as a consumer good by tracing the elements of the socio-technical network that made this success possible in their relations. Central to their study is what they identify as the "elasticity of demand" (ibid., 16) of the microwave, which means that this machine is used less as the ultimate cooking device than as a device for 
preparing food in varying situations and contexts. It is not fixed, but rather used in different ways, as Cockburn and Ormrod underline, "from a cheap and cheerful box for zapping instant meals to a complex culinary technology" (ibid., 129). The microwave is a clear example of a market success, and a machine that is used in different ways depending on the demands with which the various users approach it.

In what follows, I briefly discuss Cockburn and Ormrod's insights into the different ways in which the microwave is used in relation to the context of this machine, the domestic sphere, which is theorized as a site of complex social relations of power and hierarchy, installed by the modern gendered division of public and private and the complementary rise of the heteronormative nuclear family as a model for the organization of individuals. Moreover, the kitchen holds a special meaning for the household and the cycle of daily housework because it is the space in which people (usually women) provide themselves and others with food, which means to perform materially life-sustaining practices. As Cockburn and Ormrod argue, "[o]f all the facets of housework [...] the provision of food is, materially and symbolically, central" (ibid., 134). ${ }^{13}$ Instead of organizing the provision of food societally, for example in communal kitchens, industrialization led to the success of the model of the domestic kitchen. The responsibility for the provision of food is, in accordance with this model, solely assigned to domestic kitchens, supposedly operated by women, who serve their families (ibid.). This gender and technology dimension is interesting not simply in relation to historical divisions of labor and the gendering of technologies, but in what thought models are available for present-day emerging technologies, such as the domestic robot, which is imagined as a helper in the kitchen.

Along these lines, I am also interested in the automation of tasks that is facilitated by the microwave. Cockburn and Ormrod argue that the daily cycles of the provision of food are based on "a great deal of tacit knowledge" (Cockburn and Ormrod 1993, 89). Cooking involves all the senses: listening, smelling, tasting, seeing and touching (ibid.). In contrast, the microwave, as Cockburn and Ormrod continue, has the effect of black-boxing the process of

13 Cockburn and Ormrod have shown how practices of cycles of housework contribute "to the reproduction of the social order" (Cockburn and Ormrod 1993, 134). On the nexus between dichotomous societal spheres and the social order see also Becker-Schmidt, 2003. 
cooking, a process that changes what is required of the cook. ${ }^{14}$ Instead of relying on her or his tacit knowledge, the cook using the microwave has to rely on her or his knowledge of this machine, which is imagined to take over the cooking process. Thus, the microwave can be regarded as a machine that automates cooking and, in this sense, also as a machine that re-delegates labor.

However, Cockburn and Ormrod's study reveals how such a transition of labor is related to a valuing of tasks, which is indivisible from the societal organization of labor. For example, opening the black box of the microwave, the authors describe the engineering process from which this machine emerges. In short, it becomes clear that cooking is a technology, although it is not acknowledged as such (ibid., 98). The authors underscore that "engineering as a masculine technology is ascribed high value, cooking as a female not-technology a relatively low value" (ibid.). The microwave therefore appears to incorporate the gendered division of labor that underlies the valuing of engineering in contrast to the devaluing of cooking. My argument here is that forms of labor manifest differently in the automaton: it appears that the labor of making up recipes, for example, can be neglected because it is regarded as standing in opposition to the engineering of this device. Cockburn and Ormrod's study, in contrast, traces exactly the invisible labor as well as the modern power differentials constitutive of the valuing of labor and the negotiations of categories such as cooking and engineering.

Although the microwave is imagined and presented as a machine that makes cooking as easy as turning dials into the right position and allowing the machine to do the cooking, Cockburn and Ormrod point out that "the microwave oven enters into existing food and cooking practices that [...] have a very particular and pronounced symbolic significance within the heterosexual relationship in the context of the contemporary nuclear family household" (ibid., 151). With this observation, Cockburn and Ormrod's study further complicates the ways in which imaginings and realizations of automation devices shape practices of technological development on the one hand and, on the other, possible human-machine interfaces in the kitchen.

\footnotetext{
${ }^{14}$ Domestic cooking is assigned in accordance with the historically long-standing gendered division of labor: "Stretching back to the wood fire and the clay, this one had traditionally been in women's hands" (Cockburn and Ormrod 1993, 3).
} 
Moreover, the authors analyzed the use of the microwave in concrete households. One of their insights that I would like to emphasize here is that, once the microwave enters the private sphere, it imposes a double responsibility on women in the daily cycles of housework. It enables them to manage both: housework and market work. Thus, this automaton not only shapes social relations and the individual's identity in the sphere of the private, it also has meaning for the individual's integration into the broader societal economic network, in which domestic kitchens are embedded (ibid., 149). This enablement, however, is also a source of stress for women, because of the new demands that are placed on the housewife's efficiency. As the authors show, one demand is to optimize the provision of food in accordance with the preference of every member of the household and another is to have more time for other things beyond the provision of food with the help of the microwave ${ }^{15}$ primarily more time for being included in the labor market.

This effect of causing stress can be related to Cowan's prominent argument that domestic appliances have a reputation for reducing the amount of housework, while in fact they mostly re-organize the tasks in a manner that requires women to be more efficient in completing the daily cycle of housework. Cowan calls this specific articulation of capitalist logics of exploitation "the irony of modern household technologies" (Cowan 1983), which Cockburn and Ormrod further connect with the use of the microwave. In accordance with their study, microwaves "came into the home as engineered products, but this was in no way incompatible with women continuing to be the labourers - operatorives of domestic technology" (Cockburn and Ormrod 1993, 132). The microwave therefore provides important insights into how domestic appliances shape the ways in which humans relate to each other in taking over responsibility for the daily cycles of reproductive service, the concomitant delegations of labor, and the relation

\footnotetext{
${ }^{15}$ Importantly, domestic devices are only one aspect of fulfilling demands in accordance with the new efficiency that re-organizes domestic life. As feminist studies on the re-organization of reproductive labor in the light of growing participation in the labor market by Western women have pointed out, care work has been largely re-delegated in the process of globalization. One prominent concept is that of "global care chains" (Hochschild 2000, Yeates 2004), which highlights the significance of "transnational care services and the international division of reproductive labour as integral features of the contemporary international economy that are otherwise neglected" (Yeates 2004, 370).
} 
between existing practices and suturing the new into existing regimes of responsibility and care.

Furthermore, I learn from feminist epistemologists such as Sandra Harding that these existing practices can be contextualized within what she framed as "Western modernities" (Harding 2008), that is, the (thinking) tradition of scientific and technological development in the West. As she points out:

Scientific rationality and technical expertise are presented [...] [as enabl[ing] elite Westerners and men around the globe to escape the bonds of tradition, leaving behind for others the responsibility for the flourishing of women, children and other kin, households, and communities [...]. These others must do the $[\ldots]$ reproductive and 'craft' labor [...]. These others are mostly women and non-Western men. (Harding 2008, 2)

I find Harding's line of thought insightful as it describes the delegation of labor between scientific rationality and technical expertise on the one hand and reproductive and craft labor on the other in its analysis of the differentiation and naturalization of social categories of ordering as fundamentally modern. Existing practices of doing the chores in contemporary households appear to be entrenched in the constitutive horizon of Western modernities that creates a separation between the public and private spheres, scientific and reproductive labor, and elite Westerners and their Others.

Cockburn and Ormrod's study is primarily concerned with the ways in which the microwave ties in with the gendered division of labor and concomitant responsibilities in the household. In this regard, the microwave is an example of how an artifact is gendered and incorporates gendering effects. Furthermore, their study illustrates that the way in which gender as a category of social ordering and an identity category gets into the artifact, so to speak, is a highly complex process, which is not pre-determined by the artifact itself, nor by any single stage of the development and bringing into use of this appliance. Rather, I draw from their study an understanding of gendering which highlights that the microwave is characterized by an elasticity of demand. The purely technical content and basic unit of this machine, the magnetron, is a product of military research, which does not determine its usability as a domestic appliance. However, as the authors further point out, the machine's elasticity of demand is not discernible from existing practices of cooking and the attendant responsibilities. 
Hence, the microwave succeeded as a domestic appliance, which connotes the household as the sphere of the housewife, and assigns the operation of this device primarily to women, who are responsible for the provision of food in the nuclear, heterosexual family. The gendering of the artifact derives from the general elasticity of demand that it incorporates, and it relies on the existing practices and imaginings of responsibilities in modern Western households.

I take several insights from the example of the microwave that are useful for my analysis of the practices and imaginings that surround the making of the robot companion as a new class of technology. Firstly, I consider this machine to be a domestic robot that ties in with the long-standing idea of increasing efficiency at home, but which nevertheless implements the dichotomous relation between households as sites of reproductive service and craft labor on the one hand and, on the other hand, factories and technoscientific laboratories as the sites of scientific rationality and technical expertise. Secondly, Cockburn and Ormrod's approach is helpful in learning to trace the socio-technical entanglements through which technologies emerge and then enter into one of the dichotomous thought spheres. ${ }^{16}$ Artifacts such as domestic appliances are embedded in and at the same time evoke relations between the artifact and the different kinds of possible uses. They are entrenched in the socio-technical imaginary of Western technological development. For example, the microwave displays the attempt to engineer tasks that are part of the daily cycle of housework, while its actual use depicts that these practices cannot be divorced from the socio-cultural context of this machine. This includes - not comprehensively - the negotiations of automation in laboratories engaged in technological development, the daily organization of housework at home, the modern societal organization of gender and class, pairing into heteronormative couples and the gendered and, equally important, transnational division of labor.

\footnotetext{
${ }^{16}$ This account of the microwave marks a rupture with determinism in (feminist) science and technology studies. More precisely, they develop an understanding of both technology and gender as not being pre-fixed entities that act on each other; see especially Corinna Bath, 2009.
} 


\subsection{Configurations of Early AI: Primacy of Cognition}

"[A]t the inaugural moment of the computer age, the erasure of embodiment is performed so that 'intelligence' becomes a property of the formal manipulation of symbols rather than enaction in the human life-world." Katherine Hayles, How we became posthuman, 1999, xi Katherine Hayles describes the beginning of "classic AI" (Johnston 2008, 287) as the inaugural moment of the computer age, and at the same time as the origin of the erasure of embodiment in computational science. An analysis of the correlation between the computer age and the erasure of embodiment in the work on intelligent machines adds a useful historical dimension to the socio-technical imaginary of modern automation technology for this thesis. It provides me with important insights not only into early concepts of how to build automata of the class of artificial intelligence, but also into the tremendous influence these have had in shaping the computer age. More precisely, I decided to sketch aspects of the work on machine intelligence carried out by the mathematician Alan Turing, who became prominent as one of the key figures in the inaugural moment of the computer age. Doing so enables me to develop analytical threads for a historical framing of the possible human-machine interfaces that the class of intelligent machines entails. This includes exploring historical understandings of both intelligence and intelligent properties of the machine at the human-machine interface and how this relates to the future robot companion.

To begin with, these two events, namely, the formalization of intelligence and the erasure of embodiment in the performance of intelligence, are connected in early AI. As John Johnston puts it, strands of early AI were primarily "seeking to mechanize or automate thought using logic and algorithmic computing" (Johnston 2008, 287). In this chapter, I will briefly delve into technologies and concepts that are relevant to Turing's work. In doing so, I will, on the one hand, follow Hayles' line of critique. On the other hand, I will draw on what the feminist psychologist Elizabeth Wilson frames as "the affective networks within which mid-twentieth century computational devices were anticipated and then built" (Wilson 2010, ix). I sketch the historical context of one of the beginnings of the computer age, in order to map out the socio-technological imaginings that surround what then became the project of the formalization and mechanization of thought through 
computational means in its prioritization of the manipulation of symbols over embodied interaction in modern models of intelligence. Furthermore, I suggest framing this in terms of the primacy of cognition, as this is what characterizes the class of intelligent machines that are modern automata, which I then analyze using Wilson's study of the affective network of imagining and building these machines.

Going through the historical example of Turing's work, Hayles' critique offers important arguments for understanding how such a primacy of cognition figures in $\mathrm{AI}$, and the consequences with which it operates. Nevertheless, it appears enriching to bring these arguments together with Wilson's study of Turing's work. Wilson focuses on the meaning of affect as it is articulated in the work of practitioners of early AI, including Alan Turing. More specifically, she emphasizes that Turing "was interested in unorthodox conjunctions of intellect and affect" (Wilson 2010, ix). I regard these conjunctions, in accordance with Vicki Kirby and Wilson, as a "key intellectual and political concern" (Kirby and Wilson 2011, 227) of feminist thinking. By making affect a concern when considering the work of Alan Turing, amongst other computer scientists, Kirby and Wilson further highlight the meaning of interrelations between intelligence and affect in "the imagining of computational worlds" (ibid.). Along these lines, I draw on Wilson's insights in order to grapple with imaginings of computational worlds as one central historical dimension of the contemporary sociotechnical imaginary of robot companions.

Notably, the scope of this section only extends to aspects of affective networks in symbolic AI, rather than comprehensively covering the details of Wilson's work - especially with the ongoing discussions about the affective turn in the humanities and the multiple queer and feminist conceptualizations of affect in the background. ${ }^{17}$ Furthermore, the meaning of affect in work on artificial intelligence and building intelligent systems is a topic to which I will return in different chapters of this thesis. For now, however, Wilson's insights guide my account of Turing's work. More precisely, I am interested in complicating the ways in which Turing's model of cognition is constitutive of the class of the intelligent automaton. Firstly, I intend to develop an

\footnotetext{
${ }^{17}$ For an overview of affect theory see, for example: Patricia Ticineto Clough and Jean Halley, 2007; Melissa Gregg and Gregory Seighworth, 2010.
} 
understanding of how, when, and why machines are considered to be intelligent. Secondly, by applying this understanding, I also intend to query how "the dynamics of affectivity" (Wilson 2010, ix) have had a lasting effect on the shaping of the fantasy landscape of modern automation under the register of the intelligent automaton.

The early work on AI is embedded in the Anglo-American context of the late 1950s, the first period of cybernetics. Without delving into the details of this context, I underscore that this early work leads into the dominance of one approach: symbolic AI. This approach is characterized, in short, by the idea that meaningful action can be conceptualized as a search with the goal of problem solving. As Alison Adam points out in her study of "gender and the thinking machine" (Adam 1998), "the emphasis of early AI on search was based on a model of rational, one step at a time, or serial decision making" (Adam 1998, 36), which, as she continues, describes an "excessively deterministic" (ibid.) process. ${ }^{18}$ The objective is to simulate action, which is furthermore considered to consist of cognitive behavior in accordance with the emphasis on search, and which is replicable in the digital machine, the computer.

The endeavor to automate thought comprises the ultimate goal of AI, that is, to build an artificial mind. This goal, as Sherry Turkle highlights, is an “ambition of mythic proportion" (Turkle 2005, 220). This idea of artificial mind also figures in Turing's work. However, Wilson proposes to look closer at his "peculiar vision" (Wilson 2003, 38) of "making mechanical models of the brain" (ibid.). According to her, Turing not only connects with the work of cyberneticists (ibid.), but also with "neurologists, biologists" (Wilson 2003, 40) and, equally importantly, he also began to practice chemistry, and studied the dream theory of Jungian psychology (ibid.). Illustrating the broad, interdisciplinary scope of Turing's approach to constructing a mechanical model of mind, Wilson concludes the following: "[Turing] was perhaps less focused on computers than we might presume and more captivated by the inter-relation of certain mathematical, emotional, social, and engineering

${ }^{18}$ Adam's concept of gender is not relevant to the arguments that I develop in reading her study. However, it seems worth explaining, firstly, that one of her main concerns is women in the history of AI and, secondly, that her concept of gender, especially in relation to technology, could be framed in terms of deterministic strands in feminist science and technology studies, rather than deconstructivism. 
puzzles" (ibid.). Wilson argues that Turing, who has become extremely prominent in relation to a specific model of the computer, and associated with the mechanization of mind through the computer, was engaged in mathematical, emotional, social, and engineering puzzles that exceed the limits of the idea of artificial mind as a number-crunching machine. She further suggests that his "enthusiastic concerns" (ibid.) are equally part of his work. I find this suggestion interesting as a way of approaching the Turing machine as one central example of modern automata through a perspective that equally acknowledges the success of the primacy of cognition and the concomitant disembodiment of intelligence, alongside the affective networks of early AI. However, before I explore this machine in detail, I will unfold the general outlines of symbolic AI as they generate the context of Turing's work.

With the ultimate goal of building an artificial mind in the background, I highlight in what follows two different ways of modeling intelligence that became prominent in AI: the first conceives of intelligence as the capacity to play chess and the second as the ability to pass the Turing test. I will return to the latter in detail shortly, while the first seems worth mentioning briefly. AI researchers selected the capacity to play board or parlor games based on two premises. Firstly, these researchers "naturally looked to themselves" (Adam 1998, 35), and secondly, when looking at themselves, they furthermore defined the activity of playing chess as performing intelligent action, because the researchers themselves, who were mostly mathematicians, played it (Franchi and Güzeldere 2005, 46). Chess succeeded as the model for some aspects of intelligence, and became "the test bed for ideas about creating intelligence" (Turkle 2005, 220). Consequently, intelligence was tackled as "a complex, completely formalizable, and yet totally worldless domain" (Franchi and Güzeldere 2005, 48). These two premises display not only how problems in AI research were defined, but also what kind of intelligence seemed to matter and might continue to matter.

For example, Adam emphasizes that such an approach to the project of artificial mind entails that key researchers of early AI "regard themselves as the gold standard of universal subjects" (Adam 1998, 5). She continues by contesting the establishment of such a gold standard of subjectivity, which seems to incorporate scientific rationality and technical expertise, by highlighting its gendered dimensions, which also have gendering effects. 
Adam terms this the "gendered patterns of rationality" (ibid., 6) of AI. Even touching very briefly upon the gendered dimensions of this gold standard as carved out in Adam's work, the implications of the establishment of chess as a test bed for AI nevertheless become clear. AI researchers appear to factor out socio-cultural circumstances when neglecting, for example, that by looking at themselves, they are executing a powerful gesture of inequality and equally excluding aspects that are important in defining intelligent action in everyday life. This furthermore disregards social relations of domination between men and women by re-establishing the powerful divide between rational and irrational (ibid., 5ff.) in the enactment of what they identify as a neutral approach to intelligence. ${ }^{19}$

In what follows, I examine Turing's work because it can be accounted for as having fed into the success of symbolic, or artificial, $\mathrm{AI} .{ }^{20}$ However, and importantly, I am less interested in reconstructing more than 50 years of AI development in detail than I am in tracing a tension between the basics of the computer age, namely, the mechanization of mind and the erasure of embodiment, as it is passed on as the core of Turing's work and the historical modes of imagining human-machine interfaces, which might expand the hegemonic image of the intelligent machine as the epitome of scientific rationality.

\section{The Universal Machine - The Turing Machine}

In 1950, Turing developed what Suchmann describes as "a now-famous, and still controversial, test for machine intelligence" (Suchman 2007, 47). Basically, his goal in formulating this test was to answer the question of whether machines can think or not. What is most interesting in an analysis of this test, which is generally known as the Turing test, is the conditions that inspired

\footnotetext{
19 How intersectional categories of social ordering are stabilized and destabilized through machines, scientific knowledge and practices in the labs of computer scientists and engineers is a recurring theme of this dissertation which is discussed across the different chapters. To read more on this see for example Haraway 1997, Suchman 2007, Kember 2009.

${ }^{20}$ Alan Turing was gay and in consequence persecuted and penalized during the early 1950s. This also led to his suicide, which he committed only shortly after being penalized. Most books and articles that I read did not mention this information about Turing. However, I decided to include it as important information about the personal and social circumstances of Turing's work.
} 
Turing. ${ }^{21}$ As Wilson points out, "[t]he test is a way of exploring the imaginable limits of computational machines; and for Turing there is no justification for imagining that these limits must exclude the capacity for intelligent thought" (Wilson 2003, 43). In Wilson's argument, what has become famous as the Turing test started as an impulse to scrutinize the imaginable limits of machines as they regulated the socio-technical imaginary of automata in the 1950s. However, when the Turing test developed into a cornerstone for the idea of intelligent machines, it began to be seen as a long-standing and "sufficient evidence for intelligence" (Suchman 2007, 47) in the machine. As John Johnston puts it, "Turing made possible not only the modern computer but the very idea of cognition as a mechanically reproducible computational process" (Johnston 2008, 286). Thus, on the one hand, passing the Turing test is established as a goal of AI (Brooks 1991, 5) and, on the other hand, the test inspires a conflation between human and machine and artificial and natural based on the formalization and mechanization of thinking, which focuses on a somehow measurable output of intelligent action. Thinking is conceptualized as an output-oriented operation of information processing (Suchman 2007, 47), although Turing's enthusiasm in exploring imaginable limits seems not to play any role in this canonical form of the test and its reductive concept of intelligence.

Obviously, the Turing test has had a lasting influence in shaping the fantasy landscape of human-machine interfaces. To set a wider context, his work on machine thinking related thought and language in a manner that obviously emanated from his encounter with Cartesian philosophy. ${ }^{22}$ From Descartes, Turing draws one of his main concerns, which is, how language

\footnotetext{
${ }^{21}$ In short, the Turing test started out as "a game called the 'imitation game" (Suchman 2007, 47). The imitation game brings together one person with either another person or a computer, the first person asking questions via teletype and then guessing whether it is a human or a machine answering the questions at the other end of the wire (Görz and Nebel 2003, 21). Notably, Turing initially designed this test to determine whether the gender of a person at the other end of the wire can be determined in this situation and therefore operated initially with a crude gender binarism, which cements an essential difference between men and women (Suchman 2007, 47; Wilson 2003, 42 ff.). Others have written extensively on the Turing test (Suchman 2007, 47); however, I follow Wilson's line of thought in my interest in the Turing test as she highlights that it signifies an intriguing desire to pose anew the question of the possibilities of machine thinking (Wilson 2003, 44).

${ }^{22}$ When bringing Turing and Descartes together, I highlight certain aspects over others in the work of the latter. An important question, which French philosopher René Descartes (1596-1650) dwelt upon, is how thought and language relate to one another (Franchi and Güzeldere 2005, 41).
} 
and thought relate. This leads to the privilege of linguistic behavior as an indicator for thought. The implication of this is that linguistic behavior can be abstracted from thinking, and the goal becomes "to reproduce a process" (Franchi and Güzeldere 2005, 49). Notably, this idea includes, as Stefano Franchi and Güven Güzeldere note, "adopt[ing] and operat[ing] on a very specific and narrow conception of intelligence" (Franchi and Güzeldere 2005, 46). This narrow concept of intelligence as executing steps along a "serial, rational, step-by-step path" (Adam 1998, 36) came to dominate in AI research in general and mapped the terrain "for the next three decades" (Adam 1998, 35).

Furthermore, the logic of such a strict mechanical determination can be contextualized within the "rationalist tradition in modern philosophy" (Franchi and Güzeldere 2005, 47), which Descartes certainly represents. To develop a conceptualization of intelligence in the machine in a Cartesian sense ${ }^{23}$ thus locates the mind externally to the body, and subtracts everything material from the symbolic output of the computer. This proceeding, in line with Franchi and Güzeldere, clearly displays a "lack of interest in analysis of the material conditioning of the thought process, starting from the material embodiment of the mind" (Franchi and Güzeldere 2005, 48). The mechanization of thought entails conceptualizing the mechanisms of algorithmic computing as the abstract, dis-embodied manipulation of symbols, which in turn becomes the model for thinking. This concept mirrors the rationalist tradition of Western, modern philosophy very tangibly, as it perpetuates the widely influential split between body and mind. This split is fostered by the rationalist tradition in modern philosophy, most prominently known as the Cartesian split.

This split constitutes the "homo duplex" (Honegger 2011, 95); a figure which, in line with Claudia Honegger, can be described as the "primordiality' of thinking, [which] [enforces] a fundamental difference between the divisible body and the non-divisible mind" (Honegger 2011, 95; translation: PT). In short, this ontological split describes the hierarchical relation between the

\footnotetext{
${ }^{23}$ Descartes most prominently coined the image of the body as "some kind of machine" (Descartes 1870, in: von Braun 2006, 24-25, translation: PT), in which the cogs in its mechanical determinism become the picture for the principles of life and nature. Hence, the body is thought of as healthy when the organs operate in a smooth flow, similar to the frictionless running of cogs (von Braun 2006, 23-24).
} 
body as imperfect and the mind as perfect, and therefore facilitates the idea of rationalism, which depicts the execution of intelligent action as strictly mechanically determinable. Certainly, I cannot delve genealogically into the history of ideas in a manner that would be appropriate to comprehend the historical lineage and to trace the idea of mind as number-crunching machine in its meaning for computer science and philosophy, as well as psychology and other disciplines. Therefore, after illustrating briefly both the context of the mind as number-crunching machine and the dis-embodiment of mind as historically rich images, I intend to relate aspects of this context to Turing's work. In doing so, my focus is to link both connections and possibilities of rupture with certain thinking traditions and imaginable limits, which will become useful for my map of the robot companion that I understand to be one current model of the intelligent machine.

So far, I have presented Turing's contribution as the foundational work par excellence on what Bruno Latour regards as one of the "icons" of "formalism" (Latour 2004, 257), the computer. However, my engagement with this iconic image of the number-crunching machine that I wish to develop also takes into account the ways in which Turing's work moves beyond the very mechanical determinism that he seems to be propelling. Here, I once again find Wilson's work very helpful when taking affectivity as an indicator for finding such ways in Turing's work. In line with Wilson, affect is part of the "richly inventive, richly heterogeneous context" (Wilson 2003, 41), in which the Turing machine stands. I regard as one such example of a non-deterministic engagement with the machine what Wilson frames as Turing's "capacity to be surprised" (ibid., 45; emphasis in original). Through this, he allowed "unexpected behavior" (ibid.) to become a core quality that he constantly cultivated when building artificial minds. Latour furthermore argues in a similar vein, when he states: "The computer is in for many surprises; you get out of it much more than you put into it" (Latour 2004, 247). It is exactly this quality of being surprised by the model of the automation of thought and the emerging surprises you get out of the actual machine, which move us beyond assuming a strictly deterministic relationship between input and output and the idea of thinking as calculable process. Turing himself thus emphasized that his calculations of the computer are "naturally [...] often wrong" (Turing, in Wilson 2003, 45). Presenting one of Turing's insights, Wilson emphasizes 
that his work opposes the thought that "computational machines are intelligent in only the most narrow [...], the most unsurprising sense of the world" (Wilson 2003, 45; emphasis in original). Thereby, she focuses on "show[ing] how they [the devices] were also built out of feeling, and mutuality, and worldliness" (Wilson with Kirby 2011, 229). Along these lines, I understand Turing's work on the project of the automation of mind in its relation to affective networks, which includes affects like joy, excitement, and surprise, as core aspects of engineering practices. Furthermore, mapping affective networks is one way to link the practices of imagining and building technological devices to their worldliness, that is, the rich context and conditions from which, for example, the capacity for intelligent behavior emerges.

Recapitulating central insights into the relevance of affect for Turing's work and the evolving computer, I highlight that a certain tension between the surprising machine, that is, the machine embedded in an affective, worldly network, and the unsurprising, or number-crunching, dis-embodied machine becomes apparent. This tension is of interest for my map of the socio-technical imaginary of contemporary robotics; firstly, because it depicts the imaginable limits of the dominant model of the intelligent machine and, secondly, it makes palpable that the boundaries of these limits are contingent. I find this extremely useful in developing an account of automata in their socio-technical entanglements. Instead of regarding the limits of technological imagination as something that the artifact itself determines, I contest the idea that these limits are inherent either to concepts or models of the computer or to the actual machine. Rather, imaginable limits seem to depend on the practices of engaging with the machine, as Wilson's study of Turing's account of the machine depicts; that is, a process which involves an array of actors and actions - a network - on different scales.

My argument here is to suggest that the Turing test is a clear example of what Eve Kosofsky Sedgwick and Adam Frank identify in their analysis of early cybernetics as an "intellectual moment" of "technological imagination" (Sedgwick and Frank 2003, 105) at the historical junction at which 'cognitive machines', such as computers, became thinkable, but not yet realizable (ibid.). These forms of imagination encompass the thought models and practices of engineering the human-machine interfaces of the present day, but also modes 
of thinking that did not succeed. This genealogical dimension of intelligent automata will help me in a later section of this thesis to draw historical lines between the forms of technological imagination that are incorporated in, for example, the Turing machine, and the practices of imagining and building an intelligent machine that compose the robot companion.

I furthermore propose that the technological imagination of early AI can be captured through the terms of a primacy of cognition. The ideas of symbolic AI set out to define intelligence strictly in terms of mechanically determinable cognitive behavior, which I contemplate as a contingent figuration of the idea of formalism. Furthermore, this formalism can not only be related but also contested through the non-formalism that can be found in Turing's work. Certain properties of the machine become apparent to Turing because he engages with the artifact through affects like curiosity, excitement, and surprise. Through this engagement, he also locates the capacity to surprise within the machine. I will use the insights of this sub-section in my analysis by making them a part of the map that I use to unfold imaginable limits as they regulate contemporary imaginings and to recuperate their contingency. The design of a new class of intelligent machines is not only always rooted in research traditions, whether in the form of a continuation or a rupture, but also entails a peculiar vision of the intelligent machine, which entangles interpretations of the machine and the material qualities of this artifact in a specific manner.

Resuming here, the unsurprising machine manifests as a model of the intelligent machine, which operates with a specific and narrow concept of intelligence and favors such intelligent behavior in a number-crunching sense over all other possible behaviors that could evolve at the human-machine interface. Further implications of this model are that the material conditions and context of thought are factored out of it. In order to model intelligent action, it becomes prerequisite that, firstly, the machine has an internal representation of the symbolic system and, secondly, that it has to be somehow able to know when it is engaging in thinking with another entity that is also capable of thinking. Hence, the thinking machine is predominantly regarded as a machine that qualifies as unsurprising. This historical dimension of modern automation technologies will further enrich my map of the robot companion by querying the imaginable limits of this machine in 
relation to the image of the surprising machine, which also provides points of departure to debunk connections between the rationalist tradition of modern philosophy and computer science. This also entails expanding metaphors of everyday life that are deeply entrenched in the idea of mind as numbercrunching machine. ${ }^{24}$

\subsection{Human-Machine Interfaces - A Historical Framework}

In this chapter, I have discussed contextualizing facets of the robot companion and presented historical examples of imaginings and realizations of humanmachine interfaces from which I draw themes, concepts and issues that emerge when engaging with contemporary artifacts in vision and action. One important insight is that all four categories: the social, the technical, the human and the nonhuman are contingent, and the process of determining the boundaries of these categories, and, accordingly, which parts of the world can be sorted into which category, is the result of technoscientific production, rather than the foundation of technoscientific research and innovation. This idea is easier to comprehend against the background of the historical context of new modes of technological imagination that surround the historical phase of cybernetics.

After World War II, the extreme challenges to reason and humanity that people had witnessed provoked the urge to reinvent science or, even more broadly and in line with Evelyn Fox Keller, to reinvent every "aspect of human existence" (Keller 2002, 56). However, these efforts led, as Haraway reminds us, to "crucial boundary breakdowns" (Haraway 1991, 151). These

\footnotetext{
${ }^{24}$ Though not delving into Turkle's highly prominent study of the computer as "the second self" ([1984] 2005) in detail, I highlight her line of thought that computer science, which evolved from symbolic AI, allows us "to think differently about human thought" (Turkle 2005, 1; emphasis in original). As she elaborates, a theory of mind evolved from AI research, which propelled an extensive, conceptual exchange between psychology and computer science (ibid., 1ff). Concepts of the mind as thinking machine "invaded the field of psychology" (ibid., 222). This process is based on the mutual transfer of terms and concepts (ibid., 2), through which the metaphor of "mind as program" (ibid., 222) evolved as a commonplace, which on the one hand lastingly shaped the relation between human and machine and, on the other hand, led to the rise of cognitive science (cf. Clark 2001), which is primarily signified by a scientification of psychology. As Suchman points out, "the study of cognition is to be empiricized not by a strict adherence to behaviorism but by the use of a new technology: namely, the computer" (Suchman 2007, 36). This metaphor thus shaped how we think about computers and about humans and therefore depicts an important dimension of the historical framing of the imaginings of the intelligent machine at large.
} 
crucial breakdowns are the points at which, as Haraway continues, "a common ontology" (Haraway 2003b, 48) crystallized. The spectrum of such a common ontology ranges from the intention to "functionally simulate human mental activity" (Görz and Nebel 2003, 17; translation: P.T.) to the postulation that "cybernetic terms and concepts might be able to offer an adequate description of the condition humana" (Hagner and Hörl 2008, 7; translation: PT, emphasis in original).

Both statements display the mythic proportions of the reinvention of science and human existence. Notably, these points of crystallization of a common ontology between human and machine also bring with them different modes of reinvention and practices of automation. One vision of reinvention figures in the work of Turing, and how his work has been passed on. Beyond this, what becomes apparent to me when writing a historical framework is that this is not an innocent endeavor, but rather a powerful operation, charged with securing the success of certain approaches and ideas over others. Taking into account the operations of power in historically contextualizing certain works and ideas therefore provides a productive resource for the analytical framework of this thesis.

The British mathematician, Charles Babbage, inventor of the 'analytical engine' in the 19th century (cf. Görz and Nebel 2003, 6), described the rationalization of production as the substitution of man through machines. He described it in terms of inventing "machines, which can supersede the ability and strength of the human arm" (Babbage 832, in: Görz and Nebel 2003, 16; translation: PT). Heralding "the magic of modern automatization" (Wiener 1964, 52; in: Bowker 1993, 113), speculations and desires similar to the one articulated by Babbage are articulated in the work of cyberneticists, but, as I will continue to argue, these also had a lasting influence on the socio-technical practices of imagining and building automata. Technological development in the world after World War II marked an advancement in the convergence of bio-techno-science, and was defined through the shared goal of technology development, which Rodney Brooks frames as: "[T]he construction of useful intelligent systems and the understanding of human intelligence" (Brooks 1991, 7). The goal of building machines that are replications of or even supersede humans and are useful to humans in the sense that they can take over a variety of tasks and behaviors, from cooking to thinking, becomes 
apparent as a core objective in the development of technoscientific technology. Thus, I will investigate how dimensions of this core objective relate to the making of the robot companion.

Moreover, implied in this objective are specific visions of proper categories and boundaries between social, technical, human and nonhuman and how these relate. To simplify this with the example of the intelligent machine, I highlight that early AI produced the category of the human, in which the human figures as cognitive agent, basically a number-crunching machine, while her_his cognitive capacities seem to be independent of the physical world and individual body. This representation contributes to AI as a functionalist project, which works on the premise of the primacy of cognition.

Furthermore, this conception of cognition in terms of reproducible behavior is linked to the abiding fascination with the automation of behaviors on different scales. As Suchman observes, "[t]he project of making automata is a recent manifestation of a more long-standing preoccupation, with the agential - and more specifically human - properties of material things" (Suchman 2007, 228). Notably, work on the artificial mind in particular illustrates the complexities of the socio-technical production of the useful intelligent system: the metaphor of mind as program evolves from early AI, succeeds in cognitive science at large and, in turn, becomes the model for the artificial mind and modeling cognitive behavior. The idea of artificial mind thus describes the mutual transgression and re-demarcation of boundaries though which proper categories of non/human sorting become established.

The example of the microwave allows the conclusion that technological development and engineering are research and innovation endeavors, which do not take place outside of the social, nor are they purely social. These insights are vital for tracing the socio-technical entanglements of the future robot companion as a machine that is imagined as taking over in the kitchen. Along these lines, the emergence of the robot as domestic appliance is a feminist issue that requires scrutinizing the making of this machine, and tracing its contextualization within the division of societal spheres and existing practices of doing the chores in contemporary households, which are based on powerful relations of social ordering between men, women, children, and other kin. 
I will use the insights that I have drawn from both examples, the microwave and Turing's model of the computer, in my continuing map of the making of the robot companion from a perspective that tunes me in to the socio-technical entanglements and sorting operations on different scales, from becoming attentive toward the multiple actors, existing practices of valuing work along modern power differentials and the concomitant associations of tasks and properties in the machine with humanness, to taking into account affect and its meaning for the project of automating labor. However, one important aspect is also to contest the promises and logics of engineering a task as the endeavor to make someone more efficient in the household and to instead highlight the irony of modern automation technologies.

The turns, shifts and layerings of sorting operations in technoscientific practices are of special interest for this thesis. Therefore, in the remainder of this chapter I will connect aspects of the analytical framework with the historical framing of the robot companion. By doing so, I develop a historically and empirically saturated understanding of how human-machine interfaces configure that I will use in my account of the robot companion in the chapters that follow. To configure is a verb that I draw from Suchman's work on the feminist science of the artificial (Suchman 2007; 2008). Moreover, the term configuring allows for a sense of humans and machines as inseparable, rather than intertwined, but nevertheless individual, entities. Thus, configuration suggests conceptualizing technological development, in line with Suchman, as "forming materialized figuration; that is they bring together assemblages of stuff and meaning into more and less stable arrangements" (Suchman 2007, 227). I will use Suchman's outline of analyzing machines as assemblages of stuff and meaning that stabilize into a materialized figuration to map practices of imagining and building the robot companion and to take into account the fact that neither human and machine nor social and technical existed prior to their historically specific, configured relations.

Although the human-machine configurations that I draw upon each articulate a different engagement with the reinvention of science and existence, from cybernetics' claim to have developed a description of the conditio humana to the development of the microwave as a supplementary kitchen device for cooking food, they share impulses of technological 
development. Technoscientific technology development is initiated from three different, though overlapping, fields of research and innovation in capitalist societies: the military and war science, the domestic home as a consumerist sphere and the market sphere of mass production. In addition, the idea of machines as useful intelligent systems for humans at war, home and work raises questions which, as Judy Wajcman notes, leave "[t]he nature of work, consumption and social interaction [...] in a state of flux" (Wajcman 2004, 1-2). These include questions such as: What are 'human cognitive skills'? Can robotic machines perform these? And: How can one be at war when cyborgs and robot soldiers are serving in the army? Or: How should we re-organize labor - housework as much as waged work - when technologies from supplementary devices to robot companions can assist? In line with Wajcman, technological development can be thought to initiate a "changing [of] the idea of what it means to be human, and even our sense of self" (Wajcman 2004, 2). This description of technoscientific practices as potentially changing the idea of what it means to be human, as well as our sense of self, represents one of the main findings of this chapter. Human-machine configurations are embedded in and propel relations between humans and machines, and through these processes a common ontology crystallizes.

In “A Cyborg Manifesto" (Haraway 1991), Haraway analyzes three lines of technological development which are changing the idea of what it means to be human on different levels: "Microelectronics mediates the translations of labour into robotics and word processing, sex into genetic engineering and reproductive technologies, and mind into artificial intelligence and decision procedure" (Haraway 1991, 151). I touch upon two of these in my selection of human-machine configurations: the translation of labor and the translation of mind. As John Law points out: "[T]ranslation is both about making equivalent and about shifting" (Law 2009, 144). Translation is one of the core operations through which the boundaries of categories, as well as of technological imaginations, are drawn and redrawn. Along these lines, I suggest that translation is an analytical term, grappling as it does with the shifts, turns and layerings in technoscientific socio-technical production, that will be of continuing interest for this thesis. Thus, my map will emphasize tracing practices of mutual translation between the human and the non-human, nature and culture, organic and artificial in the making of this machine. 
The robot companion is indeed a machine, which emerges, not from nowhere, but rather from a historically specific conjunction of technoscientific socio-technical production, and is embedded in the long-standing promise of developing automata that replicate or even supersede human abilities in order to become useful as ordinary objects in everyday life. 


\section{The Anthropoid in Public: Introducing Human-Machine Relations in Anthropomorphic Configurations}

In this chapter, I will describe the robotic engineering laboratories as I encountered them during the socio-ethnographic phases of this dissertation. While few people, even very few social scientists, actually get to experience the inside of a laboratory, a basic assumption here is that laboratories must be regarded as public spaces, open to inspection and outside influences (Latour and Woolgar 1979; Knorr Cetina 1981). Since the time of Robert Boyle in the 17th century (Shapin and Schaffer 1985), science and engineering have been made public due to science's societal role, especially in terms of its promises of technological progress (Haraway 1997), its tax-funded status, the social and collaborative history of scientific knowledge production (Traweek 1988) and, more recently, due to the ever-increasing demands on scientists and engineers to present their results to a wide audience. However, in this chapter I will also outline my socio-technical approach to anthropomatic robotics, its "service economy" (Suchman 2007), and especially to the "Institute for Anthropomatics and Robotics" (IAR), as I experienced it.

In this way, I will introduce some key elements of my socio-ethnographic study and my analytical work from a queer-feminist perspective of technoscientific laboratory studies, focusing on the human-robot interface as it is socially imagined, practiced and publicly realized within one robotics departments. This chapter thus explores public images of anthropomatics and in particular publicly available images of a specific machine, named Armar, at its location, the IAR at the Karlsruhe Institute of Technology (KIT). Notably, I am also interested in the public image of anthropomatic robotics as research and innovation under the rubric of developing robot companions at large, and will use this chapter to pin down certain key features of the socio-technical fantasy landscape of anthropoid robotics as they appear in public media. I therefore explore a selection of anthropomatic human-machine relations that will further contribute to and structure my map of the making of the anthropoid robot model.

To begin with, I present the central topics of this whole dissertation by, amongst other things, drawing on one remarkable example of a (self)representation of Armar. In a news broadcast that I watched very early on in my doctoral research, the importance of the public acceptance of this new 
technology became tangible for me. In addition, I also experienced this as displaying some key features of how exactly anthropoid robots are made sense of or, rather, how they become legible as prospective companions, in public, and perhaps even how they are marketed and "sold" (Nelkin 1995) to a more general audience, and thus made socially recognizable. The status and role of a robotic machine intended for reproductive service and care work is after all something that needs to be presented as convincing and worthy of investment as a branch of technoscience. There is no shortage of fantasy images of both good and evil robots in contemporary culture, so a new class of robotic technologies has to navigate these and provide a re-negotiated, beneficial image of the technology: namely Armar. The way in which the current model of the Armar series, Armar IIIa, which by now is quite famous, was introduced onto the political and public scene in its home-town of Karlsruhe in Germany might therefore work here as a condensed example of anthropomatic human-machine relations and how they might function in their public dimensions more widely.

On November 14, 2010, the "humanoid robot Armar"25 was featured in a news broadcast on German television as it was demonstrated at a conference held by German chancellor Angela Merkel's party, the CDU (Christian Democratic Union). This encounter vividly depicts the human-robot interface that emerges from the building of advanced anthropoid robots, as seen in the screen shot and transcript of the encounter below.

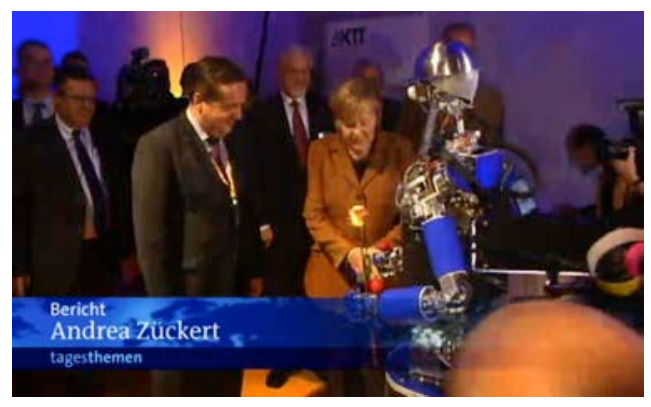

“Good evening, Madam Chancellor. Welcome to Karlsruhe. May I introduce myself? My name is Armar. I was born at the Karlsruhe Institute of Technology. I am pleased to meet you. I wish you a nice evening". ${ }^{26}$

Picture 1: Screen-shot of "Tagesthemen", a German news broadcast

\footnotetext{
${ }^{25}$ http: / / his.anthropomatik.kit.edu/241.php.

${ }^{26}$ http: / / his.anthropomatik.kit.edu/241.php.
} 
The robot here is made to enact a very polite encounter between the political leader of the nation and one of its new "subject objects" (Suchman 2011), the robot companion. There are apparently specific bodily and technological gestures, phrases and ways of behaving and introducing oneself politely that constitute what would pass as a socially fitting and meaningful human-robot encounter. Indeed, a close reading of this example of a publicly broadcast encounter enables specific societal codes of conduct and cultural scripts to appear. Moreover, I read this encounter as displaying socio-cultural conventions and how these are both affirmed and negotiated. For example, the robot appears on screen as a machine having approximately the same size as an average tall, able-bodied human adult. Height-wise, Armar fits in with the people who surround it. The robot rolls up to Merkel in an appropriately respectful and familiar manner of standing neither too close nor too distant, its body and head facing toward her, even giving the impression that it is looking into her face while reaching out with its robotic hand at a right angle in order to shake hands, speaking to her, grasping her hand. This means both closing its hand when touching hands and squeezing, also in an appropriate manner - not too softly and not too hard. Amar then lets go of her hand again to finally give her the rose which it is holding in its other hand.

These gestures certainly constitute a polite political encounter between the latest offspring of the rapidly developing frontier of robotic research and a political head of state. Just like national events where children are trained to give flowers to political leaders, this is a publicly staged moment. As a public spectacle, it also renders itself open to interpretations of what went on as it were behind the scenes, and the preparations that must have taken place. My argument here is that this encounter was a well-orchestrated staging that needed to be prepared, rehearsed in advance, and of course programmed into Armar. I even suggest that we can contemplate Armar's introductory words as charged with meaning comparable to the famous phrase "a small step for man and a giant leap for mankind" that NASA astronaut Neil Armstrong publicly performed when he first stepped onto the surface of the moon. However, it also lays open the cultural scripts and expectations of a public figure and leader such as Merkel, who was probably also well prepared in advance to smilingly accept Armar's outstretched robotic hand, which she does without any visible hint of fear of getting her hand crushed by a mishap 
in the robot's programming, and politely accept the flower. As with the moon landing, this is a case of doing technoscience in public (Gieryn 1983; Star and Griesemer 1989) and as such it conforms to specific societal scripts while simultaneously adding to and negotiating the imaginary of the robot-human interface.

I have chosen this public encounter between Armar and Merkel because I regard it as a highly typical, even iconic, example of a socially scripted, imagined and staged human-machine encounter. In many ways it opens a peephole onto the socio-technical imaginary of contemporary robotics. It displays the interrelations between the creation of a new class of technology, namely the humanoid Armar, politics, represented by Merkel, and the public, as this is part of a national news broadcast. The robot illustrates, even embodies, the large-scale potentialities of German technological development. This includes economic aspects of Germany as a business location, which are of course a continuing topic in politics. Beyond this, and equally fascinating, are also the tasks which this machine executes. Although viewers cannot really identify the shape of the grappler or other details, it is intriguing that this machine is obviously equipped with a tactile device like a hand with which it is able to grasp such seemingly fragile objects as rose stems - or human hands. In relation to this, I have chosen this example because Armar and Merkel are meeting each other on what I suggest framing as human-shaped grounds. This encounter between Armar and Chancellor Merkel indicates an association of the robot with the human gestalt. This further evokes a form of individualistic and self-governed subjectivity that is tied to the behavior of the machine as it performs the highly complex gesture of touching and shaking hands, including appropriate proximity to Merkel. The robot appears to be relating itself to persons and, in this way it becomes legible as "almost human" ([Haraway 1989] Suchman 2011).

Armar thus appears to redeem the promises of the 'robot companion network', the online network aiming to facilitate the societal introduction of anthropomorphic robotics that was described in the introduction, which promises a form of robotics for citizens. Their slogan "robots for citizens" could even be read as a plea for robots as citizens. Such a doubled idea, of robots as a product available to all citizens as well as the future human-like citizens themselves, is equally supported by the words chosen as Armar's 
self-introduction: this machine fits into the class of artificial, intelligent, and embodied creatures, which are actually "born" (see Armar's statement when meeting Merkel; emphasis added), rather than constructed. Such a classification of this robot sorts it into an emerging class of machines that incorporate promises of automation as well as naturalizing this automaton, making it more natural.

Along these lines, a feature that is central to studying the practices of imagining and realizing the Armar-human interface is the machine's humanness, which seems to be related to its capacities for (inter-)action. The employment of humanlike behavior through affirming socio-cultural scripts, as demonstrated in the example above, is thus a topic of continuing interest that I will emphasize in this chapter and throughout this thesis. More precisely, I will ask how such preconceptions of what I earlier framed as human-shaped grounds are revealed in the (self-)representations of the research group. This chapter deals with the various processes of, and material-discursive consequences behind, configuring human and machine through publicly presentable encounters that are expressed at specific sites of anthropomatics. The data and material upon which I primarily draw in this chapter are the central outlines, goals and context of anthropomatics as they are formulated in the compact statements that I found on the IAR's homepage and project-related sub-homepages, amongst other locations. These are of interest because they serve the goal of making Armar, and anthropomatics generally, more public. In addition, in my analytical work in this chapter I also draw on my field notes from both periods of fieldwork, as well as transcripts of informal talks and expert interviews. The latter helped me to develop a deeper understanding of statements and explanations that I found online.

My analytical work is largely informed by strands of technoscience studies that investigate technoscience in public. Here, I am thinking for instance of Geoffrey Bowker, who proposes a method for tracing the "organizational environment" (Star and Ruhleder 1996, 131) around an artifact such as the humanoid robot at the center of this study that he frames in terms of "infrastructural inversion" (Bowker 1994, in: Bowker and Star 2000, 34, emphasis in original). Bowker explains that inversion invites one "to look closely at technologies and arrangements that, by design and by habit, tend to 
fade into the woodwork" (ibid.). I use this aspect of Bowker's methodological strategy to reconstruct dimensions of work practices of anthropomatic research and innovation in their specific arrangements as they become apparent in my initial reading of (self-) representations.

Furthermore, I bring this methodological strategy into conversation with Haraway's account of scientific innovation and research as figurative storytelling. In short, the scope of this research, in line with Haraway, "emphasize[s] figuration to make explicit and inescapable the tropic quality of all material-semiotic processes, especially in technoscience" (Haraway 1997, 11). Technoscientific narratives of possible human-machine interfaces are saturated with tropes, figures of speech such as metaphors, icons, allegories etc. Along these lines, I will analyze the material in this chapter by mapping the material-semiotic processes of shifting, turning, and layering as well as translations between human and machine at the location of anthropomatic robotics. By doing so, I propose an infrastructural inversion; this means looking closely at that which is taken for granted. Infrastructure and (con-)figuration thus serve as analytical concepts through which I give an initial account of my engagement with the socio-technical production of Armar and the relevance of actions in the selected laboratories; that is to say, the interdependencies between bodies, tasks, labors, capacities and concerns in anthropomatics and how these relate human with machine.

\subsection{Entering the Laboratories}

The first in situ contact I had with the IAR was during the institute's inauguration in 2010, which I attended. This event was my opportunity to get to know more about the institute, as well as the broader landscape of humanoid robotics through the inauguration talks and demonstrations of the humanoid robots, Armar IIIa and IIIb. Furthermore, this was also my first opportunity to stand in the laboratories and watch a 'live' demonstration of Armar III $a$ and b. After the presentations, I initiated a brief conversation with one of the practitioners in the kitchen, in which I introduced myself and told him about my inquiry. Right from this beginning of initiating my field studies, I experienced everyone I spoke with as friendly and open to the idea of several visits to the IAR. These first conversations led to several invitations for visits at the institute over the following years. 


\section{Open Labs - the Atmosphere at the IAR}

During both stays I was integrated into the IAR, working at my own desk in an office I shared with one of the practitioners. In addition, I received a keycard that gave me access to the building and the library, as well as a visitor's email account with access to the online library of the KIT. I was also informed about special events at the IAR, such as inaugural and guest lectures, PhD defenses, and more informal events like a summer barbecue at the Institute at the end of term. Furthermore, the secretary of the IAR was instructed to assist me in contacting a number of selected, cooperating professors, who are not located at the "Humanoids and Intelligence Systems Labs $^{\prime 27}$, but also contribute to the research carried out there.

The IAR is located on the ground floor of the left wing of a big, mansionlike building. One part of the ground-floor hallway leads into another office on the left and opposite to this on the right is the main laboratory, the kitchen lab. This kitchen lab is fully equipped with an L-shaped kitchenette on the right side of the wall and the adjoining wall. The entrance to this lab is a sliding door, which is wider than the other doors on this hallway. The kitchen is arranged in such a manner that it looks like a 'real' kitchen with all the appliances one would expect. On the left of the kitchenette, also close to the wall and under the windows, is a table with a workstation and several PCs. Going further to the left, there is some space that appears to be designated for visitors: on the wall to the left is more kitchen furniture, including another table, which looks like a breakfast bar with bar stools. Big windows are inserted into the wall on the left-hand side and the wall next to the door on the right-hand side.

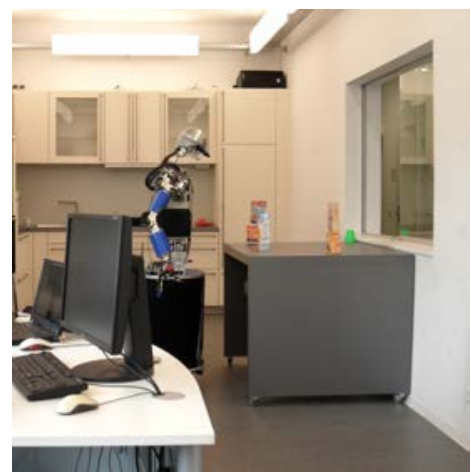

The kitchenette lab is equipped with a fairly new white and shiny kitchen, which is arranged architecturally in such a manner that this room appears friendly and bright. The bright lights are always switched on and the additional windows in the walls support this impression. The windows also contribute to the overall welcoming atmosphere of the lab,

Picture 2: Armar IIIa in the Kitchen Lab

\footnotetext{
${ }^{27}$ https: / / his.anthropomatik.kit.edu.
} 
not only by filling the room with light, but also by creating what I call an 'open lab'. Clearly, such a visitor-friendly design has the effect of rendering the processes of research and innovation on humanoid robots as fostered by the IAR transparent and objective. The importance of this design on its functionalities will be explored at length in the next chapter, when I analyze the kitchen lab and other human and non-human elements in action.

The lab, in short, is the place where Armar 'lives': here the machine was built, here it learns to 'interact', and this is also where its capabilities are demonstrated to a wider audience. Accordingly, I have spent most of my time during my research stays in this laboratory. The empirical data that I collected at this site of making the robot domestic encompasses recordings, pictures, short video clips and field notes, which between them capture the day-to-day practices of work on and with the robot. In this way, I grapple with the laboratory as the organizational environment from which anthropomatics and the anthropoid robot, Armar, emerge. This organizational environment is constitutive of and constituted by an infrastructure which, as briefly described above, is something that is "frequently taken for granted" (Bowker and Star, 2000 98). However, the question of for whom a certain infrastructure operates as a self-evident resource and for whom that same infrastructure appears as an insuperable barrier to a certain field of knowledge (production) is a matter of location and access because, as Bowker and Star point out, "[i]nfrastructures are never transparent for everyone" (Bowker and Star 2000, 33). Highlighting this thought that the infrastructure of the open labs as the location of Armar is, firstly, that which is taken for granted and, secondly, not transparent for everyone, I will briefly sketch in what follows how I experienced the process of entering and staying in the labs in relation to theoretical and methodological insights that I draw from feminist technoscience studies.

\section{Engaging in Entanglements in the Robotic Kitchen Laboratory}

After arriving at the institute early on a Monday in July 2011, I was immediately assigned an office space at the IAR on the fourth floor. Sharing the office with a practitioner working at the institute, I quickly became part of daily, collective routines like taking coffee breaks and going for lunch together. During these communal breaks, it was possible to engage with the 
practitioners in more informal conversations about the work of the IAR, their positions at the institute, and my field study. Furthermore, during my second communal lunch break, one of the practitioners, who was sitting across the table, told me that "with our research, we haven't got that far yet ... it's not like on TV or anything ... it will take years" (field notes, July 2011; translation: PT). This assessment first of all positions the person who was sitting at the table across from me as an expert, who knows the state of the art in robotics, in contrast to me. Secondly, it exposes a discrepancy between cultural imaginations of humanoid robots as they are articulated through popular scientific reports and science fictional films, and what has actually been accomplished in robotics so far - according to how this practitioner experiences it. This evaluation not only clarified the actual state of the art in robotics, but also felt like an adjustment directed at me in the sense of: "Look, the robot is not yet ready to enter the social sphere."

I mention this early conversation that took place during one of the multiple lunch breaks as I regard this rather small situation as a great opportunity to discuss the basis of my approach to anthropomatics. As I will continue to elaborate upon, my approach centers on researching the ways in which this robot, even though it is not yet ready to step out of the kitchen lab into the social sphere, the sphere for which I am supposedly an expert, is already a powerful social agent. This includes querying whether there is such a clear distinction between these two realms and choosing to trace the multiple relations of co-constitution; the relationships of socio-technical entanglement.

In her studies on the construction of knowledge and work in Artificial Intelligence, Diane Forsythe points out that the researched AI practitioners mostly regarded their work "as being beyond or outside of culture" (Forsythe 2002 , 17). Thus, she reconstructs the ways in which AI practitioners "[bring] values and assumptions [...] to their work, the practices that constitute that work" (ibid.). As displayed in the statement made during the lunch break, described above, the labors of engineering the humanoid robot also appear to be a research endeavor that seems to be considered to lie outside of culture and the social sphere. I find Forsythe's work useful for scrutinizing the relationship between what appear to be two separate realms: the realm of values and socio-culture on the one hand and, on the other, the realm of facts, scientific rationality and technological expertise. 
There is a long tradition in science studies in general, and in queer and feminist technoscience studies in particular, of contesting the idea that facts and values can be treated as clearly separate from each other (cf. Fraser 2006, 46ff.; Haraway 1997, 33ff.; Forsythe 2002, 17ff.; Barad 2007, 40ff.). Barad, for example, theorizes the relation between facts and values very vividly when she points out that:

[m]atters of fact are not produced in isolation from meanings and values. This is an ethico-onto-epistemological issue. Ethical considerations can't take place after the facts are settled, after the research is done. This is the wrong temporality. Values and facts are cooked together as part of one brew. (Barad 2012c, 15-16)

With this metaphor, she queries the idea that facts, including artifacts, are produced under 'value-neutral' conditions as well as the thought that ethical considerations have to take place after the facts are settled and artifacts have been built. Barad helps me to think the temporality of the making of the robot companion in relation to the temporality of the ethical considerations that arise with the figure of the robot companion. In accordance with Barad's claim, I underscore the importance of engaging with the robot even though or rather exactly because - this machine is not yet ready to step into the social sphere, which is thought of as separate from the laboratories of contemporary robotics. The ethical considerations concerning the making of the robot companion cannot be separated from this making.

My thesis maps key aspects of knowledge production, including the production of matters of fact and artifacts, in vision and action in a specific laboratory. In mapping the development of the humanoid companion, I propose a shift in line with Karen Barad's suggestion that we move "in studies of science from the traditional emphasis on theory construction to the examination of experimental practice" (Barad 2007, 41). Such a shift in research from categorical debates to concrete enactments has been widely enacted; for example, by Lucy Suchman (2007), Donna Haraway (1997, 2008), Karen Barad (2007) and Adele Clarke (2003). Notably, such an examination of experimental practice can be related to the tradition of laboratory studies as they became established in the early 1970s, with these early studies researching the "social construction" (Latour and Woolgar 1979) or "manufacture" (Knorr-Cetina, 1981) of knowledge in terms of complex negotiations of facts. Although I do not employ the social constructivist 
framework used in these early laboratory studies, it is nevertheless notable that these strands, which are gathered under the umbrella of laboratory studies, foster detailed descriptions of "experimental practices" (Shapin and Schaffer 1985, 3). The generation of detailed descriptions of experimental practices is also the focus of Barad and Haraway's work. However, they rework constructivist approaches in their description of laboratory practices, as I will continue to argue.

In what follows, I sketch some of the methodological-theoretical implications of a research perspective that insists on an understanding of the social and technical, values and facts, epistemology and ontology as being cooked together in one brew in the making of robot companions. More precisely, I regard this kind of research with Barad as an "enagagement with science [which is] [...] commit[ted] to be in the science, not to [...] be above or outside of it" (Barad 2012, 207). Through this approach, furthermore, I draw on Barad's insights as they interact with Haraway's situated knowledges and the wider frame of cyborg feminisms as well as Haraway's more recent work on multi-species ethnography (Haraway 2008). I identify shared concerns between Barad and Haraway that touch upon the meaning of entanglements and encounters as well as contact and intimacy for queer and feminist technoscience studies. Along these lines, in my study I am interested in mapping the ways in which a seemingly clear distinction between the social and the technical becomes palpable as rather porous as well as the everyday work of re-establishing proper boundaries and categories within this specific context.

\section{Entering the Labs - Getting in Touch}

As briefly addressed in the introduction, a prerequisite for participating in the everyday labors of project work in robotics was to be invited to the institute as a guest, which was primarily motivated by an interest in the question of how other disciplines, such as the humanities and social sciences, perceive and evaluate contemporary robotics and in making this specific robot model more public. Thus, when engaging with one location of contemporary robotics, I experienced a steady interest from the anthropomatic practitioners in explaining the details of their research to me as well as in asking me what 
exactly it is that I am doing. I regard this interest as a leverage point for my engagement 'in' science.

A variety of practitioners approached me during shorter breaks, or even engaged in longer conversations throughout my research stays. In this sense, I understand the invitation to stay as a guest at the laboratories of anthropomatics as becoming very productive in creating what Haraway calls a "contact zone" (Haraway 2008). I picture this contact zone as a methodological strategy for researching 'from within' the field to be researched that follows the paradigm of situated knowledges. Such contact zones, in line with Haraway, unfold through "mundane" practices of "accountability, caring for, being affected, and entering into responsibility" (Haraway 2008, 36). My argument here is that, by participating in the everyday project work in the anthropomatic laboratories, including the collective daily routines, I was able to depict such mundane practices of creating a contact zone between anthropomatic robotics and a queer feminist mapping of contemporary robotics.

Along these lines, both the engineers' interest in my research and their enthusiasm in sharing their own work became leverage points not only for researching the 'anthropomatic others' in their work practices, but also for taking responsibility for fostering situated knowledges and conditions for dialogue between a recent strand of technoscientific research and innovation and queer and feminist technoscience studies. However, these condensed situations of contact occasionally evoked feelings of overwhelming expectations expressed toward me. Thus, at times, I chose to participate only silently in these breaks. Feelings of being overwhelmed emerged when I could not follow what was explained to me, even when it was repeated. Similar feelings developed when I felt that, even though I was talking and explaining what kind of research I was doing, the other person did not understand what I was saying.

I regard the feelings described here as being one important affective dimension of my engagement with robotics, which expresses my commitment to researching the selected strand of robotics 'from within'. Furthermore, informed by the methodological-theoretical pillars of, principally, Barad's and Haraway's work, I contemplate my experiences as being at the same time a foundational opportunity and a challenge. On the one hand, feelings of being 
a "tourist [...] in the world of high-tech science" (Bryld and Lykke 1999, 27) are not surprising. This picture of the tourist reverberates with how I experienced myself several times during everyday encounters at the laboratories when situations caused a silence or irritation. Thus, I experienced some conversations as ending in some kind of impasse in communication between two experts from different fields of knowledge. On the other hand, however, I would like to tweak these feelings of impasse or overwhelming interest in each other's field of expertise as also being affects that demarcate a collapse of the idea of robotic sciences and engineering as research endeavors 'outside of culture', and as an indicator of how porous the boundaries between the seemingly distinct realms of, for example, the social and the technical are. In this sense, to engage in contact zones across disciplinary boundaries involves, as Åsberg points out, "step[ping] outside the comfort zones [especially] of, human (culture), 'humanism', and the humanities" (Åsberg 2013, 11). To take seriously the affects that emerge when stepping out of one's analytical comfort zones and to foster an engagement 'in' technoscience beyond feelings of impasse and being overwhelmed became essential mundane practices in creating a contact zone that allows a mapping of the making of Armar.

Furthermore, I use the picture of what Barad calls "meeting [each other] halfway" (Barad 2007) as the archetype of establishing conditions for dialogue and a contact zone. I associate with the idea of meeting people halfway the possibility of developing ethical considerations across disciplinary boundaries that divide, for example, ethics and technical expertise, and instead to acknowledge the synchrony and entanglements between innovation and the emergence of ethical dimensions. I read Barad's sketch of an "ethico-ontoepistemology" (Barad 2007, 90), a methodology that does not make a separation between ethics, ontology and epistemology (ibid.), as reverberating with Haraway's idea of "attachment sites for world making" (Haraway 2008, 36) and the concept of mundane practices of researching in the contact zone beyond the realm of the comfort zone.

More precisely, I draw on Barad's rich contestation of atomistic accounts of id $/$ entities $^{28}$ within which certain properties and capabilities are assumed.

\footnotetext{
${ }^{28}$ I suggest the concept of id/entities here as a term for capturing the co-production of human and machine as both entities and identities.
} 
Here, I am thinking, for example, of Barad's analytical shift from researching interaction to researching "intra-action" (Barad 2003; 2007). As she explains, "the notion of intra-action recognizes that distinct agencies do not precede, but rather emerge through, their intra-action" (Barad 2007, 33). In short, Barad introduces the term intra-action to signify the inherent entanglements of what are perceived as proper id/entities of research. Her suggestion to adjust the analytical lens from finding the right description for representing 'what things are' to building a sensitivity for 'how things become' largely informs my analytical perspective, as I will continue to argue throughout this dissertation.

Barad's rich oeuvre provides me with vital insights into how to map the making of the robot model Armar through acknowledging, firstly, the ethicoonto-epistemological entanglements and, secondly, the array of actions and intra-actions in the laboratory. However, here I would like to highlight the ways in which she links her conceptual-theoretical frame to methodological strategies of "collaborative research" (Barad 2012a, 215). When outlining the possibilities of collaborative research across the humanities and natural sciences, she delves into the "nature of touching" (ibid, 207) and through this develops an account of theorizing through being 'in touch', creating a close relationality or intimacy between oneself and the field and things of study (ibid.). Maria Puig de la Bellacasa argues in a similar vein, when she reminds me that the term touching is composed of rich "literal and figural meanings" (Puig de la Bellacasa 2009, 297) that, she argues, invoke "awareness of the embodied character of perception, affect and thinking" (ibid.). Touch as contact highlights the perceptive and affective dimensions of embodied knowing. Exactly this potential of touch as a methodology of collaborative research also becomes vivid in the following extract from Barad:

Like good bench scientists, these practitioners work the equipment, theoretical and experimental, without any illusion of clean hands and unapologetically express their enthusiasm and amazement for the world and the possibilities of fostering just relationships among the world's diverse ways of being/ becoming. (Barad 2012a, 207)

Studying the making of the iconic figure of the robot companion in situ, I emphasize the ways in which Barad's approach attunes me to my own positionality as researcher, as someone produced in relation. Notably, and in line with Barad, the potentialities of touch for collaborative research lie in refraining from maintaining a comfortable distance or the illusion of 'clean 
hands'. In line with Barad, getting in touch is a non-innocent engagement; more precisely, this engagement is about getting my hands dirty.

Furthermore, this sketch of touch as a methodology can be said to rest on the idea of what Puig de la Bellacasa calls a "reclaiming [of] touch" (Puig de la Bellacasa 2009, 297) within feminist and queer technoscience studies. This reclaiming of touch is thus a responsible and caring practice of "assembling neglected things" (Puig de la Bellacasa 2010, 85), which become the "matters of care" (ibid., 92) in studying socio-technical production. As she explains, "[t]o think with touch has a potential to inspire a sense of connectedness that can further problematize abstractions and disengagements of (epistemological) distances - between subjects and objects, knowledge and the world, affects and facts, politics and science" (Puig de la Bellacasa 2009, 298). Touch is thus not only an experience of close relationality, but also - in line with queer and feminist politics of situated knowledges - a tool for locating knowledge production within its material-semiotic conditions and practices of technoscientific production. The implications of touch as outlined here are that, as it works in the vein of situated knowledges, touch is important for the focus of this thesis as it reconfigures the relationship between the subjects and objects of study. It invites me to become immersed through quasi-inescapable close engagements in the area of study as touching problematizes abstractions and disengagements of (epistemological) distances.

I am interested in constantly engaging in contact zones that overcome (epistemological) distances as a research paradigm that structures my map. It became vital during my research stays to get my hands dirty through embodied and affective knowing as fostered, for example, through informal conversations. One reason why these practitioners generally agreed to get in touch with me seems to be grounded in speculations that were raised during my times at the lab, and with which one of the practitioners confronted me. These speculations concerned the purpose of my stays. Basically, most of the practitioners assumed that inviting me must be part of the efforts to make anthropomatics, and especially the robots, more popular in society. Furthermore, as a social scientist, I should supposedly be serving this goal very well. These speculations reified themselves at least partially through expectations of my research that were tentatively, but nevertheless openly, formulated. My role seemed to become one of producing 'hard facts' on 
questions like what society expects from robotics and how robotics could in turn meet these expectations. For example, in one conversation that I had with one of the practitioners right at the beginning of my first stay, I was addressed as a researcher who could help to find out what people really need and want from technology, especially from the perspective of another discipline. Thus, I regard this as one major pivot in creating attachment sites for world-making between queer and feminist matters of care and robotic practices of imagining and realizing the companion robot. My take on creating attachment sites for worlding builds on taking this question seriously and developing ideas about what kind of contribution to the field of anthropomatics my research could deliver throughout this thesis.

\subsection{Overview of Anthropomatics}

In introducing the IAR, I need to highlight that this overview is particular and selective as it is based on my situated attempts to create a contact zone within which it was possible to foster "conditions for dialogue" (Suchman 2008, 153). To begin with, the word anthropomatics is obviously a neologism coined to describe an evolving strand of research and innovation in building automata that will be brought into contact with the anthropos, the human. In what follows, I will map out dimensions of the organizational groundings, including literal-figural elements, of this neologism of connection.

One of the practitioners at the IAR describes anthropomatics to me as follows:

Anthropomatics is [...] the connection between human and machine [...] this is the basic idea, we are developing technologies which are proximate to the human, which are beneficial to the human - that is the basic idea. (interview practitioner CD, July 2011; translation: $\mathrm{PT})^{29}$

I regard this explanation as representative of the basic idea behind anthropomatics - to construct machines proximate to and beneficial to humans. Therefore, I identify this statement as central to the analysis of anthropomatics as an area that works on the human-machine relations of proximity. My engagement with the field of anthropomatics, though, is not comprehensive, but rather serves to pin down how practices of imagining and

${ }^{29}$ The German expression is "Technologien, die dem Menschen nahe sind" and I decided to translate the adjective "nahe" with proximate and to try to capture the different meanings of "nahe", that is, close and similar, in the continuing analysis of articulations of this basic idea in the imagining and realization of the robot. 
realizing a connection between the human and the machine take shape. Along these lines, I conceive of the infrastructure of anthropomatic research and innovation through the systematizing practices of classification, categorization and standardization of human-machine relations of connection and proximity between human and machine.

\section{The IAR's Organizational Structure}

The Institute of Anthropomatics and Robotics (IAR) is a sub-institute of the Karlsruhe Institute of Technology (KIT), anchored in the Department of Informatics. At the center of my field study is the research area called "Focus Anthropomatics and Robotics (APR)", ${ }^{30}$ which is embedded in a larger overall research structure within the KIT. Anthropomatics is described by one of the practitioners as "a frame" and "the spatial basis [...] which builds the formal and financial frame within which one can just carry out work" (interview practitioner CD, July 2011; translation: PT). The Institute of Anthropomatics provides the formal and financial academic frame between different research areas. It is important to note that cooperation between these fields of research already existed before this new frame was created (ibid.). Anthropomatics, however, provides spatial conditions that foster this existing cooperation.

The organization of anthropomatics as a frame emerged largely from the research cluster "Collaborative Research Center 588: Humanoid Robots Learning and Cooperating Multimodal Robots". ${ }^{31}$ This third-party-funded cluster was constitutive of one of the initial groups of cooperation through which the key research areas of the IAR at the KIT were established. The SFB 588 was funded by the German Research Council [DFG] and ran from July 2001 until June 2012. ${ }^{32}$ One practitioner explained the details of this collaboration in the following way: "In the SFB we have computer scientists, mechanical engineers, electrical engineers, and sports scientists involved. [...] [S]o our group here, we are leading the entire integration or the development of the demonstrator" (interview practitioner AB, July 2011; translation: PT). This practitioner's description illustrates that the research cluster on humanoid robots has brought together different academic disciplines. This work context has then stabilized into an academic field, anthropomatics,

\footnotetext{
${ }^{30}$ http: / / www.anthropomatics-robotics.kit. edu/english/index.php.

${ }^{31} \mathrm{http}$ :/ / his.anthropomatik.kit.edu/english/101_397.php.

${ }^{32}$ http: / / www.sfb588.uni-karlsruhe.de/about/ projectinformation.html.
} 
which, although housed in the department of informatics, nevertheless continues with project work across disciplines.

The description of the cluster 'SFB 588' that I cite above displays a work division in reaching the anthropomatic goal of designing and building machines with a fixed set of capabilities. The listed abilities range from vision to learning and communication to building an array of tasks in modeling what is conceptualized as interactive, human-like behavior. It seems that the variety of tasks involved in realizing humanoid robots and robot technologies is identified within this interdisciplinary frame, to be then re-delegated to the different scientific fields of computer sciences, mechanical and electrical engineering, and sports science.

Thus, the composition of the assembled areas of research displays how tasks are assigned. Furthermore, it makes tangible an already-existing work division between disciplines that I associate with the rise of modern science; in short, technical research deals with machines and biological research deals with organisms. At the same time, such a clear work division experienced many revisions throughout the 20th century, emerging in particular after World War II (Fox Keller 2002; Hagner and Hörl 2008). Touching only briefly upon the historical dimension of a division of labor in realizing the project of humanoid robot companions, I want to underscore that anthropomatics as a newly funded research area raises questions about a possible re-organization of existing forms of disciplinary work division.

So far, it has become apparent that cooperation between disciplinary fields and collaborative research are key aspects of anthropomatics. The possibilities of cooperation are formed alongside defining a shared aim of reaching a collaborative goal. Anthropomatics functions as an umbrella group, which administers the emerging collaborations financially, spatially, and conceptually. Furthermore, an important role within this context is to merge the work carried out in different projects and in varying disciplinary fields. In accordance with the explanations of the practitioner that I quote above, the laboratories that are at the focus of my research take on a leading role in this process as they conduct the entire integration of partial work onto the platform, the humanoid robot. In consequence, the robot model functions as intersection and demonstrator of the entire work context. 
In addition, during my third stay at the IAR (in July 2012), a new chair was inaugurated, arising from the academic institutionalization of anthropomatics, called: "High Performance Humanoid Technologies $\left(\mathrm{H}^{2} \mathrm{~T}\right)$ ". This chair, according to the webpage, "focuses on 24/7 humanoid robotics technologies and systems able to predict, act, and interact in the real world and perform a wide variety of tasks." ${ }^{\prime 33}$ High performance indicates both hightech machines that display abilities conceptualized as complex and interactive, and the continuous availability of these machines. The image of such a high-performance robot displays properties the potential robot owners are presumed to want. I identify high performance as a trope through which promises of what Suchman calls a "service economy" (Suchman 2007, 217) figure. $^{34}$

The fantasy of high-performance robots crafts an image of the robot as humanoid, always available to perform at your service, and therefore making it the ideal $24 / 7$ service agent. However, although speaking to the imaginary of the service economy of information technology as it is staged in the development of ubiquitous software agents (Suchman 2007, 217), the highperformance agent envisioned in anthropomatics is described as operating in the real world. More precisely, this emphasis on the real world is an important aspect of analyzing the figurations of anthropomatic humanmachine interfaces, which illustrates practices of relating between human and machine. The stakes of such an idealized image of a humanoid robot, which fulfills dreams of the service economy, are a topic I will follow throughout this thesis by gradually thickening my map of anthropomatics.

Recapitulating my first insights into the organizational structure of anthropomatics, I get an initial picture of the systemized organization of complex relationships between different kinds of practices, spatial

\footnotetext{
${ }^{33}$ http: / / h2t.anthropomatik.kit.edu / english/index.php.

${ }^{34}$ Suchman uses the term 'service economy' to discuss the idea of service delivered by agents who are always available, and how this relates to imaginings of service agents at the interface between software agents and humans (Suchman 2007, 206ff). She includes wearable computing technologies and intelligent environments in her study (Suchman 2007, 217ff.). Suchman furthermore delineates a contrast between multiple-service-agent technologies and robots, the first as contributing to the service economy, the latter as a technology of the industrial rather than the service economy (Suchman 2007, 219). However, my argument for drawing on Suchman's take on the service economy is that the traditional dichotomous relations between the industrial and service economies change within the socio-technical imaginary of the contemporary humanoid robot, demarcating new connections between these as separate spheres of thought, as briefly stated in the introduction.
} 
arrangements, people and artifacts. Anthropomatics serves as a financial and institutional frame for a shared infrastructure between the various fields of innovation and research. These are involved in working on human-machine interfaces through relations of proximity and benefit. This work requires multiple levels of organization, which are held together by a division of tasks, and the administration of knowledge and technologies delivered through a leading unit, the IAR.

\section{Anthropomatics - Basic Outlines of the Humanoids Group}

So far, I have analyzed the complex relations of disciplining a research context in terms of tasks and spatial design as well as financial arrangements. This sub-section examines the conceptual groundings through which the IAR (re-) presents work carried out within the Humanoids and Intelligence Group. I begin by contextualizing the neologism anthropomatics, as it is introduced on the IAR's homepage:

The term 'Anthropomatics' was coined by a Karlsruhe informatics professor ten years ago as the science of symbiosis between human and humanoid and refers to a research field, which focuses on human-centered environments, with an aim to researching and developing people-friendly systems using informatics. ${ }^{35}$

Although the IAR was only inaugurated in 2010, it is introduced as a research area with a long tradition. Anthropomatics, as the cutting-edge science of symbioses between human and humanoid at the end of the first decade of the 21st century, has its roots in a decade of research at the KIT. The term anthropomatics itself combines the Greek ánthrōpos, human being, and matics, deriving from the Greek automaton, self-propelled machine. Thus, this term describes the linguistic fusion between anthropos and automaton, which supposedly signifies both the cutting-edge character of global interest within this field of research and the reference to a local research tradition anchored in the KIT.

Furthermore, anthropomatics is described as a research and innovation endeavor that draws on the term human-centered as an indicator of peoplefriendly machines. Rob Kling and Susan Leigh Star discuss the "intellectual roots" $(1998,22)$ of the term, and problematize the use of this notion as a

\footnotetext{
${ }^{35}$ http: / / www.informatik.kit.edu / english / 1323.php; http:/ / www.kit.edu/besuchen/ 8881.php.
} 
"buzzword" (ibid., 23) for a machine that helps people (ibid.). In line with their argument, such a use associates a certain quality with a machine, in this example people-friendliness, while at the same time it also defines the criteria for such a people-friendliness in a universalizing gesture. The idea of a people-friendly system assesses this quality as intrinsic to the machine and in this sense defines the possible human-machine relations at the interface of people-friendly machine and user. However, as Kling and Star point out, “"one size fits all' seems distinctively non human-centered" (ibid.). Thus, the use of human-centered as a buzzword invites me to raise questions such as what the distinctively human, the human-centered, and therefore also a human-centered environment in anthropomatic terms means. These questions challenge, on the one hand, the pre-conceptions that underlie the realization of the human-centered robot model and, on the other hand, the nature of the pertinent technological practices of automation, as well as how these shape "what it means to be human, and even our sense of self" (Wajcman 2004, 2), and will be of interest throughout the remaining chapters.

The quote cited above connects human-centered with another buzzword in designing people-friendly machines in informatics, namely, symbiosis. Etymologically, this term is a composite of the ancient Greek syn, which means together, and bios, which means living. Thus, symbiosis specifies a vision of a human-centered machine as one that enables a living together between an evolving new class of machines and humans. Furthermore, the idea of machine helpers reverberates with what I define as the classical biological concept of symbiosis that - without aiming to unify this concept could be described as a relationship between two organisms that belong to differently classified biological species that receive a mutual benefit from their relationship. Symbiosis in this sense describes human-machine relations that, again, build on qualities intrinsic to two entities that meet at the human-robot interface. Thus, the emphasis in building human-centered robots is on a symbiotic relationship of people-friendliness.

Historically, the term symbiosis has been established most prominently in informatics research at the intersection of psychology and early AI at the beginning of the 1960s through the work of the psychologist Joseph Carl Robnett Licklider. Licklider focuses on symbiosis as signifying a "heav[y] interdependen[ce]" (Licklider 1960, 1) between two organisms - in his 
example that of the fig tree and the Blastophaga grossorum, a gall-wasp (ibid.). He furthermore conceives of this interdependence as "not only a viable but a productive and thriving partnership" (ibid.). This thriving partnership targets increasing efficiency in "technical and scientific thinking" (ibid.). Licklider's peculiar vision of "men-computer symbiosis" (ibid.) pictures a living together of men [sic] and computers. Furthermore, Licklider imagines computers as devices that automate "the routinizable work that must be done to prepare the way for insights and decisions in [...] thinking" (ibid.). Hence, Licklider's take on symbiosis opts for a partnership that supposedly enables higher cognitive abilities in humans, defined as thinking.

Notably, the subject of this symbiosis is universal man, and the relation between human and machine is hierarchical. Thus, this notion of symbiosis carries the idea of augmentation, or even human enhancement, which is tied to what Haraway identifies as "technoscientific salvation stories full of promise" (Haraway 1997, 8). Tentatively developing this argument, I underscore that Licklider's man-computer symbiosis promises salvation from, and therefore also an end to, the troubles of routinizable work that prepares thinking and the constraints of a peculiar vision of cognitive abilities. The technological practices that figure in the early model of the computer become the route for reaching this salvation. Moreover, these promises of salvation tie in with, and are propelled by, capitalist logics of exploitation, which opt for a delegation of labor that constantly shifts the value of labor. Within Licklider's concept of symbiosis, thinking appears to be a highly regarded activity, while the activities that prepare the way for the actual activity of thinking are devalued in comparison.

Jumping to recent work on the concept of symbiosis in AI, I briefly draw on the work of the popular British cyberneticist of the 21st century, Kevin Warwick. In his article "Cybernetic Enhancement" (Warwick 2008), he outlines his work on the "Brain-Computer Interface (BCI)" (ibid, 123), targeted at a wider audience interested in (prospective) human-machine interfaces (ibid.). It is precisely Warwick's self-positioning as a cyberneticist that speaks to a similarity between the cybernetic idea of human-machine coupling and the concept of human-machine symbiosis. In his take on symbiosis, he suggests

that connecting a human brain, by means of an implant, with a computer 
network could in the long term open up the distinct advantages of machine intelligence, communication and sensing abilities to the implanted individual. (ibid., 127)

As he argues for his "concept of human-machine symbiosis" (ibid.), the machine he envisions is not a computer or technological device like the computer, but an implant that consists of microelectrodes in a chip that measures " $4 \times 4 \mathrm{~mm}$ " (ibid., 128). The concept of symbiosis determines the kind of connection between human and machine, in this case by suggesting a fusion: the machine is implanted into the human, creating the prosthetic individual. ${ }^{36}$

Warwick brings symbiosis and implantation together in his work on the BCI, creating new forms of symbiotic connection: symbiosis through incorporation. The partners in this kind of symbiosis are the human brain and the electronic micro-device. Arguments in favor of his concept of humanmachine symbiosis are grounded in the expected mechanical advantages for humans: intelligence, communication, and sensing. Thus, I argue that Warwick's model of symbiosis evokes associations with cyborg amalgamation and fusion between human and machine that operate at the level of cognitive and sensual enhancement of 'the human body'.

Returning to anthropomatics, the partners in symbiosis here are thought of as humans and humanoid systems that are people-friendly. In addition, both human and humanoid are situated within human-centered environments. So far it remains unclear how such an environment will be shaped, and what it will be composed of besides humans and humanoids. However, the basic idea of anthropomatics, articulated in building machines that are proximate and beneficial to humans, figures in the application of symbiosis as a trope for partnership, which entails a range of possible relations encompassing the complementing machine as much as the enhancing one.

Symbiosis and modeling are both key terms for understanding this institute's infrastructure, as well as the material-semiotic figurations of human-likeness and the attendant processes of categorical work that sort

\footnotetext{
${ }^{36}$ The notion of the prosthetic individual indicates an understanding of machines as a prosthesis. Although I do not explore this thought here, it is important to flag the idea of machines as prosthesis as an issue of care of my continuing analysis. As Margrit Shildrick points out, prosthesis in its rich metaphorical meaning is marked by an "uncharted [queering] potential" of "surprising connections, the capacity to innovate, and the productive troubling of intentionality" that are grounded in "the concorporeality [...] of the organic and inorganic" of prostheses (Shildrick 2009, 133).
} 
entities into the categories of human, machine and human-like. Both terms, namely symbiosis and modeling, have long traditions in computer science the latter even as a foundational principle for computation. Of further interest for this study is how the practice of modeling and the objective of connecting human and machine through symbiosis are brought together in local practices of imagining, arranging, and negotiating the anthropoid robot.

\section{The Humanoid Robot at the IAR: Socio-Techno Strategies of Mimicry}

During my three years of conducting research (2010-2012), the IAR was working on the Armar models IIIa, IIIb, and IV, the latest models of the "Armar Family".

The design of this robot model is presented on the homepage as follows:

In the design of our robot ARMAR-IIIa in 2006, we desired a humanoid that closely mimics the sensory and sensorimotor capabilities of the human. The robot should be able to deal with household environments and the wide variety of objects and activities encountered in it. ${ }^{37}$

According to the description on the website of the humanoids group, Armar models IIIa and IIIb are both humanoid machines. Moreover, the description emphasizes that these machines are conceptualized as being capable of mimicking what is identified as the sensory abilities of the human. This means that the machine is imagined as incorporating sensory abilities that allow it to mimic the human; that is, being able to deal with everyday human environments, which are determined as household environments. Mimicry, as a concept of modeling a humanoid machine, is charged with the literal meaning of the Greek mimetikos - imitative. This third buzzword, mimicry, figures in imaginings of the humanoid machine as imitating the human. Notably, such a relationship of imitation is not limited to the human-like shape of the machine, but also encompasses its capacity to help humans in household environments. Such imitation comprises several modi operandi, including making robots look like humans, talk like humans and behave like humans. It is relevant for this thesis to map both these different levels on which mimicry seems to operate, and the conceptions of the human that are established through imagining and realizing such a human-like machine.

\footnotetext{
${ }^{37}$ http: / / his.anthropomatik.kit.edu/english/241.php; Armar III a and b were both built in 2006 (ibid.).
} 
In its meaning of signifying a literal-figural representation between two distinct things, the term mimicry and the derivational mimesis are concepts that have been developed in different fields within both the humanities and biology. Thus, I will now move on to outline some dimensions of this key term in anthropomatic robotic modeling. In its biological use, mimicry describes complex relations of imitation between different species or a species and aspects of its environment (such as a leaf or a stone). Mimicry in this sense serves primarily to secure one or both species from threats like extinction. This adaptive mechanism, targeted at a species' survival, encompasses strategies of imitation, replication, and deception, allowing one species to pass as the other or as a feature of the environment, ${ }^{38}$ becoming more or less indistinguishable from one another. Imitation, replication, and deception are precisely strategies of interest for the analysis of how relations between self and other, difference and sameness, and the accomplishing representational forms of difference, are configured in anthropomatics.

Mimicry and mimesis articulate a mode and form of representation that implement a relation between copy and original, the first representing the latter. Feminist, queer and postcolonial critiques of representation query how mimicry and mimesis as thought models for representation implement a relationship between copy and original that is constitutive of powerful differentiations between the norm and its Others (Butler 1993; Bhaba 1994; Haraway 1997; Barad 2007). Although highly diverse in their thinking, I argue that these three strands of thought have in common that they target a deconstruction, or a diffraction, ${ }^{39}$ of forms of representation of difference and the complementing relations of domination and injustice.

It is not relevant to this chapter to recount the heavily debated cultural conceptualizations of mimicry in all its dimensions. What I want to underscore is an understanding of strategies of mimicry as complex adaptive

\footnotetext{
${ }^{38}$ These strategies also have an evolutionary coloration, which basically grounds the alterability of biologically identified species conceptually.

${ }^{39}$ I draw on diffraction as a term coined by Donna Haraway and also used by Karen Barad. A "diffractive methodology" (Barad 2007; 2012) employs reading and writing practices that, in accordance with Haraway, provide new forms of critical engagement. As she argues: "Reflexivity has been much recommended as a critical practice, but my suspicion is that reflexivity, like reflection, displaces the same elsewhere" (Haraway 1997, 16). She continues to underscore that "[w]hat we need is to [...] diffract the rays of technoscience so that we get more promising interference patterns on the recording films of our lives and bodies" (ibid.).
} 
mechanisms that go beyond species survival as they have become an important trope for (re-)figurations of the relationship between the norm and its Others, especially within feminist and queer technoscience studies. Suchman, for example, underscores that "mimesis [...] works as a powerful disclosing agent for associated assumptions about the human" (Suchman $2007,241)$ in a science of the artificial such as robotics. Hence, this term evokes questions concerned with the politics of representation with which the anthropomatic understanding of mimicry and mimesis operates that will be relevant throughout this thesis. These touch upon how and with what discursive-material consequences the core strategies of mimicry, including imitation, replication, and deception, become strategies for designing and building machines that display proximity to the human in gestalt and capabilities and how this, in turn, impacts the understanding of the human in the present.

\section{The Un-Caged Robot}

The explanation I cite above depicts the kinds of robot models for which anthropomatics strives. It highlights the fact that mimicry is necessary in order to realize the robot in the envisioned field of operation, the household. What exactly this environment consists of is not delineated on the webpage, and the wide variety of objects and activities that may be included remains abstract for now. Nevertheless, this vision integrates the humanoid robot into the household. As discussed in chapter two, the Western household, established as a bourgeois, consumerist space equipped with an array of domestic appliances, is traditionally operated by housewives or maids.

Robotic automation technology has been primarily applied in areas of industrial production, such as the automobile industry. In this field of operation, industrial robots are equipped with robotic arms, with which they maneuver such objects as heavy car parts. These robots with grapplers are stationary while they operate and mostly perform one programmed task repetitively. Hence, they are specialized in a specific task, which is either dangerous (handling car parts) or boring (repetitive, monotonous assignments performed on assembly lines) for humans. In addition, they are built in order to perform these tasks faster than 'human workers'. However, models of stationary grapplers, operating at high speeds, also require specific 
safety regulations, to prevent workplace accidents. ${ }^{40}$ Suchman points out that "[i]ndustrial robots - highly specialized, computer-controlled devices designed to perform autonomously a single repetitive physical task [...] [are] still confined to specialized activities, under controlled conditions" (Suchman 2007, 37-38). One of the most prevalent safety devices for these controlled conditions is a cage built around the robot. The word "cage" might invoke a picture of bars made of iron or laser barriers, depending on the size of the robot, the tasks this machine performs, and the work environment in which the machine is operating. This cage is an important instance of control, which also signifies the drastic confinement of robots. Clearly a robot in a cage is not an artifact at the stage of interactive communication or useful manipulation in the sense of safe co-existence between human and humanoid.

By means of this contrast between industrial robots and the anthropoid robot, I consider the cage to serve as an allegory for what the technological development of the household robot has to overcome: the limitations of the potentially dangerous machine only performing highly specialized activities under controlled conditions. Anthropomatic robotics targets this problem as follows: "With the aid of this partially anthromorphic robot system, it will be possible to step out of the 'robot cage' to realise a direct contact to humans" ${ }^{41}$ The idea of the robot stepping out of its cage is of fundamental significance for the humanoid shape of this machine. A prerequisite for the entry of the robot into our households - realizing direct contact between human and robot - is the anthropomorphic design of this machine. Even if it remains partially anthropomorphic in the description above, this nevertheless fosters an entanglement between the evolution of robots into everyday machines, operating even as close as at home, and the anthropomorphic design of the robot, which calls into play imaginings of humanoids such as the Stepford Wives and the like. ${ }^{42}$

\footnotetext{
${ }^{40}$ Standards for machine safety in industrial production are defined globally through the International Organization for Standardization (ISO).

${ }^{41}$ http: / / www.sfb588.uni-karlsruhe.de/ about.

42 The (house-)wives in Stepford are portrayed as embodying the ideal of the efficient, good-looking American wife of the 1960s, incorporating traditional family values and gender roles. These perfect housewives, however, are in reality not what they seem; every woman in this small town (which is organized exclusively into heterosexual nuclear families) has been replaced by a robotic replica by her husband. So the original story goes. In a film adaptation from 2004, the wives are not replaced, but altered into cyborgs through microchips implanted into their brains through
} 


\subsection{Human-Machine in the Loop: Configuring Anthropomorphism}

In this subsection, I explore anthropomorphism in both of its dimension: firstly as one central aspect of how knowledge is organized at the IAR and secondly as a trope that configures human-machine relations of sameness and difference. As I will continue to argue, anthropomorphism is of interest to this study as a key trope that organizes both how human and machine are configured and the politics and economy of representation that underlie the configurations of human-machine relations of anthropomorphism. Not least, such a map of figurations in their tropic qualities might serve to open up possible departures for queer and feminist refigurations. Thus, I will continue to ask how anthropomorphism organizes the practices of imagining and realizing the robot model Armar.

So far, I have identified the idea of machines as proximal and beneficial to humans and two tropes that figure this idea; namely, the tropes of symbiosis and mimicry. In what follows, I will focus on the question of how the anthropomorphism of anthropomatic research operates with these buzzwords in their tropic qualities when introducing the robot companion as a prospective agent that will enter the domestic sphere, 'our' households. One pivotal point in this subsection is that anthropomorphism is constitutive of configuring human-machine relations through which both human and machine function as references for each other. The focus of what follows is thus an initial interest in the sorting and configuration operations of anthropomorphism and to identify what I contemplate in terms of an anthropomorphic human-machine referentiality, which I will then analyze and theorize further in the following chapters.

In her article "Computing the Human" ([2002] 2003), Katherine Hayles points out that the fields of computational research and innovation involving intelligent machines such as robots are a site for projecting futures in which "humans and intelligent machines become virtually indistinguishable from one another" (Hayles 2003, 99). Following her argument, these projected futures are of interest for our present, hence they define "present concepts" (ibid.) through "long-term predictions" (ibid., 100). The question is not what might happen in the future, in terms of evaluating technological feasibility,

which their husbands control and manipulate their behavior. On the sexing and gendering of modern automation technology, see especially Braidotti 2013, 105ff. 
but rather how "we understand what it means to be human" (ibid.) in the present. Moreover, Hayles identifies a "two-cycled phenomenon [...] at work: humans create objects, which in turn help to shape humans" (ibid.). ${ }^{43}$ I find Hayles' work useful for mapping the ways in which anthropomorphization operates as a two-cycled process of creating a kind of onto-epistemological indistinguishability between human and machine.

Hayles' analysis of the mechanisms of a two-cycled co-shaping between human and machine is helpful in grappling with the literal-figural meanings of anthropomorphism, as I will continue to argue. She describes these mechanisms as the "use [of] a rhetoric that first takes human behavior as the inspiration for machine design and then, in a reverse feedback loop, reinterprets human behavior in light of the machines" (ibid., 101). Thus, she conceives of this rhetoric as the two-cycled phenomenon of defining human capabilities in machinelike terms in order to then find human-like capabilities in the machine. ${ }^{44}$ The movements of a reverse feedback loop describe an analytical tool for exploring configurations of anthropomorphism.

To begin with, I return to the IAR's homepage, on which I found explanations of how "human-like information processing" in the machine is thought of:

Regardless of the application area, one of the common problems tackled in humanoid robotics research is the investigation towards understanding of human-like information processing and the underlying mechanisms of the human brain in dealing with the real world. Our hypothesis is that such understanding can only be attained if we consider the human in the loop. ${ }^{45}$

Notably, anthropomatics deals with the construction of anthropomatic machines as it is a project to build machines that are supposedly able to demonstrate human-like information processing. Therefore, anthropomatic practitioners do consider the human in the loop. So far, we have not been given any further information about how such a loop is assembled or what

\footnotetext{
${ }^{43}$ Hayles draws on rhetorics of predicting a future that includes intelligent machines, in which "this convergence [between human and machine] [...] [becomes] the endpoint of human evolution" (Hayles 2003, 101). Independent of assessing the feasibility of this claim, the very claim that human-machine convergence is the endpoint of evolution is a pattern for differentiation between human and machine, which shapes imaginations and material effects in the present. Although I draw on Hayles' work, I consider the term evolution to be too heavily connoted with progressive transformation, which implies a positivist determination of humanmachine relations.

${ }^{44}$ Hayles' analysis on this point is similar to Lucy Suchman's; see end of this chapter.

${ }^{45}$ http: / / www.sfb588.uni-karlsruhe.de/about.
} 
kinds of practices it involves. However, I take the notion of a loop as a description of how the human and the human brain are positioned in relation to the machine as an indicator of a referentiality that seems to perform movements of reverse feedback looping. The reverse feedback looping in this sense functions on the one hand as a thought model for anthropomatic robotics and on the other as an analytical term to query exactly how the human and the humanoid both become reference points in establishing the category of the human-like always in relation to the category of the human. The focus in the following subsections is on the intended loop and, in consequence, the complementing mechanisms of looping, which seem to be constitutive of this machine's human-likeness.

\section{The Humanoid Gestalt: Systemic Architecture in the Human-Humanoid Loop}

The gestalt of the robot is organized through the architecture of the system. As commonly used in informatics, architecture describes how a system is built from its individual components. More precisely, the model of the anthropoid robot as an elaborate machine is characterized by a complex control, software, and hardware architecture (cf. Regenstein 2010). This convoluted, threelayered architecture will also be the topic of chapter six; however, in this chapter I sketch selected outlines of the anthropoid's systemic architecture in relation to the idea of anthropomorphism in the machine.

In what follows, I assemble selected first insights on Armar's architecture that draw upon Kristian Regenstein's dissertation: "Modular, distributed hardware-software architectures for humanoid robots" (2010; translation: PT). ${ }^{46}$ Regenstein's work depicts the robot's architecture as one of anthropomatics' main areas of knowledge production and technological development. Reading this dissertation, I could see that it displays very well how the seemingly distinct realms of socio-culture and technological expertise are interwoven. For example, Regenstein refers to current humanoid robotics as "auspicious approaches" (Regenstein 2010, 1; translation: PT) with regard to the "long-cherished dream of the human to develop machines that will

\footnotetext{
46 "Modulare, verteilte Hardware-Software Architekturen für humanoide Roboter" (Regenstein 2010). This dissertation was based on research that was conducted at the Humanoids \& Intelligence Labs, KIT (ibid.). Several practitioners pointed me to this dissertation as a reference for acquiring a better understanding of certain aspects of the anthropoid robot in particular and humanoid robotics in general.
} 
facilitate his [sic] work or even take over from him [sic]" (ibid.). Regenstein explains that current strands of robotics are devoted to the development of machines that can supposedly take over from humans in - apparently - any sector of work.

Furthermore, this explanation depicts the ways in which popular robotic imaginings and the most recent cutting-edge research are entangled. Here, I am thinking for example of the long-standing vision of automata that, in line with Babbage's postulation of the useful machine, will take over from and even supersede the human, as discussed in chapter two. In this regard, the figure of the robot companion as it becomes iconic for contemporary robotics appears to be an actualization of this dream of modern automation with its pivotal points of increasing efficiency through industrialization. Notably, rather than replacing humans at work, this kind of automaton is imagined as a cooperative workforce in what Regenstein calls the "shared workspace" (ibid.). I consider the historical line that I draw here in terms of the simultaneous actualization and renewal of the historical figure of the 'robota' as it evolved during the 19th and 20th centuries through the contemporary figure of the robot companion. Thus, I will continue to investigate how the class of the proper humanoid robotized machine of the 21st century arises from and reworks the idea of modern automation technologies. In order to map the practices of imagining and realizing this new class of automation technology, the robot companion, I will delve in what follows into the "hybrid architecture" (ibid., 3; translation: PT), as it characterizes the machine that qualifies as human-like and thus demarcates this class of robots from other intelligent machines.

The hybrid architecture of the anthropoid machine is explained as a design strategy of realizing both "reactive" and "deliberative" (ibid., 50) actions in the robot. Without going into the details of decades of humanoid robotics in detail, this combination of approaches to the humanoid's architecture is central to the project of building machines that will supposedly be operating together with humans. In short, the main difference between the reactive and the deliberative model of systemic architecture lies in the conceptualizations of action offered by each of these two approaches. As Regenstein points out, the deliberative model divides between "the phases sense-plan-act", which "are run through sequentially, which means that information on the 
environment is captured through the sensors, and only after the planning is completed will an instruction be transmitted to the actuators" (ibid., 26; translation: PT, emphasis in original). The reactive schema reduces the process of action to the phases of "sense-act" (ibid.) and does not rely on "a model of the environment" (ibid., 27-28, translation: PT), because it lacks a planning component (ibid., 28).

According to Regenstein, the reactive architecture is a result of dissatisfaction with the deliberative one (ibid., 27). This dissatisfaction stems from the slow response time of the latter (ibid.). Therefore, the hybrid architecture is a "mixture" (ibid., 29; translation: PT), which is thought of as combining the "advantages of both approaches" (ibid.). The planning component is not run through sequentially, but rather functions as a control component in "the connection between sensors and actuators" (ibid., 30; translation: PT). Details of the hybrid architecture are the topic of chapter six. For now, it is important to understand that building the robot companion is tackled through a division of phases of action into the three "functional blocks" (ibid., 60; translation: PT) of "planning", "perception", and "action" (ibid.). Furthermore, these three functional blocks are related in such a manner that a functional-logical structure of how the robot will proceed emerges.

This account of the architecture of the robot can be contextualized within what Hayles identifies as "the STA paradigm" (Hayles 2003, 100); the paradigm to develop a sense-think-act schema in realizing a machine that is supposedly equipped with abilities for complex human-machine interactions. According to her, the different research programs under this paradigm are characterized by "a tendency to extrapolate from relatively simple mechanical behaviors to much more complex human situations and a consequent redescription of the human in terms of the intelligent machine" (ibid.). Hayles illustrates the mechanisms of a reverse feedback loop in their quality of extrapolating socially meaningful behaviors from simple mechanical behaviors and how such extrapolation functions as a strategy for referencing between human and machine. I find Hayles' work useful for mapping configurations of anthropomorphism alongside the movements and mechanisms of looping between human and machine in the making of the human-like robot. 


\section{Not Like the Classic Robot: Human-like Movements}

The robot companion is imagined as a machine that operates with humans in a shared workplace. Thus, it becomes necessary to realize a machine that can be brought into direct contact with humans in executing the multiple tasks of everyday life. The hybrid architecture briefly described in the subsection above organizes the design of this machine. Another important dimension of the design is ideas about how it will interact with humans. For example, one practitioner emphasizes: "the robot - if possible - shouldn't move like the classic robot" (interview practitioner SP, July 2011). The classic robot calls up images of mechanical movements, which makes me think of my wind-up tin toy robots. The robot companion of the future, however, should not move like such a classic robot.

In this subsection, I explore aspects of design of the robot's body in relation to how it should execute tasks and how both these aspects lead to humanlikeness in the machine. My argument here is that the performance of motion as it is modeled in anthropomatics is a great resource for understanding the human-likeness of this robot. As one practitioner explains:

One quite simple example is that, currently, we are building the Armar IV, which has legs, and [...] this robot should not only make a few steps, but the Armar X should also play tennis - that means it should act like [Rafael] Nadal on the court, it should hit [the ball like him], it should not fall - and it should supposedly be able to get by with the energy that Nadal normally takes in before a match. (Demo 1, July 2011; translation: PT)

The current robots, Armar III a and b, are built with a torso fixed to a platform on wheels. The forthcoming model, Armar IV, had not been completed during my field research, but was assembled by July 2012. Although I do not discuss similarities and differences between these two models in detail, it is worth noticing that the most recent model, Armar IV, incorporates legs. These legs indicate not only a big step forward a more anthropomorphic shape, but also future possibilities for human-like performances by the robot. The statement of one of the practitioners, which I quote above, illustrates that this vision of a robot that does not move like a classic, mechanistic machine, fuels forms of technological imagination that envision the robot as a machine that plays tennis as well as the person who holds first place in the world rankings. Clearly, in this vision, the humanoid robot not only exceeds the abilities of previous robot models, but it becomes an athlete and outstrips the embodied 
capacities of an average person. Armar $X$ embodies the idea of a robot that is "reaching far into the future" (ibid.). Notably, and in line with Hayles, the projected future of a tennis-playing humanoid affects the very present including our understanding of what it means to be human. It impacts upon present imaginations of what kind of machines should be built and envisioned as companions to humans.

Moreover, another practitioner details the goal of anthropomatic robot modeling, including the modeling of human-like movements, by explaining "that one [should] always realize immediately that it is a machine and not a human [...]. I'm not attempting to replicate man, but actually just trying to improve human quality of life" (interview practitioner AB, July 2011; translation: PT). Although the anthropoid robot should not move like a classic robot, it is explicitly not envisioned as indistinguishable from humans. The practitioner underscores this by differentiating between the replication of man and the improvement of human quality of life. When one stands in front of such a humanoid robot, this machine should remain recognizable as a machine. The anthropomorphic modeling of the human-like thus appears to be envisioned within certain limits, which are drawn in relation to the beneficial characteristics this machine should supposedly demonstrate. Consequently, the humanoid is conceived of as a machine that will improve human quality of life. This line of thought constitutes an analytical thread that I will follow throughout the remainder of this study.

Because I regard this as a highly important dimension of robot modeling, I will briefly sketch how a peculiar anthropomatic version of human-like movements in the robot is connected to the idea of an improvement in the quality of lives. To delve into this connection appears to be vital in order to trace the relations between companionship, reproductive service, quality of life and the politics of differentiation and valuing labor as they configure the (prospective) Armar-human interface. My argument here is that the idea of the machine as improving human quality of life opens up yet another dimension of symbiosis. As described in the following, this machine is firstly envisioned as a robot that becomes useful for "everyone" and, secondly, especially useful for people with "bodily disabilities":

[This improvement of human quality of life will be realized] firstly by providing this service or supportive assistant/worker for everyone [...] Secondly, by building or developing assistant systems for people with bodily 
or sensory disabilities or limitations to also improve their quality of life. (interview practitioner, July 2011; translation: PT; emphasis in original)

The human-likeness of this machine seems to carry a promise that it will become beneficial to everyone, and especially to disable-bodied humans. This again speaks to the logic of a service economy, which stabilizes through assumptions about the desire for an improvement in the quality of life of prospective consumers of robots. To include everyone into this group of consumers mirrors a neoliberal desire for a progressive transformation of society through technology, which operates with a highly problematic, and thus very exclusive, concept of "everyone". ${ }^{47}$

So far, I have not discovered either what kinds of service and assistance the robot will be providing for everyone, or how this machine will support and assist people with their bodily and sensory abilities. In another section of the same interview, however, I learn more about the latter:

That means people who cannot move their arms well any more, who cannot carry heavy objects, that we provide support [for them], [...] in lifting a crate of beer or [...] that one builds a walking frame, so that people who cannot climb the stairs easily, [they] can do that for extended periods. (interview practitioner AB, July 2011; translation: PT).

The humanoid robot is imagined as a machine that will help in lifting heavy objects - similar to the industrial robot. This picture again invokes a similar idea of the robot as a "helping hand" (von Bose and Treusch 2013, 253; translation: PT). ${ }^{48}$ Furthermore, I find the choice of what object needs to be lifted interesting. The industrial robot has to lift heavy car parts during automobile production, and the humanoid of nowadays is depicted as useful because it could lift what is thought of as a heavy everyday object: a crate of beer. To have such a complex, intelligent robot lifting a crate of beer appears quite luxurious.

Besides this luxurious-appearing task, the humanoid robot is also pictured as a walking frame. In both examples, the humanoid companion robot is envisioned as helping with different tasks or even with bodily and sensory

\footnotetext{
${ }^{47}$ As Hanna Meißner highlights such a "vision of a better life for everyone" (Meißner 2013, 164; translation: PT) is imbued in a "normative perspective" (ibid.) of envisioning what this 'better' means and who this 'everyone' encompasses. Thus, everyone is a term that in its determining operations ties in with the idea of a humancentered machine full of promises of improving everyone's everyday life, as it performs a similiar universalizing gesture.

${ }^{48}$ I have touched upon aspects of lines of thought that I develop in this and the following subsections in: von Bose and Treusch 2013.
} 
abilities. Charging this machine with imaginings of human enhancement, I underscore the tropic, and hence symbiotic, quality of this picture of the prospective robot companion in its possible fields of operation. Bodily and sensory abilities, which allow tasks like lifting objects and walking up stairs, become the measure for realizing the human-like robot that qualifies as useful and proximate to humans, and therefore these abilities constitute multiple points of reference between human and machine. How, in turn, the robot supposedly embodies these abilities and how such an anthropomorphic body looks and moves in the kitchen laboratory will be at the heart of chapters five and six. In the following subsection, I describe the first aspects of the robot's anthropomorphic shape in relation to the spatial context in which it will supposedly be operating and operated.

\section{Because the Household is Perfect for Human Size: Space in the Human- Humanoid Loop}

Stepping out of its cage, the envisioned robot finds a new field of operation outside of factory halls. As one practitioner highlights: "What we have been focusing on in the last 12 years [...], is actually to build systems that move something in the household, that means robots which are humanoid, because the household is perfect for human size, human motility" (interview practitioner AB, July 2011; translation: $\mathrm{PT}$ ). This statement clearly displays the idea that space and kinematics somehow appear to intertwine the body and its environment. They seem to be brought into a relationship in which one defines the other. This is expressed, for example, in the claim that the household is perfect for the human size. Notably, this claim not only naturalizes human size, but also the furniture, which according to this statement is made in a way that perfectly fits human size. Thus, the domestic household seems to emerge as some kind of anthropological constant, rather than as a standardized model of how housework is organized, which would include the division that sets the private household sphere in opposition to the public and market sphere, and the distribution of tasks and responsibilities along gendered and transnational divisions of labor.

Industrialization and its waves of technologization took place, and still occur, in both industrial production and at home (Cowan 1983). In this regard, I now ask what form of automation of the household is entailed by the 
idea of robots that will move things. To conceive of the kitchen as a site of industrialization in which an array of machines and furniture is arranged in a certain, functional manner has a long tradition. As historical studies have made clear, this tradition is primarily rooted in the 1920s in Europe. "The magic word of the[se] 'golden [...] years' is 'rationalization'" (anonymous 1990, 47; translation: PT). ${ }^{49}$ Different strands of housework studies were established, which focused on how to proceed with housework. This also includes the kitchen, which became the "central piece of the domestic operation, [in which] modern household appliances are regarded as tools and supplies for work" (ibid.). Historians agree that efforts at rationalization are deeply connected with capitalism and that the waves of industrialization and therefore the technological development of automation in Western European societies further propelled the urge for rationalization in the household, with the kitchen at its core. The model of the standardized Western kitchenette, which became a huge market success, emerged from this urge. This is of interest because it highlights again that the kitchen as 'we' have become familiar with it evolved from socio-historically specific conditions that also regulated the pairing of individuals and the gendered division of responsibilities within the household. Therefore, it is highly relevant to trace possible ideas of rationalization of housework as they are implemented in the peculiar vision of the robot companion as assistant in the kitchen.

So far, I have only discovered that humanoids are envisioned as moving something in the household, but I have not learned whose household this robot is thought of as operating in and whose tasks it might be taking over or helping with. Still, the expression to move something in the household carries two different meanings: firstly, it signifies that this robot is being developed as a machine that is able to physically operate in the household, specifically the Western, standardized model of the kitchenette. Secondly, to move something can also be understood in the sense of setting something in motion - in this case the household. I suggest that the figure of the robot companion is charged with the idea of transformations of, or progress in, the household. Such a figuration of progress operates with promises of salvation from the

49 The citations without authors are taken from "HaushaltsTräume", edited by Barbara Orland et al., 1990, which was published as an outcome of and catalogue to the corresponding exhibition. Imprints of documents that were exhibited include text that is not ascribed to particular authors. 
burdens of work in human everyday lives. However, these promises operate with a peculiar vision of the household as a field of operation and of the future co-workers of the robot and robot owners that are not separable from the existing practices of companionship and care or from the distribution of responsibility for reproductive service. In addition, these visions will shape the existing practices and forms of distribution of the future. Thus, I will continue to investigate the anthropomatic referentiality between human and machine, as it is constitutive of reverse feedback loopings, deployed on the level of human individuality and sociality, and how these loopings become established through the tropes of symbiosis and mimicry.

\subsection{Conclusions: Human-Machine Relations of Anthropo-Alikeness}

In this chapter, I have presented my first insights into human-machine configurations as they are imagined and realized in anthropomatics. I used a public meeting between the anthropoid robot model Armar and the German chancellor Angela Merkel, which was broadcast on national news, as an entry to my field of research. Further, I explored this as an iconic example of the socio-technical imaginary of contemporary robotics with its focus on a new class of robots, the robot companion. Thus, I addressed key dimensions of the Armar-Merkel interface to then further analyze public (self-)representations of this robot model in its organizational environment, namely the IAR at the KIT.

Initial insights into the public images of this specific model of a robot companion, which take as their pivotal point the un-caging of this robot as a machine that mimics the human and enters into a symbiotic relationship with humans, point to the core of technoscientific socio-technical production that was addressed in the previous chapter. The robot Armar is constantly negotiated in terms of a 'machine other' in its relations to the human self, while the conditions and practices of relating are regulated by tropes such as symbiosis and mimicry. Both of these indicate a form of materialized figuration that allows shifts between categories and, as I have highlighted throughout this chapter, thus makes translations possible between self and other, human and machine, and nature and artificial. Furthermore, I argue that the tropic qualities of symbiosis and mimicry illustrate very clearly the connections 
between translations, loopings and shifts and how these are constitutive of sorting as configuration operations.

Central to robo-techno strategies of translation, however, are formalizations, specifically to create formal representations of the human as much as the human everyday world, in this case figured in the domestic kitchen. This formalization serves the idea of modeling the behavior of the living, material world, whereas I underscored that the act of creation disappears behind the translation and subsequently behind the model generated. Thus, I presented the first steps in mapping the modeling of the embodied individual and the complementary abilities to perform tasks in the kitchen. Furthermore, by understanding these formalizations as material figurations, I underscore both their reductive and constructive character. In this sense, formalization operates with reductions and at the same time constructs specific models of the embodied individual and its environment, namely the human-like always in relations of reverse feedback loopings with the human.

Moreover, these processes of socio-technical production are charged with a politics of representation because, as Corinna Bath argues, they "make the particular visible, while something else is rendered invisible" (Bath 2009, 177; translation: PT). Along these lines, I underscore that anthropomatic modeling articulates a politics of representation that perceives the universalized human as embodying a particular set of sensory and motor abilities and the human gestalt, as well as the model of the embodied individual in relation to its environment. In addition, I highlighted that mimicry operates with an economy of representation in its normative dimensions of relating self and other, while symbiosis carries what I describe as a logics of enhancement that even points toward salvation from the burden of domestic everyday lives. Here I am thinking of what Haraway identifies as "technoscientific salvation stories full of promise" (Haraway 1997, 8). Furthermore, I regard these tropes as constitutive of material-semiotic field forces that regulate the materializing configurations of humans and robots in anthropomatics. Hence, I especially want to open up possibilities for contingency in understanding the human, forms of human-machine co-shaping, and the reorganization of work through new human-machine interfaces in the remainder of this thesis. 
The anthropomorphic machine in contemporary robotics can be contextualized within what I identify as a turn to the body in robotics. This "paradigm shift" (Weber and Bath 2007, 53) in AI paves the way for machines such as the companion robot. The intelligent domestic robot is based on the idea of a thinking machine that mimics the performance of what is thought of as human behavior, such as cooperation through language and gesture, as well as on the idea of a symbiotic machine that rationalizes work by, for instance, becoming an extension of the human arm in a task like lifting a crate of beer. The embodied (human) individual and the household, especially the kitchen, appear to be ideal models for designing the robot companion, while the labors, circumstances and politics of representation, differentiation and valuing seem to be excluded from this model. In addition, this model contains forms of companionship that are designed to produce a likeness between human and machine, based on what I identify with Haraway as a common ontology (Haraway 2003).

Anthropomatics can be contextualized within a specific "domain of science and technology" (Suchman 2008, 139), which, as Suchman continues, is characterized by "the shifting boundary of nature and artifice [that] [...] figures between humans and computational machines" (ibid.). Secondly, as Suchman argues, this shifting boundary, which can be identified with "the project of engineering the humanlike machine" (ibid., 142; emphasis in original), is constitutive of and constituted by "specific cultural assumptions [about] the nature of the human and the foundations of humanness as a distinctive species property" (ibid., 150). The current model of the prospective robot companion, Armar, is presented and presents itself in public as interactive. Through the public images that I have assembled in this chapter, I get a first impression of the interrelations between embodying human-likeness and agency, as the latter becomes a distinctive species property and an indicator of humanness.

From what I have so far learned about the anthropoid human-machine configuration, this machine is a domestic and intelligent machine, while the human emerges as a potential consumer, driven by the twin desires of a fascination with humanoid automata, and a fascination with the idea of machines taking over work and assisting with many tasks. Even forms of prosthetic completion which are contemplated in the Armar X, a machine that 
functions as a walking aid, are included in this interface with the anthropoid robot. Consequently, the anthropomatic articulation of the human-machine interface seems to invoke salvation through technological promises that seem to be a vital resource for the fantasy landscape of human-machine configurations in anthropomatics as a branch of contemporary robotics.

However, my approach to this fantasy landscape and its materialized figurations of the robot-human interface takes as its pivotal point the demand to develop a deeper understanding of ontological practices in queer feminist technoscience studies. Thus, analyzing the ways in which robotic practices rework the socio-technical imaginary of companionship, human-like-ness and human-machine interfaces particularly explores sorting operations in their ontologizations. In this sense, I regard my cartography as an endeavor that reverberates with Sabine Hark's suggestion of a "gender-critical ontology of the present" (Hark 2007; translation: PT). Such a perspective entails focusing on "transformations of the triangle 'nature-culture-gender', as well as [...] specific modern categories of classification and ordering, for which the binary gender system is the paradigmatic pattern of ordering, and their differentiating power, for example, in determining norm and deviation" (Hark 2007, 11; translation: PT).

From this perspective, the human is a historically-ontologically specific concept, which cannot be disentangled from the sorting operations of sociotechnical production through which the proper human takes form. Thus, I underline the fact that the human form as it appears as both the blueprint for and part of prospective human-Armar interfaces is grounded in and at the same time propels, as Haraway argues, historically specific "constructions of universal humanity" (Haraway 1997, 214). From this perspective, one principal matter of care in mapping the socio-technical imaginary of contemporary robotics is the question of how to retrieve the human from its universality, as it articulates in relations of commonality between human and machine, and connect it to the apparatuses of its production, as I will continue to elaborate upon throughout the remainder of this thesis.

Again, I have learned so far that specific capacities for action appear to distinguish this robot from other machines, as they serve as an indicator for humanness in the machine. I find Suchman's account of the emergence of capacities for action, or agential properties, at the robot-human interface very 
insightful in this regard (Suchman 2007, 151). She prominently coined the concept of "situated action" (Suchman [1987] 2007), which, as she emphasizes, has a two-fold objective:

One objective in studying situated action is to consider those fleeting circumstances that our interpretations of action systematically rely on, but which our accounts of action routinely ignore. A second objective is to make the relation between interpretations of action and action's circumstances our subject matter (Suchman 2007, 85).

At its core, situated action fosters accounts of human-machine configurations that revive the fleeting circumstances of action in relation to the interpretations. In this way, she proposes an approach to action that situates the construction of the intelligent machine as interactive device within the material-semiotic conditions and practices of this interaction. In line with Barad and Haraway, Suchman draws on the notion of apparatuses through which, as she highlights, "stabilized entities are [conceived as] constructed out of specific apparatuses of sociomaterial 'intra-action'” (Suchman 2008, 151). Thus, I find the concept of apparatuses useful in attuning me toward the ways in which negotiations of human-machine relations and the boundaries between artifice and nature are charged with both ontological and epistemological dimensions of establishing the category and the interactive body' of the human-like always in relation to the human.

These dimensions appear, for example, in outlines of computational modeling based on the idea of the world as simultaneously present and representable. Through this epistemological stance, the researcher relates him/herself to the material, in which the latter is conceived of as passive and out there, while the former takes on the position of objective vision, the ability to see everything from nowhere. Secondly, this position of formally representing the material also implies authority over the world, to which predicting and controlling what is thought of as properties of the material is assigned, while the researcher operates from a comfortable distance, keeping her/his hands 'clean'. In line with Barad, apparatuses of socio-technical production are an analytical concept through which I will map selected ethico-onto-epistemological dimensions of configuring the Armar-human interface.

As I centrally draw from Harawayan embodied objectivity and as I can think this through touch, the attempt to define key dimensions and topics of 
my map is clearly requiring great care. Thus, I underscore that my approach builds on the refusal to apply the god-trick of seeing everything from nowhere. Rather, it fosters forms of embodied cognition by getting in touch with the laboratory practices of engineering the human-like robot companion, as these are at the center of the following two chapters. 


\section{Mapping Human-Machine Relations during Demonstrations: Performing the Kitchen in the Robotic Laboratory}

This chapter analyzes a specific setting for the public testing of one robot model, Armar, and asks how this machine comes to matter as a prospective human-like agent that will supposedly become useful in this setting of a kitchen. Thus, the focus of this chapter is the demonstrations of Armar in 'its' kitchen setting. This is one important realm of laboratory practices of imagining and realizing the figure of the human-like robot companion. The kitchen is after all the domestic workplace where the robot's services are imagined to be most needed in the future.

In chapter three, I introduced the robot model Armar and the IAR by firstly describing the Armar-Merkel interface as it was displayed on the German TV news and secondly by tracing the tropes of anthropomatic configuration; that is to say, the material-semiotic fields of force of anthropomatics through which matter and meaning become entangled. In this chapter, my focus continues to be on how bodies, movements and meanings at the humanArmar interface are configured and how these configurations are then constitutive of what is regarded as a successful interaction between humans and the robot - for example, as suggested by the picture of a shared workplace - at the same time as it accounts for the always more than human making of artifacts and facts. In doing so, my map mainly follows a Harawayan trajectory of scrutinizing who is making whom, rather than assuming pre-determined agents with specific properties and complementing causal relations. Therefore, I will emphasize the apparatuses of configuration, or rather of bodily co-production - a derivate of Haraway's corporeal discourse concept "apparatus of bodily production" (Haraway 1991, 200) - as analytical concepts that unsettle fixed origins and instead underscore the processual and porous character of the materialization of bodily boundaries.

A central aspect of analyzing selected examples of the public testing of Armar is that I participated in these events. From my perspective of queer feminist technoscience studies, which researches the production of phenomena from a position located within the science and engineering of interactions in the kitchen, I develop in this chapter a deeper understanding of the ethico-onto-epistemological dimensions of laboratory practices. 
Suchman et al. invite me to rethink the making of technologies when they insist on an understanding of "making technologies [as] [...] a practice of configuring new alignments between the social and the material that are both localized and able to travel, stable and reconfigurable, intelligibly familiar, and recognizably new" (Suchman et al. 2002, 164; emphasis in original). Along these lines, I approach the selected demonstrations of Armar in terms of such an alignment of the social and the material through practices of configuration. In this way, I map processes of making the robot a companion that becomes useful in the kitchen through, firstly, practices of aligning and, secondly, becoming attentive to a multiplicity of apparatuses and agential capacities on different scales in the robotic laboratory.

When I entered the kitchen laboratory, at first sight, different objects and subjects as well as the distinction between subjects and objects all appeared to be crystal clear. However, as I immersed myself in the daily work routine of demonstrations, I noticed that, during these events in particular, things did not seem to be so distinct, and it became apparent that the boundaries between, for example, subjects and objects were rather precarious. Here, I am thinking of multiple situations in which the capacity for action that the robot supposedly embodies became apparent as depending on a myriad of other things, such as headphones, the computer screen in the middle of the room on which we see the kitchen through Armar's 'camera eyes', but also other subjects, including those who are already familiar with the robot in its functional setting and those who are yet to become familiar with it. Beyond this, it also became apparent that, even though there seem to exist clear assignments between the myriad of objects and subjects involved in the demonstration and its success, the execution of tasks in the kitchen also appears to depend on something above or beyond this. This something is addressed during demonstrations as a "hope" or "wish"; for example, that "the robot feels like demonstrating today" (demo 1, July 2011; translation: PT). I therefore suggest a mapping of the myriad things, both human and morethan-human, that are involved in making demonstrations a success and ensuring that the robot is efficient in front of an audience, that will highlight the inseparability of bodies and apparatuses of bodily production. Furthermore, I draw on these apparatuses, in line with Barad, as "the material 
conditions of possibility and impossibility of mattering" (Barad 2007, 148; emphasis in original), that are, in short, "boundary-making practices" (ibid.).

I address the public testing of Armar as a performative event in which boundaries are enacted. I find the concept of "posthumanist performativity" (Barad 2003; 2007) useful in developing what I define as a fine-grained account of the process of alignment and the apparatuses of bodily production described above. Here, in line with Barad, I draw on the queer/ing legacy of performativity as it became prominent through, for example, Butler's work on "how bodies come to matter" (Butler 1993), in which she accounts for bodies as discursively materialized, instead of fixed, natural, and given entities. Hence, the Butlerian account of performativity conceives of the cultural markers that sexualize, gender, racialize and ableize bodies, through the discursive practice of iterative citation of norms and as material sedimentations (Butler 1993).

In this sense, materialization is an ongoing process, and the material effects or sedimentations of this process can be understood, in short, through the operations of their performative enactment, again opening up an understanding of bodies as contingent. Shifting the perspective from how bodies come to matter to how matter comes to matter, Barad develops an account of materialization that expands the very concept of performativity beyond what could be called the humanist terms of linguistic signification and control (Barad 2003; 2007). In accordance with such a Baradian understanding of performative materialization through the dynamics of intraactivity, ${ }^{50}$ I suggest exploring the practices of aligning as boundary-making practices of a posthumanist performative enactment of the practitioner-Armar interface. Thus, I will query the ways in which human-like capacities for action emerge through co-productions and ask how to trace these through the analytical prism of intra-activity.

\subsection{Demonstrations: The Theatre of Use and Theatre of Proof of Armar}

Demonstrations of Armar are of great relevance not only to the project work in anthropomatics, but also to my map of how a specific machine comes to

\footnotetext{
50 As Barad notes: "The world is a dynamic process of intra-activity and materialization in the enactment of determinate causal structures with determinate boundaries, properties, meanings, and patterns of marks on bodies" (Barad 2007, 140).
} 
matter as a human-like robot companion for humans. Suchman points out that, during demonstrations, machines such as the contemporary humanoid robot become "worldly" (Suchman 2011, 119) as a "figure of the Human" (ibid., 124) on two levels: in their capacities for interaction and in their embodiment of these capacities. She further argues that "humanoid robots are objects engineered to be models for bodies conceptualized as identifiably Human subjects" (ibid., 123). Hence, to participate in demonstrations means to participate in processes in which such an identification of the robot with the universalized human is tested in front of an audience. Important concerns and questions that arose within the setting of demonstrations seemed to include whether the audience - either other robotics practitioners or future robot owners - will recognize and acknowledge this machine as human-like and a possible future companion in the realm of the household. In addition, and equally important, was the question of whether the robot will execute its tasks and show capacities for action as planned or not.

My approach to anthropomatics in general and to demonstrations in particular is strongly informed by Suchman's work, as should be apparent. Moreover, in this chapter I emphasize that part of her work in which she brings together the Latourian term of the "theatre of proof" (Latour 1988, in: Suchman 2011, 123) and Wally Smith's "theatre of use" (Smith 2009, in: ibid.). Anchored in Latour's study of the "Pasteurization of France" (Latour 1988), the theater of proof depicts, in short, a socio-ethnographic approach to how things stabilize through networks of action. The theater of use accomplishes this nicely; hence, it directs the analytical attention toward the "layered propositions of material and imaginary, present and projected future [...] folded together within a single event" (Suchman 2011, 124). This account of demonstrations as theaters of proof and of use will structure this chapter in various ways.

For example, this combined outline of demonstrations as theaters of use and proof will help me to understand the specific setting of demonstrations in which robotics practitioners, the robot and prospective consumers meet. Furthermore, it will also attune me toward the interactions that make the robot efficient in front of an audience. As Suchman puts it, demonstrations are "a kind of double-drama that includes the enactment of an encounter with a technology that is itself embedded in an encounter between the demonstrator 
and their audience" (ibid.). Thus, to query how demonstrations at the IAR also articulate such forms of double-drama between the enactment of an encounter and a second encounter between robot and visitor is of interest for this chapter. Hence, the study of demonstrations is one pillar of my cartography of this machine's map that addresses local practices of configuring human and machine with an emphasis on enacting such doubledrama. In this way, mapping practices of alignment between social and material, familiar and new, as well as stable and reconfigurable, through the apparatuses of bodily production at work in demonstrations serves both to pin down categorical work as the drawing and redrawing of boundaries between subject and object, self and other, human and machine and, equally importantly, to identify failures of such an enactment of proper categories with assumed embodiment of agential properties. The latter will become palpable in situations where the fragile qualities of this double-drama of demonstrations become apparent.

Demonstrations are a specific genre of public testing that plays a key role in establishing "objectivist science" (Suchman 2009, 214) and the rise of modern, experimental science (cf. Smith 2009; Suchman 2007, 214; Haraway 1998, 173ff.). As Smith notes, the robotics demonstrations are "distant cousins of the scientific demonstration" (Smith 2009, 450). He further identifies a "common thread" (ibid.) between both kinds of demonstrations. As he points out, "spectators supposedly witness some natural or technological object directly, as opposed to merely being informed about it indirectly" (ibid.). This witnessing, importantly, is not only about being informed, but is rather a fundamental part of this branch of technoscientific knowledge and object production. Through their encounter with the robot in action, the audience is not only informed about how the robot performed - in this specific case, as a kitchen robot - but also the demonstrations are a situation in which prospective robot owners can experience what such a human-robot interface looks like and could look like. In turn, the visitors as prospective owners comment and interact with practitioners and robots during the event of the demonstration, and in doing so deliver insights into how people react to the contemporary robot model.

Moreover, Suchman emphasizes that demonstrations are "the canonical story form" (Suchman 2011, 124) of displaying a new technology in AI, 
especially robotics, to a wider audience. She further highlights that "live' demonstrations [are events], where a technology is animated by those invested in its efficacy for an audience of variously interested observers" (ibid.). I take the process of animation, as Suchman frames it, as a point of departure for getting in touch with live demonstrations as a practice of making a technology efficient in front of prospective consumers. Thus, in what follows, I present my understanding of demonstrations as firstly used by practitioners as a test-bed for the robot, and secondly as a performative event of boundary-making practices. The latter encompasses a set of methodological-theoretical sensitizations toward ethico-onto-epistemological dimensions in analyzing demonstrations that will attune me to the conditions for and practices of making this robot worldly as an identifiably human-like machine, as I will continue to elaborate upon.

Suchman further helps me to understand the stakes involved in developing a deeper understanding of ethico-onto-epistemological dimensions in this specific setting of the robotic kitchen laboratory. She describes the process of animation in terms of "the perplexing mix of enchantment and mystification that comprises the search for intelligibility in artificial life" (Suchman 2011, 120). In line with Suchman, I will ask for the ways in which the robot becomes identifiable as human-like and the human-robot interface becomes socially meaningful through a mix of enchantment and mystification at demonstrations. Further, I regard both which both delineate interpretative engagements with the machine as a kind of enlivenment that fetishizes the object (Suchman 2007, 238 ff.). In this way, I will contemplate and complicate my understanding of the ethico-onto-epistemological dimensions of the public testing of robotic machines as a specific form of experimental practices that constantly (re-)craft the human-like always in relation to the human and the boundaries between nature and artifice. ${ }^{51}$

The idea of fetishization will be useful in tracing how an object such as the robot model appears to be present and given in an unmediated way during

\footnotetext{
${ }^{51}$ Moreover, Suchman derives her account of fetishization from Sara Ahmed, and highlights an understanding in which "fetishism involves cutting off a figure from the histories of its determination through particular, embodied encounters" (ibid., 244). She furthermore works with the idea of fetishism to develop the notion of the fetishized object by drawing on her concept of situated action as one that recuperates that which has been cut off from the enlivened machine. I introduced the concept of situated action in chapter three and will continue working with it in this chapter.
} 
specific situations of embodied encounter such as demonstrations; that is, naturalized in its being and cut off from the interdependencies and labors that are constitutive of it. To approach the robot in demonstrations as a fetishized object thus means to contest the idea that this machine can be purified of its contingent relations of being produced and producing boundaries between object and subject, self and other, and nature and artificial, and to query the ways in which such purifications carry "an individualist conception of agency" (ibid., 240). In this regard, the concept of fetishization as purification and enlivenment of the robot makes palpable how agency at the humanmachine interface matters as a capacity that is thought of as the property of an individual entity.

However, and importantly, this also entails moving beyond seemingly 'human inscriptions' of agential properties and human-like features to the machine. The robot that is modeled on the human challenges the idea of analyzing material agency and actors in the lab where agency serves constant processes of association, translation and re-demarcation between the machine other and the human self. Here I am thinking primarily of the practices through which the robot is made legible as 'almost human'. Again, I regard Suchman's way of addressing such a non-anthropocentric understanding of fetishization very insightful. She suggests thinking the process of making the robot worldly through Haraway's concept of becoming worldly as a practice of "becoming with" (Haraway 2008). In short, I find the change in phrasing from making worldly to becoming worldly with useful for grappling with the practices of fetishization that are constitutive of boundaries between entities with (agential) properties. Here, I am interested in what Åsberg calls the "posthumanist concerns [with ontology] outside of human control and language" (Åsberg 2010, 12). This approach to mapping, which takes into account posthumanist concerns, will expand my understanding of demonstrations as key performative events of a becoming worldly of the robot with 'its' humans that avoids a deterministic explanation, such as that which figures, for example, in the idea of the 'human maker' of the enlivened machine. Such a de-centering of the anthropos as the creator of human-like technologies in favor of laboratory practices of alignment and multiple apparatuses of production also acknowledges a non-individualist conception of agency. The latter means to understand agency not as something that is $a$ 
priori inherent in subjects or objects, the human or the machine, that is, a property belonging to id/entities, but rather something that describes the material-semiotic enactment of relations a posteriori.

In this regard, Morana Alač's study: "Moving Android: On Social Robots and Body-in-Interaction" (Alač 2009) also became of central importance in my approach to demonstrations. Especially insightful are her thoughts on the humanoid robot, in her study the android, as a machine that is simultaneously an instrument and a model for robotics practitioners. ${ }^{52}$ I will develop this thought in detail in the next chapter, but for now it is important to mention that Alač distinguishes between these two kinds of humanmachine relations in order to find "a way to think about the dynamics between human bodies and robotic technology, starting from local acts of work and multimodal interaction in the laboratory" (ibid., 523). Along these lines, I will also work centrally with two further units of analysis that I draw from Alač's work. These are "interactional sequence" (ibid., 491) and the concept of the "body-in-interaction" (ibid., 523), which I will develop in detail throughout my analysis. In short, Alač is suggesting, in a Baradian vein, an engagement with bodies-in-interaction as a perspective that challenges the idea of the individual body and of agency as a property of the individual (Alač 2009, 497).

\section{Demonstrations as a Site of 'Smooth Engineering'}

Before exploring selected interactional sequences, I briefly sketch in what follows the relation between the 'demonstrator', Armar, cooperative project work in anthropomatics as discussed in chapter three, and the specific practices of making the robot efficient in demonstrations. In doing so, I approach the specificities of relating to Armar as model and instrument as they emerge in the context of anthropomatics.

In an interview that I conducted in July 2011, a robotics practitioner working at the IAR explains the challenges in using the demonstrator not only

\footnotetext{
${ }^{52}$ Drawing on Alač's description of her field of study, the android is a humanlike machine, which "aims to be a particularly accurate replica of an individual" (Alač 2009, 497). The android thus differs from the humanoid - at least through the descriptions of the humanoid I encountered in my field study in which the humanoid is explicitly circumscribed as a machine that, although human-like, is always comprehensible as the 'machine other'. To explore the details of this machine other is the topic of my continuing analysis.
} 
for research purposes, for example in cooperative project work, but also for making the project more public.

So, we have for our EU projects the Armar, the so-called demonstrator, but since this is a platform that draws attention, because it's a humanoid robot, one gets financed more easily, this simply is the demonstrator and this means that things have to be shown here. Our partners reside all over Europe but everything has to run here. We have to coordinate this and ideally we have to provide the knowledge so that they can do this all by themselves, but the robot is not a product one can easily say, "hey, here you go, the perfect simulation environment, just use this, travel here and then everything will work out," this simply isn't true and we have to fill these gaps. (interview practitioner CD, July 2011; translation: PT)

This description of how the robotics practitioners at the IAR have to fill in the gaps illustrates aspects of how project work takes shape and the attendant division of labor involved in integrating this work into the robot. The practitioners on-site have to take on responsibility for the efficiency of the demonstrator, which in turn guarantees the success of this project as much as the funding of prospective projects. ${ }^{53}$

Moreover, knowledge about this machine's technicalities is not regarded as self-evident. The interviewee points out that the ideal case would be if someone could propagate this knowledge among the project partners so that they could work equally on and with the robot. As this is not the case, the practitioners working on-site are, on the one hand, experts who have highly specific expert knowledge about the current robot model, and, on the other hand, they have the responsibility for making things work. These local practices of making things work are particularly relevant for understanding demonstrations and how these are involved in relating to Armar as model and instrument of anthropomatics.

In a later section of the same interview, practitioner $C D$ suggests a differentiation through which he categorizes two different types of work; namely, science and engineering. I find this insightful for grappling with the complexities of the double-drama of demonstrations. Making the Armarhuman interface efficient in front of an audience relies on the 'smooth

\footnotetext{
${ }^{53}$ The interviewee makes a connection between the robot's humanoid design and the funding. Unfortunately, I did not have the chance to query why he sees this connection. Nevertheless, I suggest that this link illustrates knowledge that is regarded as common sense: the humanoid design is the ideal design. The humanoid robot deployed as labor and companion in the household appears to be especially worthy of funding and this connection is regarded as obvious and self-evident.
} 
engineering' of the robot, which seems to consist mainly of problem-solving strategies, such as tinkering, and to hope that everything that lies beyond the control of the practitioners will work out somehow.

Excerpt interview practitioner CD, July 2011; translation: PT (emphasis: English in original)

Pat: So, this integration and development of [...] software is then extremely complex. CD: Yes, and also this is not the scientific part, this is the pure engineering part at maximum, this is only software, problems, there exist some problems and one solves them somehow; you don't make science from this, but a demo is called in three weeks and by then everything has to run [on the robot] and you don't write a paper about this [both laugh], with this, one takes the path that somehow works and then this will also work out somehow.

Pat: Interesting.

CD: Nerve-wracking.

Pat: And because you just said engineering and science - in which one do you work?

$\mathrm{CD}$ : Oh, ah, I find this strangely difficult, this boundary between, so if we were talking in English, we would use the term engineering for what we're doing here, completely, yes [...] science and engineering and science is something like for example observing the human, the brain, and how parameters will change if one makes a movement ... this is classic science, so observe the human ["am Menschen gucken" in German] and we don't do this here. Finally, I would say that we're an institute that does engineering, but this doesn't mean that we don't do science... I think this is also the boundary between science and engineering, [with] engineering, you have a problem, you solve it, the problem is solved and you're happy, but this won't yield anything for anyone else, so it runs on your platform and in science it's important that you have a response for the community, that you have a result that others can work with in their scientific processes and this is something we should all attempt to do.

\section{End of Excerpt}

The robotics practitioner, seemingly somewhat unsure, speculates about what differentiates science and engineering, and draws a boundary between these divided realms by explaining, in short, that science means observing how things work, while engineering implies the labor of getting things to work and then, eventually, to say how things work. I find this differentiation very interesting because, by this definition, demonstrations seem to belong primarily in the realm of engineering, of getting things to work. 


\subsection{A Selection of Interactional Sequences: Anthropoid-Human Bodies-in- Interaction}

Against the backdrop of the basic idea behind anthropomatics, that is, to build machines that are proximate and beneficial to humans, in what follows I assemble a selection of interactional sequences. These sequences serve as examples of how the idea of a machine proximate and useful to humans is enacted through local practices of making the robot efficient in the doubledrama of the setting of demonstrations in the robotics laboratory kitchen.

My focus in presenting this selection of sequences is on the practices that make the double-drama of demonstrations a success and the machine efficient in the kitchen. I also wish to open up aspects of contingency as that which becomes apparent, for instance, when the smooth engineering does not work out as planned in the procedure of demonstrations. Through the latter, I will emphasize moments in which the interplay between bodies begins to stutter, describes circular forms of (re-)alignment of stuff and meaning, and might even display forms of a becoming worldly beyond the planned forms of bodies-in-interaction. My argument here is that such situations, which go beyond the smooth demonstrations that are characterized by efficiency, also make palpable exactly those material-semiotic circumstances and labors that otherwise disappear behind seemingly clear boundaries, properties and causal relations of individual bodies that also supposedly signify equally clear assignments of tasks. I further contemplate this trajectory of mapping in terms of an endeavor that centers on assembling neglected things by turning them into matters of care. In this sense, I understand my role as participating in the double-drama through the mundane practices of caring for and entering into responsibility for creating attachment sites of making robotic worlds, as I will continue to argue.

\section{Introducing Armar's Body}

I begin by describing the interactional sequence of initializing Armar; a process that mostly took place before the demonstrations, but was eventually integrated into them, as the following example depicts. Particularly because this process marks the beginning of the demonstrations, this sequence also appears to be the ideal point of departure for delving deeper into how the bodies, movements, and meanings involved in the situation of demonstration 
are 'co-produced' so that the robot comes to matter as a human-like machine.

\section{Excerpt D1}

Practitioner A: You see here Armar IIIa [...]. And as one sees, we can communicate

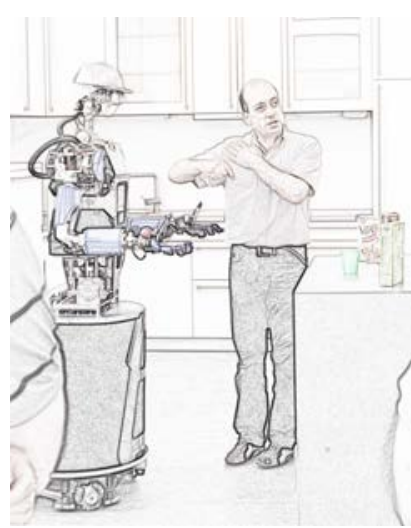

Picture 3 with the robot completely through language and I will explain the robot's joints. [Talking to practitioner B] Could you initialize? [Talking to the visitors again] Even though the robot is initialized and ready, the first thing the robot does, when it wakes up is Practitioner B: Initialize robot.

Armar IIIa: Do you really want to initialize me?

Practitioner B: Yes.

Armar IIIa: Initializing robot.

Practitioner A: So, first of all, it has a neck, and a head, and arms with elbows, which we are seeing. The head has seven degrees of freedom of motion, so to the front, to the back, to the side. It can also rotate around the body axes up to 320 degrees, so significantly more than the human can do. Then of course joints, which one can see, two eyes, shoulder joints such as in the human arm, so flexion, abduction, adduction, upper arm rotation, elbow, which we have seen, then a hip joint, which also allows a rotation [...], so that it can hand objects to someone without moving the platform, which is extremely heavy, because there are two truck batteries, which weigh 80 kilos, in it, [...] a five-finger hand as one can see here, which is powered by fluid actuators, [...] two cameras per eye, [to practitioner B] could you Practitioner B: Look to the right.

Armar IIIa: Looking to the right.

Practitioner A: - and two times close angular ranges, visual ranges, close and wide, replicating the human visual range only approximately. We can focus on one object in grasping it, for example, while still looking at what is happening around it. A camera system that can do this using only one sensor is actually not yet technologically feasible in the size we want them here, therefore we have this solution with two cameras. What one can see here

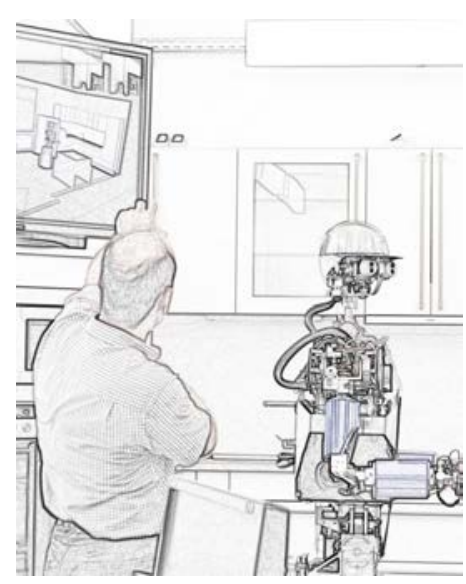

Picture 4 is a moment in the environment; this is what the robot - at the moment - knows about its environment. It knows that there is a work surface, that this here is a kitchen. It knows, over there is the fridge and that there is a dishwasher. This is all 
programmed [knowledge], but apart from that it doesn't recognize any persons at the moment or any objects now at the beginning and now we'll wait and see what happens, what Armar is able to do today. Let's start - it will react today to what [...] [practitioner B] says.

Practitioner A: It can do a lot but, I hope, he feels like demonstrating this today [both engineers laugh]..$^{54}$

\section{End of Excerpt}

In this initializing sequence, the visitors, including me, get to learn a lot about the features of the robot's body. The initialization designates the start of the demo, during which the machine basically calibrates its parts and the processors boot up. To describe the booting-up routine as analogous to waking up is clearly supposed to invoke associations between human and robot that charge the latter with anthropomorphism. However, the robot's movements appeared to me as quite 'un-human-like' because, in order to calibrate its parts, the machine has to move within its full range of degrees of freedom, that is, more than 300 degrees. ${ }^{55}$ Thus, I consider this waking as a maneuver of boundary (re-)drawing that allows associations between two seemingly distinct realms: that of the human and that of the machine. Hence, I regard the initial situation as a delicate maneuver of creating the conditions for identification as, firstly, the robot's movements become human-like while the human as frame of reference then evokes a normative concept of the possible angles through which human joints can move, based on commonsense knowledge. Thus, I consider this analogy to be a strategy of implementing mimesis between human and robot that operates as a disclosing agent in what counts as a human-like body and the according

\footnotetext{
${ }^{54}$ In translating this sentence, I decided to translate the German personal pronoun for the robot in two different ways, according to what I identify as a double meaning inherent in the German 'er (he)', the pronoun for the robot (in German the robot, 'der Roboter', is a masculine noun): on the one hand the robot is a machine, which the practitioners are demonstrating to the visitors and, on the other hand, the robot is individualized and personalized - at least within certain degrees - by addressing it as an agent in demonstrating what it is capable of. Therefore, the pronoun indicates two different ways of relating to the humanoid in demonstrations, which I will analyze further throughout this chapter. However, in order to have both of these meanings present in referring to the robot, I will refer to the machine as it, and where it seems necessary, also as he.

${ }^{55}$ In my experience, it was exactly these movements of more than 300 degree that displayed a strong contrast between the engineer's explanations and my experience of this machine's human-likeness. Thus, this analogy might even be understood as underlining the difference between the robot and the human, rather than creating proximity.
} 
execution of movements.

Furthermore, I read the next step of the initializing process as also displaying the performative enactment of mimicry in its tropic qualities. When the practitioner enumerates body parts, he firstly refers to his own body and then secondly also endows the robot with these parts. In addition, as the practitioner constantly highlights that 'one can see' this attribution of parts that are conceived of as human body parts, this endowment of the robot establishes a bodily scheme that invokes the norm of the human body. This norm thus functions, again, as a framework for how to read the robot's body, specifically its embodiment of anthropomorphism. This is of interest for my map as this semiotic-material practice of figuring the human in the robot's body is a clear example of the robot's animation as the alignment of a humanmachine configuration of anthropomatic mimicry that is imbued in a peculiar economy of representation. So far, this initial description has focused on the robot model Armar IIIa through the verbal and gestural introduction to this machine. I contemplate this form of introduction as already revealing first insights into the possibilities and impossibilities of mattering during demonstrations and thus I regard the process of making Armar legible as almost human as one vital part of the apparatuses of bodily co-production.

Another dimension of how this specific machine comes to matter as efficient through an encounter with the practitioners and the audience is the way in which the humanoid shape, even though only partially realized, becomes apparent as the ideal design for this machine. When the practitioner introduces the humanoid robot Armar IIIa to the audience, these abilities are defined as being able, firstly, to grasp any object (in the household) and, secondly, to communicate through natural channels. Both invoke the robot as a prospective companion that will become useful as a service agent at home, which I further interpret in terms of making Armar domestic. This 'domestication' of the robot as a prospective co-worker in the kitchen illustrates the enactment of a human-machine configuration of symbiosis that carries the idea of a complementing partnership. In addition, it shows that such practices, which prove that this machine is realized as human-like because it embodies certain features and properties, intermingle with practices that demonstrate its usefulness. 
So far, we are getting to know the body model of Armar through the features assigned with properties, as they are central to the initializing process described above. Here I already catch a glimpse of the dimensions of the double-drama and also of a fetishization of the human-like object at the heart of these demonstrations. In what follows, I discuss selected aspects of these two key dimensions of demonstrations with the interactional sequence at hand. In general, this sequence dictates that the tasks in operating the robot are divided between practitioners $\mathrm{A}$ and $\mathrm{B}$ as announced by practitioner $\mathrm{A}$. He describes the robot to the visitors, and refers to this activity as explaining Armar, while practitioner B wears a headset and talks to the robot. ${ }^{56}$

I identify the headset as a mostly taken-for-granted means of interaction through which the robot is made an interlocutor and through which Armar becomes legible as embodying the capacity for 'hearing' and communication through language - even though it is riddled with very precise requirements, as I will explain further with the example of a different interactional sequence in a later section of this chapter. The communication starts as the practitioner commands Armar to 'initialize'. The robot appears to comprehend this command when it answers by asking: "Do you really want to initialize me?" In this staged communication, the practitioner now has to answer with: "Yes", before Armar then begins the initialization. ${ }^{57}$ The robot becomes a reactive machine that appears to make sure that it got the command right by 'checking back'. In this way, human-like communication skills figure as an agential property of the machine that the audience can experience 'live'.

Thus, I contemplate the role of the audience in demonstrations of Armar as being that of a witness to both the theater of proof and the theater of use. Hence, I want to include the audience as part of the apparatuses of coproduction that are at work in demonstrations. The visitors are informing themselves and experiencing the prospective human-robot companion interface. In this way, they not only become part of the alignment through which the figure of the robot companion works as being at the same time both

\footnotetext{
${ }^{56}$ As I will also argue in a later section of this chapter, this headset as a channel of communication is a clear example of how a body in encounter is cut off from the histories of its production and, importantly, the ways in which it is producing modes of encountering.

${ }^{57}$ Both partners in this communication have to proceed in accordance to a plan - if the practitioner does not speak in a certain manner into the microphone, the robot will not be able to react, as will become apparent in the transcription of another interactional sequence later.
} 
new and familiar technology, but they also become invested in making this interface efficient.

Practitioner B does not rely on a keyboard or any other kind of input device, apart from the headset. This mode of giving commands to the machine deploys an image of the companion robot as incorporating possibilities of speech recognition similar to those that have been introduced in pocket-sized devices such as smartphones. The machine's seemingly reactive skills have a special meaning for the demonstration. Through these skills, the human-likeness of the robot figures differently: It seems to be something every visitor can already see, and something that they learn to see through the practitioner's verbal and gestural explanations, as well as something that the robot itself displays. The object of description, the humanoid robot, is at the same time an object presented by the practitioner, and one that seems to literally speak for itself. The latter signifies a change in the relationship between objects and their interpretations in laboratories working with intelligent machines that Suchman explains as follows: "Now the artifact, the intelligent object, speaks for itself, while similarly erasing, rendering invisible, its coauthors" (Suchman 2007, 214). The object that speaks for itself appears comprehensible through seeing it with one's own eyes and hearing it with one's own ears.

Along these lines, I consider the object that speaks for itself to be a figuration of intelligence in the machine that also implements new forms of neglected labor, which go into the animation of the robot, such as teaching the audience to see and speak with the robot. Thus, to scrutinize forms of coauthoring that are erased in the process of bringing this machine to speak for itself in front of an audience is of interest for mapping the enactment of capacities for action, especially beyond imaginations of proper entities with agential properties. Thus, I want to continue to explore the linkages between the animation of the robot, the erasure of forms of co-authoring and the modest witnessing of an audience that learns to see and, equally importantly, to experience the robot as a prospective domestic companion.

Here, I am thinking especially of Alač's idea of the robot as a machine that functions as both instrument and model of laboratory practice (Alač 2009, 496). Armar's human-likeness is made legible through a peculiar set of displaying practices comprised of relations to the robot as both model and 
instrument of this demonstration. These encompass practices of explanation just as much as the oral language skills of the machine. The former illustrates a bodily scheme that makes the human-like, individual body identifiable and the latter illustrates a behavior that invokes human-like cognitive abilities of communication as embodied by the robot.

Furthermore, I suggest tweaking the process of endowing the robot with human-like body parts as a practice of the posthumanist performative enactment of bodies-in-interaction. With this observation, I want to move beyond the idea of pre-established entities that meet during demonstrations toward an understanding of "phenomena" (Barad 2007) that become legible through both human and more-than human interaction, specifically intraaction. $^{58}$ Through such a refusal to designate pre-determined positions with clear bodily boundaries, I will further continue to argue that both human and machine are enacted in the laboratory through multi-layered relations of interaction or, in Baradian terms, they come into existence through their "relata" (Barad 2007, 139). Thus, these practices of relating through interaction are of central importance for mapping the bodily co-production during demonstrations.

Alač further helps me in thinking this enactment of differentiation with the Baradian term of intra-action (Alač 2009, 496). She "challenge[s] the idea that the human body primarily belongs to a single individual who exchanges information with the external world, as implied by [...] contemporary cognitive science and social robotics" (ibid., 496-497). In what follows, I will draw on Alač's concept of bodies-in-interaction and how to think this through intra-action to develop a deeper account of the ethico-onto-epistemological dimensions of the initializing process. However, a careful working through of this argument seems vital, and the differences between inter-action and intraaction as both laboratory practices and conceptual tools for analyzing laboratory practice (as relational) remain central topics of this chapter.

To begin with, I suggest zooming in once again on micro-practices of endowing the robot with body parts, in order to resolve the convoluted

\footnotetext{
${ }^{58}$ Barad coins this term in order to, in short, re-describe the analytical unit of things. She points out that "[r]eality is composed not of things-in-themselves or thingsbehind-phenomena but of things-in-phenomena" (Barad 2007, 140). I find this helpful to think what appears to be an established entity through its contingent and always more-than-human relations of becoming and co-production.
} 
referentiality between the organization of the human body and the humanoid's body. I am interested in enumerating the ways in which bodily boundaries are determined through their posthumanist performative enactment, rather than given and fixed. When he explains Armar's body, practitioner A not only refers firstly to his own and then to the robot's shoulders, but also moves his shoulder, while touching it, as picture 3 illustrates. He lifts his right arm in a specific manner, the arm bent at an angle of approximately 90 degrees, trying to move only his shoulder and holding the rest of his arm fixed in this position. His other hand rests on the front of his shoulder with outstretched fingers, palpating the movement of the right shoulder joint. He stands right next to Armar, facing the visitors, and describes the robot through the enumeration of body parts, highlighting the shoulders through this gesture as "shoulder joints such as in the human arm, so flexion, abduction, adduction, upper arm rotation, elbow, which we have seen." I understand this scene in which Armar becomes identifiable as a human subject as one of enacting mimesis. Moreover, I regard this performative enactment of mimesis between the two bodies as an event in which the seemingly distinct two bodies become palpable as bodies-ininteraction.

In line with Alač, the idea of bodies-in-interaction in the robotics laboratory encompasses practices of "'getting into' the body of the machine" (ibid., 496). Getting into the body, as I will continue to argue, describes the process of learning to see and, importantly, experience this new class of human-machine interface. To unfold this thought further in relation to the initialization, I begin by arguing that picture 3 illustrates a scene in which practitioner $\mathrm{A}$ is getting into the body of the machine as a multi-directional, feedback-looped enactment of bodies in intra-action in a literally and figuratively tangible manner. More precisely, practitioner A gets into the body of the humanoid, figured in the particular body of the Armar IIIa model, by holding his arm at a specific angle and fixing it so that he can only move his shoulder. In this way, he puts himself in the position of the robot, and his shoulder becomes intelligible as a robotic shoulder that is a human-like shoulder. However, at the same time, when palpating the movements of his shoulder, he uses his left hand to get (back) into his own body. In this sense, it might become useful to 
analyze practices of getting into the body when tracing complex reciprocities rather than mono-causal forms of enactment.

In addition, a prerequisite for getting into the body is a shared, or rather common ontology between 'the two bodies'. This common ontology becomes apparent through the appellation of body parts that organize both bodies. As Alač argues, such "indexing [of] the two bodies [...]" stipulates "physical proximity" which "allows for exploration through touch" (ibid.). The process of physically signifying the shoulder is a moment of proximity between the practitioners familiar with the robot, the visitors, and the humanoid model that allows an exploration through touch, a procedure constitutive of the two bodies as indexed via their human-likeness. Orchestrated by the practitioner, proximity serves to demonstrate the object as a model of technologically embodied human-likeness, which in turn becomes worldly as a human-like artifact, which speaks for itself. Furthermore, when body parts are listed, the exploratory gesture of touching a body underscores and articulates the indexing quality of this listing. Alač identifies this kind of indexing in the android laboratory as "sens[ing] the 'mechanical structure of his own body" (ibid.) while getting into the robot's body. This thought is highly appealing as it invokes the multi-dimensionality of getting into the body. Further, Alač captures this multi-dimensionality by framing such sensing of the mechanical structure of one's own body as becoming a "hybrid body" (Alač 2009, 516).

Moreover, I connect the hybrid body with Hayles' idea of human and robot as reference points for each other. The reverse feedback loop describes a movement that appears to capture the enacted transposition between humanlike capacities in the machine and machine-like features in the human. The audience also plays a crucial role in this as an additional reference point. The visitors witness the demonstration of the technology as a procedure grounded in reverse feedback loops between practitioner and robot, as relations unfold along the evoked transpositions between human-machine-human-like. It is also of interest for this thesis that touch seems to work as an enhancement of particular associations with the robot in this process of identifying the robot as human-like. It underpins what the audience is supposed to already be seeing: the robot in its technological embodiment of a human-like body. In this sense, the robotic human-like body becomes comprehensible through 
multimodal appellations of getting into the body; the body as the human arm that is the robotic arm that is the human-like arm.

What I identify as a feedback-looped process of getting into the body - into the machine's body as well as into 'his own' body - thus challenges the idea of pre-figured id/entities. Along these lines, I will continue to explore the apparatuses of bodily production and how these regulate the possibilities of mattering, namely the animation and therefore the efficiency of this robot as identifiably human, during demonstrations. Clearly, touching one's own shoulder or the mechanical hand joint are both empathic gestures in which the act of touching signifies, as Alač puts it, "trying to attain a bodily sense for what a machine can and should be doing" (Alač 2009, 496). Through gestures involved with naming, including touching and pointing, the double-drama of demonstrations is figured: the visitors can identify with the body operating the human-like machine, as well as with the body of Armar. In short, they have to attain a bodily sense of this machine by getting into the practitioner's body as the latter gets into the body of the robot that in turn becomes worldly as being almost like the practitioner. In this way, I consider the witnesses to be playing an active part in human-machine configurings because they become the point of reference for making the robot intelligible as a domestic companion. Both practitioners, as well as the audience, are first indexing their bodies to then experience with their own eyes and bodies what this machine can and should be doing in the kitchen. They learn to attain a sense of Armar.

The enactment of the human-like shoulder is a relevant example to make my argument. When practitioner A explores Armar's shoulder, he starts to move a single joint and tries to fix the other joints. Next, practitioner A touches his own shoulder with his left hand. Through this gesture, the practitioner not only illustrates that this requires attaining a sense for what a robotic shoulder can and should do, but also senses his own shoulder in a manner similar to the mechanical structure of the robot's shoulder that is, for example, reduced in its degrees of freedom. As he fixes any other part of his arm, he organizes the exploration of Armar's shoulder in his own shoulder by pointing out that this is "a shoulder joint [...] such as in the human arm", therefore, highlighting the similarity in capacities, comprised of "flexion, abduction, adduction, upper arm rotation". Through touching his own shoulder, he intends to index his and the other body, performing mimesis 
through becoming a hybrid body. This enactment seems to involve practices of indexing through an exploration that demands exploring the 'two bodies' through touch - a touch that is organized by human taxonomy. The practitioner's enactment of the hybrid body, that is, sensing the mechanical structure of his own body, depends on both his own individual embodiment and the design of the robot's body. Thus, I regard this exercise as an apparatus of bodily production, which ties abstract ideas such as human taxonomy to concrete practices of enacting a distinctively human-like body.

Moreover, these practices of enactment also raise questions of agency in the laboratory: Although it seems that, in this initial sequence, the robot has not become very active, it is already being addressed as an actor in its own becoming worldly. Practitioner A articulates this when he says "It can do a lot, but I hope he feels like demonstrating this today." In this part of the excerpt, it appears appropriate to switch from it to he to make audible the personifying undertone in addressing Armar IIIa as a machine, which is addressed as having characteristic traits. The success of the demonstration seems to depend upon the robot's mood, as it might not feel like performing. Here, systemic failure (during the demonstrations) is acknowledged as a possibility, but at the same time it becomes individualized in the response of the robot. In this way, the machine is assigned not only characteristic traits, but also agential properties that exceed 'human control' over it. In addition, I contemplate such an engagement with the machine in terms of the enchantment and fetishization of the object, which cuts the robot off from its histories of its determination. Moreover, the practitioner's articulation of concern about the demonstration provokes laughter in the room; hence, there is a tangible contrast between the machine's actions and the practitioners' actions. The first - although standing at the center of the demonstration - is mainly still an object that is inactive, while the practitioners play a central role in talking about and explaining this machine in addition to its seemingly obvious human-likeness. In what follows, I explore interactional sequences in which the humanoid becomes interactive in the kitchen.

\section{Grasping a Food Box - The Humanoid in Action}

In the following section, I draw on interactional sequences in which the robot is demonstrated as a helper in the kitchen with an emphasis on grasping. Two 
recurring demonstrations of Armar's ability to grasp are, firstly, to bring an object from the sideboard and, secondly, to bring an object from the fridge. As before, the grasping process involves the robot, the practitioners, the kitchen, the visitors, and the screen.

\section{Excerpt D1}

Practitioner B: What can you see now?

Armar IIIa: (4 sec) I can see the following objects: a vitalis cereal, a wok noodles, a rice box, a wheatbran,

a green cup, a wok noodles.

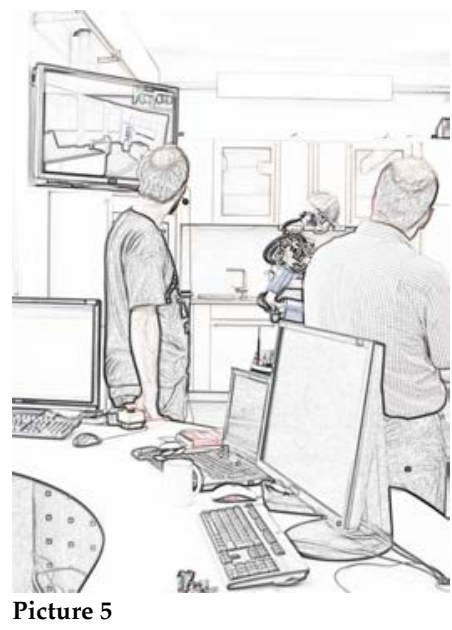

Practitioner B: This means he recognized the wok noodles twice; this was an error, because he took three looks and possibly they overlapped here so that it didn't separate them. Normally, this doesn't happen. Now it can grasp one of the objects and bring it to practitioner A, for example. If... [practitioner A mumbles something, both laugh] - which object should it grasp? Do

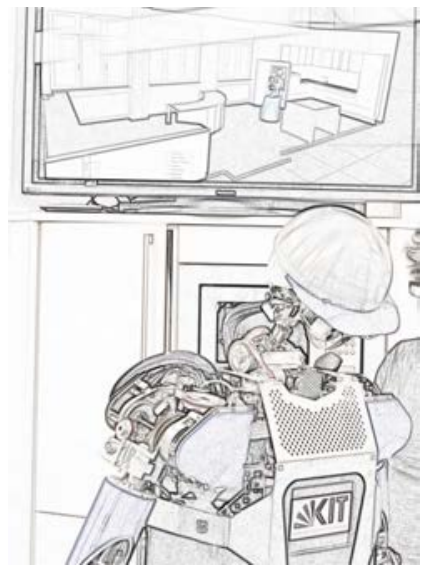
you have any wishes? Visitor: Wok noodles.

Practitioner B: Wok noodles? [Everyone laughs] [To Armar] Armar, bring me the wok noodles.

Armar IIIa: $(5 \mathrm{sec})$ From where should I take it?

Practitioner B: From the table.

Armar IIIa: (2 sec) Going to bring you wok noodles from the table.

Practitioner B: One can see now, looking up there [on the screen] that the objects are recorded.

Practitioner A: ... this means they are now in its Picture 6 memory...

Practitioner B: It also now directly knows that...

Practitioner A: No - because it got them twice.

Practitioner B: ... it has had them twice.

Practitioner A: It had them twice earlier and now it probably has it only once. [Armar knocks one of the food boxes on the table over] Yes, what we don't have here now, we don't have collision avoidance with other objects. His style is somewhat like a little child, they also don't think about: 'if I want to get this, then I will knock over the bottle or another object'.... And what happened here is the actual localization, the recognition of objects, as we have seen before. Following ... 
Armar IIIa: Here it is.

Practitioner B: Thank you.

Armar IIIa: You're welcome. [Everyone laughs]

End of Excerpt

After Armar IIIa has reached a certain position in front of the sideboard, it starts to recognize the objects standing in front of it. These objects are pretrained, which means that the camera eyes can easily recognize these objects when looking at them. After Armar has recognized the objects, they appear in the $3 \mathrm{D}$ model of the kitchenette on the screen, as practitioner A points out: they are now "in its memory". Before the robot goes into action, practitioner B explains what the audience is going to see now as he states the task of "grasping an object".

What becomes apparent in this sequence is the role of the screen for attaining a sense for what this machine can do. The practitioners and the audience follow the robot's movements twice: through observing it directly and through watching what is happening on the screen, as pictures 5 and 6 illustrate. The visualization of the robot's perspective and of how it localizes itself in the room both appear to be necessary requirements for working on and with the robot. Therefore, in what follows I further explore the role of the screen as a circumstance and condition for capacities for (inter-)action between Armar and its environment.

Analytical complexities emerge between visual and physical forms of getting into the body. The technologies of visualization being applied are at the same time based on and embody formalizations of the kitchen setting and the people and things in this environment. This centrally entails the indexing of the world in which the robot is situated. Similar to exploration as the indexing of bodies through touch, my point here is that the image recognition embedded in Armar and depicted on the screen serves the exploration and indexing of bodies equally. However, rather than bodies being described through parts organized along a certain bodily scheme, here they emerge as being organized in relation to the kitchen environment. Further, the medium of exploring expands my notion of hybrid bodies because it includes the split screen into the hybrid bodies-in-intra-action. The split screen shows, firstly, the humanoid's body localized in the kitchen in the 3D model and, secondly, what the camera eyes can see. The screen depicts the robot's memory; that is, 
its current state of capacities for action. At the heart of the grasping task are technologies of image recognition that allow formal representations of objects and bodies in relation to the environment.

Notably, the point of reference between human and machine in verbal explanations shifts in this part of the sequence; it is no longer the engineer himself but the figure of a little child. Practitioner A invokes a similarity between how the robot grasps and how a "little child" would do it. In what follows, I dwell a bit further on this aspect of the mattering of Armar in its tropic qualities. The task Armar is (obviously) not able to perform is to grasp and act in an anticipatory manner when reaching for a certain object. If other objects are placed on the table between its hand and the object it grasps, the robot will knock some of them over. The visitors can follow Armar's process, and the behavior of the robot might be perceived as a deficiency in what this machine is able to do; a deficiency that seems to require an explanation. The practitioner explains that Armar is not yet able to detect every object on the table, or to maneuver its hand in such a way that it does not knock over the other objects. Again, the execution of the grasping task is declared to be similar to how a little a child would do it. ${ }^{59}$

The comparison between the humanoid robot as a machine still in the process of being developed and the child as a universalized figure for the human subject in the process of development provokes a specific form of relating human and machine, notably in terms of its child-like behavior. Firstly, the figure of the little child evokes a bodily sense for what the humanoid robot is and what it can do: a machine comparable to a little child. Secondly, it deploys relations between robot and practitioner of "infantcaregiver" (Suchman 2011, 129). This idea of an infant-caregiver interaction between robot and robotics practitioner not only generates possibilities to identify the robot as a human subject, but also carries a developmental connotation. As Suchman writes: "In the case of the 'infant' robot, the developmental trope underwrites a kind of perpetual promise that simultaneously accounts for the incompleteness of the project, and motivates its continuation" (ibid.). The figure of the child-like robot is charged with the perpetual promise that moves between the incompleteness of the project and

\footnotetext{
${ }^{59}$ Suchman emphasizes in her work that deploying the (little) child as a point of reference for the intelligent machine has a long tradition in computer sciences, starting with the work of Alan Turing (Suchman 2011, 129).
} 
the motivation for its continuation; in short, the robot and the project are still in the process of 'growing up'.

So far, grasping is an important task in demonstrations, and it relies strongly on visualization technologies. These, further, constitute bodies-ininteraction as they become the means for getting into the body of the machine and experiencing what this machine is capable of doing. In the example depicted above, the figure of the universalized child becomes the frame of reference for this process of becoming worldly of the robot as identifiably human. In what follows, I draw on another interactional sequence in which the robot is supposed to grasp an item and I continue to be interested in the mattering of this machine and its "affiliated humans" (Suchman 2011, 119).

\section{Excerpt D1}

Practitioner A: ... what happens now when grasping is that the robot, after localizing the object, it has to localize its own hand, too, yes? [...] Therefore we use this, this magic red ball - it's very complicated to recognize the hand visually, specifically that the hand is there in the space and the ball is easily recognizable, therefore it's also red - on the blue robot, it's red, and on the red robot, it's blue... And then, the robot starts to minimize the distance between ball and object [...]

Practitioner B: Bring me the green cup.

Armar IIIa: From where should I take it?

Practitioner B: From the table.

Practitioner A: [...] These are pre-defined Armar IIIa: Going to bring you the green cup from the table.

Practitioner A: - pre-defined [robotic] grasps [...] - as one can see. Now one sees - no one doesn't, unfortunately.

Armar IIIa: I cannot grasp the object.

Practitioner B: Well, let's do this again. [...]

Practitioner A: Okay. Let's give it a try.

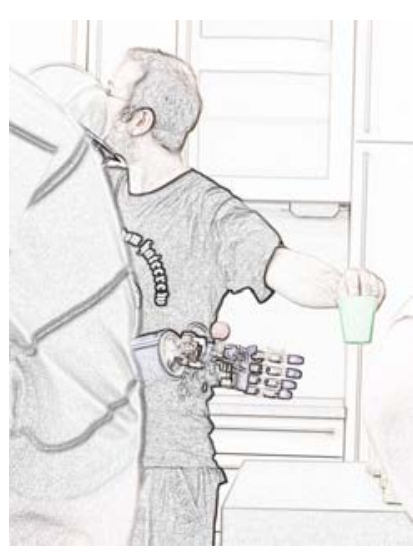

Picture 7

Practitioner B: Bring me the green cup from the table.

Armar IIIa: Going to bring you the green cup from the table.

Practitioner A: So, returning to your question, indeed, the grasps or the pressure until the hand closes or until the resistance is strong enough, there are no tactile sensors or skin on the hand, which could practically determine how sensitive or how strong [the grasping has to be] or if [the object is] rough or smooth or if the object slips, it isn't like that. 
Practitioner B: Now one can see.

Practitioner A: [commenting how high Armar lifts its arm and to Armar] Not as high as that!

Armar IIIa: Here it is.

End of Excerpt

In this sequence, practitioner A stands next to the robot and again draws on gestures and oral explanations to underpin what the audience is witnessing, namely how Armar IIIa grasps. Practitioner B now commands Armar to bring the green cup from the table, a bright green plastic cup. We can hear the sound of the compressor and electronic beeping as the robot lowers his left arm toward the objects on the sideboard. In this sequence, the left arm is closer to the green cup than the right. Next, the robot grasps the object and, as practitioner A explains, these grasps are pre-defined. Localizing an object thus implies that when Armar recognizes, for example, the green cup, it also accesses pre-loaded information that this is a cup which comes with associated styles of how to grasp it. Notably, the pre-defined grasp determines the position of the hand in relation to the object when grasping it, including how the fingers move (picture 7). The humanoid robot thus recognizes its humanoid hand as a red ball moving in space.

Again, I consider this interactional sequence to be a good illustration of how the robot model's capacities for human-like action unfold alongside the practitioner's interpretation of what the audience can already see. I further conceive of this as the performative enactment of the human-robot interface. The practitioners, further, rely on two sets of information during demonstrations; that is, what "one can see" when looking at the robot, but also what one can see on the screen. Practitioner B suggests that the procedure be repeated, commanding Armar to stop. Practitioner B then grasps the green cup himself and holds it in front of the robot's hand, while Armar's arm is still outstretched. From here, practitioner B looks at the screen behind the robot, in order to see what the robot's camera eyes can see (picture 7). After this, both practitioners decide to repeat the procedure and Armar is again asked to bring the green cup. While the robot performs the task anew, practitioner A explains further that the hand does not have "tactile sensors or skin". In this way, the practitioner reinforces the concept that the grasping process is primarily based on pre-defined movements, which Armar accesses when 
visually recognizing the objects, rather than generating information from the object directly through physically engaging with it.

From this, I get a peculiar vision of the robot as a communicative and domestic machine. The robot seems to embody dimensions of worldliness that are reduced in a specific manner. This reduction of what the robotic world contains, as it were, appears to rely on tailoring technological practices of contemporary $\mathrm{AI}$ and robotics to the environment of the kitchen with its multiple forms of action, such as grasping and handling items like food boxes, and opening and closing drawers and doors. Furthermore, it also seems to be based on practices of formalizing the world; that is, of modeling and controlling it, through 'purely' epistemological means. Thus, I think of this example of what happens when Armar should be grasping the green cup but does not recognize its own grapplers as depicting the narrowness of this robot's scope, as it is constitutive of the circumstances of its capacity for action as well as the labors necessary to perform the action.

Yet, Armar IIIa succeeds in performing the task at the second attempt, which practitioner B affirms by referring to the screen ("now one can see"). Practitioner A nevertheless comments on what the machine is doing by saying: "not as high as that", referring to how high Armar is lifting the green cup (picture 7). I find the way in which this practitioner expresses his dissatisfaction with how the robot executes this task remarkable. He addresses Armar, even though he is not wearing the headphones. Also, it is safe to say that the robot would not know how to react to this command, anyway. This spontaneous and intuitive verbal expression, I suggest, illustrates a layering of present and future in the current robot; this is what this machine is already able to do in the present and what the prospective robot might be able to do in the future. I pursue this topic further throughout this chapter.

Zooming in on local micro-practices of interaction between the humanoid and the practitioners, I emphasize that the robot appears to be highly prefigured, such that its capacity to interact with people, which primarily includes the capacity to generate information interactively, seems particularly constrained. These constraints become tangible in different ways, as discussed throughout this section. One way of thinking these constraints in the robot's capacity for interaction is with the idea of the hybrid body as bodies-in-intra- 
action. Using this idea, I want to shift the perspective from the idea of the robot itself as inherently constrained to a wider context of constrained bodiesin-intra-action. Human-like capacities for action, like communication, unfold in the sequence described above and make tangible the fact that communication at the robot-practitioner interface relies on mutual adjustments that involve mutual confinement. Although spontaneous, affective expressions of frustration are possible, these moments also highlight constraints in this communication. In addition, they articulate a certain affective stance in the project of engineering the robot, which I consider under the register of neglected labors of care.

Furthermore, the example of the task that is contained in the command: "bring me the green cup" is insightful in this regard because it is a moment in which the smooth execution of human-like grasping performances begins to stutter. I describe this moment in the demonstration as stuttering because it requires stopping the activity and then repeating it. At this moment, the hybrid embodiment of agential properties seems to become tangible, along with the attendant labors of its affiliated humans. Therefore, I suggest that we also examine moments of stuttering as departures in which the ongoing individualization and naturalization of the machine other as human subject breaks down and displays its provisional and precarious character. The example of executing a task such as "bring me the green cup", for example, requires what I consider to be an experimental re-alignment of the myriad of things that are involved in the co-production of the human-anthropoid kitchen robot interface. In addition, when practitioner $B$ re-adjusts the camera eyes by moving the green cup in a certain manner in front of them, this multimodal form of attaining a sense for what Armar can do is revealed as highly important labor in animating the domestic, interactive robot companion in demonstrations, especially when things do not work out as planned.

The repetition of the task makes it clear that agential properties, although clearly assigned to the machine in practice, are rather mutually locatable in the humanoid, the affiliated practitioners, and additional devices such as the screen. So far, local micro-practices of enacting the capacity for robotpractitioner interaction in the kitchenette have required a re-thinking of bodily boundaries and the concept of agency tied to 'a proper entity', whose 
boundaries appear self-evident. What has become tangible in analyzing these interactional sequences is that enactments of robotic tasks are highly complex and eminently staged events, in which concepts of what the machine can do, as well as what it may be able to do in the future, organize the capacities for action at the interface between robotic practitioners, the robot, and the audience. Hence, myriads of human and non-human things comprise this demonstration of the robot's capacity for action. These include: the architecture and design of the laboratory, the technological communication devices, such as visual technologies, encompassing those in the robot and those representing the robot, the headset, and also the practitioners' eyes, voices, and gestures. In other words, the enactment of interaction between robot and practitioner illustrates the nature of agency as we can think it in Baradian terms of iterative intra-activity. Accordingly, this enumeration is not comprehensive. These and other elements are vital in arranging matter and meaning so that the task of finding and bringing the green cup can be demonstrated. In the next sub-section, I delve into another interactional sequence, through which I continue to focus on the distribution of agencies as it is articulated in making bodies move.

\section{Moving Bodies in the Kitchen - Enacting Predictability}

\section{Excerpt D1}

Visitor: So, what's the reason for building these humanoids? Is this really the best technological solution or are other reasons relevant to this...?

Practitioner A: This plays an important role, so, I think that we, of course, this is a question that often comes up, a humanoid form firstly is in any case important, because, as I said, we build systems that are supposed to help humans in human environments, this means in environments that are made for humans. And these environments are optimized for our bodies, yes? The handles of drawers, of doors, everything, if one enters the tram, there you press, this is all - from an ergonomic perspective - optimized for the human shape. This is one [reason], but one could also say that we could realize this without a humanoid form. One could also, in order to grasp something up there, one could build such a tele-joint and [it] doesn't have to be humanoid. But the second argument is, if the robot is humanoid and I know, okay, by the way, how humanoid or humanlike kinematics operates, the robot will only move like this. Then I, as a human, am better able to predict the movement and behavior of the robot. This means, for example, if I'm standing here, then I will know, okay, it would never come up with the idea of knocking me over or letting me 
collide with its arm. This is absolutely possible with a non-humanoid arm like the arm of an industrial robot. This means, the predictability of the robot's behavior is better for the human, because we humans know how we move and then [guess] okay, it should also move like this.

End of Excerpt

Here, the kitchen laboratory emerges as a form of commonplace space for the human. This is interesting because such a conceptualization of the kitchen is charged with the idea that, if a robot can master the kitchen, it will also be able to deal with every mundane human environment. Furthermore, in this regard the kitchen functions as a buzzword for a specific composition of objects and tasks such as cups and grasping. Being able to accomplish these tasks and manipulate objects in a useful manner seems to be a rudimentary part of everyday human lives.

Furthermore, it is interesting for this thesis that in this description the kitchen becomes apparent as playing a central role in societies, while at the same time it remains a somewhat abstract and rather technical setting. As discussed in chapter two, for example, the household, with the kitchen at its core, is constituted and constitutive of the existing practices and imaginaries of responsibility for the flourishing of households. This includes the daily organization of negotiating housework at home, the modern societal organization of gender and class, pairing into heteronormative couples, and the gendered and, equally importantly, transnational division of labor. However, these socio-cultural dimensions seem to disappear behind the technological practices of robotic engineering of the kitchen as a research endeavor 'beyond culture'. From this perspective, human environments are defined as "environments that are made for humans", which are furthermore pinned down as "optimized for our bodies". I suggest that contemplating this explanation of the humanoid shape in relation to the kitchen environment is one form of neglecting the socio-cultural dimensions of the kitchen, and reproductive service in the sphere of the household more generally, as one important matter of care in mapping the performative enactment of the human-robot interface in demonstrations.

In addition, the idea of predictability appears to be a key dimension of relating bodies and environments. The ability to predict Armar's behavior is presented as an essential quality of the human-robot interface. Here, I find 
Suchman's analysis of intelligible interaction between human and machine useful, when she points out that this requires that both have certain "linguistic, demonstrative, and inferential resources" (Suchman 2007, 125) at their disposal, which emerge in the very act of (inter)action. In this regard, predictability designates resources that on the one hand encompass the ways in which robotics practitioners imagine what the robot should look like and be able to do, and how, in turn, the machine is animated in demonstrations. On the other hand, predictability also appears to be a powerful agent in guiding the audience as they become familiar with Armar in demonstrations.

In line with Claudia Castañeda and Suchman, I contextualize predictability as a central paradigm of interaction that links the design of bodies and movements within "the wider project of AI [as] an investment in automata not only as useful bodies (where form follows function according to operational criteria), but also as recognizable approximations of cognizing minds" (Castañeda and Suchman 2013, 2). The idea of the individual, human body emerges as that which determines the shape of the environment, for example the kitchen. Furthermore, this interrelation along the paradigm of form follows function serves as an argument for making Armar human-like. I find this connection between body and environment that objectifies and naturalizes both form and function intriguing. It displays a peculiar conceptual link between the individual body and the environment that builds on a hierarchical relation between body, mind, and world. In addition, Suchman underscores that in this hierarchical relation, "body and world remain a naturalized foundation for the workings of mind" (Suchman 2007, 231). In this way, the individual body, mind, and bodily environment are connected and at the same time produced as distinct. Following this line of thought, things like doorknobs pre-determine not only the shape of the robot's grappler but also its capacity for cognition and action. In consequence, the environment is reduced to a purely physical realm and the body to a purely physical vehicle of human existence that both are foundational for the operations of mind.

The ways in which bodies and movements become intelligible as humanlike in demonstrations, as well as the resources required for such entanglements of mattering-meaning, will remain at the center of this chapter. Thus, in what follows I delve into yet another interactional sequence. In doing 
so, my focus is on how the trope of predictability orchestrates bodies and action during the demonstration.

\section{Excerpt D1}

Practitioner B: So, we can now try to do this with the fridge. It will drive over there, and we can all follow it and look [at what it's doing]. [To Armar] Bring me the apple juice from the fridge. Armar IIIa: Going to bring you apple juice from the fridge.

Practitioner B: So the same happens as before when grasping objects, it localizes the handle of the fridge through image recognition, as one can see partially, and it localizes its own hand and tries to position it in relation to the fridge, so it can grasp [the handle]. In addition, the fridge is also explored tactilely by the haptic sensor. Particularly in this situation, it's very important

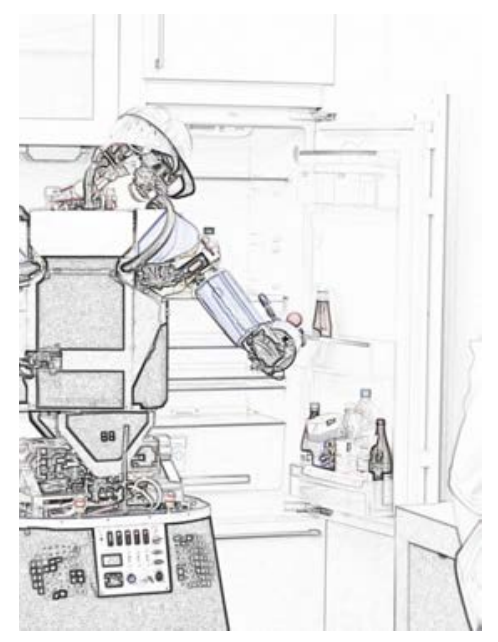

Picture 8 that the hand is in the right position, so that it can grasp the handle. Armar IIIa: I could not hand over the object.

Practitioner A: For whatever reason - I don't know what its problem is. Thus the goal was actually that it hands over the apple juice between his hands, that his right hand is free and -

Armar IIIa: Please take the apple juice and wait until I have closed the fridge.

Practitioner B: This is a bit ungainly, what it's doing here, it normally moves the apple juice [from the right hand] to the left hand and then closes the door with the right hand. [To Armar] Stop now.

End of Excerpt

The task of bringing something from the fridge is one of the more complex highlights of the demonstrations. Also, due to its complexity, the performance of this task is rather prone to failure. This quality of the task in particular makes the interactional sequence described above a useful point of departure to further discuss how predictability is enacted in a specific moment during demonstrations. The machine becomes legible as predictable, once again, through the appellations of the practitioners. These practices of appellation encompass gestures and oral language. Importantly, the audience follows what the robot is doing in the kitchen through the twin senses of watching the 
robot's movement in the room both 'live' and on the screen.

Therefore, practitioner B suggests following Armar when it wheels over to the fridge and he also explains the robot's actions by referring to the screen. The audience becomes familiar with how the robot moves and develops a sense of perceiving the world in the same manner as Armar, when they watch the object recognition visualized on the screen. As picture 8 illustrates, once the robot is standing in front of the fridge, one cannot really see what it is doing. Therefore the view through the camera eyes enabled by the visualization on the screen appears highly relevant in making legible the fact that Armar performs according to the command. I further suggest, then, that we might think of the screen as a control device that is essential in making the behavior of the robot legible as predictable.

The screen makes it possible to watch the robot moving through the kitchen in its physical and its virtual (self-)representation. Furthermore, when Armar announces that it will now close the fridge door, practitioner $\mathrm{B}$ predicts that it will not be able to execute this task. From his experience, practitioner B can tell that the robot's movement is deviating from how it is supposed to move when closing the door. In addition, he can see that the camera eyes are not able to recognize the handle, and he can thus decide that this will lead to failure. Hence, practitioner B aborts the execution of the task by saying: "stop now". Here, preconceptions of the nature of what this machine can do mingle with moment-by-moment experiences of what the robot actually does and these experiences help to build the resources for making the robot efficient as inter-active in the kitchen. In what follows, I will draw on interactional sequences in which communication through natural channels is introduced as a means of interaction at the robot-human interface, because I regard these as clear examples of exactly such interrelations between preconceptions and moment-by-moment experiences. Thus, I will continue to seek the practices and conditions of Armar's coming to matter as an interactive robot companion in the kitchen laboratory.

\section{Communication through "Natural Channels"}

During one demonstration, the practitioner wearing the headset introduces the robot by explaining that it is only able to engage in certain dialogues, which are, "very simple dialogues, tailored to the kitchen environment here" 
(D4, July 2011; translation PT), as he puts it. However, even though they are regarded as tailored to the setting, practitioner $\mathrm{A}$ nevertheless makes the following claim about the simplicity of these dialogues:

I really can't do this any longer, it's always the same dialogues, this is boring, so it would be interesting if one could make small-talk with the robot: 'where were you yesterday evening?'; 'Did you also watch the match between the USA and Japan?; Did you also watch the penalty shootout? Did the Japanese deserve to win?' Just like that, things that you'd talk about with a person when you meet each other, not only 'What can you do for me?' [...] I don't know what it would do then. (ibid.)

As the practitioner highlights, the speech recognition performed by the robot follows a certain pre-trained pattern, which, although tailored to the kitchen setting, is also perceived as 'boring'. Thus he envisions different forms of communication with the robot, which he frames as the same kind of smalltalk that one wants to make with a person. Suggested topics for this small-talk include a soccer match and this underlines that the practitioner is drawing on himself when articulating this kind of dissatisfaction with the robot's capacities for communication. Beyond this, how practitioner A wonders about the robot is also interesting. He thinks out loud about the possibility of just starting to talk to it as if it were a person he knows and whom he might have bumped into in the street and started a little chat about last night's soccer game. I regard this as expressing a form of curiosity about this machine's behavior when deflecting from the standardized routine in demonstrations.

At a later point during the same demonstration, the practitioner wonders together with the audience about possible tasks the robot could be asked to perform now. He then asks the group if anyone wants to take over the headphones from him. One of the visitors volunteers (V) and, in the following, I describe how this worked out because it is relevant for understanding the ways in which communication through language is realized in Armar III.

\section{Excerpt D4}

Practitioner A: Does someone actually want to try this? Yes? Okay. Just try whatever you want, so small-talk or suchlike. [V: Okay.] And then you always have to press 'mute' here. [V: Okay.] Give it a try! No, no, if you wanna talk then [presses the switch] like this and then like this.

$\mathrm{V}$ : And then I hold it pressed?

Practitioner A: No, no don't hold it pressed. [V: Okay.] Now it's, now it can't hear 
what you're saying [...] - you always have to slide it back and forth.

Armar IIIa: Thank you very much.

V: Hello Armar.

Practitioner A: I can tell you what it understood; it understood nothing. Once again.

V: Hello Armar.

Armar IIIa: In which direction should I go?

V: Go backwards.

Armar IIIa: In which direction should I go?

V: Go backwards.

Armar IIIa: Where do you want me to put it?

Practitioner A: Okay, tell him: 'Start over'.

V: Start over.

Armar IIIa: Aborting.

Practitioner A: Okay, now, once again, now give it a try.

V: Start over.

Practitioner A: No - that it understood, aborting.

Armar IIIa: Aborting.

V: Go backwards.

Armar IIIa: How much should I go backwards?

$\mathrm{V}$ : Hm, one step. Was that right? [to practitioner A]

Armar IIIa: How much should I go backwards?

Practitioner A: Tell him one or two steps, or -

V: 2 steps.

Practitioner A: One more time.

V: 2 steps. [Armar starts to move backwards]

Practitioner A: Say 'Stop now', please.

V: Stop - stop now.

Armar IIIa: Opening the cabinet.

Practitioner A: Stop now.

V: Stop now.

Armar IIIa: Stopping.

End of Excerpt

This sequence is very rich for several different reasons. Firstly, when giving the headphones to one of the visitors, not only does practitioner A seem to have spontaneously decided to break the routine of the demonstrations, but I consider this also to be an example of taking up the idea of encountering this machine through curiosity about its capacity for communication beyond the 
standardized dialogues. Thus, he suggests that the volunteering visitor takes over from him.

The visitor now in charge, however, decides to take up the dialogue where practitioner A left off, and to stay with the routine. This appears plausible, as the visitor is not yet familiar with his 'new role'. The latter becomes tangible when the visitor with the headphones starts operating them and the 'mute' switch, as well as when asking practitioner A for re-affirmations of what he should say to the robot. Communicating with the robot and thus controlling it is a task that requires some knowledge about how to do this. What seems to be quite obvious to practitioner $\mathrm{A}$, that is, sliding the 'mute' switch back and forth, and how this correlates with what the robot hears, does not seem to be self-evident to the volunteer. Thus, practitioner A has to continue explaining to the volunteer what to do throughout the whole sequence. Here, it becomes palpable that to communicate with the robot necessarily involves speaking its language; that is, giving pre-programmed commands.

After learning how to master the technicalities of the switch, the visitor then not only has to talk into the headphones, but also, and equally importantly, has to talk in a specific manner. This comprises the right choice of words and apparently also the right pronunciation. Both are right when the speech recognition system implemented in the robot is able to understand what the visitor said. Practitioner A furthermore remarks that "it understands him actually quite well [...] it mostly understands me [...] but it understands you actually eerily well" (D4, July 2011; translation: PT). However, even if the choice of words, the pronunciation and the handling of the 'mute switch' appear to be right, this nevertheless does not guarantee that the robot will do what it is asked. This means that the speech recognition system might have recognized speech, but this does not necessarily result in understanding what was said. In fact, the excerpt cited above is full of misunderstandings between the practitioner, who is familiar with the robot, and the visitor, who is not yet familiar and it. In this sense, I suggest that what might have started out as an endeavor to open up possibilities to encounter the machine through curiosity in the eyes of practitioner A becomes instead a situation that displays this machine's limitations rather than its range of possibilities, as though they were yet to discover. 
Moreover, I find it interesting that, while I experienced this situation as one of complex misunderstandings and to a certain degree also as a failure to make the assemblage of communication at the robot-human interface efficient, practitioner A assesses the situation as proceeding quite well. I regard this as revealing something about the nature of communication at the robot-human interface in general. It appears that it is not working as well as the picture of the boring, routine kitchen dialogues suggests. Rather, it requires multiple labors, great care in operating the headphones and the mute switch, and giving the 'right commands'. In addition, the 'mute switch' is of central importance for the efficiency of communication at the human-robot interface.

Attending to the labors and matters of care that emerge with practices of mastering the humanoid also direct my analytical attention toward the robot's actual behavior, especially in terms of how what I identify as misunderstandings in communication are integrated into the routine of the demo. Practitioner B ties this in with what I identify as a personification of the robot by referring to its behavior as he does. Practitioner B: "What happened now, is that I always have to switch off the transmitter for the microphone, so that it doesn't - when I'm now explaining something to you - hear me and might eventually understand something, then it will talk one's ears off about what it wants to get rid of at the moment, and it was my fault to not switch it off in time" (D1, July 2011; translation: PT). The robot has had enough and the failure in communication expresses its state of mind. Practitioner B further emphasizes that, when he does not use the 'mute switch' properly, the machine eventually hears what he is saying to the visitors and thus recognizes words or, more precisely, orders. He frames this robotic behavior as talking one's ear off and classifies this as some kind of nagging. Even though the 'mute switch' functions as a device that switches the practitioner to mute, in this part of the sequence it manifests rather as a device with which one can switch the robot to mute. The robot, however, reacts in an unforeseen manner, and this situation provokes laughter. By now, the visitors are a bit more familiar with Armar, and thus it immediately becomes legible as a humorous machine, which refuses to follow orders as it says goodbye when the order is repeated (D1, July 2011). 
Along these lines, I consider communication with Armar to be a highly predetermined and complex endeavor - not only for people like the visitor who volunteered to wear the headphones - but also equally for robotics practitioners who are familiar with the technicalities, procedures and limitations of this device. This draws on what has been designated as an idea behind the natural channels approach, which centrally builds on designing a machine that is able to communicate with 'everyone'. However, I experienced this communication as having many requirements, since it depends on aligning headset, voice, hearing devices, the laptop, the English language, the speech recognition program, the mute switch and the fingers on the switch. Thus, I regard the things enumerated here as also being involved in the coproduction of Armar. Furthermore, I am intrigued by the ways in which the practitioner explains and, thus, integrates the misunderstandings into the success of the demonstration, so that the robot nevertheless becomes legible as an individual, more precisely as an entity with personality and characteristic traits.

Again, I suggest challenging this process of becoming worldly as an individual and at the same time as a masterable machine from a different perspective. The sequence discussed above provides starting points for such a challenge. Here, I am thinking especially of moments in the communication at the Armar-practitioner, specifically the visitor-Armar interface, in which the smooth process of communication begins to stutter. Such stuttering makes palpable the labors, including the fleeting circumstances and the multiple resources, which are necessary at this interface, as well as an excessive sense of human mastery over the machine. I contemplate both as providing points of departure for engaging with the robot differently than enlivening or fetishizing this machine.

\subsection{Conclusions: Demonstrations as Performing the Kitchen}

In this chapter, I have mapped out how the robot is made efficient in front of an audience during demonstrations. In doing so, however, I have traced the practices of co-production of pre-figured entities with particular properties. In this regard, a posthumanist lens that takes into account action and actors beyond the humanist framework became a vital resource for mapping the interactions in the kitchen laboratory. 
Furthermore, I consider the demonstrations of Armar IIIa to be essential in making this specific robot domestic - both in the sense of manufacturing it to fit into the domestic sphere and in fueling imaginings of this machine becoming domestic. Thus, the robotic kitchen laboratory is a central site for the engineering of the human-like machine. This engineering, however, is more than the public execution of tasks by an automaton. Rather, I consider this public testing to be based on the well-orchestrated animation of this machine, which demands a relatively high flexibility in the execution of a specific task. Such an execution, however, is contemplated in terms of characteristic traits of the anthropoid machine in situations when the demonstrations begin to stutter, the execution of a task does not proceed as planned and bodies and meanings have to be re-aligned in order to achieve the goal; for example, grasping the green cup. When mapping what I call a stuttering, I want to underscore that interaction at the human-robot interface emerges as the complex, posthumanist performative enactment of entities to which clear assignments are distributed. Here, I am underscoring two things: firstly, that this public testing requires a constant doing human; specifically doing human-like, which I contemplate as the iterative citation of norms of human-like-ness in the kitchen setting. As I have shown, this citation of norms is regulated by the myriad of things that take action in the co-production of the anthropoid robot as an efficient machine in the kitchen. This leads into the second point that I would like to make: As explored in this chapter, such a doing entails human and more-than-human agency, while the emerging entities are cut off from these distributed agencies and the relations of coproduction. Thus, I suggest a notion of performativity that understands the mattering of the human-machine interface in the kitchen in terms of iterative intra-activtiy (Barad 2007, 184).

One central insight of this chapter is the way in which the robot and the human both become worldly through relations of co-production. It is the audience who learns to see and experience what a (prospective) robot looks like and what one can do with such a robot. However, as became apparent through the course of the demonstrations in which I participated, as well as the interactional sequences that I describe in this chapter, the practitioners equally have to attain a sense for the robotic "subject object" (Suchman 2011) which takes into account the fact that things might not work out as planned. 
Moreover, through recuperating what is cut off from public testing, that is, the distributed agencies and the relations of co-production, I also suggested re-working subject and object relations in the laboratory, as they determine the position of the human as the agent that animates the human-like machine. As I have shown through several interactional sequences, demonstrations rely on what I frame as a continuous process of indexing bodies and environments in relation to one another. This indexing encompasses practices of touching, of visualization and of hearing, through which bodies are related to agential capacities.

Notably, transpositions and mediations between bodies are a foundational part of the demonstration's organizational environment. They are vital for attaining a sense of what the robot can do and are built on the idea of a commonality between human and machine, specifically a common ontology. I furthermore argue that this common ontology enables figurations of hybrid bodies, which make Armar legible as an identifiable human subject and the same time as a human-like, machine other. Thus, the intertwined materialsemiotic appellation and enactment of tasks such as grasping in the robotic subject object depict a complex set of attendant labors invested in attaining a sense of this machine other and of what one can do with such a robot: the ongoing production of agential properties evoked by the re-demarcation of bodily boundaries. Hence, I foster an engagement with demonstrations by asking, in line with Suchman, "[h]ow [...] might we refigure our kinship with robots - and more broadly machines - in ways that go beyond narrow instrumentalism, while also resisting restagings of the model Human" (Suchman 2011, 137)? I regard this as an interest in re-configurations that open up possibilities for mimicry and symbiosis beyond the re-affirmation of the already powerful norms of the human.

Moreover, I have developed an account of performative enactment as the iterative citation of norms of what a human-like machine is and can do, always in relation to what a human is and can do. This is expressed, for example, in movements that I identified as reverse feedback loops between human and machine through which proper categories in the robotic laboratory become legible and bodily boundaries materialize that assign properties to individulas. Furthermore, one characteristic of technoscientific practices of engineering the human-like machine is the search for agential 
properties in 'the material', such as the mechanical structure of the body. This is illustrated, for example, in the objective of building a predictable robot, or when the robot is said to have characteristic traits, such as stubbornness. The former aims to predict and control the behavior of the material and the latter enlivens and individualizes the robot. Thus, I consider both practices to make the machine other more human in the sense of a naturalized, authentic humanness. The performative enactment of interaction in the kitchen builds on practices such as getting a sense for the robot's body as a distinctively human-like body with human-like capacities for action. My argument here is that, during demonstrations, the reciprocal character of this enactment is cut off from the processes of learning to see and feel what this machine is and can do. Instead, Armar becomes alive as a machine that is like humans and can do things that humans can supposedly do or need assistance in doing.

Thus, one pivotal point of this chapter has been to recuperate relations of reciprocal subject and object making. From this perspective, I discussed demonstrations as an ideal example of boundary-making practices in their dynamics between ongoing materialization and sedimentation that exceed an anthropocentric frame of mattering; that is, one of human language and control. Bodily boundaries that assign agential properties to individuals became palpable as provisional, porous and constantly re-crafted in the process of finding agential properties in the machine. This is a point of departure for taking into account bodies as active in the demonstration of capacities for interaction in the kitchen setting.

In addition, I suggest connecting relational practices with the basic idea of anthropomatics, that is, a literal and figural proximity between human and humanoid. Proximity here signifies that the relation between human and humanoid is one of approximation, in which the latter becomes identifiable in terms of the former. However, I suggest that tweaking the practices of indexing through touch also raises the question of boundaries and the boundary-crossing movements inherent in touching. The nature of touch can be regarded as blurring the boundaries between self and other. Furthermore, such blurring, in short, situates and is situated as it creates close intimacy. Along these lines, I contemplate touching gestures in the initializing sequence as indicating several layers of enacting human-machine relations that could become leverage points for diffracting the regimes of regulation of 
anthropomatic apparatuses of bodily production as they became apparent during the demonstrations.

Human-likeness is invoked in these practices of enactment at two levels: at the level of this machine's design and at the level of the execution of movements, including the use of oral language. I think these two levels of human-likeness with the Harawayan and Baradian notion of apparatuses of bodily production, as also deployed by Suchman. This means querying human and nonhuman practices and doings in demonstrations through the possibilities and impossibilities of mattering. Thus, in this chapter I delved into the patterns of differentiation constitutive of intelligibility in robotics, which are enacted through boundary-making practices in the laboratory and the attendant de- and re-stabilization of entities with agential properties that qualify as human-like, in order to diffract these findings. This means reading layering of complex human and more-than-human enactment through each other from the position of the queering witness.

In this way, I intended to add the fleeting circumstances of demonstrations comprised of a myriad of relational practices like appellation, touching, and (re-)arranging to the enactment of the robot-human interface. These are the material-semiotic conditions and practices of performing the kitchen in the robotic laboratory. Finally, to acknowledge the material-semiotic conditions and practices of performing the kitchen also means to add the ways in which this performing the kitchen is a becoming worldly in terms of a becoming with. 


\section{Body Modeling in the Anthropomatic Kitchen}

This chapter continues to map the practices of engineering the human-like robot and to explore how such a new class of robot is envisioned and realized as prospective companions to humans. In chapter four, I mapped these practices in terms of a posthumanist performative enactment of the demonstrator Armar that is regulated by anthropomatic apparatuses of bodily production in the specific setting of a public testing of Armar in the kitchen robotics laboratory. In doing so, I mapped the bodies meeting at the humanrobot interface not as individual id/entities with individual properties, but rather as overlapping phenomena and bodies-in-intra-action; a notion that underscores the emergence of bodily boundaries and id/entities with individual properties at the human-robot interface through a wellorchestrated distribution of agency and material-semiotic practices of relating.

Phenomena, as Barad highlights, are comprised of "ontologically primitive relations - relations without preexisting relata" (Barad 2007, 139). Bearing this in mind, I explored the enactment of material-semiotic relations that are constitutive of the machine as almost human during the public testing of Armar from the position of the queering witness. This is the position from which I analyze the human-robot interface, especially in this chapter, in its constitution of sociocultural norms around what a human body should look like. In this way, I also problematize taken-for-granted knowledge about bodies and humanness while moving beyond an anthropocentric stance as I map the making of the robot companion. This entails taking into account bodies as "an active, meaning-generating axis of the apparatus of bodily production, without ever implying immediate presence of such objects" (Haraway 1991, 200). Addressing agency in crafting relations also entails problematizing, as Haraway points out, "who makes and who is made in the relation between human and machine" (Haraway 1991, 177). Employing this analytical prism, I assemble boundary-making practices and the human and more-than-human agencies at the visitor-practitioner-Armar interface as the posthumanist matters of care and concern in making a specific technology efficient.

In this chapter, I specifically emphasize making the enactment of the almost human a posthumanist matter of care and concern. This means that I will focus on the constitutions and negotiations of the anthropoid machine's 
body with agential properties as it is then publically tested in the kitchen laboratory by asking how these become tangible. I use different material to trace the translations, shifts, and loopings between self and other, machine and human, nature and artificial as boundary-making practices than in the previous chapter. The data that I draw on in this chapter come primarily from the expert interviews, academic publications and more informal talks that I conducted and collected during my research stays at the IAR.

I will map the practices of boundary drawing and redrawing between the human self and the robotic other, nature and artificial, subject and object as these are constitutive of the human-like by, as MacLure puts it, "engaging the materiality of language itself - its material force and its entanglements in bodies and matter" (MacLure 2013, 658). This material force or, as Haraway describes it, the material-semiotic force fields of anthropomatic bodily production, also became tangible in the interviews that I conducted. With MacLure, I think of the selected aspects of the qualitative data that I assemble in this chapter in terms of material that "'glows"” (MacLure 2013, 661). As she continues: "The glow seems to invoke something abstract or intangible that exceeds propositional meaning, but also has a decidedly embodied aspect" (ibid.). I find this idea of "data that glows" helpful in mapping the material forces of anthropomatic robot body modeling as they emerge, entangled with the textual and discursive material that I collected during my research stays. I further regard such a sensation of glowing and its affective dimensions of capturing my analytical attention as, in line with Haraway, analytical work under the register of embodied cognition, specifically as contributing to situated knowledges on the making of robot companions in the kitchen.

Furthermore, in this chapter I will explore the connection between the robotic kitchen laboratory as the specific setting for a human-centered environment and the design of the anthropoid's body in its capacity for interaction with humans. In chapter three, I argued that a key idea of anthropomatics is to build robots that are proximate and useful to humans, and in chapter four I emphasized the corporeal human-robotic mimesis, or bodily analogies made in the demonstrations. Here, however, I want to focus on specific body parts and the engineering practices of dividing the body into (functional) parts which can then be re-integrated into a "whole-body model" as anthropomatic strategies of making Armar proximal and useful to humans. 
Such processes of taking the robot human-like part by human-like part, as they became apparent in anthropomatic robot modeling, are of great feminist and critical interest. This practice speaks to the Western tradition of generating representations of bodies through fixable components that are held to signify the nature of difference and the difference between norm and deviance (Schiebinger [1993] 2004; Terry and Urla 1995).

To begin, I draw on a particular article in which the kitchen is introduced as a shared workplace and thus as a space in which "contact with humans" is realized. This makes it, as the authors argue, "important that the robot is accepted by the human. A human-like appearance is as important as the ability to move like the human" (Albers et al. 2006, 308). In this explanation of the robot's design, the authors bring an acceptance of the machine into a causal relation with its looks and abilities. In this way, the human-like design is not only legitimized as necessary for close contact between human and machine, but also pinned down as equally involving a human-like appearance and ability to move. Along these lines, the quote illustrates that modeling the body with the idea of building a machine that is proximate and useful to humans means modeling both a human-like appearance and the ability to move in a human-like way. Thus, I will explore the way in which these modeling practices are operating with a peculiar concept of bodies through which appearance and abilities can firstly be separated from each other and then rejoined and how these practices relate the appearance and abilities with humanness. Core questions that I associate with this involve the normative dimensions of body modeling: what a robot companion should look like, what it should be able to do and how one should relate to such a machine.

One of the practitioners working at the IAR, however, puts human-likeness in perspective when stating that "humanlike is of course a very expendable notion" (interview practitioner AB, July 2011; translation: PT). I interpret this statement as providing a certain conceptual openness that I take as a leverage point for exploring the limits of human-likeness. It may even open up possibilities for the queering of the normative framework; for example, at the level of the transnational sexual division of labor along "global care chains" (Hochschild 2000) as well as the nuclear family, the pairing of adults into domestic households with its "heterosexual contract" (Hark and Laufenberg 
2013, 231, translation: PT) and the attendant forms of heterosexual kinship as a naturalized norm (Butler 2002).

This involves tracing boundary-making practices of differentiating between features and properties of the anthropos and the anthropoid, as much as sorting into and relating between categories of symbolic ordering. I understand such sorting, relating and boundary making as queer-feminist onto-ethicoepistemological issues of care and concern in mapping how categories of material-semiotic ordering are established. Mapping such categorical work is, again, based on my approach to anthropomatics as a queering witness, who becomes attentive toward the brittle limits between the possibilities and impossibilities of mattering in the anthropomatic kitchen.

\subsection{The Active Head - Modeling Human-like Vision}

This subsection deals with the humanoid's head as it is realized in the robot models Armar IIIa and b. My focus is on the camera eyes that this head incorporates and their perceptive capabilities. More specifically, I am interested in the concept of "active multi-view" (Welke et al. 2009) as foundational to this model of a humanoid head, and how humanoid object and motion recognition are realized through this model of a robotic head.

The head with its camera eyes holds a central place in the public testing of Armar. In the previous chapter, I analyzed how vision becomes a means of interaction between humans and the robot that makes the latter legible as almost human. Furthermore, I contemplated this performative enactment of the human-like robot through visual apparatuses as intra-active. The apparatuses of observation and visual representation, such as eyes, the screen, pointing gestures and verbal explanations, as well as the spatial arrangement, entangle or rather align the discursive and the material in the mattering of this robot as a recognizably human-like machine. In this subsection, I am interested in capturing the glow; that is, the affective intensities around the visual apparatuses of anthropomatics as they became apparent to me within my qualitative data.

To begin with, I describe a situation during one interview in which the interviewee explains the preconceptions behind creating a machine with two camera eyes. When asked how I should imagine what the robot actually sees, an interviewee responds by underscoring that "the cameras are still far away 
from the human" (interview practitioner CD, July 2011; translation: PT). However, and as he further explains, such practices of realizing a head with eyes address:

[A] big theme [...]: How do we represent our environment and our knowledge? And if we take a different sensor, if we - in the simplest case - use the haptic, let's say with hands only, the system wouldn't be able to develop any symbols or any language, internal representations that are compatible with what the human does. (interview practitioner CD, July 2011; translation: PT)

The human-like head embodying active vision is conceptualized as a central instance of building machines with a human-like capacity for using language and developing internal representations. The practitioner ranks sensors in a hierarchical relation in which vision is regarded as the ideal sensor while haptic sensors such as hands would not be sufficient to generate such formal knowledge. Of interest for this thesis are the ways in which the model of the robot's head appears to position knowledge of the world at an epistemological distance from the world as it is charged with a hierarchical division between vision and haptics.

Furthermore, such a connection between the idea of camera eyes and the use of language and the ability to generate internal representations in the robot is explained by the same practitioner when he continues that the "humanoid platform" differs from "a stereo camera system, which is standing somewhere fixed and observing the world" because "with a humanoid robot, one can use its head movements and its eye movements" (interview practitioner CD, July 2011; translation: PT). The importance of such a visual system, which is characterized by movement instead of fixation, becomes apparent when the practitioner explains that such "eye movement is [...] very interesting during the interaction with the human, so it looks much more natural when your counterpart, the robot, moves its eyes and it also makes processes transparent" (ibid.). These explanations of how the robot's head with eyes is modeled illustrate the peculiar practices of separating and rejoining appearance and abilities, that is, form and function, in relation to the idea of the robot companion as a human-like interactive machine. Beyond this, the camera eyes are thought of as making interaction more natural at the robot-human interface.

In addition, I understand this concept of making Armar more natural as being built on the idea that visual apparatuses incorporate all-pervasiveness 
and the real. The eyes, with their eye movements, are conceived of as making processes transparent, which I understand to mean enabling both representation and observation at the human-robot interface. In line with the practitioner, the eyes with their movements constitute a visual system that allows the generation of formal representations, while others can observe this process. In this regard, they appear to make cognitive abilities in the machine recognizable while also establishing vision as a primordial cognitive and interactive ability.

In agreement with Haraway, I understand this practice of modeling vision in terms of a "technological feast [in which] [...] all perspective gives way to infinitely mobile vision, which [...] puts the myth [about the god-trick of seeing everything from nowhere] into ordinary practice" (Haraway 1991, 189). As she continues, this carries an understanding "of direct, devouring, generative, and unrestricted vision, whose technological mediations are simultaneously celebrated and presented as utterly transparent" (ibid.). Thus, I contemplate the model of the humanoid head as such a technological mediation, based on the idea of direct, devouring, generative, and unrestricted vision that establishes the eyes as part of the head with specific properties that embody such vision naturally. The practitioner underpins this when he connects "two aspects [of modeling the eyes with movements in the robotic head] that [are:] one firstly says this is more natural for the human and [secondly] one can also improve the perception as one covers a bigger area" (interview practitioner CD, July 2011; translation: PT). In this sense, the artificial robotic visual system can be regarded as being simultaneously a replication of the human visual system, thus making the robot more natural for the human, and the technological implementation of unrestricted vision that moves beyond the limitations of human eyesight.

From the position of the queering witness, however, I query these associations between a robotic head with its eyes and eye movements and increasing transparency, as well as the idea that the head and eyes make Armar more natural. When I participated in demonstrations, I observed that both recognizing the cameras as eyes and understanding the meaning of eye movements depends as much on the interpretations and explanations delivered by the practitioner as on the screen as a medium that makes it possible 'to get into the eyes of the robot'. I consider both to be practices of 
learning how to see at the robot-human interface that rely on the alignment of language and the material and a peculiar distribution of agency. Thus, along with Barad, I problematize the concept of robotic vision through becoming "response-able (enabling response)" (Barad 2012c, 13) to the co-producing intra-actions and entanglements that are co-constitutive of vision at the human-machine interface; or, as Haraway puts it, through becoming "answerable [and accountable] for what we learn how to see" (Haraway 1991, 190). Thus, I suggest in what follows that we should dwell a bit longer on the design of the artificial robotic system in order to map dimensions of learning how to see as implemented by the robotic visual system. In addition, I consider this as getting in touch with robotic vision because, in line with Barad, I understand "[t]ouching [...] [as] a matter of response" (Barad 2012a, 215, emphasis in original).

\section{Realizing Active Vision - Designing the Camera Eyes}

I experienced the practices of enacting the human-like robot during demonstrations as learning to see, and in what follows I further emphasize the preconceptions that lie behind learning to see. In their article "The Karlsruhe Humanoid Head" (2008), Asfour et al. explain that "humanoid systems able to [...] interact with humans, and learn from human observation require [...] sophisticated perception systems" (Asfour et al. 2008, 447). Central to the Karlsruhe humanoid head is "the foveated structure" (ibid.) of the human visual system. The authors connect their research to biological and biomedical knowledge about human perception, which, in their words, is commonly divided into "peripheral and foveal vision" (ibid.). To comprehensively understand theories of human vision with their differences and genealogies goes beyond the scope of this thesis. However, I suggest that it would be useful to grapple with selected aspects of designing the artificial visual systems embodied by camera eyes as this is vital not only to understand the article on the humanoid head, but also in order to trace translations, layerings and loopings between human and machine, subject and object and nature and artificial. 
'Peripheral' and 'foveal' designate a division of human vision that differentiates between two dimensions of eyesight. ${ }^{60}$ This division of the visual field was heralded by Leonardo da Vinci's work on the central line of sight: "Leonardo da Vinci, who coined the term 'line of sight' was among the first to observe that perfect acuity is only possible at the center of the visual field" (Ethington 2011, 141). Largely in accordance with da Vinci's model of eyesight, the visual field of the human eye is currently conceived of as being divided between a center, the foveal line of sight, and the peripheral lines of sight.

As Haraway highlights, Leonardo da Vinci "has been appropriated for stories of origin, vision and its tools, scientific humanism, technical progress, and universal extension" (Harway 1997, 156). His work can be understood as having propelled the "conjoined Western modern sense of the 'real' and the 'natural'" (ibid., 182). In this regard, the natural is the real that is 'observable' with the right tools of (visual) measurement. Leonardo da Vinci's prominent "Vitruvian Man" (1485-1490) illustrates this as he is "the Man of Perfect Proportion [...] [, who also] has paved his way in the imaginations of technoculture" (Haraway 2008, 7). As Haraway argues further, "[t]he Man of Perfect Proportions brings both the number magic and [its] [...] real-life organic ubiquity [...] to the fore" (ibid.). By making this broadly outlined historical connection between the Italian Renaissance and technoscience, I want to underscore two things. Firstly, that the model of human eyesight that can be traced to da Vinci has guided the development of artificial visual systems in the 'Karlsruhe humanoid head'. Secondly, the relevance of this model makes palpable how knowledge travels across robotics and biomedical research, constituting a shared model that represents the idea of number magic in body models. Furthermore, the historical line that I draw also directs my attention toward Haraway's line of thought, which connects da Vinci with specific instruments of measurement and how they conjoin nature and the real.

Concepts of human eyesight divided into peripheral and foveal vision appear to be ideal points of departure for formalizing vision and replicating

\footnotetext{
${ }^{60}$ Peripheral vision is the dimension of eyesight that generates a general impression of a setting, and the foveal, or central, vision delivers detailed visual information. Foveal vision describes a line-of-sight through which high-resolution vision is possible. In contrast, peripheral vision does not generate sharp eyesight.
} 
the principles of the human visual system. This is also relevant to the humanoid head created in Karlsruhe as it has been developed in the tradition of building artificial visual systems "which mimic the foveated structure" (Asfour et al. 2008, 447). In addition, the authors highlight that it is currently not technologically feasible to "exactly mimic" (ibid.) human eyesight, and that therefore humanoid heads currently usually feature "two cameras in each eye" (ibid.). This design is also implemented in the head developed in Karlsruhe (ibid.). The relation between the foveated structure found in humans and the artificial visual system is depicted through the trope of mimicry. This trope configures a mirroring relationship between human and machine in which the machine other is thought of as mirroring the human self.

\section{Realizing Active Vision - Designing Interaction}

In the following, I will further explore the design of the anthropoid head with its camera eyes as the realization of active multi-view. Thus, my emphasis shifts slightly from understanding the practices of modeling a head with eye movements to tracing how such modeling operates in tandem with a specific notion of interaction at the human-Armar interface.

Welke et al. illustrate the meaning of active multi-view as the capacity for vision for human-robot interaction in the kitchen when they highlight that "[t]he ability of humans to search for required objects is a prerequisite to interaction" (Welke et al. 2009, 1). As the authors further note, required objects encompass "specific items which support the action" (ibid.). They support this argument by enumerating the following examples: "drinking requires a cup, eating a fork, and writing requires a pencil" (ibid.), to then conclude that "the task of searching for such objects is natural to humans [while] it is still hard to implement on a technical system" (ibid.). The visual system is central to building robot companions in the kitchen as this is thought of as embodying the ability to find the right items for executing everyday activities like eating, writing, and drinking. Furthermore, such activities are conceptualized through the subtask of searching for the required objects, which is defined as something that is natural for humans but not yet realizable in the humanoid. The term 'search' illustrates what is taken as the basis for modeling the execution of tasks in the robot. This entails a division 
into subtasks that rely heavily on vision and thus mirror the predominance of vision over any other possible way of imagining a capacity for human-robot interaction.

Suchman helps me in analyzing the division of activities into sub-tasks that are charged with a politics of valuing when she divides computational models of "the bases for action's coherence and intelligibility" (Suchman 2007, 51) along two trajectories: planned action and situated action. In short, she develops the latter as an alternative to the former. The idea of taking successive, pre-determined steps in reaching a goal along a pre-defined path assumes that action can be planned, and this has a long tradition in AI; I framed it in terms of the tradition of a primacy of cognition in chapter two. As Suchman highlights, this tradition in AI uses "plans [...] [as] prerequisite [...] and [to] prescribe action, at every level of detail" (Suchman 2007, 52). In addition, I argued in chapter two that theories of action in early AI were based on deterministic thinking that is rooted in the rationalist tradition in modern philosophy.

With Haraway, I contemplate this tradition as the basis of "Western humanism" (Haraway 1997, 155) with its "foundations of modernity" (ibid.). These encompass "produc[ing] both what can count as real and the witness to that reality" (ibid., 179). Vision, as Haraway stresses, plays a key role in establishing the rationalist tradition with its split between body and mind that also differentiates between "the marked bodies that makes the unmarked category claim the power to see and not be seen, to represent while escaping representation" (Haraway 1991, 188). She describes this unmarked category as the "modest witness", who, as she highlights, applies the god-trick of seeing everything from nowhere (Haraway 1997, 23ff.). As argued in the introduction, Haraway opposes such modest witnessing with her account of embodied cognition, which she develops alongside situated knowledges (Haraway 1991, 1997).

Informed by Haraway's work, Suchman coins the concept of situated action, which - in contrast to planned action - reveals that the "coherence of situated action is tied in essential ways not to individual predispositions or conventional rules but to local interactions contingent on the actor's particular circumstances" (Suchman 2007, 51). Thus, situated action emphasizes the circumstances and resources required to generate the capacity for action and 
therefore discards the rationalist, modernist connotation of action, helps me moving toward more performative approaches to conceptualizing and modeling action in - amongst other fields - robotics.

With the differences between these approaches as my backdrop, I delve a little further into the meaning of vision for modeling the robot. The capacity for 'active view' in the sense of finding the required object or objects for completing a task brings human, humanoid, and environment into a relation in which the environment is the space that contains the required objects and therefore this space needs to be captured through a search. The process of searching for required objects, including the ability to see and to memorize the environment visually, appears to be one of the core principles that anthropomatics intends to replicate in the humanoid, specifically the humanoid head. This search appears to be an activity that is conceived of as somehow proceeding below the level of purposeful action. At the same time, conceptualizing this search behavior also involves the idea of segmenting the environment into useful objects, while using one of these objects is tied to successive steps in the execution of a task. Thus, a formalization of action that takes into account the circumstances of that action appears to regard both as an epistemological issue, in which the execution of a task becomes a question of information processing and memory in the robot.

In addition, meaningful activities in everyday life are presented as activities that rely on embodied knowledge rather than 'pure' cognitive abilities. Hence the robot envisioned here is an embodied agent that is supposed to operate in ways that are regarded as natural for humans and therefore are the basis for socially meaningful action. In this context, meaningfulness seems to be conceptualized as emerging through action, more specifically through the use of certain objects in completing a task. It appears that, once the ability to perform a task that requires the use of a particular object is realized, the ability to interact with others will also be accomplished. The idea of interaction is pinned down further as a "focus[...]" (Welke et al. 2009,418 ) of their work, in which the robot should be able to perform object recognition with "objects in the hand of the assistant" (ibid.). Although it is thus far not clear what exactly the task of searching for an object, especially in a human-like manner, comprises, it is interesting to note that the authors 
charge their approach to the technical replication of the capacity for action with the search for objects as the key capacity.

\subsection{Modeling the Upper Body of the Human-like Robot}

So far, I have explored the role of the visual system in modeling the humanlike robot. In this subsection, I will explore the humanoid arm and hand and bring together the active head with the 'active arm with hand'. As became apparent in chapter four, the upper body, especially the shoulder and arm with hand, is also a key body part in the humanoid's design, even though on a different level from the artificial visual system and the realization of active vision in the robot. For example, a central feature of demonstrations is that this robot model embodies the capacity not only to visually identify objects, but also, and equally importantly, to grasp them. This is of great significance for the iconic image of the human-like robot companion as it embodies a prospective agent in the household that supports humans in grasping, and as an agent that is also able to hand things over to humans. I will investigate the practices of modeling the upper body, with an emphasis on the ways in which these capacities for grasping are implemented into the robot's design, and additionally how they are regarded as specific to the kitchen.

The upper body is divided into "modules" (Albers et al. 2006, 2) and the "two arms with shoulder, elbow, wrist and hands" (ibid.) are defined as one of these modules. The specifications of the humanoid upper body are explained in the following terms:

The mechatronic design of a humanoid robot is fundamentally different from that of industrial robots. Industrial robots generally have to meet requirements like mechanical stiffness, accuracy and high velocities. The key goal for this humanoid robot is not accuracy, but the ability to cooperate with humans. [...] Its kinematic properties and its range of movements have to be adjusted to humans and their environment. (ibid., 308)

The contrast that is invoked between the familiar figure of the industrial robot and the humanoid machine operating as a service robot splices this new class of robots into the familiar, that is, the image of the industrial robot as a specifically limited machine. These limitations prevent the industrial robot from cooperating with humans. In addition, this contrast also serves to illustrate the requirements that such a new class of robots has to fulfill. Notably, it becomes apparent that, in order for it to be able to cooperate with 
humans, the robot companion will be adjusted to the human in both senses: the human body in its kinematic properties and range of movements and the environment in which this body operates.

In another article on Armar's upper body, this environment is pinned down as "a kitchen environment as a prototypical human-centred one" (Asfour et al. 2007, 54). Reviving my insights into the kitchen as a humancentered environment, as discussed in chapter three, this idea is also crucial in distinguishing the humanoid robot from the industrial robot. Hence, the humanoid is thought of as able to grasp selected objects required for interaction, one of the central subtasks of cooperating with humans - a characteristic that, in contrast, the industrial robot is declared to be lacking.

In what follows, I will zoom in on one detail of the humanoid's upper body, specifically its arm and the anthropoid hand. The humanoid grappler has also been a central part of presenting the humanoid to the public and testing its capacity for action, such as grasping objects in front of an audience. For example, in one demonstration, it is presented as "a five-finger hand, as one can see, it is propelled by fluid actuators" (D 1, July 2011; translation: PT). In addition, this part is "made in Karlsruhe" (ibid.) and, as the practitioner emphasizes, it is already in use in different fields of operation: "The hand was originally developed as an artificial hand, a prosthesis, and is actually being used at the moment [as such] by many patients and it is even deployed commercially" (ibid.). When Armar is introduced to the audience, the grappler becomes legible in the double-drama of demonstrations as an artificial hand that is also commercially deployed as a prosthesis.

I perceive a similar glow around the hand as I detected around the visual system. For example, this hand was a central body part in the meeting between Armar and Chancellor Merkel; a meeting that I argued to have been heavily burdened with meaning. When Armar and Merkel shake hands, this is as much an iconic gesture of the age of robots, although such an age is yet to come, as it is a signifier of the cooperation between technoscience and politics, as the latter is highly relevant to the funding of the innovation of robot companions. Hence, with the prosthetic qualities of the hand in the background, I regard the anthropoid grappler with five fingers as an iconic image that signals anthropomatic mimicry and symbiosis between human and robot, which even entails forms of "concorporeality" (Shildrick 2009, 133). 
In what follows, I focus on tracing the dimensions of the tropic and concorporeal qualities of modeling Armar's hand.

Once, while looking over the shoulder of a practitioner as he logged into a computer at the institute, I noticed that the start screen shows an input mask that is illustrated with a picture. I noticed this by chance and began to wonder about this picture: It shows two hands reaching toward each other; one of them is identifiable as human and the other as Armar's hand. The two hands together form an A that assumingly stands for anthropomatics and that can be schematized as follows: /-- \. I consider touching hands to be one of the iconic, tropic figures of the technoscientific inventory of the socio-technical imaginary of contemporary robotics. More precisely, I consider the image of the two hands that are almost touching to be a re-staging of Michelangelo's painting of The Creation of Adam (Michelangelo 1508-1512) that decorates the ceiling of the Sistine Chapel in Rome as a powerful vision of the creation of life. ${ }^{61}$

This visual narration is of special meaning for the project of engineering the human-like robot, especially with regard to the practices of separating and rejoining form and function or appearance and abilities. At the core of this, as Jennifer Riskin points out, is the endeavor to "synthesize life out of material parts" (Riskin 2007, 2). Along these lines, I contemplate the /-- $\backslash$ as a configuration of human and human-like hands that enacts the synthesis of what I frame as human-like liveliness. Here I find Haraway's analysis of the ceiling of the Sistine Chapel very helpful, when she suggests that "the entire ceiling [...] signifies an eruption of salvation history into a newly powerful visual narrative medium" (Haraway 1997, 179). This visual narrative tells a story of creation, origin and salvation and determines the human form at a specific historical juncture. In Haraway's words, it "provide[s] a key way 'modern man' tells his story" (ibid.). Modern man tells 'his' story through indexing authorship, as Haraway puts it, because "one can hardly extend an index finger (or finger substitute) toward another hand (or hand substitute) without evoking the First Author's (or First Author's Substitute's) gesture"

\footnotetext{
${ }^{61}$ Jennifer Riskin describes the painting very vividly as follows: "In Michelangelo's portrait of the creation of life, Adam reclines on a rocky ledge while God floats [...]. God's arm stretches firmly from the right, while Adam's is draped, extended, waiting, from the left. The two arms converge in index fingers, Adam's swooning, God's pointing" (Riskin 2007, 1).
} 
(ibid., 183). Thus, I contemplate the scheme /-- $\backslash$ to be a re-staging, or reenactment, of The Creation of Man that not only implies a mimetic relationship between the two hands, but also indicates a clear relationship between creator and creation. This ties in with a kind of technoscientific storytelling, which promises salvation from, and therefore also the end of, the troubles of (domestic) work and the constraints of a peculiar vision of bodily integrity.

Thus, I regard the scheme /-- \to signify the beginning of an age in which universal man becomes the author of robots that become worldly as humanlike companions. More precisely, and in terms of anthropomatic research endeavors, it signifies the creation of robots that are proximate and useful to humans. They are envisioned as a prosthesis for humans on different levels, ranging from the domestic machine that serves us to the robot hand and walking aid. However, I suggest we also tweak this scheme in a different direction. I contemplate the re-staging configuration of human and robot in the form of touching hands to also be a leverage point for a queering of the normative framework that the technoscientific visual narrative of both mimicry and symbiosis establishes, as well as the causal and seemingly clear relations between creator and creation, nature and artificial and self and other. In line with Barad, "[t]ouching is a matter of response. Each of "us" is constituted in response-ability. Each of "us" is constituted as responsible for the other, as the other" (Barad 2012a, 215, emphasis in original). The hands are touching, and in this sense they also invoke relations of co-production, coconstitution and response-ability. Here, I take the iconography of the touching hands as an opportunity for queering the story of modern man as implemented in robotic companionship.

\section{Re-Configuring the Anthropoid Hand}

In what follows, I continue to map the practices of modeling the anthropoid hand with an emphasis on defining the size of this hand, which, as will become apparent, is a form of gender attribution of bodies. My focus here is on possible "transformations of the triangle 'nature-culture-gender" (Hark, 2007, 11; translation: PT), and especially on how such transformations are accompanied by sorting operations into, as Hark continues, "specific modern categories of classification and ordering, for which the binary gender system is the paradigmatic pattern of ordering, and their differentiating power, for 
example, for determining norm and deviation" (ibid.). This sorting and its consequences in determining norm and deviation with regard to the anthropomatic hand became very vivid during one of the interviews. Thus, I consider this situation to be rich in intensities of affect and therefore vital for analytical work around data that glows. As MacLure points out, such a glow emerges "not under our conscious or intentional control as analysts" (MacLure 2013, 662), but rather through becoming affected (in a Deleuzian sense) by data (ibid.). Along these lines, I once again highlight how being affected by data and selecting examples of data along intensities that produce a glow both describe strategies of qualitative research that allow forms of embodied cognition as well as acknowledging material forces in engaging with qualitative data (cf. also Lather and St. Pierre 2013). In what follows, I first briefly outline the details of the modeling of the "anthropomorphic hand" (Werner et al. 2010), and then engage with the intensities of negotiating the difference between norm and deviation during one interview. In this way, I will analyze the apparatuses of bodily production through the apparatus of gender.

The anthropoid grappler was constructed "firstly for medical applications" (Werner et al. 2010, 681-682; translation: PT). Thus, Armar's robotic hand is a realization of cooperative work between biomedical research and innovation in the building of artificial limbs and robotic technologies of automation. I suggest that we explore the basis of modeling this hand as one dimension of what appears to be making the anthropoid's body legible as almost human and as an artificial limb for humans. Werner et al. explain that the concept for the design of different prototypes of this anthropomorphic hand "includes a mechanical basic structure with anthropomorphic features" (Werner et al. 2010, 682; translation: PT). In order to further trace this combination of a mechanical structure and anthropomorphic features, I focus on reading the following two passages, the first labeled as "kinematic" (ibid.) and the second as "technological features" (ibid., 683; translation: PT), whereas the remaining passages focus on the implementation of this hand rather than its construction. I begin by drawing on what is defined as the "most important feature" (ibid., 682; translation: PT) of this robotic hand.

The authors state that this feature is that the hand "combines the characteristics of an anthropomorphic hand and those of a robotic grappler" 
(ibid.). They further explain that this primarily comprises a specific alignment of "artificial joints and bones" (ibid.). Furthermore, the palm is thought of as a "frame" (ibid.) that is endowed with "two joints" (ibid.). According to the authors, the appearance of this hand changes, depending on the status of the actuators. If the pneumatic actuators are empty, the palm and fingers will be in a position in which the frame is stretched out and the fingers aligned parallel to each other. This is depicted in a technical drawing inserted into the article and described by the authors as a "form similar to a robotic grappler" (ibid.). In contrast, if the actuators are filled, the hand will take on "the anthropomorphic appearance" (ibid.), which is depicted through a photo illustrating a close-up view of Armar's hand grasping a ball the size of a tennis ball.

In this description, the fluid actuators become a core element in developing an anthropomorphic robot hand at the level of replicating the kinematic structure of the human hand and building an artificial hand that becomes legible as human-like or almost human. In addition, when exploring the outlines of the design of this hand, I read the following: "The width of the hand, at 93mm, corresponds to a large male hand" (ibid.). Here, it becomes apparent that the biomechanical modeling of the robot onto the human body is based on a body that is clearly sexed as male, as the embodiment of universal humanness. This recursion to anthropometric data beyond cultural markers also reminded me of a situation during an interview with one of the practitioners that I conducted in July 2011. In this interview, we talked about the hand of the next robot, Armar IV.

\section{Excerpt interview practitioner GH, July 2011, translation: PT}

GH: And this here, this is already [a part of] Armar IV, this is the thorax, and as one can see, this is all significantly smaller [than the Armar III] and it has exactly the size of, let me say, the figure of a woman, they actually took a female as model, so the hands are still missing, but on these [hands] you can see it [the difference] very well, I have to say, so they are actually - they are like yours, actually - smaller (GH laughs).

PT: But mine are as big as yours (PT and GH laugh).

GH: I see, okay, mine are small (both are laughing, again).

End of Excerpt 
When presenting the upper body, with its arms and hands, of the next model of the Armar series, the practitioner explains that this machine is different from the previous models as it is modeled on the female sexed body. In doing so, he refers to this as being obvious in the gestalt of the robot - a reduced size supposedly indicates a female figure. This situation is of interest for this thesis in two ways. Firstly, it illustrates how anthropomatic body modeling draws from seemingly common knowledge about sex and gender and, secondly, how the female figure as the embodiment of the sexually marked other supports the embodiment of the culturally unmarked gender in previous robot models of the Armar series.

Furthermore, from the position of the queering witness, I find it interesting that the situation generates laughter when the practitioner intends to make a point by saying that these female hands will be similar in size to my hands. Clearly, I appear to be female, but I answer to this invocation of my hands as signifying corporeal differences between our embodiments of sexual difference by stretching out my hands and highlighting that they are the same size as his. The suggested comparison between my hands and the hands of Armar IV draws on the embodiment of sexual difference as common knowledge. However, I suggest tweaking this situation of comparison within a binary gendered normative frame as, rather than affirming such seemingly common knowledge, turning out to make it possible to shake up such thinking. The idea of a sexed norm in the size of hands in its lack of ambiguity becomes brittle within certain limits. Notably, to restore the lack of ambiguity, the practitioner suggests that his hands are smaller than the male norm, while mine - according to this logic - again become clearly 'female hands'.

This situation underpins two important insights into the negotiation of gender in robotics. Firstly, I identify this sequence as an incident in which the ambiguity in the size of hands amongst individual embodiments within a continuum of gender identity, rather than a binary, becomes tangible, and I highlight that this points to the performative nature of gender identity and the mattering of sexed bodies. However, this ambiguity is quickly turned into a lack of ambiguity about corporeal sexual differences and my argument here is that this has the effect that the doing of gender as the iterative citation of norms is once again made invisible, along with the attendant normalization of bodies as sexed. Thus, the categories of social ordering as grounds for 
imaginings of individual embodiment in binary sexed terms in the biomedical and mechanical modeling of bodies remain untouched.

That these categories of ordering play a crucial role in modeling the anthropomatic robot also becomes apparent in another sequence during the same interview. As I have just learned at the beginning of this interview that the next robot model is built on the model of the female figure, I begin to wonder about the details of this design in conversation with the practitioner.

Excerpt interview practitioner GH, July 2011; translation: PT

PT: Will it have breasts?

GH: Yes.

PT: Really?

GH: So, this was the state of the art, this comes from the research center and the lowpressure and high-pressure tanks [for the pneumatic hands] will be stored in them.

PT: Okay.

GH: Yes, this is because the hands are pneumatic, so it isn't because it looks beautiful, but it has spirit and purpose, we really use every installation space, so if we say we would like to have something here and there, they [from the construction office, PT] always say: "uh- no space, no space!" so everything is as minimized as possible, surely, also to reduce the weight, because the thorax by itself is already relatively heavy - you can try to lift it.

PT: I don't think so.

GH: And in this, one tries to optimize the weight, and also to model it on the human for its outward appearance, the gestalt, ... because it is thought of [as a machine] for the household and later it should be operating somewhere in the kitchen and therefore it should have a friendly appearance.

End of Excerpt

When asked if the robot will have breasts, the interviewee answers in the affirmative and I cannot refrain from showing my astonishment at this design detail. The situation generates emotions that continue to affect me long after the interview has taken place. What puzzled me most was how the interviewee goes on to explain the decision for endowing the robot with breasts as a rational one, as it addresses the space restrictions of such a robot model. The tanks for the pneumatic hands are stored in the platform in the robot model Armar III and, in consequence, in Armar IV, which will have legs, the practitioners have to find a new place to store these tanks. This logic seems to be a clear example of how form and function are separated and 
rejoined through anthropomatic robot modeling. What are considered to be female breasts are thus presented as ideal storage space. I contemplate this connection between appearance and ability as displaying transformations between natural and artificial that seem to work, while a stable binary gender system seems to operate as a foil for these boundary re-drawings.

Beyond such engineering considerations, this decision also becomes apparent as a design strategy to make the robot look friendlier, which, I argue, is connected with making the robot more appropriate for working in the female workaday environment of the household, especially the kitchen. As Helma Lutz points out, reproductive labor in the private sector is an area of employment in the "twilight zone" (Lutz 2002, 163; emphasis in original) as it is poorly documented. Most domestic workers are either next of kin or work migrants who are not provided with proper working conditions, such as compensation based on the trade agreement or health and pension benefits. Despite the fact that the exact numbers of kin and domestic workers employed in German households are unclear, in contrast, the gender of these workers is certain. "[M] ore than 90\%" (ibid., 164) of these next of kin and domestic workers are female. Imaginings of ways in which the friendliness of this machine's appearance can be increased in relation to its predominant field of operation appear to be connected to its design being modeled on the female figure. The social organization of labor and the attendant sexual and transnational division of labor appear to be taken for granted when building on this connection. ${ }^{62}$ The gendering of bodies, in this sense, displays the relation between science and politics, and facts and values in practices of modeling the robot on the human.

\subsection{The 'Whole-Body Model' - Patterns of Modeling the Human-Like Body}

So far, I have discussed selected bodily parts as they are realized in the robot model Armar III, which was the most current model during my research. In what follows, I will further map practices of biomechanical modeling of the robot's body as a 'whole-body model', the concomitant forms of connecting

\footnotetext{
${ }^{62}$ Interestingly, and important to note, during my next stay at the laboratories, the following summer, July 2012, the Armar IV was already at a more final stage of assembly and I noticed that this model does not have breasts. When asking around why the design had obviously changed, I was told that "we couldn't possibly be as chauvinistic as that!" (field notes, July 2012). So far it remains unclear to me, however, where the tanks for the hands will be stored in Armar IV.
} 
capacities for action to this body, and the evolving modes of embodying human-likeness in the machine.

One of the many papers accessible on the webpage of the $\mathrm{IAR}^{63}$ sounds very promising in this regard. This paper is a technical report on the research cluster 588: "Spezifikationen zu den Ganzkörpermenschmodellen im SFB 588" (Simonidis et al. 2009), which - as the title indicates - is about "specifications of the whole-body models" used in developing the robot. Although I intend to present a careful and detailed reading of this paper, I refrain from comprehensively explaining the details of (bio-)"mechatronic" (ibid.) body modeling. Rather, I trace how whole-body models are negotiated and how these negotiations employ human-likeness. As I will continue to argue, specifications of the whole-human-body model are a great conceptual resource for understanding the apparatuses of bodily production of anthropomatic robotics in their material-semiotic fields of co-constitution.

This report is grounded in cooperative work between bio-mechatronics and mechatronics and addresses the development of the unified body model that will be applied in anthropomatics (ibid., 1). The paper, in short, proposes a whole-body model, which, although modeling the robot after the human, takes into account the fact that "in comparison to the human, the robot comprises fewer mechanical degrees of freedom" (ibid., 3; translation: PT). In this sense, designing a robot model appears to proceed in multi-layered translations between anthropos and anthropoid, instead of linear steps of transferring the human into the machine, so to speak. These translations seem to be conditioned by technological possibilities, bio-mechanical measurements of the human body and bio-mechatronic modeling of the humanoid robot.

In the report, the cooperative work on a shared model is described as a method of "creating binding standards" (ibid.) between the varying research areas involved in the project work at the IAR. The unified body model thus appears to be a foundational prerequisite for cooperation, which, as pointed out by the authors, aims to "bridge the gap between the study of movements in the human [...] and the execution of these movements in a robot" (ibid.). The conceptualization of the gap between how humans move and building a robot that moves like a human seems to operate with a concept of embodied

\footnotetext{
${ }^{63}$ https: / / his.anthropomatik.kit.edu/21_622.php,

http:/ / digbib.ubka.uni-karlsruhe.de/volltexte/1000013547.
} 
agential properties that links bodily structure to the execution of movements in realizing the embodiment of human-likeness. Of further interest for this thesis is how such a gap is invoked to then present an approach that will bridge the gap between the ideal of a human embodiment of movements and movements in the robot as the replication of this body.

The rhetorics of engineering the human-like machine as the project of bridging a gap also became a topic in an interview that I conducted with one of the robotics practitioners. He differentiates between replicating the human and building humanoids. The practitioner states the following:

Human biology and science fiction movies, these really are two sources of ideas, whereupon I personally don't tend to only copy everything from nature and to simply replicate [the human] in a technical system, rather I [tend to] understand the principles of the biological example and try to replicate aspects of these principles. (interview practitioner CD, July 2011; translation: PT)

Cultural imaginaries of technological methods of replicating the human, along with biological discourses, are listed as the inspiration for anthropomatic robotics. However, as the interviewee highlights, anthropomatics works with such inspiration in a manner that differentiates between "simply copying nature" and "understanding biological principles". Although this difference sounds quite minor, I argue that it is in fact a tremendous difference. I understand this differentiation to deploy a hierarchy between simply copying everything and understanding the principles. Along these lines, I also identify a statement that anthropomatics is an endeavor that can bridge gaps which previous $\mathrm{AI}$ and robotics projects were not able to do.

Anthropomatic modeling as an endeavor to understand and replicate the principles of the human is based on the idea that such principles can be read from the biological example, in this case, the human body as comprised of multiple functional principles. Such reading further requires instruments, and I consider that the unified model presented in this technical report depicts such an instrument. However, and as feminist technoscience studies have long argued, the idea of an instrument with which knowledge can be read from bodies operates with the assumption that the human body specifically, and biological material more generally, is a passive substance. As discussed in the previous chapters, my intention is to query scientific practices in terms of apparatuses of bodily production; a perspective that queers norms and maps the entanglement of ontological, political and epistemological issues with an 
ethos of care. In what follows, I intend to make this scope productive in further exploring the knowledge production about bodies that materializes in this technical report.

At the core of the report is the unified whole-body model, the "MasterMotor Map" (Azad et al. 2007, 2560; Simonids et al. 2009, 3), or the MMM standard model (Simonids et al. 2009, 3), which is presented as a technological solution that "should serve as an interchange format" (ibid., 15; translation: PT). I identify interchange as a buzzword that designates the bridging of the gap between biomechanical standard models and the mechatronic robot model and therefore also of the gap between nature and the artificial. Units of information conversion appear to be crucial in building a robotic embodiment of the human body. Interchange in this sense designates a mode of formalization that generates a model through which the human body appears to be measurable, along with movements that appear to be a property of that body, ordered into categories of human sorting, and transferred onto a model of this body, which then supposedly executes movements in a similar manner. Thus, I consider this biomechanical modeling to be a key dimension of translation between human and machine, self and other and nature and artificial.

The authors further explain that the MMM functions as a "reference kinematic model" (Azad et al. 2007, 2563), which is sub-divided into a kinematic, a statistical, and a dynamic model. Each of these sub-models carries different levels of modeling and mediations between the biomechanical whole-body model and the mechatronic specifications. However, my focus here is on the statistical sub-model as I consider it to be very insightful in regard to tracing translations in their operations of formalization. In line with Suchman, I ask how such modeling appears to contribute to "a formal theory that represents just those aspects of the phenomenon that are true regardless of particular circumstances" (Suchman 2007, 176). In short, a formal theory as it materializes in the whole-body model conceives of the human as a biological example through computational-mathematical means that cut the human from its particular circumstances and contingencies. From this perspective, I explore the statistical data presented under the rubric of the statistical sub-model of the MMM and ask how this data establishes a normative frame of reference and 
with which norms such a model operates. As I will continue to argue, the MMM establishes a normative frame for both the human as an individual entity with distinctive species properties, and of the species human as it is constitutive of populations.

\section{Statistical Modeling - The Species Human as Average Human}

The authors write that the statistical model delivers the "human-model parameters" (Simonidis et al. 2009, 6; translation: PT) that are needed for the MMM. These parameters are further explained as defining the individual segments of the body (ibid.). The report also explains that, in general, such statistical modeling is "realized on the basis of an average human [Durchschnittsmenschen]" (ibid., 7; translation: PT; emphasis added). Without delving into the anthropomatic take on statistical modeling in detail, what I want to underscore here is how the average human is defined through "anthropometric model parameters" (ibid., 15; translation: PT). The term parameter, in short, connects composition and capacity conceptually, as it divides a body into segments with features.

The conceptual dimensions on which these practices of defining parameters are based become apparent when the authors explain how differences among the model subjects who are measured that are measured in order to generate statistical data are integrated into the evolving data. They point out the following:

It is important to mention that the anthropometric parameters should not be used outside of the population in which they were generated. Various studies [...] have shown that differences in the parameters of the model depend on age, gender, ethnicity, and (ethnic) morphology. (Simonidis et al. 2009, 16; translation: PT)

In this explanation it becomes apparent that the parameters of anthropomatic modeling are understood as varying in different populations. The notion of population is thus used as a concept for a group of people who can apparently be characterized via categories of social ordering: age, gender, and ethnicity. Furthermore, these categories seem to be anchored in the body, which the notion of morphology indicates, and in turn embodiments of age, gender, and ethnicity appear to be what determines groups of population.

As the authors note, the data that is used in developing the whole-body model as an interchange format between how the human body moves and 
how the robot executes movements is based on statistical data collected within one population. They further explain that the statistical model is based on a demographic evaluation that was carried out on the "population of white Americans" (ibid., 16; translation: PT). In addition, this kind of population is defined as "comparable with the population as it can mainly be found in Western Europe" (ibid.). This statement identifies the statistically average human not only as Western European, but also as white and comparable to the white American.

Population becomes tangible in this technical report on modeling as a functional term for grappling with the sorting of individuals into groups. I suggest contemplating this notion from a genealogical perspective in a Foucauldian sense. Considered in this way, population is a highly problematic concept that evolved, in short, from the historical juncture of the transition between feudalism and capitalism. From the late 18th century onwards, population was derived as a pivot between the two axes of regulation that are determined by the modern formation of power, biopower: the body of the individual and the social body (Meißner 2010, 107ff.). Modern biopower encompasses productive operations of disciplining and biopolitical regulation at the intersections of the individual and the collective, or social, body (Meißner 2010, 108). As Meißner highlights, “only through subjectifying, disciplining and mass-constituting regulations can the subject become and remain a productive part of the social body" (Meißner 2010, 113; translation: PT). Demographic parameters (Meißner 2010, 111) can be accounted for as a key instrument of the execution of power.

Without delving into the instruments of biopower in detail, what I would like to emphasize here is that demographic evaluation is charged with the biopolitics of regulation which, as Meißner points out and in accordance with Foucault, describe the social body as a constant that does not consist of the "sum of individuals", but rather comprises "a biological entity, based on the 'species human'” ((Foucault 1992, 30, in: Meißner 2010, 11; translation: PT). Thus, the act of drawing on a population not only assumes a classification of individuals into a group, but also determines the parameters of the species human as a biological entity. Species depicts a category of sorting, which reflects the basic taxonomic rank in the modern biological classification system that, in short, grounds human exceptionalism as it is expressed in the 
notion homo sapiens. The species human therefore is a denominator for biopolitical regulations in the form of statistics and demographics. ${ }^{64}$

I suggest that the species human becomes articulated in the average human of anthropomatic statistical modeling. I further see the species human as it figures in anthropomatic whole-body modeling in terms of figuring the norm of the white male European, who also inhabits the category of the culturally unmarked. To trace how the dichotomy between the unmarked body of universal man and the marked body of the gendered, racialized and dis-abled other is negotiated in engineering the human-like robot companion Armar will be of further interest for the remainder of this thesis.

So far, I have primarily explored anthropomatic body modeling as a project of engineering the human-like body through generating statistical data. Recapitulating the central insights I gained from reading this report, I underscore that the MMM is the result of cooperative work at the intersection of biomechanical modeling as it is applied in sports science and computational as well as mechatronic modeling, comprising robotic methods of modeling. The objective is to create a binding standard that can be implemented as a method for and concept of the complex creation of a human-like machine that is able to interact. This process of creation, specifically the crafting of the interactive, human-like body of the robot companion, is furthermore presented as a research endeavor that will bridge the gap between the ideal of the body as the embodiment of human movements and the technological replication of this body. In addition, knowledge about bodies appears in this report as factual and emerging from bodies, more precisely, the bodies of the model subjects who are measured. The composition of the MMM standard model is grounded in the conceptual division of the human body into a kinematic structure and segments with anthropometric properties. This division appears to be a highly technicalfunctional mapping of bodies, which operates with different levels and methods of formalization that I understand to be constitutive of the species

\footnotetext{
${ }^{64}$ Here I am thinking, for example, of popular definitions of certain risk groups within a population. One very prominent example is the group of so-called obese people, who constitute a group that is associated with high death rates among those who sort into this group. What is intriguing is the intertwining of disciplining practices of subjectification that assess the belly-size and the measurement of body weight in accordance with height-weight relata as signifiers that are constitutive of this group (cf. Wirtz 2012).
} 
human as that which determines the distinctive human individual and social body.

\subsection{Conclusions: Modeling the Robot Companion - Configuring the Human-Like Body in Parts in the Kitchen}

In this chapter, I have investigated the design of the robot's body, asking what it means to be human-like and which technoscientific practices of boundary drawing and redrawing have been used to establish the category of the human-like in material-semiotic fields of mattering. Keeping my findings on the role of attaining a sense for the technological embodiment of humanlikeness as it figures in demonstrations, as discussed in chapter four, as a backdrop, I suggest that the delicate process of establishing the category of the human-like orchestrates the always-more-than-human performative enactment of the almost human.

The realization of the MMM builds on the adjustment of the biomechanical model to the robot model. Foundational to such an adjustment is a separation between form and function; here, the kinematic structure and the properties of segments. In turn, such a separation allows a reduction in the degrees of freedom of the body model, for example in the human-like arm, while the properties of this segment remain the same as in the arm of the average human - within certain limitations. I consider the anthropoid design practices of parameterizing bodies to be a core strategy in naturalizing the human body and in making the robot more natural.

The processes of parameterizing and formalizing bodies also becomes apparent in the example of the head and its design as an active head that is similar to the human head in size and shape. This normalized size and shape is then further defined as connecting structure and capacities for action, such as eye and head movements, as they are apparently understood as constitutive of the human visual system. This idea of the visual system operates with a Western, able-bodied norm in the background, which can be traced back to the Vitruvian man.

Anne Balsamo prominently analyzed "[t]he artificial reconstruction of the human body in parts and pieces" (Balsamo 1996, 1). She further highlights that such a dissection into parts and pieces operates by differentiating between "functional" and "nonfunctional" (ibid., 6) parts, while, as she 
argues, this differentiation also carries forms of gendering of the artificially reconstructed body (ibid.). She points out that "while the body has been recoded within discourses of biotechnology and medicine as belonging to an order of culture rather than of nature, gender remains a naturalized marker of human identity" (ibid., 9). To grapple with the relation between bodies and technologies, Balsamo puts forward the notion of "technologies of the gendered body" (ibid.). In this way, she analyzes gender as "both a determining cultural condition and a social consequence of technological deployment" (ibid.; emphasis in original). In line with Balsamo, I consider the anthropomatic whole-body model as it materializes in the MMM to be a form of modeling that enables a design of the humanoid robot which ties in with the idea of the artificial reconstruction of the human body.

Notably, as highlighted several times in this chapter, the apparatuses of gender involved in such modeling of a human-like appearance and abilities appear to re-establish the opposition between the unmarked body of universal man and the marked body of the gendered, racialized and dis-abled other. In line with Balsamo, gender - amongst other categories of social ordering - remains a naturalized marker of human identity in the reworking of our realm of experience. In short, by highlighting these insights I am interested in making the design of Armar the matter of care and concern as this means, as Haraway puts it, "to bring the technical and the political back into realignment so that questions about possible livable worlds lie visibly at the heart of our best science" (Haraway 1997, 39).

Such a realignment builds on attuning to the "force fields" (Haraway 1997, 38), the apparatuses of bodily production of the material-semiotic fields of mattering constituted by anthropomatic robot modeling. The design of the artificial visual system and the artificial hand as two main segments of the humanoid's body illustrates such tropic movements in defining the anthropoid's kinematic structure. These include turns and shifts between natural and artificial, human and nonhuman. The example of the design of the humanoid head displays how a bodily part is defined as human-like in size and shape. Beyond this definition, the head is classified as human-like only when it shows similar capacities, for example with respect to human eyesight. Here it becomes tangible how boundaries are drawn and redrawn in differentiating between the form and function, or looks and behavior, of 
naturalized humanness. I consider this in terms of a processual disentanglement and re-entanglement of form with function, which carries a circular logic: A humanoid head looks human-like because it shows similar behaviors. Or: A humanoid head behaves in a human-like way, because it looks human-like.

The local practices of crafting the robot model can be contextualized within contemporary approaches to AI and robotics, which conceive of "embodiment, rather than being coincidental, [...] [as being] a fundamental condition for intelligence" (Suchman 2007, 230). The foundations of such approaches of "embodied action" (ibid.) conceive of cognition as a "property of action" (ibid; emphasis in original). In line with Suchman's trajectory of thinking, this concept of cognition entails a hierarchical relation between mind, body, and environment (cf. Suchman 2007, 231). Body and world appear to exist prior to cognitive behavior, and the embodied individual and a fixed world appear somehow prior to embodied action. This has the effect that "both body and world remain a naturalized foundation for the workings of mind" (Suchman 2007, 231). Anthropomatic robot modeling operates with an understanding of body and world as naturalized foundations for what are understood to be conventional social behaviors, such as helping in the kitchen, but also eye movements.

Recapitulating the apparatuses of bodily production of anthropomatics, I emphasize that they deploy the universal human as species human in the design of the robot model. This historically and socioculturally specific human comprised of statistical data generated by using specific algorithms emerges as the pattern of differentiation between human and proper anthropoid. As Suchman points out, "[t]he problem [...] is how to understand the nature of difference differently" (Suchman 2007, 260). From this perspective, I contemplate the anthropoid as figuring on the one hand the species human, and on the other hand a machine that is built for the domestic sphere, especially the kitchen. Tropes of this figurative enactment of the category of the proper anthropoid are adjustment and mimesis. Both tropes carry the idea of human mastery and control over nature and subsequently also over the machine, which fuels fantasies of hyper-productivity along the lines of a logic of capitalist exploitation and the normative framework of the distinctive species human. 


\section{Bringing Bodies into Motion in the Anthropomatic Kitchen}

This chapter deals with practices of engineering a machine that will move into domestic households with humans, and, very importantly, that is also thought of as being able to move things in the household. As discussed in previous chapters, to realize the design of such a robot as companion is conceived of as creating a machine that embodies human-like motility.

In chapter four, I focused on how such human-like motility is performatively enacted in the anthropomatic kitchen laboratories during the staging of public tests of Armar as one dimension of everyday work practices at this location of contemporary robotics. Here, a 'common motility' based on a shared kinematic structure between human and machine became apparent as fueled by the idea of a "common ontology" (Haraway 2003b, 48) between the two bodies; for example, when the practitioner demonstrated ways to generate a sense of the robot's body by getting into the body of Armar as a body that is a replication of the human body that can be described through its kinematic structure as being similar to the mechanical structure of the robot. Furthermore, and in line with Alač, I tweaked this feedback-looping dimension of the performative enactment of the two bodies with a common motility in terms of a posthumanist enactment, that is, a re-configuring account of the ways in which boundaries between self and other, subject and object, machine and human are enacted through more-than-human agencies. Thus, I argued that the notion of the "hybrid body" (Alač 2009, 516) captures the relations of co-constitution and intra-active entanglement in performing the kitchen.

These apparatuses of anthropomatic bodily production are also the focus of this chapter. More precisely, I will explore dimensions of bodily coproduction with an emphasis on what is termed the "enablement" of "multimodal human-robot interaction for the Karlsruhe humanoid robot" (Stiefelhagen et al. 2007, 1). It is vital to linger over this term as it invites me to trace its connection with two different, though overlapping, realms of meaning: technological practices of automation and ideas of human enhancement. It points to technoscientific practices as they stand at the heart of modern automation (cf. Haraway 1991). Secondly, these practices also articulate forms of enablement through technologies at the intersection of 
cultural imaginaries that contest and/or reify the norm of able-bodiedness ${ }^{65}$ and technoscientific desires for fusion between human and machine. Such associations across realms of meaning as they matter in enabling the anthropoid robot to interact appear to be an important dimension of practices of enabling the robot, which I further contemplate as central apparatuses of bodily co-production. The enablement of the robot cannot be separated from ideas of enhancing human bodies. Thus, I will ask how such enablement relates bodies and agential properties in the kitchen and will continue to scrutinize "who makes and who is made in the relation between human and machine" (Haraway 1991, 177). In this way, I will trace the material force of language and its entanglements in bodies and matter (MacLure 2013, 658) along with anthropomatic discourses of enabling a human-like robotic other. Along these lines, I suggest a reading of this notion of enablement in terms of a tropic configuration of a robot that will become proximate and beneficial to humans, that is, a robot that moves in with humans and moves things in the context of everyday lives that are burdened with work and characterized by demands for seemingly ever-growing neoliberal efficiency.

With this conceptual configuration as my analytical prism, in this chapter I will map how the enabled machine firstly configures the anthropoid robot and affiliated human as both being "reified bod[ies]" (Haraway 1991, 195), through which patterns of differentiation between norm and deviation are brought into play. Here, my analytical work will scrutinize the relations between the enablement of the anthropomatic robotic body, "compulsory heterosexuality" (Rich 1980) and "compulsory able-bodiedness" (McRuer 2006). This will attune me to the normative framework and therefore the possibilities and impossibilities of mattering when negotiating the enabled human-like as a figuration of the reified body. Secondly, in line with Åsberg, I understand this scope to be a queer feminist, technoscientific research endeavor that requires "[m]oving beyond thinking either-or, good and evil", and which instead wants to "'unpack' or 'open up' clusters of material meaning in a much more complex and open-ended way" (Åsberg 2010, 17). In addition, I associate such a plea for unpacking material meaning, that is,

\footnotetext{
${ }^{65}$ Here, I am thinking of debates about the use of prosthetic technologies in sports in general and in the Paralympics in particular, as they are constitutive of, for example, the figure of the "supercrip" (Howe 2011, 868) as a figuration of technological promises of enhancement and enablement beyond human limitations.
} 
entangled naturecultures, and the need for "new imaginative ways" (ibid.) to research these with the idea of mapping data that glows. I take the glow not only as an indicator of affective intensities, but also as one of contingencies and a queer/ing potential that arises from engaging with these affective intensities.

Here I am thinking of analyzing qualitative data from the position of the queering witness who engages in unpacking data by attempting to move beyond either/or, good and evil. Queer, in this sense, describes a doing - a queering - that is, a reconfiguring of entanglements that is characterized by "the continual unhinging of certainties and the systematic disturbing of the familiar" (Giffney and Hird 2008, 4). I regard such witnessing as, firstly, and in line with Giffney and Hird, an "attempt to undo normative entanglements and fashion alternative imaginaries" (ibid.). Secondly, by making normative entanglements, for example of the matrix of sorting operations between the categories of sex, gender, able-bodiedness and race, the matters of care, I underscore the posthumanist concerns with such sorting operations in the robotic laboratories, and thus foster an account of anthropomatic normative entanglements of the enabled, reified body that is attentive toward relations of a mutual human-machine making and the concomitant ways in which human as well as nonhuman become un/done.

As Judith Butler emphasizes very prominently, concepts of bodily autonomy are linked to a normative vision of the humane and human modes of existence. She argues that "there are norms of recognition by which the 'human' is constituted" (Butler 2004, 13). Without delving into the details of her thought in its Hegelian tradition in detail, what I want to emphasize here is the idea of norms of recognition and how these are constitutive of the human. As Butler writes, these norms of recognition comprise "the power differentials embedded in the construction of the category of the "human'" (Butler 2004, 13), such as the categories of symbolic ordering of sex, gender, race and ableism. Jennifer Robertson argues in a similar vein, when she emphasizes in her study on the sexing of contemporary robot models in Japan (Robertson 2010) that "[g]ender attribution is a process of reality construction" (Robertson 2010, 1). Following this argument, a central aspect of mapping the practices of enabling this robot model to interact as anthropoid companion is to include the norms of recognition in which the 'enabled 
machine' seems to be entrenched. This means asking how the human-likeness of this machine is crafted in relation to the norms of recognition that constitute the category of the human, as well as to further ask how the human-like might re-craft these norms.

In chapter five, I developed a method of analysis that I understand as one of embodied cognition that inevitably draws on bodies; importantly, including my own body, as "material-semiotic generative nodes", specifically “a cumbersome entity called a 'material-semiotic actor"” (Haraway 1991, 200) in the production of bodily boundaries. One of the practitioners introduced the next generation of the Armar series by highlighting that the body modeling of this version differs from previous body modeling. He explained that the body is designed to present "a female image" and emphasized the smaller size of the hands of this machine. He then referred to my hands and after that he concluded that the robot's hands would actually be smaller than mine. I have detailed this example of embodiment of the sexually marked versus the unmarked body at length in the previous chapter. What I would like to emphasize here is my account of mapping the apparatuses of anthropomatic robotic production in relation to embodied cognition, especially the role of my body as the basis for generating situated knowledges, as the latter becomes tangible in this specific situation. In this way, I underscore that my map aims for both: tracing alignments of meaning and material, new and familiar and human and machine, as well as opening up possibilities for queering those alignments; for queer reconfigurings of matter and meaning, new and familiar and human and machine. The situation in which I decoupled what is considered to be common knowledge about bodies and the materialities of bodies, by stressing that my hand is similar in size to that of the male practitioner, illustrates not only how norms and deviations are negotiated in the anthropomatic modeling of the humanlike, and equally the universalized human body, but also makes tangible the affective intensities of bodily production that I use to queer what are conceived of as certainties about the binary sexed and universalized human body.

I consider this chapter to be in conversation with chapters four and five, and thus my analytical work will move in a similar vein. In chapter five, I explored dimensions of the apparatuses of bodily production that are 
primarily occupied with the kinematic structure of the individual body conceptualized as a whole in its physical environment. In this chapter, I will continue to analyze how motions are associated with segments of the body. Thus, I will argue that the anthropoid body as 'enabled robot' comes to matter at this intersection between segmenting the body in its environment and motions associated with segments across the individual body and environment. Furthermore, I suggest approaching this as the intersection of apparatuses of bodily production that is constituted by and constitutive of the enactment of a peculiar vision of human and human-like bodily autonomy and integrity as well as able-bodiedness. Thus, I will, for example, query the ways in which concepts of an embodiment of the self are linked to agential and cognitive capacities that boost the idea of human exceptionalism. This scope of analysis will attune me toward the re-workings of our sociomaterial foundations of persons and bodies, including the valuing of able-bodiedness, autonomy and interdependencies between bodies in human-robot configurations. Hence, I intend to explore the anthropomatic extrapolations and redescriptions of human and humanoid robot at the human-robot interface in the kitchen setting. In this way, I will scrutinize the concept of enablement with reference to its ontologizations of entities with (agential) properties that are sorted into the categories of the human and the humanlike.

\subsection{Current Embodiments of the Enabled Anthropoid}

At the focus of this subsection is the effort to understand the control architecture and how this operates with a concept of interaction as physical, hence embodied in an individual body and embedded within a physical environment. This becomes apparent as being based, as one of the practitioners puts it, on "new principles of information processing to be roughly proximal to the actual performance of natural systems" (interview practitioner AB, July 2011; translation: PT). The human is thought of as a natural system while the anthropomatic take on enabling the robot seems to promise possibilities to not only generate knowledge about what is called the actual performance of such natural systems, but also about how to replicate this performance in the robot through information processing. As I will continue to show, the control architecture is a central aspect of achieving this 
goal. Moreover, this phrasing of the idea of a robot that is proximate to the human in its performance also evokes an association between the natural and the artificial that reminds me of the rhetoric of bridging a gap as I identified it in previous chapters.

When I further ask the practitioner about how to think the relation between software, hardware and abilities, he explains that the "basis for this is the general or so-called kind of cognitive structure of the robot, which in practical terms is the infrastructure for the complete organization of perception and the generation of action, learning, acting and deciding" (interview practitioner AB, July 2011, translation: PT). The complete organization and integration of skills on the robotic platform is regulated by the cognitive structure of the robot. To designate this structure as a cognitive infrastructure assumes that the skills of perception and action enumerated above, such as learning and deciding, are regarded as cognitive skills. The control architecture is interesting for this thesis due to the ways in which it relates physical interaction and cognitive skills as embodied in the robot with the kind of bodies such architecture produces.

Armar's cognitive structure is divided between "a task planning level, a synchronization and coordination level and a sensor-motor level" (Asfour et al. 2007, 56). Any task that the robot has to execute is, in accordance with this division, also "decomposed into several subtasks" (ibid.). Such subtasks, as the authors explain, "represent sequences of actions the subsystems of the robot must carry out to accomplish the task goal" (ibid.). The control architecture in this sense is the structure that coordinates "the execution of a task [, which] requires the scheduling of the subtasks and their synchronization with logical conditions, external and internal events" (ibid.). Skills with which the robot needs to be enabled are structured along the division of its control architecture into a cognitive level of planning, a sensormotor level of perception and manipulation and a level in between, as it were, which coordinates the other two levels. However, as one practitioner highlights, "it's still an open area how such a structure has to look like" (interview practitioner AB, July 2011, translation: PT).

Furthermore, when this cognitive architecture is presented as taking into account both external and internal events, this description reminds me of how I introduced the robot's architecture in chapter three. As already briefly 
discussed there, the anthropoid's robot control architecture is a hybrid structure that combines the approach of the sense-plan-act paradigm with the sense-act schemata. This means, in short, that this architecture reworks the function of the planning component. Instead of the system running through three successive phases of sense, plan and act, the anthropomatic system is built with a planning component that is thought of as connecting sensors and actors. This planning component functions as the 'in-between' between sensing and acting, rather than the 'thinking instance' which calculates the logical output of a sensorial input. This hybrid architecture appears to denote not only a rupture with symbolic AI, as the primary representative of research under the rubric of the sense-plan-act schemata, but also with popular metaphors of the mind as a number-crunching machine. Thus, I suggest contemplating this figuration of the reified body as mobilizing the idea of the cognitive subject in his/her bodily autonomy in its normative framework and thus also the sociomaterial grounds of how 'we' experience 'ourselves'. In this sense, such a paradigm shift in constructing intelligent machines can be regarded as initiating what Judy Wajcman frames as a "changing [of] the idea of what it means to be human, and even our sense of self" (Wajcman 2004, 2).

It is of interest for this thesis to explore the ways in which this hybrid architecture re-describes the human in terms of the intelligent machine through forms of what Hayles identifies as an extrapolation of intelligent behavior from simple mechanical behaviors (Hayles 2003, 100), as I have also initially discussed them in chapter three. The idea of a redescription through reverse feedback loops speaks to my interest in practices of translation between human and machine. In addition, I suggest tweaking this with Suchman's insights into the reduced sense-act schema as it operates with the concept of pre-established entities. As Suchman describes it, the latter "inevitably locate[s] [...] [the body's] importance vis-à-vis the successful operations of mind or at least of some form of instrumental cognition" (Suchman 2007, 230). Such an instrumental understanding of cognition, as she continues, defines it as "the background of action [...] not the world as such, but knowledge about the world" (Suchman 2007, 64). I find it useful to read Hayles and Suchman together, in order to develop an understanding of extrapolation as a form of translation between human and machine and how this works with a concept of cognition located in the body, but nevertheless 
understood as operations of the mind. The effect is the determination of bodily boundaries, agential capacities, and causal relations between bodies and their environment. To further trace how such a concept of instrumental cognition is implemented in the hybrid architecture of Armar, and how this then stipulates metaphors of mind as, for example, a flexible in-between unit that coordinates between sensing and acting in relation to internal and external factors, are the topics of the remainder of this chapter.

\section{The Equipped and Integrated Body}

In what follows, I illustrate aspects of an enablement of the robot that is described in terms of 'equipping the robot with skills' in relation to the concept of 'integrated humanoids'. This intersection of two strategies of anthropomatic bodily production emerges when I immerse myself in the details of the practices that are described as enabling the robot. Along these lines, I firstly associate a glow with this intersection and secondly it reverberates with my analytical work on whole-body modeling as presented in chapter five. Thus, I will query the ways in which the idea of the humanlike body as one that integrates parts and abilities, or form and function, speaks to my findings with respect to whole-body modeling.

To begin, I draw on the first aspect of enablement, that is, "humanoid manipulation in human-centered environments" (Asfour et al. 2007, 54), which, as the authors explain, means to "equip them with manipulative, perceptive and communicative skills necessary for real-time interaction with the environment and humans" (ibid.). The enabled robot is thought in this regard as a machine that is equipped with capacities for action. Notably, this phrasing invokes the idea of a capacity for interaction embodied by the robot that appears to conflate environment and humans. In this sense, the robot relates to both through differing encounters with 'different materials'. However, what this quote does not reveal is exactly which skills such an enablement comprises. In contrast, the question of how to separate necessary from unnecessary skills in crafting the human-like interactive body was a topic in several interviews that I conducted during my research stays. One interview immediately comes to mind in which the practitioner details this very vividly. As he points out, the robot: 
shouldn't be compulsively like the human, but humanlike from a pragmatic perspective; this means that the robot shouldn't have a digestive system, but it should be built in such a manner that it can operate appliances that were developed to be operated by a human. (interview practitioner OP, July 2012; translation: PT)

This interviewee defines the anthropomorphism of anthropomatic robot models as applying a pragmatic perspective when drawing the boundaries between useful and useless forms of similarity between human and robot. He defines as a useful proximity between humans and the human-like machine that both should be able to operate the same appliances. An imagined practical interaction thus articulates as a pattern of recognizing the humanlike machine, which divides between useful, which means functional, skills and redundant skills in realizing the human-like form. The latter, the practitioner suggests, includes skills like endowing the machine with a human-like ability to digest food. Furthermore, this implements a pragmatic view of the human body in its 'biological functions' that seems to emphasize a relation to the universalized body as an instrument of possibly increasing efficiency in the light of a service economy implemented by robotic companionship.

In addition, the endowment of the robot's body with human-like skills on different levels is thought of, as another interviewee highlights, as the "complete integration or seamless integration of software, hardware and abilities of the robot" (interview practitioner AB, July 2011, translation: PT). As he continues, this is an "extremely important point" and, at the same time, "not an easy task, which has not been solved in an optimal manner, yet" (ibid.). However, he further states that the IAR has found a way to realize such complete integration, "which allows [Armar] to perform quite complex tasks in a kitchen environment" (ibid.). This also distinguishes the IAR from other robotic institutes because "this is a thing which hardly anyone around the globe can demonstrate" (ibid.). The practitioner further explains that complete integration means that "software and hardware - the whole body of the robot, they are inseparable from each other" (interview practitioner AB, July 2011; translation: PT). The humanoid body is signified by inseparability between software and hardware. I consider the approach of complete integration to designate one key strategy in dividing bodies into appearance and abilities, or form and function. 
Along these lines, I understand complete integration as designating a pragmatic translation between organic body and artificial system, so that the latter embodies a peculiar vision of human-likeness, and, tied to this, it also implies an individualist concept of agency. These delicate maneuvers of boundary drawing and boundary crossing - between organic and artificial, human and machine, and nature and technology - ground embodiments of cognitive and agential properties that determine the distinctive skills of the human species, which then make the machine more human. In this sense, the human body as a model for the humanoid body seems to appear as a functional unit, which can be divided into useful and useless organic parts. This valuing of abilities demonstrates tendencies toward naturalizing and objectifying a hierarchical relation between those abilities that are defined as cognitive and those that are seen as non-cognitive, vegetative abilities, such as digesting food. I further contemplate this hierarchy as being charged with an anthropocentric conceptualization of interaction that also shapes the idea of what it means to be human, even including 'our' sense of self.

This argument becomes more tangible in a statement made by one of the practitioners in which he defines the idea of complete integration as working on "cognitive research questions; this means how can robots learn autonomously, actually, how can robots understand the consequences of their own doing, as well as the consequences of others' or of agents' doings?" (interview practitioner AB, July 2011; translation: PT). The take on a humanlike enablement of the system presented here means not only making the robot aware of its own actions, but also of what other individuals are doing and, equally importantly, making a machine accountable for what it does. This scope of cognitive research questions sounds intriguing to me. The abilities that the interviewee touches upon in this quote comprise the core of dominant cultural imaginaries of the human self and self-identity as an autonomous subject of knowledge and agency, as scholars of feminist science of the artificial, such as Suchman, have pointed out (Suchman 2007; 2008; 2011).

Thus, in line with Suchman, in this description of human-like dimensions of enabling the machine to interact, I identify a vision of the human-robot interface "as the meeting of a human and a machine, each figured as a selfstanding entity possessed of preestablished capabilities" (Suchman 2007, 245). 
Furthermore, as Suchman highlights, this vision "is typically stripped of its contingency, locatedness, historicity, and specific embodiments" (ibid.). I contemplate such imaginings of enabling the robot to become a cognitive agent that embodies humanness as technological research and innovation endeavors that foster the idea of a separation between an id/entity and its environment. The image of the self-standing entity with pre-established capabilities cuts the robot off from its specific embodiment, which I further understand as the worldliness of the machine. This, as I will continue to argue, encompasses the relations of human and non-human making in their co-producing co-constitution. The idea of the self-standing id/entity is charged with practices of cutting off the local conditions, reciprocities and contingencies, while my thesis constantly underscores that the self-standing id/entity can only emerge precisely because it is imbued with these local specificities.

So far, I have assembled neglected things in the architecturizing of interaction. The apparatuses of anthropomatic bodily production re-work "the sociomaterial grounds of agency and lived experience, of bodies and persons, of resemblance and difference, and of relations across the human/machine boundary" (ibid., 140). I regard the cognitive architecture of the robot as determining who will be meeting at the human-robot interface and also how they will meet, because it regulates the material-semiotic conditions of such a meeting. Thus, it is of interest in this chapter to query the ways in which concepts of the enabled robot envisage cognitive abilities as being the possession of a self-standing entity and to trace practices of cutting off local conditions and circumstances as well as contingencies of specific embodiments of the human-like.

\section{The Anthropoid's Control Architecture}

In an interview that I conducted in July 2011, the interviewee explained the robot model's structure to me in a very accessible manner. In what follows, I draw on different sequences from this interview that touch upon various dimensions of the robot's architecture. In general, the practitioners at the IAR are working with an approach that "has its roots in the longstanding Karlsruhian tradition" (interview practitioner AB, July 2011; translation: PT), 
namely the complete integration of software and hardware in the robot. The interviewee explains the outlines of this approach in what follows:

We have a hierarchical system, in which on the lowest level reside the basic regulatory tasks and sensor processing; not only the classical ones, but abilities of the robot that are comparable with reflexes in the human, for example a stepaway reflex [Seitenschrittreflex]. The highest level is the so-called semantic level on which the robot actually has knowledge in an abstract form of itself, the environment, of other robots, other persons. This means he knows what a fridge is, what a book is, it knows what a cup is and not only through its [the cup's] form and color, but also through its functionality, which is tied to [the knowledge] 'okay, a cup is a container, which I can fill with something, which I can empty out, but this is not a bucket, because I can drink from it' [...] this means this complete knowledge is present on these higher levels. (interview practitioner AB, July 2011; translation: PT)

The Karlsruhian approach to the cognitive structure of the humanoid robot divides this structure into different levels, as mentioned briefly above. These different levels are described in a hierarchical relation. In this structure, the basic regulation and sensory tasks are defined as the lowest level and abstract knowledge about the robot itself, its environment and other entities as the highest level of this structure. Thus, complete integration designates an enablement of the robot with agential properties that situates these properties within the different levels of the architecture, including those that "are comparable with reflexes in the human". Therefore, integrating reflexes into the robotic architecture means including action below the level of purposeful action in the cognitive structure. Both action below the level of purposeful action and purposeful action itself can apparently be registered as data flows. This allows algorithmic formalization and translation of social as well as physical interaction into information processing.

In what follows, I draw on a sequence from the same interview, in which the interviewee explains to me the third level and the interplay between levels. Again, I find this interview very insightful because the interviewee explains these details to me as an obvious tourist in the high-tech world of robotics.

And what we are attempting here is - through observation of the human we derive sensor-motor data at the lower level and we attempt to understand these data flows, [generating] semantics, this means understanding the 
demonstrations of the human. To understand means that we know, okay, which parts of the movement are actually important to execute an action and how I can represent these parts so that I can use them later on. This means we attempt to abstract from observing the human and to generate this semantic knowledge, which later on can be transferred to other tasks and robots and this transfer or this image [of the observed] is a task performed by the middle level of our architecture. This means, the most important level, which has the duty [...] to abstract knowledge from sensory and motor data flows into a higher level. (interview practitioner AB, July 2011, translation: PT)

In this sequence, the third level, the level of synchronization and coordination, is introduced as mediating between the levels of task planning, the highest level, and the lowest, sensor-motor level, or level of reflexes. Notably, the capacities for action of the natural system are conceptualized as being measurable in the form of data flows and as observable and therefore, importantly, also representable. In this sense, behavior of any kind, whether purposeful or below the level of purposeful action, can be recognized and represented in a formal system of categorization, the semantics of behavior, and thus in turn modeled on the humanoid. In doing so, sensors and motors are connected through the level that abstracts and parameterizes knowledge. This third level in the hierarchical structure, or the intermediate level between sensors and motors, is of special importance as it mediates between input and output. To construct such a robot system that integrates all three levels into the humanoid's body is a highly complex endeavor and in what follows, I suggest exploring the details of the robot's architecture in relation to what is framed as enabling the robot, that is, equipping the robot with skills, a bit further.

\section{Segmenting a Task through Motion Sequences}

In this subsection, I will map practices of the anthropomatic synthesis of motion and how this depicts an area of research that not only deals with the aim of building a robot that is enabled to recognize when, how, and why things and human bodies in the kitchen are moving, but also makes the robot perform a distinct motion in a manner that is similar to how humans move. Enabling the robot to interact in a human-like way is believed to guarantee the success of this machine. As Gehrig et al. describe it: "In order to support the humans at their best, humanoid robots need to behave interactively like 
humans" (Gehrig et al. 2011, 4819). I contemplate this statement as stipulating a reverse feedback loop between how humans interact, how robots should interact and, in consequence, how humanoid robots and humans will interact. In this sense, I consider the ways in which the robot is enabled to be boundary-making practices of configuring pre-established entities with specific properties at the human-anthropoid robot interface. Such processes of enablement seem to promote the production of certain bodies and interdependencies between bodies over others. Furthermore, this concept is introduced as follows: "In the field of robotics exists an increasing need for knowledge about human motions, as a humanoid robot has to be empowered with knowledge about motion sequences" (Gehrig et al. 2010, 1). In this description, enabling the robot to interact becomes apparent as empowering it with knowledge. From this perspective, enablement appears to be an epistemological issue.

In addition, the abstract of this article summarizes it as follows: "In our work we propose a procedure for segmenting motions according to their functional goals, which allows a structuring and modeling of functional motion primitives" (Gehrig et al. 2010, 1). Here, the anthropomatic approach to motion segmentation is introduced as a two-step procedure. It consists of a first step of defining and segmenting motions according to pre-determined functional goals. The second step involves modeling functional motion primitives that derive from the segmentation of motion into sequences. The term functional goal suggests a quality inherent to motion that allows a segmentation of movements as distinct motions that are carried out in order to perform a specific task. This task in turn is accomplished when the goal is met. The function of a movement is thus brought into a relationship of correlation with the achievement of a goal. This phrasing also reverberates with the idea of a pragmatic view in differentiating between useful and useless capacities when building a robot with, firstly, the capacity to recognize motions and, secondly, the capacity to execute those motions. This connection seems to carry with it the idea of pre-existing goals and that the right motion in achieving this goal can not only be determined, but also in consequence can be modeled in computational terms. Thus, function and movement are firstly identified as two distinct parts of performing a task, and secondly they are re-entangled in order to synthesize a particular version of 
behavior in the humanoid machine. Moreover, I suggest considering the idea of functional goals as also being charged with what are understood to be human desires for robot technologies, as the robot's functions should meet the desires of their prospective owners. However, this connection between realizing capacities for interaction, the idea of functional goals, which determine these capacities, and the concept of invoking a desire for these automation technologies in humans also allow us to speculate about yet another dimension of co-production: the ways in which the development of robotics technology will change the desire to own these robots, re-organizing everyday lives around them and engaging in multiple forms of proximity to and companionship with such robots.

Against this backdrop, I underscore that the idea of the human-like robot as embodying functional motion primitives is contextualized within "new robotics" (Schaal 2007). Informing myself about new robotics, I encountered an argument that is already well known. New robotics was introduced as a turn in robotics that implies an intention to "move [...] away from its primary focus on industrial applications" (Schaal 2007, 115). Instead, new robotics focuses on "increasingly more human-like robots that can live among us and take over tasks where our current society has shortcomings" (ibid.). The dimensions of this claim are immense when Stefan Schaal further explains that examples of such shortcomings are primarily "[e]lder care, physical therapy, child education, search and rescue, and general assistance in daily life situations" (ibid.). In this vision, new robots appear to become ubiquitous and daily life without them seems to become inconceivable. Although these examples of shortcomings in human society appear to be largely drawn from the public sector, the emphasis on general assistance in everyday life nevertheless confirms the idea of robots as companions that primarily operate in the domestic sphere. When serving to bridge society's shortcomings, this technology evokes multiple desires to own such new robot companions.

Returning to the process of synthesizing motion, which is contextualized within new robotics, in what follows I trace practices and imaginings within this specific project that speak to the idea of robots that will live 'among us'. Gehrig et al. state that their research objective is an extremely challenging task, because motion has a "continuous nature" (Gehrig et al. 2010, 1). In accordance with this continuous nature of motion sequences, defining 
"motion primitives" (ibid.) means to implement "arbitrary boundaries" (ibid.). Gehrig et al. are critical of this procedure and declare that the segmentation of motion sequences is at the same time an "impossible" (ibid.) and a "useful" (ibid.) project. In order to make this argument, the authors draw on knowledge about how humans distinguish motion sequences, which they draw from neuroscientific research (ibid., endnotes 5 and 6). They detail this knowledge as follows: "[H]umans tend to perceive motion in terms of discrete motion primitives [...] and thus motion segmentation is still considered useful for some applications" (ibid., 1). It is thus important to draw on neuroscientific research in order to make the sequencing of motion into motion primitives not only useful but also meaningful, and to depict a practice of deploying this model of meaningfulness in the human-like robot.

I understand the narrative of the segmentation of movements into distinct, meaningful motion primitives that is grounded in how humans perceive movements, in line with Haraway, as the production process of the real and the witness to the real. This requires shared models of mind between robot and human in its tropic qualities of co-production, including processes of translation, layering and feedback loops between what it means to be human and what it means to be human-like.

\subsection{Equipping the Robot with Vision as a Means of Enablement}

In this subsection, I focus on a skill that the robot is supposed to embody that was also a topic in the previous chapter on whole-body modeling: vision. In chapter five, I explored the apparatuses of production of a robotic head with human-like vision. In short, the robot is thought of as mimicking human vision. I further explored the meaning that such active vision is given in the context of interaction in the anthropomatic kitchen. Endowing the robot with a head that embodies active vision is conceived of as making it more natural to humans on two levels: its human-like appearance and its human-like abilities, primarily the ability to interact. In what follows, I will further explore the connection between vision in the robot and interaction at the human-robot interface under the category of the human-like. I consider the realization of vision in its entangled matter-meanings to be a great resource for my analytical work tracing how individual id/entities are produced at this 
interface, rather than assuming given bodily boundaries and agential properties.

To begin with, I draw on an interview with a sports scientist that I conducted in July 2011. The interviewee explained the motion-capture system, which is also used in segmenting motion, in a very comprehensible manner, when stating the following:

We captured these [motion sequences] for the robot project with these Vicon cameras, which you can see here, these little black cameras. By now, we have 13 cameras. These are infrared cameras, the whole system is an infrared camera system. Different motion-capture systems exist, but this one, the one from Vicon, is the most precise, the gold standard, so it's deployed in many sports science departments, but also in many medical facilities, especially in orthopedic specialists' offices. But it's also a system that's used in the film industry, for example in animation, these actually are firstly recorded with a person and then, via this modeling, the animation is drawn over that, so that in the end it looks like a human movement. (interview practitioner EF, July 2011; translation: PT, emphasis: English in original) ${ }^{66}$

The Vicon motion-capture system is a commercial success because it is broadly applied within different branches of the visual effects industry. This specific system, furthermore, is regarded as the "gold standard" of capturing motion, as it allows models of motion to be generated, which picture human movement. I regard this specific motion-capture system to point toward an interrelation between animation and automation. Stacey and Suchman discuss such an interrelation in terms of an "exchange between film studies and STS" (Stacey and Suchman 2012, 4). They define animation as "the capacity to bring things to life through movement" (ibid., 2) while they point out that automation is "the replacement of human bodies with machinic labour" (ibid.). In line with Stacey and Suchman, I argue that what is at stake at this intersection is nothing less than "what gets rendered invisible in discourses of automation [...] [and how this] is central to debates regarding the interdependencies of bodies, machines, labour and care" (ibid., 3). Stacey and Suchman thus direct my analytical attention toward the intersection between animation and automation as a material-semiotic field of acknowledging and neglecting forms of bodily co-production as they underlie the animation of

\footnotetext{
${ }^{66}$ Vicon is the brand name of a very common motion-capture system that is used in biomedical research, engineering and the animation industry. See: http://www.vicon.com.
} 
the robot. In this sense, I see the motion-capture system as being the ideal instrument, or rather apparatus, not only for segmenting motion, but also for replicating motion in anthropomatics. This aspect of enabling human-robot interactivity thus produces a connection between bodily materialities and movements that relates the automation of labor with animation that invokes humanness.

In what follows, I draw on another sequence from the interview with the same practitioner in which she explains how this system works. Her description enriches my understanding of this intersection between automation and animation as it makes palpable the ways in which this apparatus of bodily co-production both acknowledges and neglects aspects of interdependency between bodies and labors in enabling the human-like robot to interact with humans.

The system ... is an infrared-camera system, this means you can see these LEDs, this ring around the lens, these LEDs transmit infrared light and this light - if we glue a marker onto our models, these markers will reflect [the light], and this is reflector tape that is glued [onto the marker]. Every other part of the body won't reflect the light, so [the light] is reflected and captured by this camera and in the camera is an infrared filter. This means the camera only detects the infrared light and we don't have any other picture information, these are our tools, and actually what's exciting about this is that we reduce our human totally, so we take [away] every bit of information apart from the marker information [...] and this won't resemble the person anymore, but actually resembles this person anatomically. So, one of course says, [...] one gets the proportions of the person, but in the end, we won't have any picture information about where the eyes are - if we didn't marker them - [...] one really has to consider what information do I need, because I will have to glue markers there, let's say. (interview practitioner EF, July 2011; translation: $\mathrm{PT}$ )

The motion-capture system allows the operator to cover every detail of a body. However, at the same time, it is regarded as a fascinating technological practice that is based on reduction. The information generated by this system reduces the human to the infrared reflections that are captured. Furthermore, the idea of markers as representing segments in their kinematic structure also speaks to an understanding of the human body as divisible into functional units that are then either regarded as useless, like the digestive system, or as useful, like the arm. 
Moreover, I suggest pondering the motion capture system in its production of specific bodies that emphasize its quality as a visual apparatus. In line with Haraway, "the power of the technology of perspective to discipline vision [is] to produce a new kind of knowledge of form" (Haraway 1997, 180). This new kind of knowledge of form that Haraway discusses emerged genealogically from "Renaissance visual technology" (ibid., 182) and operates with the opposition between vision and touch as a clearly gendered division (ibid., 180ff.). Moreover, drawing on Haraway's line of thought in regard to the motion-capture system as powerful visual apparatus, I bring this together with what she calls the "potent stock of Renaissance" as a "legitimate lineage and origin story for [contemporary] technical revolutions" (ibid., 182). As Haraway points out, it is vital to trace this lineage because it reveals the "conjoined Western modern sense of the 'real' and the 'natural'" (ibid., 182). Visual technologies are apparatuses of bodily production that produce what counts as real, ergo also as natural, and the witness to this reality, specifically nature. These witnesses become observers, who, as Haraway points out, "forget the conditions, apparatuses, and histories of [...] [the] production" (ibid.) of reality as nature. To problematize the relation between object and subject, specifically observer and observed, and the ways in which these $\mathrm{id} /$ entities are cut off from their apparatuses of production, is one key topic of this chapter.

\section{Motion, Activity and Intention Recognition - The State Estimator as Model for the 'Human's Rationale'}

This subsection continues with motion recognition as a key topic of anthropomatic research and innovation practices. It also expands the scope by illustrating that motion recognition is only one component of assembling the robot companion as a class of machines that "are specifically aimed at supporting humans in every-day life tasks" (Gehrig et al. 2011, 4819), as Gehrig et al. point out. Such phrasing can be read as demarcating the beginning of the age of robots, which also makes the robot a ubiquitous machine. Thus, I suggest developing a deeper understanding of activity at the human-robot interface in anthropomatics in its ontologizations. This includes zooming in on practices of configuring entities with specific properties that are supposed to meet at the human-robot interface. 
The connection between motion primitives, intention, and activity in developing humanoid motion recognition is introduced as follows:

For example, the task Prepare Cereals may be coarsely described as movements and manipulations in a specific area of a kitchen. We term this an activity. In contrast, the motion sequences of the task can be modeled in detail as a sequence of clearly defined motion primitives, such as Place Object on Table, Pour, or Stir. An intention combines these models with domain knowledge, e.g., object presence or time of the day. (Gehrig et al. 2011, 4819, emphasis in original)

The robot is imagined as supporting humans in the kitchen in everyday life. In order to enable the robot to become such a supportive labor force, the development of capacities for action are divided between knowledge of how to execute an activity and domain knowledge, which are then combined once again. More precisely, "motion primitives" are considered to provide knowledge of how to execute an activity. Domain knowledge is thought of as providing knowledge of intentions. Thus, the pre-defined activity, for example, the task of preparing cereals, is conceived of as being composed of motion primitives, which, as the authors describe, can be clearly separated and also defined as relating to apparently equally clear intentions. So far, this approach appears to suggest a take on activity which, again, positions the body vis-à-vis the operations of mind.

Framed as the enablement of the robot to interact, my emphasis in this chapter is on the anthropomatic approach of building a cognitive structure for the human-like machine. More precisely, I examine how the three levels of planning, acting and the in-between are realized in this approach. What I have learned so far is that this combined approach is based on defining motion primitives. As Gehrig et al. point out, these motion primitives "serve as an alphabet for a context-free grammar describing motion sequences" (Gehrig et al. 2011, 4819). This idea of a context-free grammar is charged with imaginings of formalizing activity that are similar to early traditions in computer science. The authors further underline this when they relate their project to "symbolic approaches" (ibid.) that operate with "plan recognition" (Gehrig et al. 2011, 4820). However, they also highlight that their approach "extends" (ibid.) the existing work. In accordance with Gehrig et al., such an extension of existing work is a prerequisite for household robotics. The authors point out the following: "Since activities in the household scenario 
usually consist of a quasi-periodic repetition of short action sequences, we follow a different strategy and infer the activity within a temporal window directly from video features" (ibid.). Activity in the household is understood as the quasi-periodic repetition of short action sequences, which allows segmentation into motion primitives. This concept of household activities reminds me of the kind of activities for which the industrial robot is deployed; that is, short, repetitive, quasi-periodic tasks. However, it also speaks well to the longstanding idea of a rationalization of the household and the concomitant devaluing of reproductive services as unchallenging and monotonous, repetitive tasks, in contrast to market work, which supports the gendered and transnational division of labor.

The ability to realize capacities for motion recognition in the anthropoid robot is envisioned as making the robot useful in the kitchen. The kitchen, again, is defined as a human-centered environment, which comes with specific domain knowledge. Gehrig et al.'s approach proposes modeling how humans perceive movement in their environment through video-based, computational methods of image processing. This suggests that movement can be captured through a formal system of categorization that disciplines vision embodied by the machine and at the same time determines how the visual apparatus of the human operates. Furthermore, in her analysis of computational accounts of modeling human behavior, Suchman addresses the idea that the latter is "observable" (Suchman 2007, 64). To problematize this idea further, I draw on Haraway's concept of "a heterogeneous world in which people and instruments are immersed and that is always prestructured within material-semiotic fields" (Haraway 1997, 301; footnote 12). In line with Haraway, both observer and instruments are constituted by and constitutive of material-semiotic fields of mattering. Furthermore, this perspective also speaks to Barad's agential realism (Haraway 1997, 302; footnote 12). In short, Barad contemplates the idea of an observable world with her concept of an onto-epistemological inseparability between observer and observed. As she notes, observing is a practice of "specific material engagements that participate in (re)configuring the world" (Barad 2007, 91; emphasis in original). Hence, to conceive of movements in their social meaningfulness as observable, removes the practices of observing from the observed. However, in line with Haraway and Barad, the observer is always 
engaging in material practices of mattering. Thus, I contemplate the process of, for example, generating a context-free grammar in the enablement of the robot based on observing as being at the same time a way of disciplining vision and of producing a certain reality for the observed while both realitychanging operations are cut off from the heterogeneous circumstances and the inseparability between observed and observer that are the very conditions of both vision and reality. To put it differently, I underscore that what is removed is the ways in which feedback looped robotic vision and human vision are co-producing a disciplined vision and reality.

To thoroughly understand selected aspects of the functional unit of the state estimation is very insightful in this regard. It displays how the observable is connected with socially meaningful behavior in enabling the robot to interact. Furthermore, this unit in the control loop of the robot is designated as the "Model of Human's Rationale" (Gehrig et al. 2011, 4819, fig. 1, emphasis in original). I stumbled across this phrasing as it depicts the state estimator as a model of the core of human behavior, captured in the term rationale. The authors further explain their line of thought as "[m]odeling the behavior of the human in terms of intentions causing manipulations of the world, which [...] corresponds to modeling the causal dependencies of the human's rationale" (ibid., 4819). What I have learnt from this so far is that the enablement of the robot seems to be oriented toward creating a machine that mirrors the causal dependencies of the human's rationale and in doing so also determines what the human's rationale is. Furthermore, Gehrig et al. highlight that the state estimator "directly impacts the robot's usability" (ibid.) and is therefore a foundational part of the "overall robot control loop" (ibid., 4820). This control loop is explained as follows:

The combined intention, activity, and motion recognition is used for estimating the state of the human. This state estimate together with domain knowledge is input to a higher level control system governing the robot's actuators, i.e., his manipulations of the world. (ibid.)

The combined intention, activity, and motion recognition, the state estimator, is the synchronizing and coordination unit that processes data flows from multimodal sensors and thus provides the input for the higher level of the architecture at which action is generated. Intention recognition, the ability to recognize how and why a person at the robot-human interface is moving, 
thus functions as estimator of the state of the world and living things in the world, as well as enabling the robot to infer appropriate behavior to transform this state in cooperation with humans. This is characterized by a high degree of formalization and displays very clearly the disciplining of vision and the reality-changing dimensions implemented by this model of the robot's control loop, specifically its cognitive architecture. The state estimator is an apparatus through which the state of the world and living things in the world, as well as the appropriate behavior of the machine, become not only observable, but also determinable. Gehrig et al. further explain that:

[f] or the acquisition of our data set, we used a single video camera in a setup that resembles the application of our system on a humanoid robot. We imagine the robot to act as a 'butler' observing the scene from a position that does not obstruct the human and offering his service whenever he assesses that it might be appreciated. (ibid.)

The state estimator can thus be described as the realization of the third level of the robot's architecture, which aims for complete integration. This peculiar vision of combining activity, motion and intention operates with imaginings and practices of companionship, such as observing the human from a position apart from the action and then offering to help. In the experiments, the robot model is reduced to a camera wired up to the computer units that are necessary for processing the visual data, which are fixed. This artificial visual system is the centralized technology for recognizing the partner in an interaction as well as the action performed in the kitchen setting. Again, supposedly pre-figured entities with specified properties meet at the robothuman interface. However, as discussed in chapter four, the enactment of this interface also exceeds such a conceptual framing.

Moreover, the realization of the robot as a butler is tied to the state estimator as the third level of the robot's architecture. This architecture of interaction, I will argue in the last section of this chapter, produces a specific reality of bodies with specified properties, relations and labors in the kitchen setting that makes knowledge - in the form of data flows - the background to action. In this sense, practices of architecturizing interaction also produce bodies that incorporate a specific version of cognitive abilities as the primordial capacity of relating to others and the world. 


\subsection{Armar III - The Kitchen Boy}

So far, the infrastructure of enabling the robot to interact has become apparent as a highly functionalist project, which operates with the logics of instrumental cognition. This positions the pre-figured individual body and the physical environment in opposition to the operations of the mind, understood as information processing. The process of enabling the robot is thus a process of establishing entities with desirable properties at the humanrobot interface. In this and the following subsection, I explore how this enablement ties in with norms of recognition and existing power differentials modeled on bodily abilities.

In line with Robertson, I understand the enablement of the robot, as described in the papers and interview passages that I cited above, as amounting to "theorizing about human robot relations [that] treat [...] humans and robots as gender-neutral categories" (Robertson 2010, 15). However, as she further points out, seemingly gender-neutral human and humanoid robot relations, as for example envisioned in making robots domestic, carry a lot of "evidence to the contrary" (ibid.) Thus, I intend in the following to discuss the enablement of interaction as one revealing site of theorizing human and robot relations. These appear to operate with a genderneutral concept of the human, the robot and the delegation of labor, but I will scrutinize such seeming neutrality.

I begin by delving deeper into the anthropomatic practitioners' experience of working on and with the robot model Armar as an 'enabled machine'. Therefore, I draw on an interview which I conducted in July 2011. The practitioner and I were both sitting in the kitchenette laboratory and other practitioners kept dropping in and out, occasionally joining our conversation, which framed this interview more as a group discussion and created a special kind of attachment site between the practitioners and me. The following passage is of interest as the practitioner precisely highlights the relationship between movement and humanness in the robot model Armar III.

\section{Excerpt interview practitioner KL, July 2011, translation: PT}

Pat: So, you personally, how do you see human-likeness when you see Armar?

KL: Increasingly less [laughing].

Pat: But in which situations? 
KL: Hm, so I find this dialogue system, when he talks about random stuff, this sometimes has human traits, when he says that he runs out of steam [laughing]. Of course, this is all justifiable, because he misunderstood something and then reacts like this, but these situations are so comical, in which you see some humanness [...]. But then, exactly with such things that you haven't seen that often, I believe one has this surprise effect, even though in my case I've been here for a long time. And I guess that external people see something they haven't seen so far or not often and that it has something human - I don't know - actually how was it with you?

Pat: I have to say that every form of movement [in the machine] invoked such associations [...]. So it's the mix of gestalt, but also movement.

End of Excerpt

This practitioner describes situations in which the robot becomes legible as human as comical. The humor derives from behaviors of the machine that are regarded as unexpected, and which have a surprising effect - even for practitioners who are already familiar with the machine. It appears that Armar III becomes legible as almost human when it fails to execute an order. This, in turn, is interpreted as a form of dissident behavior by the machine. Affects such as surprise, which guide interpretations, however, appear to be fundamental in granting the machine humanness. Furthermore, the practitioner explains that he knows what is 'behind' the behavior of the robot, but nevertheless experiences these situations as surprising - even though increasingly less so. In chapter five, I discussed several such comical situations.

Suchman analyzes such forms of interpretative engagements with the machine as an enlivenment that fetishizes the object (Suchman 2007, $238 \mathrm{ff}$.). In line with Sara Ahmed, she describes this "fetishism [as] involv[ing] [to] cut [...] off a figure from the histories of its determination through particular, embodied encounters" (ibid., 244). This further has the effect that the object appears to be present and given in an unmediated way; that is, naturalized in its being and reduced to the interdependencies and labors that are constitutive of it. She also contemplates such a "masking of labors" as "'enchantment"' (ibid., 244). As she goes on to emphasize, the fetishized object, purified of its contingent relations of being produced and producing boundaries between object and subject, self and other, and nature and artificial, carries with it "an individualist conception of agency" (Suchman 
2007, 240). Furthermore, this individualist concept of agency naturalizes bodily autonomy and the related power differentials.

In addition, the importance of such practices of enchantment also becomes tangible when one practitioner differentiates between "associations" (interview practitioner KL, July 2011, translation: PT) and "abilities" (ibid.) in an interview that I conducted in July 2011. As he further explains, "one has associations, the abilities are still lacking, one also associates it with - I don't know - let's say science fiction movies, such as WALL*E [Santon, 2008], or suchlike, which one also immediately feels extremely sympathetic about" (ibid.). I find this relevant as, firstly, it illustrates that enabling the humanoid machine requires that we enable abilities in the machine that are tied to its human-like design. Secondly, this also involves invoking associations between the machine and humanness that are linked to cultural imaginaries of the sympathetic machine, as figured for example in the robot "WALL ${ }^{*}$ " (Disney 2008). The humanlike design is supposed to invoke associations between the human and the humanoid from which expectations arise about how such a machine should behave. I consider these associations to be based on mirroring relations, of finding the self in the other. As Margrit Shildrick points out, the "mirroring of the selfsame" (Shildrick 2002, 119) is a doubling process, which establishes self-identity by "precisely [...] mapping [...] the boundaries between singular selves and bodies and those of others that authorises our being-in-the-world as subjects" (ibid., 50). The robotic embodiment of the execution of movements is highly relevant for deploying a mirroring relationship between human and humanoid. It illustrates a mapping of boundaries, which authorizes subjectivity as well as the natural authenticity of universal man.

In what follows, I bring together one predominant appellation of Armar III to scrutinize the associations and mirroring relations invoked by this naming, which I consider to be foundational for the anthropomatic enactment of making robots domestic. During my first stay at the IAR, "the magazine for research, teaching, innovation" of the KIT, "LOOKKIT" (02/2011) was published, entitled: "In the Name of Man: Anthropomatics and Robotics" (LOOKKIT, 2011). This issue focuses on the IAR, with Armar as the central robot. It includes several interviews with the head of department, Prof. Rüdiger Dillmann, and the team leader, Prof. Tamim Asfour. In addition, we 
see Armar in different settings, for example one image sets Armar into the scene as a chef, serving food, and another depicts the robot in the kitchen setting together with a practitioner who is sitting at a computer, and the reader can see a 3D model of Armar on the computer screen.

I focus on the picture of Armar as chef, which fills a complete page of this LOOKKIT issue. Armar is outfitted with a chef's hat, as well as with a serving dome, which it holds in its left hand. The photo illustrates a cut-out of the robot's anthropomorphic upper body, composed of the torso, the head, the two arms and the right hand. The robot's head is facing the camera and the view of the torso is half of a front-on perspective from the right. This perspective supports the impression that the robot is moving, and that the picture is some kind of a snapshot of 'Armar in action'. The snapshot character of this picture underpins the impression that the robot is moving across the camera's field of view, from left to right. The robot's right arm is bent and the thumb and forefinger of the right hand form an ' $\mathrm{O}$ ', which is the hand signal for okay. In the context of the kitchen and as Armar is wearing a chef's hat and holding a serving dome in its other hand, this okay is linked to the quality of the food and a high standard of gastronomy. This illustration of Armar as robot chef simultaneously figures expertise and service.

In addition, the robot appears to be glowing. The outlines of Armar are shining in a bright pink. Details of the torso are shining in a bright blueyturquoise. The glowing outlines enhance the impression that this is a snapshot of a robot capturing the dynamic movement of serving and hand signaling. The color pink has two effects: firstly, it is a shockingly bright color. Secondly, it is a color that signifies flourishing and living (as in the saying: "to be in the pink of health"). The chef's hat signifies a professional, predominately male position in the kitchen, whereas the serving dome is an object that service workers lower in the hierarchy usually carry; the service personnel. Armar III illustrated in this style of presentation invokes professionalism, as it appears to incorporate the figure of the chef. It is a figure that stands in opposition to that of the housewife and the maid, who are positioned as others to the predominately male chef. This opposition is grounded in the sexual and transnational division of labor, the dualistic relation between production and reproduction in modern, Western societies, and the attendant valuing of labor. As Harding reminds us, it is predominantly these others who are 
constantly made responsible for the flourishing of lives and the so-called productive labor in the private sector (Harding 2008, 1), while "[t]hese others are mostly women and non-Western men" (ibid.). Thus, this picture of Armar is interesting as it invokes the idea of the robot as both chef and kitchen service worker.

Moreover, page 14 of this issue of LOOKKIT shows a close-up of the robot's head looking at its hand in front of its camera eyes. Armar is holding something that looks like an egg with two fingers of its hand. This photo is interesting because it shows the robot seemingly performing a grasping task that requires high precision. This picture, again, fills a whole page and serves as illustration for the accompanying introductory article about Armar, which also highlights the development of the robot's capacity to grasp. Throughout this article, the robot becomes legible as a "helper in the household" (PhamHuu 2011, 16). Furthermore, it is entitled: "Humanoid Robots: The Electronic Apprentice Cook. Scientists at the Institute of Anthropomatics Instruct Humanoid Machines in Mastering Complex Tasks" (Pham-Huu 2011, 14). Page 16, however, includes a box with a summary of the article in German. In this, the title differs slightly from its English translation, as it reads “Elektronischer Küchenjunge” (Pham-Huu 2011, 16) instead of electronic apprentice cook. ${ }^{67}$

As the German text was the original, and the English is a translation, I suggest a different translation, which takes into account the meanings of the German name for Armar III; that is, Armar the electronic kitchen boy. When I first read this appellation, I was struck by this title as it invokes multiple meanings. In turn, I included questions about it in some of the interviews that I conducted with practitioners at the IAR, asking about the ways in which Armar is regarded as a kitchen boy, aiming to trace the obvious gendering and hierarchy between kitchen boy and kitchen master generated by this figure. In addition, to call the robot a boy also ties in with what I have previously observed as identifying the robot with the figure of the child. As discussed in previous sections, this trope of evolutionary development designates a mirroring relationship between human and humanoid that, as

\footnotetext{
${ }^{67}$ The YouTube channel of the KIT also broadcasts a short video that introduces Armar as "elektrischer Küchenjunge"(electronic kitchen boy), see: www.youtube.com/watch?v $=5 \times 1 G 0 \mathrm{nkSd} 9 \mathrm{w}$.
} 
Suchman argues, "inherited within colonial imaginaries carries with it a process of becoming made up of inevitable stages and unfulfilled potentialities" (Suchman 2011, 129).

As one practitioner confirms, when asked why he thinks that Armar is a kitchen boy, the appellation "'boy' is very accurate, because he still screws up a bit, and so on, so ... this fits very well" (interview practitioner KL, July 2011, translation: PT). Armar is a machine that embodies unfulfilled potentialities. Imaginings of prospective robot models thus entails the vision articulated by the practitioner as follows: "Some day we will have systems that really are like a little child, learning like a human, because you can't include everything when you program a system, this just won't work, it would just take a lot of time and not work out in the end" (ibid.). As Jutta Weber reminds us, such "models of the human-machine interaction as caregiver/infant or partnership" (Weber 2014, 187) work with individualist conceptions of agency and cognition. The figure of the child also encourages behaviors of "empathizing with the robot" (ibid., 194) as the human-like machine that mirrors the self-same. Thus, the figure of the child, in this sense, also fosters relations between human and machine, in which the human is thought of as caring and empathizing with the robot. However, in the final chapter of this thesis, I will consider such affective relations as not only being instruments of cementing specific relations and interdependencies, such as the caregiver/infant relation in its hierarchical connotations. Rather, I will suggest taking affects as a point of departure for shaking up configurations of pre-established entities with specific properties.

In what follows, I draw on another interview with a practitioner that I conducted in July 2011. Again, I asked about the appellation of Armar as kitchen boy and if and how the practitioner thinks that this fits.

Excerpt interview practitioner CD, July 2011, translation: PT

Pat: In the most recent issue of LOOKKIT Armar was designated as a kitchen boy CD: As what?

Pat: Kitchen boy. What do you think, why kitchen boy?

CD: The article [in the LOOKKIT Magazine].

Pat: So, what do you think - how does the robot get into the kitchen and what makes it a boy? 
CD: Yes, what makes it a boy is, why it's a boy, this is a good question. Armar IV will supposedly be a woman, we also have a child, Kawai, a sort of baby robot, so supposedly there will be a robot family. Why male? I also don't know now, to be honest - I mean, the antenna is in any case in the wrong place, or else one could say it's because of the antenna [both laugh]. And the kitchen, I think the kitchen is simply an interesting area, these days the kitchen is deployed in many robotics projects as a scenario, but I believe one can truly say - I wasn't present, so it's no self-praise - that Karlsruhe [robotics] was the first place to start using the kitchen scenario and this scenario is far from being exhausted yet; we still aren't actually handling food, we're still occupied with opening and closing the fridge, getting some beverages from the fridge, pouring them, we haven't cut anything so far and other groups haven't either, so the kitchen provides a lot of possibilities.

\section{End of Excerpt}

This sequence illustrates the intertwined parameterization of bodies and of space, namely the domestic kitchen, in the process of modeling the robot on the human. The domestic sphere becomes apparent in the description above as an interesting scenario for automation technologies. It provides robotics practitioners with a lot of challenges in realizing a human-like machine that is able to take over everyday tasks such as pouring, cutting, opening and closing drawers and doors. This stands in contrast to what I have learned about segmenting tasks into distinct motions in the kitchen; from such a perspective these tasks appear to be unchallenging. However, the tasks that are the focus of this robotics scenario are composed of labors that are de-valued or neglected in Western societies in accordance with the gendered and transnational organization of labor. When the practitioner further explains that the robotic representation of the domestic space includes building a family, this family represents the heterosexual nuclear family, specifically the Oedipal triangle of mother, father and baby. I will return to the topic of kinship in the final subsection of this chapter, but in what follows I further explore the gendering and sexing of Armar's body.

The interviewee makes a genital-related joke about the robot's antenna, over which I stumbled. I found this connection between the gender identity of the robot - as I am asking about the appellation of kitchen boy - and its construction in comparison to 'the sexed human anatomy' irritating. I would like to suggest that this connection between the appellation as a boy and the reference to the antenna appears to express a conceptualization of gender as 
sex. The implications of such an understanding of gender as sex are enormous, as it grounds gender identity and the attendant gendered social behaviors in the idea of sexed bodies. As Robertson explains: "[r]obots lack actual physical genitals and these play no role in their initial gender assignment" (Robertson 2010, 5). In accordance with Robertson's distinction between actual physical genitals and gender assignments, I consider the possible sexing of Armar via the antenna as endowing the robot with "“cultural genitals"' (ibid.). The practitioner draws on the antenna as symbolic of the male phallus.

As Butler argues, the "morphological imaginary" (Butler 1993, 57) of human gender identity relates gender and sex by defining gender as sex. Following on from this, such a concept of gender is linked to a gender binary, which also carries an understanding of "sexual difference [that] is often invoked as an issue of material differences" (ibid., 1). As Butler continues, "the category of 'sex' is [...] a 'regulatory ideal"' and thus "part of a regulatory practice that produces the bodies it governs, that is, whose regulatory force is made clear as a kind of productive power, the power to produce - demarcate, circulate, differentiate - the bodies it controls" (ibid.). Butler's discursive-deconstructivist and performative approach toward the regulation of gender is of central importance for grappling with the understanding of gender that grounds the anthropomatic co-production of reality at the human-robot interface. This involves querying the ways in which gender establishes a morphological imaginary and is an apparatus of bodily production; more precisely, and in line with Butler, an "apparatus", "which appears independent of the practices that it governs" (Butler 2004, 48).

The robot model Armar III seems to be a machine in which the functional aspects of constructing a humanoid are foregrounded and prioritized over the embodiment of sexual difference. At the same time, this artifact seems to be clearly gendered as male. The interviewee's explanations underscore this idea of a simultaneously gendered/ungendered, sexed/unsexed machine. When asked about Armar's appellation as kitchen boy, practitioner KL answers that this appellation "actually isn't too bad" (interview practitioner KL, July 2011, translation: PT). Next, I ask why he thinks that it isn't too bad and he explains that Armar is "in any case male, I would say, as everyone says 'der Armar'" (ibid.). Using the male pronoun, which is in accordance with the gender of the 
word robot in German, he refers to this as the obvious reason for gendering the robot.

In contrast, another practitioner, when asked about why Armar is supposedly a kitchen boy, emphasizes that "I couldn't care less about the look, what is essential is that it fulfills expectations, so that it has the abilities, mechanically, that it should have" (interview practitioner OP, July 2012; translation: PT). This practitioner further ponders about the possibilities of a gendered robot when asked about the gendering of both models Armar III and IV and rejects the possibility that Armar will ever "have a gender" (ibid.) - even though the robot might be "regarded in its inner representation as a bit of a man or woman," in relation to finding out what people like, when "throwing the robot into the market" (ibid.). Thus, he concludes that some people might prefer the design of a "stewardess" (ibid.) once the robot enters the household. While this practitioner refrains from gendering the robot, this also illustrates a form of gender attribution as reality construction. The robot will not have an intrinsic gender, but will become gendered as soon as it begins to operate with its human owners, that is, as soon as it becomes worldly and real as part of everyday human lives. Notably, he also attributes a specific gender to this prospective robot model. The practitioner associates this future robot with the female figure of the serving stewardess as the design that consumers are most likely to prefer.

Apparently, 'significant maleness' in the machine is regarded as something that the robot does not explicitly embody, but that rather becomes tangible, in line with Nancy Hartsock, as a form of "abstract masculinity" (Hartsock 1987, 170). My argument, is that this machine nevertheless embodies significant maleness in the form of self-sameness. Firstly, this is embedded in relations of mirroring the selfsame between practitioner and robot, in which the unmarked male norm is held up as the standard for the design of the humanlike machine, which integrates looks, abilities and behavior. Secondly, I consider the development of Armar to be entrenched in preconceptions about sexual difference as well as in able-bodiedness and the sexual, transnational division of labor. This is articulated in the idea of the high-performance kitchen boy, which could also become a personal stewardess at home.

The body model of the robot cannot be divorced from the idea of the species human, represented as universal man and described as a white male 
European, as I discussed in chapter five. The gendering and racializing of Armar is grounded in biological concepts of sexual and racial differences that are invoked as material differences during the processes of parameterization of the body of the species human. In this chapter, I have demonstrated how segmenting motions and associating them with functional parts of the body is at the heart of enabling the robot model. Bringing these two dimensions of the apparatuses of bodily production together, I understand them as regulated by patterns of differentiation between nature and culture, self and other and subject and object as reifying dominant power differentials. Here, I think again in line with Balsamo, who argues that the body is "belonging to an order of culture rather than of nature, [while] gender remains a naturalized marker of human identity" (Balsamo 1996, 9; see also chapter 6). Along these lines, I contemplate the enablement of the robot with the ability to interact as being equally entrenched in the gender binary and sexual difference as material difference in the modeling of the robot's body.

\subsection{Conclusions: Configuring the Humanoid Kitchen Service Robot}

"Discourses of agency at the interface at once naturalize the desirability of 'service provision', and further obscure the specific sociomaterial infrastructures - including growing numbers of human workers - on which smooth interactions at the interface continue to depend." Lucy Suchman, Human-Machine Reconfigurations, 2007

In this chapter, I have discussed aspects of the architecture of the robot model Armar, which designates the construction of this robot. As already briefly mapped in chapter three, to conceptualize the robot's architecture is fundamental for realizing a certain capacity for action in the robot. In Armar III, the practitioners implemented a hybrid architecture, which operates with two models of replicating behavior in a humanoid manner: firstly the senseplan-act model and secondly the sense-act model. The hybrid approach combines these two models and integrates the planning component into the robot as a central control component. Doing so results in the 'enabled machine' as a powerful figuration of what it means to be human.

Recapitulating the central insights of this chapter, I emphasize that the enabled machine's architecture is based on a design that conceives of embodied action as an epistemological issue. Thus, the capacity to act becomes the cognitive ability to process information. Cognition is deployed in 
the form of information processing as an instrument of embodied and embedded interaction. On the one hand, this instrumental take on cognition installs a model of bodily autonomy and social relations that is entrenched in modern power differentials. On the other hand, it also fuels an understanding of the human that is evolving from a new class of machines; machines that are enabled to perform cognitive behavior through a regulated interplay between internal and external factors.

In this final subsection, I consider the architecture of the robot as a deployment of human-machine relations through which the robot becomes animated as the automation of a human-like appearance and behavior. The processes of architecturizing interaction comprise one central dimension of the apparatuses of bodily co-production in anthropomatics through which individual bodies with specific properties emerge. The idea of interaction is built on two premises: firstly on the assumption that there exist preestablished entities with identifiable properties and secondly on a naturalization of what Suchman frames as service provision. In this chapter, I have suggested several ways to scrutinize these premises by highlighting the co-produced nature of such animation and automation at the human-robot interface. This included mapping the apparatuses of bodily production along the interdependencies between bodies, labor and care, which become visible only under certain conditions, for example in the interviews that I conducted, or in the demonstrations of Armar in its kitchen.

Armar is made domestic as an 'enabled machine', which has multiple abilities at its disposal. This embodiment of capacities for (inter-)action is regarded as making the robot fit into human everyday life. New robotics, for example, assigns this robot to become useful in areas such as elder-care and child-care. Problems in both areas are framed as shortcomings of society for which humanoid robots will provide a solution. Notably, the areas listed compose a specific employment sector that is associated with a feminization and ethnicization of the marketplace. Both result from the sociomaterial infrastructures of the sexual, transnational division of labor and are characterized by poor working conditions. In this regard, I wonder about the connection that is being made here between certain unnamed politics of the delegation of labor and valuing of market work and the high-tech project of building increasingly more human-like robots. This perspective points to a 
class of new robots that become worldly in the sense of becoming not only a personal asset for their prospective owners, but also an asset for Western societies as these robots will re-organize the delegation of labor.

This means two further things: firstly, I argue that negotiating the possible benefits and societal changes cannot be separated from the existing practices of delegating and valuing labor and responsibilities. These include, for example, the outsourcing of labor from Western societies and binding collective labor agreements to areas in which the latter have not been substantially established, so that the profits of companies that mass-produce computer technologies, or other products requiring human labor, can be maximized..$^{68}$ Secondly, I argue that I have shown throughout this thesis that, even though the envisioned enablement of the robot is targeted at making it fit the human, in its specificities of embodying human-likeness, the robot challenges its affiliated humans to constantly learn to experience the machine as other and in this sense to adjust to the robot in order to make the robothuman interface efficient. For example, imbuing the robot with the figure of the child is one way in which such adjustments take shape. I further understand this as constitutive of interdependencies between bodies and a politics of valuing labor that carries a reversal of roles in the provision of service between robot and human. In this regard, the question of 'Who is making whom?' becomes one of 'Who is serving whom?'. With this, I contrast the idea of enabling the robot to serve as central part of the anthropomatic service economy with the practices of such enablement that seem to rather point toward the irony of modern automation technologies in the household, as discussed in chapter two.

Subsequently, I would like to ask in the conclusions of this chapter: "In what sociomaterial arrangements are we differentially implicated, and with what political and economic consequences?" (Suchman 2007, 245). This appears to be one central question vital to bear in mind in regard to analyzing the forms of robotic companionship that emerge from the making of anthropomatic kitchen robots. In addition, I consider tied to this question to

\footnotetext{
${ }^{68}$ The contrast between valuing labor invested in the mass production that is oriented toward the logic of capitalist exploitation and the labor invested in building parts for Armar became apparent in different situations. For example, I was informed that one of Armar III's joints alone costs about 1000 Euros, and the robot has approximately 72 of these (field notes, July 2011).
} 
develop an understanding of, in line with Suchman, "effective encounters at the computer interface [...] [as] those moments of moving complicity between persons and things achieved through particular, dynamic materialities and extended socialities" (ibid.). Thus, I argue that the insights on anthropomatic body modeling as presented in this chapter are useful for tracing key dimensions of the dynamic materialities and extended socialities as they are arranged in anthropomatic companionship.

Tracing the ways in which the enablement of the robot is conceptualized and realized in this specific robot model, I underscore that these practices reveal the deployment of a form of instrumental cognition through which tasks in the kitchen are acknowledged as complex and challenging. However, as I have argued, this acknowledgment refers not to a task itself, for example laying the table, but rather to the process of generating knowledge about this task and implementing this in the robot. This encompasses the disciplining of vision, as it supposedly equips the robot's visual apparatus to observe and to react. Here, I contemplate kitchen robotics, especially practices of enabling the robot, as supporting a valuing of scientific expertise and rationality over a devaluing of reproductive labor.

Zooming even further into local specificities regarding the dynamic materialities and extended socialities of anthropomatic robot modeling, I underscore that the term semantic within computer science and informatics is central for grappling with the relation between world, body and mind deployed by anthropomatics. Furthermore, this relation is foundational for understanding the kind of meeting at the robot-human interface as fostered by the anthropomatic enablement of the machine and how this is made an effective encounter. The formal analysis of the execution of 'human movements' at the center of synthesizing motions is based on the visual technology - the motion-capture system - which requires a mapping of bodies as they move through pre-determined segments of motion. I contemplate this procedure of synthesizing motion through semantic segmentation in terms of conceiving action as a formal system of categorization that is based on embodied motility. The architecturizing of interactivity captures the ways in which bodies move while the motion performed is regarded as a sequence with attendant semantics. I understand semantic segmentation in terms of apparatuses that govern the practices of 
bodily co-production. They produce models of what the human-like should look like and how 'we' should relate to it. Synthesizing motion, for example, imagines the robot-human interface as based on recognizing motion primitives and thereby enhancing the intelligibility of the machine as human and the legibility of the human for the machine in a reciprocal logic.

Thus, I consider the design of such a robot system, which incorporates the combined, multi-level approach to human behavior laid out by Gehrig et al., as organizing bodies, labors, and knowledge in space. As Sabine Hark and Mike Laufenberg remind us, the gendered organization of labor is supported through compulsory heterosexuality which is, in short, the institutionalization of heterosexuality as the structuring basis of everyday life, constitutive of the "heterosexual contract" (Hark and Laufenberg 2013, 231, translation: PT). They regard this, in agreement with Monique Wittig, as the basic social contract (ibid.). As Hark and Laufenberg further argue:

the category of analysis of compulsory heterosexuality means to attune to the mechanisms of reproduction, interrelations and institutional compulsions, which ensure that heterosexuality appears as timeless, unalterable, and at the same time as epitome of history and as beyond history. (ibid.)

I draw on the heterosexual contract as an analytical unit in accordance with Hark and Laufenberg's trajectory to grapple with the forms of de/gendering that become tangible in the sections above as a rich resource for tracing the dynamic materialities and extended socialities at work in anthropomatic modeling of bodies, environments and interactive relations between humans and machines in the domectic kitchen. My argument here is that it is vital to take into account the ways in which the heterosexual contract is constitutive of interdependencies between bodies, labor and care in the kitchen and to relate the anthropomatic kitchen to these interdependencies.

My query about the kitchen boy is the pivotal point for what I identify as simultaneity between a de/gendering of the humanoid body as it is intertwined with the kitchen setting. The current generation of anthropoid robot can be read as a kitchen boy, while the next generation is considered to be a female robot. This production of binary gendered bodies speaks to Robertson's finding that "[h]ow robot-makers gender their humanoids is a tangible manifestation of their tacit understanding of femininity in relation to masculinity, and vice versa" (Robertson 2010, 4). If the next robot is thought 
to be female in contrast to the current model, then this current model has to be male. This binary logic is then complemented by the idea of kinship as always heterosexual, which deploys the heterosexual, nuclear family as the core of the household, the home of the domestic kitchen. Butler queries the ways in which "kinship is always already heterosexual" (Butler 2002, 14). She further suggest re-thinking to re-frame kinship in the following terms: "kinship practices will be those that emerge to address fundamental forms of human dependency, which may include birth, child-rearing, relations of emotional dependency and support, generational ties, illness, dying, and death" (Butler 2002, 15). Her suggestion to re-frame kinship beyond its entrenchment in compulsory heterosexuality speaks well to a queering of what became apparent as the heteronormative framework of robotic companionship in its affirmative reworking of kinship. 


\section{Conclusions: Robot Companions - Machines to Become with?}

"Theory has only observed the world; the point is to touch it."

Maria Puig de la Bellacasa, Touching Technologies, Touching Visions..., 2009

In this thesis, I have analyzed the making of a specific robot model, Armar, as it is being developed at the KIT. I opened the thesis by pointing out that a new class of robot models is emerging from contemporary robotics. This class is characterized as robot companions for citizens that will serve 'us humans', keep us company and look like 'us'. In short, this class of robot models furnishes the contemporary socio-technical imaginary of robots being made domestic as machines that live and work with humans.

Thus, as one pivotal point, this thesis explored human-machine relations of human-likeness. As I have emphasized throughout, the human and the humanoid robot are configured through a peculiar vision of anthropomorphism. This specific form of anthropomorphism crystallizes in anthropomatics as the goal to build machines that are proximate and useful to humans, whereas these two qualities condition each other: only a machine that is proximate to humans, in the sense of its being both built to look like the human and built to operate next to the human, will be useful to humans. Anthropomorphism, in this regard, figures as specific sets of relations of sameness and difference between human and machine in contemporary robotics in general, and in anthropomatics in particular. In the case of anthropomatic robots, the ideal is a relationship of intimate companionship and shared features (for recognition) but distinct otherness. Therefore, I have mapped the details of realizing a robot model by implementing humanlikeness in the machine and I have asked how this shapes what it means to be human.

In regard to the latter, I can make statements in relation to the confined frame of my study only, as the robot is still operating in the restricted space of the robotics kitchen laboratory and not stepping into households, yet. However, from what I have observed, this co-production takes shape in the kitchen laboratory on multiple levels and, thus, it is precisely this making of anthropomatic kitchen robots that delivers insights into relations of a coproduction within this specific configuration of human and machine. The anthropoid robot-human interface is constitutive of a common ontology 
between human and anthropoid robot that is constantly being negotiated. These negotiations entail material-semiotic practices of enacting humanmachine configurations that draw centrally on the tropes of mimicry and symbiosis. I will recapitulate these tropes of configuration and co-production in what follows.

Furthermore, claiming the category of the human-like for the prospective robot companion has the effect that this robot is imagined and becomes worldly as being in its appearance and abilities similar, or rather proximate to, the universal human. At the same time, when robots are built that are 'like us humans' then this model of the human-like centrally shapes what it means to be human. As I will elaborate upon in the following conclusions, such epistemological sorting operations into categories of social ordering also mobilize the very sociomaterial grounds of (human) subjectivity, agency and sociality. I thus regard the anthropoid robot as it is imagined and realized in the kitchen not only as a "model (in)organism" (Suchman 2011, 119) that functions as a platform for generating knowledge about the human, but also as an agent of a re-division of responsibilities within the domestic sphere in its normative framework of the heterosexual contract and the gendered and transnational division of labor. This latter dimension of a co-production thus highlights the dynamic materialities and extended socialities, encompassing the societal organization of care work and reproductive services in the domestic sphere - both traditionally assigned to the other by the unmarked, universal human, that is, to women and non-Western men.

To do my fieldwork, I was invited in a very welcoming and open manner to participate in the day-to-day work on and with the robot model Armar as it was carried out in the centralized laboratory of the Institute of Anthropomatics and Robotics (IAR): the kitchen laboratory. This invitation meant that I was able to become a witness who observes the making of a cutting-edge technology from the position of a social researcher. Precisely such temporality of social research on a new class of technology while this technology is still in the making also illustrates a key dimension of my study. Firstly, it enabled me to map practices of engineering one model of the robot companion, especially in its context of bringing this machine into use; namely the robotic kitchen laboratory that is used for demonstrations of this prospective helper and companion in the domestic kitchen. Secondly, the 
endeavor of mapping how artifacts and facts are produced in the robotic kitchen laboratory also opens up a valuable opportunity to create contact zones between robotics and queer and feminist technoscience studies and posthumanities, and thus to generate leverage points for a shared vision of robotic companionship. In what follows, I will recapitulate the central insights of this study into how the robot becomes worldly, including the array of actions and actors that are involved in this, as well as into points of departure for developing a shared vision.

To begin with, I underscore that my research praxis cannot be separated from the theoretical insights that I gained from reading strands of feminist and queer technoscience studies and posthumanities in their turn to the material - or their ontological turn. Throughout my study of robotic companionship, I have developed four narrative strands as starting points for different contact zones between one example of contemporary robotics and feminist and queer technoscience studies and posthumanities. These narrative strands begin by putting what is new about this class of emerging technology into its historical context. The development of a historical framework for the robot companion played an important role in my thesis writing. I drew on a selection of machines to illustrate how these have shaped the thought models that are presently available for imagining what machines should look like and what we should be able to do with them. Through this exploration of a wide range of examples, I identify two different genealogical lines with the technological limits of human-machine relations: building the domestic machine and the intelligent machine.

For instance, the microwave is an appliance (with a military historical past) that, having entered into the domestic sphere, also enters into existing practices of distributing responsibilities in the household. These interfere with the seemingly clear logic of increasing efficiency through automation technologies. Thus, I highlighted the entanglements between the negotiations of what tasks should be taken over by automata, the daily organization of housework at home, the modern societal organization of gender and class, pairing into heteronormative couples and the gendered and, equally importantly, transnational division of labor as illustrated by the example of the microwave. Understanding these entanglements turned out to be vital for my analysis of the robot Armar, which is intended to operate in a domestic 
kitchen, and allows me to contemplate the socio-technical dimensions of what I frame as making this robot a domestic companion.

In order to trace the genealogical lines of the intelligent machine, I explore the Turing machine and symbolic AI with an emphasis here is on how intelligent behavior in the machine is conceptualized, tested and realized. I was fascinated by the belief that intelligence is somehow a replicable mechanism, and how the process of replicating what has previously been thought of as a solely human property is realized, especially for instance in relation to the question of what role the body plays in cognition - or if it plays a role at all. In short, cybernetics is seen to have encouraged the breakdown of old scientific certainties through its conflation of the human and the machine, while symbolic AI is thought of as dis-embodying cognition and new robotics fosters the re-embodiment and physical embedding of cognition - again.

It became apparent that the anthropoid robot is situated within new robotics. Thus, I have traced the historical line that is used to tell narrations of a linear progress in technological development. However, as I have shown, the idea of linear progress is only one possible narration and also one that erases complexity. In addition, the ways in which what is thought of as socially meaningful behavior is modeled and implemented in Armar do not support such a narration of linear progress. Here I am thinking of what I have called the primacy of cognition. With this term, I designated a set of concepts and practices in $\mathrm{AI}$ and robotics that, in short, reduces the project of engineering the human-like machine to an epistemological issue, as they are thought of as primarily representative of symbolic AI. This entails conceiving of the body vis-à-vis the operations of the mind. As my analyses have shown, I identified a continuation of the primacy of cognition, for instance, with the material-semiotic practices of architecturizing interaction in the robot. Such architecturizing divides socially meaningful behavior into sequences of motion with attendant semantics that can then be implemented into the robot through its hybrid architecture. The hybrid cognitive structure of the robot conceptualizes the 'enabled robot' through the interplay of components of robotic control, which ties in with the abiding idea of human agency and (bodily) autonomy.

To recapitulate the importance of the historical framework for my thesis, I underscore an understanding of the social, the technical, the human and the 
machine as contingent. Thus, the historical framework in its genealogical dimensions opens up a perspective through which the boundaries of these categories - and, accordingly, what part of the world can be sorted into which category - are the result of technoscientific production, rather than the foundation of technoscientific research and innovation. Thus, my thesis provides vital insights into the processes of imagining and realizing robotic companionship in their sorting operations and therefore also in their normative framework.

Next, I presented my entry to the field, which necessarily includes a description of the process of finding my role. I described this as being a tourist in robotics who opts to become a queering witness to the socio-technical entanglements in the robotics kitchen laboratory. Along these lines, I developed an ethico-onto-epistemological approach to the making of anthropomatic kitchen robots; that is, an account of the intertwining of being, knowing and ethics that moves beyond a humanist framework of analysis in social research. In addition, I consider this prism of analysis as a way of becoming sensitized to the material-semiotic lines of force that are constitutive of and constituted by the selected strand of contemporary robotics. Initial insights into how this specific model of robot companion is made public reveal what I frame as the un-caging of this robot; a process that crafts a machine that supposedly mimics the human and enters into a symbiotic relationship with humans. This indicates the core of technoscientific sociotechnical production; namely, the building of machines that can take over from humans, or even supersede them. Furthermore, the robot Armar is a machine that is designed to operate in a shared work environment with the human; more precisely, this environment is depicted as the domestic kitchen.

As I have highlighted throughout, the design of this model of a helper and robot companion, including processes of envisioning and realizing, is negotiated in relation to the universalized human self. Armar, as I came to understand, is conceived of as a robot model that is proximate and beneficial to humans. This proximity combines a human-like appearance with humanlike abilities in the machine. Furthermore, I connected this combination with tropic figurations of the human-like in relation to the human. These encompass anthropomatic strategies of mimicry and symbiosis: both terms are intended to illustrate the machine's human-likeness and its possibilities 
for companionship. The robot is considered to embody human-likeness by firstly mimicking the human, that is, mirroring the human self as an embodied self, and secondly by enabling a symbiotic partnership, a relationship of benefit through automation technologies. Thus, I highlight that the agency embodied by the robot becomes apparent as a property of the distinctively human species and therefore an indicator of humanness in the robot.

The investigation continues by mapping agency in the laboratory. From a perspective of laboratory studies in conversation with queer and feminist technoscience studies and posthumanities, I develop an account of the making of the machine that takes into consideration the array of human and nonhuman actors and actions that are enrolled in this making. However, and as outlined above, agency carries a special meaning in the robotics laboratory because it serves as an indicator of humanness in the machine. Thus, one important insight is that it is not possible to just translate the idea of material agency, taking into account how the material acts and signifies itself within the context of the robotics laboratory. Rather, I identify some dangers and pitfalls around, for example, granting the robot agency. The robot that is modeled on the human challenges the idea of analyzing material agency and actors in the lab when agency constantly serves the processes of association, translation and re-demarcation between the machine other and the human self. Here I am thinking of the practices through which the robot is made legible as 'almost human'.

These practices are thus at the focus of chapter four, in which I analyze the double-drama of demonstrations, asking how interactions at the interface between visitors, robot and practitioners are enacted during demonstrations of Armar and how these negotiate and establish the normal categories of the anthropoid and the human. I map the conditions and practices through which agency emerges; in fact, agency that is held to be a property of both of the entities, the human and the human-like robot, that meet at the human-robot interface. Thus, it became very important for my dissertation to develop a robust account of agency by reading feminist materialisms and posthumanities through anthropomatic robotics and engineering practices of the human-like robot. Therefore, my focus is on the drawing of boundaries that results from this specific vision of capacities for action in the machine, 
specifically at the human-machine interface, and I developed an account of these enactments of capacities for action in the robotics kitchen laboratory through the reciprocities of human and non-human making. In this way, I traced the apparatuses of co-production and the plethora of circumstances of interaction at the human-like robot/practitioner/visitor interface and how they re-work seemingly fixed subject and object relations. These re-workings of subject and object relations figure in the robot in its role as, at the same time, a model of human-like liveliness in a machine and an instrument for the execution of human-like interaction. I theorized this in terms of hybridbodies-in-intra-action. Moreover, I suggest capturing human-anthropoid relations in the lab through the notion of performing the kitchen.

In this way, I develop an understanding of demonstrations as the performative enactment of the categories of human and human-like as both being identity categories to which specific bodies with boundaries and properties are assigned. Essential to this enactment is the process of making Armar legible as almost human; for example, when the robot is introduced to an audience. This introduction entails explaining the robot's construction, for example, its shoulder. In my thesis, I used this example to explore the ways in which human and machine function - in this explanation - as a point of reference for each other. This point of reference functions to determine sameness and difference between human and machine: the robot's shoulder is described as human-like through a process of touching the human shoulder. The human shoulder that is the robotic shoulder that is the human-like shoulder.

I contemplate this in terms of a feedback-looped enactment of the humanlike that mirrors the human and vice versa. Furthermore, I analyzed this performative enactment through the lens of posthumanist performativity as an appreciation of the co-producing entanglements of becoming human and machine. Thus, I conceive of the partners that meet in the lab as phenomena in iterative intra-activity. In this sense, the shoulder maps or indexes the bodies that meet, while such indexing makes tangible a common ontology between robot and human. Again, the bodies that meet are experienced by the practitioners and visitors through indexing the mechanical structure and shared motility that such a structure implements. The human shoulder is the robotic shoulder that embodies a human-like kinematic and motility that is 
regulated by the mechanical structure of the design of the robot's shoulder that is modeled on the mechanical structure of the human shoulder.

Thus, I traced the relations of co-production during demonstrations. The visitors learn to see and experience the human-like robot companion; they are trained by the practitioners to attain a sense of this machine and its body and what it is able to do with it, and also what it should be able to do. This learning to see and experience the robot encompasses practices, objects and spatial arrangements. At the same time, however, I argued that this is not only the case with the visitors, people who are new to this machine, but that, similarly, the practitioners, who are familiar with the robot, also have to newly attain - at least dimensions of - this sense of the machine in every demonstration.

By describing these demonstrations as performing the kitchen, I captured agency as being tied to its circumstances and conditions as well as in its materializing and boundary-drawing effects. On the other hand, agency in the lab also became a point of departure for a queering of the sorting operations between human and human-like, and between valued and neglected labors in their normative framework that establishes normal categories of social ordering such as sex and gender, race and able-bodiedness with the category of the human and of the human-like. This means that we need to regard agency as also being an indicator of the subversion of normal categories, a subversion that operates at the level of material-semiotic forces and that challenges the idea of pre-established entities with individual properties and moves instead toward relations of reciprocity.

I further explored Armar as the model (in)organism for what it means to be human(-like) in the next two chapters. Therefore, I delved firstly into the practices of designing the robot's body and secondly into the practices of enabling the robot to interact. As I have highlighted, these practices propel transformations in the triangle of nature-culture-gender. They primarily articulate through the rhetorics of having to bridge a gap between the human and the anthropoid robot. As Suchman reminds us, these rhetorics envision the human-like machine as "to be made like us - in order that we can be reunited with [...] [it]. It is the presumed separation between humans and artifacts, in other words, that animates the project of humanlike machines" (Suchman 2007, 213). I suggested that these rhetorics of separation and 
reunion can be regarded as being based on a mobilization of the boundary between nature and culture, while, as I argued further, movements at these boundaries describe reverse feedback loops between human and machine. These reverse feedback loops establish either the human or the machine as a pre-figured entity with (agential) properties as a point of reference for the other, and vice versa.

Knowledge about the human is essential for building the anthropoid robot as a human-like machine, and to then evaluate this human-likeness of the robot to generate further knowledge about the human. Such circular logics operate with the objectification and naturalization of knowledge in which the real and nature are conjoined. As discussed in the last two chapters of this thesis, these objectifications and naturalizations of what it means to be human-like, and in consequence also what it means to be human, require an apparatus of gender production.

In this regard, I carved out the ways in which the anthropoid robot model appears on the one hand to be gender neutral, as it embodies universalized principles of the species human, and on the other hand it becomes palpable that this embodied humanness mirrors 'the unmarked self'. Moreover, the robot Armar, embodying the seemingly neutral universal human, is idealized in a description from the public relations department as 'the kitchen boy'. I used this appellation to further query the apparatuses of gender, and one of my main insights re-affirms that to construct reality means to attribute gender. However, the gender attribution of the human-like machine, which I contemplate as operating through the material-semiotic enactment of a common ontology, operates on two levels. Firstly, the level that comprises practices of enacting the universal human as the gold standard of what it means to be human. This human is, in short, a historical formation that was established along with modern science and is quietly inhabited by the position of the rational white male subject of knowledge, whose subjectivity is his objectivity. The second level is that of the materialization of cultural markers on bodies; markers that sort into categories of sex and gender - in their interdependencies with other categories of differentiation, such as race and able-bodiedness. Beyond this, I also elaborated upon the way in which designing and imagining a robot to become useful as a human-like machine is entrenched in imaginings of the domestic sphere - in the form of the modern 
household with the domestic kitchen at its core - that are associated with the heterosexual nuclear family as the ideal of human kinship as it is established in the Global North.

I highlighted the circular logics that emerge when arguing that a kitchen is designed for humans and therefore the robot supposedly operating in the kitchen has to be designed like the human. This thinking is deterministic, insofar as what currently is (the domestic kitchen as 'we' are familiar with it) is held up as the explanatory resource for how things have to be. In this way, common-sense knowledge about the kitchen as a human environment is objectified and naturalized, as the domestic kitchen is extracted, firstly, from its historicity and, secondly, from existing practices in the household. Thus, I developed a thicker account of this environment that takes into account its history and existing practices, as well as the societal organization of labor implied in the model of the domestic kitchen. This means opening up possibilities of contingency for this space and the attending modes of organizing the flourishing of our lives.

The forms of companionship with which this robot model is charged are built on proximity between the anthropoid and the distinctive species of universalized humanness, as well as forms of usefulness that require the latter. These possibilities and impossibilities of mattering of the human-like also became tangible in interviews and conversations with robotics practitioners and in reading articles about this robot model in robotics journals. Discourses in this regard are accounted for as apparatuses of bodily co-production. I have shown that Armar's body is modeled in its structure on the human and that this design is argued for as making Armar more natural to humans. This process additionally encompasses what is called the enablement of the machine; that is, equipping the robot with skills.

Furthermore, the making of Armar is intertwined with an affective stance toward the machine. Affects that I witnessed include the capacities to wonder, to laugh and to be surprised. These affects are fundamental in the realm of experiencing technology and drawing the limits of the contemporary sociotechnical imaginary. Along these lines, I query how we might add relationalities to the existing regime of intelligibility without having to determine what the possibilities for an alternative imaginary might look like. I regard this as becoming response-able for co-constitutions of mattering. 
Affects in the laboratory primarily illustrated the experience of a gap between what Armar can do and what the practitioners and visitors as the affiliated humans can do. The laughter evoked when Armar fails to execute a command or when one of the practitioners wonders about what will happen if he attempts to engage in small-talk with the robot illustrates the limits of the socio-technical imaginary, although within different ranges. The laughter underlines the constraints of successful interaction at the robot-human interface, which are integrated into the peculiar vision of anthropomorphism. The robot is either described as a child, thus evoking a prominent figuration of developmental potential, or assigned characteristic traits, such as stubbornness. Both forms of identifying humanness in the machine and its behavior, however, deploy norms of the distinctive species human and the complementing distinctively human life. The relations enacted through this deployment are relations of human-machine separation and re-union, in which the machine mirrors the self-same.

The second example of affects (wondering) that I draw on here, however, also involves practices of making the robot a matter of concern, more precisely the proper capacities for communication with it. As discussed in chapter four, these concerns articulate on the one hand as dissatisfaction with what has been realized in the robot model so far. On the other hand, I suggest that we consider the possibility that they also articulate a potential to transcend the limits of the socio-technical imaginary of the domestic robot, as I have sketched it so far. As detailed in chapter four, the practitioner raises this concern and then invites one of the visitors to take over the headset; this means taking over the communication with Armar. The visitor, even though constantly asked to just say something and see what happens, tries to communicate successfully with the robot in a manner similar to that used by the practitioners. The conditions and circumstances of successful communication, in accordance with my analysis, can be seen as interdependencies between bodies and labors at the robot-practitioner interface as they become palpable at the robot-visitor interface. Beyond this, the visitor in this human-machine assemblage is expected to engage in communication that is different from what has been presented before. He is constantly prompted to realize the thought of just starting small-talk and seeing what will happen. Thus, I regard this situation as one in which an 
affective stance toward the robot in its seemingly pre-established capacities is enacted, which nevertheless expands the idea of pre-figured abilities and imaginings of human control and mastery over the machine. The practitioner expresses a curiosity about what a machine can do that I connect with thinking intelligent machines beyond a strict determinism between input and output as discussed in chapter two.

Furthermore, a key trope of the socio-technological imaginary implemented by anthropomatics is mimicry. In accordance with Suchman, this trope has "historical prevalence" (Suchman 2011, 121) in the design of humanoid machines. It constitutes "a form of relation that privileges vision, and looks to find in the Other a differently embodied reproduction of the Self" (ibid.). During demonstrations, such a privileging of vision and looks is also accomplished by a set of touching gestures that enact the vision of the other as a differently embodied reproduction of the self. Thus, I grapple with the laboratory practices of performing the kitchen as material-semiotic practices of figuration that, in line with Haraway, are characterized by an inescapable tropic quality. Mimesis propels relations of separation from and re-union with the self that installs the normative framework of modern power differentials. However, such tropic qualities are, as Haraway puts it, "representational and mimetic" (Haraway 1997, 11), but never "self-identical" (ibid.). Therefore, I consider the figuration of robot companionship in the kitchen as the enactment of 'significant sameness', but also an excess of matter-meaning that points toward the ways in which materialities signify and act.

Haraway underscores that such tropic qualities in figuring, for example, human-machine relations "involve at least some kind of displacement that can trouble identifications and certainties" (Haraway 1997, 11). Furthermore, especially during interviews, the co-producing character of anthropomatic apparatuses of robot modeling became apparent: the bodies in the room again served as a point of reference for feedback loops. Here I am thinking, for instance, of a specific feature like the human hand and the robotic grappler as I have described it in my thesis in detail - and in doing so, these feedback loops established a common ontology. Or rather, I should say, were supposed to. I regard interview situations as especially meaningful in meeting 
anthropomatics halfway and developing the ability to respond because the discursive feedback loops during the interviews involved my body.

Making the robot companion a matter of care in my study, I appreciate my body as a generative node that is part of the co-production. More precisely, and staying with the example: my hands became apparent as a generative node when they queered the feedback-looped referencing and thus also the common ontology: they refused to be assigned a mark of binary sexual difference. The certainty about the clearly sexed size of human hands is troubled when I point out to the practitioner (during the interview) that his hands and mine, hands as female* sexed hands, are the same size. In this situation, practices designed to attain a sense of the robot's body fail, as the appearances of the self (myself attributed with female-sexed hands) and the 'quasi-other' (the envisioned female robot model) become tangible as incongruent. The displacement in gender and sex attribution between human hands and robot hands illustrates the ways in which contiguity as well as similarity between self and other craft the figure of the self-same (in the other) as a form not of replicating the self, but rather, as I would like to argue, of reinventing the species human self. The queering engagement with uncertainties and disidentifications that I propose in this thesis could become the leverage point for a troubling of the relation between copy and original toward, in line with Butler, the idea of copies without originals. This idea points to an unfixing of origins which is at the heart of my queer and feminist performative stance, and that prompts me to take into account the processual production of the self-same in its material-semiotic conditions, as well as the practices of this production.

As Haraway emphasizes: "I am not so much against mimesis in storytelling as I am convinced that the play of mimicry has got to be a lot less reassuring for the already powerful" (Haraway 1997, 112). After resuming and discussing the central insights of this thesis, I conclude that performing the kitchen is comprised of material-semiotic practices of enacting categories of kind (the distinctive species human) and kin (the distinctively human modes of being and knowing) that mimic the already powerful. In chapter six, for example, I connect Butler's query as to whether kinship always has to be heterosexual with the idea of making domestic robots coupled into binarysexed pairs with babies. In short, Butler deconstructs the institution of the 
nuclear family by valuing the existing practices of kinship beyond this institutionalized mode of relating and caring.

Companionship in the robotics laboratory as it is enacted in the kitchen operates with a vision of the autonomous human-like machine that can be regarded as the fulfillment of long-standing postulations of modern automation technologies. However, I argue that demonstrations in their acts of performing the kitchen also suggest a quite different picture of companionship; one that speaks more to feminist considerations of what this word means. One cannot touch without being touched. I have shown in my thesis the provisional character of making the robot efficient in front of an audience. I would like to conclude by underscoring that, throughout my thesis, I have mapped the ways in which the robotic replication of the human self is already much more of a "'becoming with' as a practice of becoming worldly" (Haraway 2008, 3). By taking into account such posthumanist concerns with making the robot-human interface a success, I acknowledged the ways in which a becoming-with the robot companion might also allow one to become differently in relations of human-robotic companionship.

\section{Epilogue}

So far, I have unfolded the entanglements of norms and concerns in reciprocities of human and non-human making in the kitchen laboratory. In what follows, I briefly sketch aspects of an account of making robots domestic that problematizes this making in terms of the creation of artificial life as it articulates technoscientific stories of salvation. I contemplate this in terms of re-configuring narrations of beginnings and endings and how to think these through the touch of the two hands as a figuration of relationships of care and concern between humans and robots. Thus, this sketch both draws on the insights of this thesis and goes beyond the scope of what I have presented so far.

As described in chapter five, the touching hands that are displayed on the computer when the robotics practitioners log on form one of the iconic, metonymic figures of the technoscientific inventory of crafting stories and bodies. More precisely, I suggested a reading of the $/--\backslash$, two hands that are almost touching, as a re-staging of Michelangelo's painting The Creation of Adam (Michelangelo 1508-1512) that decorates the ceiling of the Sistine 
Chapel in Rome, as a powerful vision of the creation of life. This visual narration is of special meaning for AI as the abiding tradition of research under the rubric of understanding and "synthesiz[ing] life out of material parts" (Riskin 2007, 2). In this epilogue, I want to develop leverage points for a re-configuring engagement with this picture. I further contemplate this as getting in touch with the technoscientific practices as they enact the act of creation; here in the sense of re-creating the socio-material grounds of a distinctively human subjectivity, agency and sociality.

The scheme /-- $\backslash$ signifies the beginning of an age in which universal man becomes the author of robots that come to life. More precisely, and in terms of anthropomatic research endeavors, it signifies the creation of robots that are proximate and useful to humans. They are envisioned as a prosthesis for humans on different levels, ranging from the domestic machine that serves us to the robot suit we will one day wear. In such a vision, this kind of technoscientific storytelling is not only replacing God with man, but is also promising salvation from, and therefore also the end of, the troubles of (domestic) work and the constraints of a peculiar vision of bodily integrity. In this regard the /-- $\backslash$ reifies both bodies as separate entities with specific properties in a fixed relation of creator and creation. Universal man is the author of artificial life, while the robot embodies artificial life that figures human-like liveliness. Notably, the robot Armar also resembles the gendering of the creature, as Adam embodies significant maleness.

Furthermore, as Riskin points out, "the representation of life" (Riskin 2007, 1) in this iconic picture is "the gap" that exists "between the two fingers" (ibid.). The gap between the human maker and the human-like machine is a motif that I found several times as a rhetorical figure in defining the aim of anthropomatics. Anthropomatics is the science of bridging that gap. By following Armar in the making, my queer and feminist intervention into technoscientific storytelling assesses this gap; more precisely, I insist on an understanding of bridging this gap as an ethico-onto-epistemological issue of care and concern with stories of beginnings and endings. Bridging the gap is about the material engagement of getting in touch, drawing on an understanding of touching, in line with Barad, as coming to matter in response-ability for, with, and as the other: "Each of 'us' is constituted as responsible for the other, as the other" (Barad 2012a, 215, emphasis in original). In 
this sense, my vision of the touch between two hands figures the deconstruction, or rather diffraction, of fixed origins and stipulates an ongoing engagement with human-machine relations of becoming with as a becoming worldly in relations of co-production.

In what follows, I briefly spotlight a leverage point for diffracting the picture of genesis at the robot-human interface. My argument here is that the beginning of an age of ubiquitous robots is also the beginning for stories of an ending, namely the story of salvation from 'human burdens': Aud Sissel Hoel and Iris van der Tuin's account of "technicity" (Hoel and Van der Tuin 2012). As I regard this as a playful, initial engagement with further possibilities for research, I refrain from trying to do justice to this strand of contemporary materialist feminist thought.

Hoel and Van der Tuin discuss Ernst Cassirer and Gilbert Simondon's work $^{69}$ in short, on grappling with technology as shaping our realm of experience and modes of existence (Hoel and Van der Tuin 2012, 1). Furthermore, they suggest a diffractive reading "of these thinkers for present-day theorizing" (ibid.). Mapping the work of these two philosophers, Hoel and Van der Tuin explain how it implements "a new ontological status" (Hoel and Van der Tuin 2012, 4) for technology, which they capture with the term "technicity" (ibid.). They explain this as "technology tak[ing] on ontological import in and through the forces that it exercises on other beings as well as [...] [that which] it brings into being" (Hoel and van der Tuin 2012, 45). Along these lines, I consider the notion of technicity, as Hoel and Van der Tuin work with it, to be a useful term for queer and feminist refigurings of the /-- $\backslash$. In short, the idea of ontological forces diffracts understandings of who is making whom. Further, the authors highlight that Simondon associates "'genesis"” with technology, which underscores the emergence ontology of his thinking as it makes technology "a "unit of becoming'" (Hoel and Van der Tuin 2012, 5). In a similar way, Simondon develops an account of genesis that goes beyond the distinctively human and animal genesis (ibid.). This thinking

\footnotetext{
${ }^{69}$ These are philosophers of technology from the first half and middle of the 20th century, respectively.

${ }^{70}$ Notably, although drawn from the work of Haraway and Barad, Hoel and Van der Tuin propose a take on diffraction that is also deployed in the article at hand. They explain that they use diffraction "as an experimental strategy of reading that aims to produce an open cartography of theoretical work" (Hoel and Van der Tuin 2012, 3). This speaks very well to the map of the socio-technical imaginary of contemporary robotics that I have produced in this thesis.
} 
could thus also become useful for a queer feminist refiguration of the /-- $\backslash$ that functions as an allegory of installing universal man as the force behind genesis in the age of robots.

Throughout this $\mathrm{PhD}$ project I have been developing an approach to queer and feminist technoscience studies that I brought together through a common interest in, or rather turn to, ontology. Along these lines, I enacted a meeting halfway through knowing in encounters. Beings touched and were touched and, through this, the actors and actions of a co-production of human and anthropoid robot unfolded. Furthermore, this is also a move beyond stories of beginnings and endings toward diffractive and ongoing re-configuring of a mutual human and nonhuman becoming with in co-production. Thus, I also highlighted the politics of my encounter with this co-production, which arose from the desire for a queering of power differentials that builds the normative framework of the apparatuses of production and thus regulates the ontological forces of technologies.

In this sense, I suggest that we think human-machine relations as reciprocal: We are and we act always in concert with organic and inorganic others. What is at stake is nothing less than acknowledging the interdependencies and vulnerabilities of our bodies and modes of relating. Anthropomatics works with a peculiar vision of norms of recognition, including what it means to be human. These encompass the 'enabled body', capacities for (inter-)action and modes of kinship. Tracing this re-invention of the species human and the sorting operations that establish both the distinctively human and the human-like, I also developed a strong ethicoonto-epistemological critique of the entangled regimes of knowing and being. I showed that such a turn to ontology means engaging in a non-antagonistic and non-deterministic thinking in mapping processes of co-production without determining what these should look like, rather than mapping what is.

Finally, getting in touch meant taking the risk of becoming warped and I am warped. I know of the passion, the anxieties, the efforts and time invested, as well as the pleasures of all the actors in meeting each other's universes halfway. My take on touch as a queer and feminist methodology of technoscience studies depicts a strong account of risking the relations of human and nonhuman becoming in concert. This methodology points beyond 
the scope of this thesis toward the broad field of research that could continue raising questions concerning the relations of a co-production between technology and society, as well as human and machines. 


\section{Bibliography}

Adam, Alison (1998): Artificial Knowing. Gender and the Thinking Machine, Routledge Chapman \& Hall

Alač, Morana (2009): Moving Android. On Social Robots and Body-inInteraction, in: Social Studies of Science, Vol. 39, No. 4, pages 491 $-528$

Alaimo, Stacey (2010): Bodily Natures. Science, Environment, and the Material Self, Indian University Press, Bloomington and Hekman, Susan (eds.) (2008): Material Feminisms, Indiana

University Press, Bloomington

Albers, Albert and Brudniok, Sven and Ottnad, Jens and Sauter, Christian and Sedchaicharn, Korkiat (2006): Armar III - Design of the Upper Body, in: Humanoids 06 - 2006 IEEE-RAS, International Conference on Humanoid Robots, December 4 to 6, 2006 in Genova, Italy

Amelang, Katrin (2012): Laborstudien, in: Beck, Stefan and Niewöhner, Jörg and Sörensen, Estrid (eds.): Science and Technology Studies. Eine sozialanthropologische Einführung, Transcript, Bielefeld

Åsberg, Cecilia (2010): Enter Cyborg. Tracing the Historiography and Ontological Turn of Feminist Technoscience Studies, in: International Journal of Feminist Technoscience, version 1.1. 2010-06-03, pages 1 - 25

- (2013): The Timely Ethics of Posthumanist Gender Studies, in:

Feministische Studien 1/13, pages 7 - 12

. (2014): Imagining Posthumanities, Enlivening Feminisms, in:

Blaagaard, Bolette and Van der Tuin, Iris (eds.): The Subject of Rosi Braidotti, Bloomsburry, New York . and Johnson, Ericka (2009): Viagra Selfhood: Pharmaceutical Advertising and the Visual Formation of Swedish Masculinity, in: Health Care Analysis, Vol. 17, No. 1, pages $144-157$ and Lykke, Nina (2010): Editorial. Feminist technoscience studies, in: European Journal of Women's Studies, Vol. 17, No. 4, pages 299 305 
Asfour, Tamim and Azad, Pedram and Vahrenkamp, Nikolas and Regenstein, Kristian and Bierbaum, Alexander and Welke, Kai and Schröder, J. and Dillmann, Rüdiger (2007): Toward humanoid manipulation in human-centred environments, in: Robotics and Autonomous Systems, Vol. 56, pages $54-65$ and Welke, Kai and Azad, Pedram and Ude, Ales and Dillmann, Rüdiger (2008): The Karlsruhe Humanoid Head, in: Proceedings of the 8th IEEE-RAS International Conference on Humanoid Robots December 1 -3, 2008, Daejeon, Korea, pages 447 - 453

Barad, Karen (2003): Posthumanist Performativity. Toward an Understanding of How Matter Comes to Matter, in: Signs, Vol. 28, No. 3, pages $801-831$

. (2007): Meeting the Universe Halfway, Duke University Press, Durham

(2008): Queer Causation and the Ethics of Mattering, in: Giffney, Noreen and Hird, Myra J. (eds.): Queering the Non/Human, Ashgate Hampshire, pages $311-338$

. (2012a): On Touching - The Inhuman That Therefore I Am, in: differences: A Journal of Feminist Cultural Studies, Vol. 23, No. 3, pages 206-223

. with Dolphijn, Rick and Van der Tuin, Iris (2012b): Interview with Karen Barad, in: Dolphijn, Rick and Van der Tuin, Iris (eds.): New Materailism. Interviews \& Cartographies, Open Humanities Press, University of Michigan, MPublishing, pages $48-70$ . with Juelskjær, Malou and Schwennesen, Nette (2012c): Intra-Active Entanglements - An Interview with Karen Barad, in: Kvinder, Køn \& Forskning Nr. 1-2, pages $10-24$

Bath, Corinna (2009): De-Gendering informatischer Artefakte. Grundlagen einer kritisch-feministischen Technikgestaltung, Dissertation, Universität Bremen, http:/ / elib.suub.uni-bremen.de/edocs/00102741-1.pdf

Becker-Schmidt, Regina (2003): Zur doppelten Vergesellschaftung von Frauen. Soziologische Grundlegung, empirische Rekonstruktion, in: gender...politik...online, pages $1-18$, 
http:/ / www.fuberlin.de/sites/gpo/soz_eth/Geschlecht_als_Kat egorie/Die_doppelte_Vergesellschaftung_von_Frauen/becker_sc hmidt_ohne.pdf

Bekey, George and Ambrose, Robert and Kumar, Vijay and Lavery, David and Sanderson, Arthur and Wilcox, Brian and Yuh, Junku and Zheng, Yuan (2008): Introduction, in: idem: Robotics. State of the Art and Future Challenges, Imperial College Press, London, pages $1-10$

Bell, David (2007): Cyperculture Theorists. Manuell Castells and Donna Haraway, Routledge, New York

Benería, Lourdes (2008): The crisis of care, international migration, and public policy, in: Feminist Economics, Vol. 14, No. 3, pages 1-21

Berns, K. and Asfour, T. and Dillmann, R. (1999): ARMAR - An Anthropomorphic Arm for Humanoid Service Robot, in: Proceedings of the 1999 IEEE, International Conference on Robotics \& Automation, Detroit, Michigan, May 1999, pages 702 $-707$

Bhabha, Homi K. (1994): Of Mimicry and Man. The Ambivalence of Colonial Discourse, in: idem: The Location of Culture, Routledge, New York, pages 85-92

Bowker, Geoffrey (1993): How to be Universal. Some Cybernetic Strategies, 1943-70, in: Social Studies of Science, Vol. 23, pages 107 - 127 and Star, Susan Leigh (2000): Sorting things out. Classifications and its Consequences. MIT Press, Campridge, London

von Bose, Käthe and Treusch, Pat (2013): Von 'helfenden Händen' in Robotik und Krankenhaus. Zur Bedeutung einzelner Handgriffe in aktuellen Aushandlungen um Pflege, in: Feministische Studien Heft 2/ 2013, pages $253-266$

Braidotti, Rosi (2002): Metamorphoses. Towards A Materialist Theory Of Becoming, Polity Press, Cambridge. . (2006): Transpositions, Polity Press, Cambridge.

von Braun, Christina (2006): Gender, Geschlecht und Geschichte, in: idem and Stephan, Inge (eds.): Gender Studien. Eine Einführung, J.B. Metzler, Weimar, pages $10-51$ 
Brooks, Rodney (1991): Intelligence Without Reason, Artificial Intelligence Laboratory, A.I. Memo No. 1293,

http: / / people.csail.mit.edu/brooks / papers / AIM- 1293.pdf.

Butler, Judith (1991): Gender Trouble, Routledge, New York

. (1993): Bodies that Matter. On the Discursive Limits of "Sex",

Routledge, New York

(1994): Against Proper Objects. Introduction, in: differences. A

Journal of Feminist Cultural Studies, Vol. 6, No. 2, pages 1 - 26

(2002): Is Kinship Always Already Heterosexual?, in: differences. A

Journal of Feminist Cultural Studies, Vol. 13, No. 1, pages $14-44$ (2004): Undoing Gender. Routledge, New York

Caroll, Chris and Aguilera-Hellweg, Max (2011): Us. And them.Robots are being created that can think, act, and relate to humans. Are we ready?,

http:/ / ngm.nationalgeographic.com/2011/08/ robots/ carroll-

text

Castañeda, Claudia and Suchman, Lucy (2013): Robot Visions, in: Social Studies of Science, Vol. 43, No. 6, pages 1-27

Castro Varela, María do Mar and Dhawan, Nikita (2005): Postkoloniale Theorie. Eine kritische Einführung, Transcript, Bielefeld

Charmaz, Kathy (2006): Constructing Grounded Theory. A Practical Guide Through Qualitative Analysis, Sage, London

Clark, Andy (2001): Mindware. An Introduction to the Philosophy of Cognitive Science, Oxford University Press

Clarke, Adele E. (2005): Situational Analysis: Grounded Theory After the Postmodern Turn, Sage, London . and Star, Susan Leigh (2008): The Social Worlds Framework. A Theory/Methods Package, in: Hackett, Edward J. and Amsterdamska, Olga and Lynch, Michael and Wajcman, Judy (eds.): The Handbook of Science and Technology Studies, Third Edition, The MIT Press, Cambridge, London, pages 113 - 138

Clough, Patricia Ticineto and Halley, Jean (eds.) (2007): The Affective Turn. Theorizing the Social, Duke University Press, Durham

Cockburn, Cynthia and Ormrod, Susan (1993): Gender \& Technology in the Making, Sage, London, Thousand Oaks, New Dheli 
DB mobil, April 2010,

http://www.bahn.de/p/view/service/information/db_mobil.s html

Do, Martin and Schill, Julian and Ernesti, Johannes and Asfour, Tamim (2014):

Learn to Wipe: A Case Study of Structural Bootstrapping from Sensorimotor Experience, pages $1-7$, http:/ / h2t.anthropomatik.kit.edu/pdf/Do2014.pdf

Dolphijn, Rick and Van der Tuin, Iris (2012) (eds.): New Materialism. Interviews \& Cartographies, Open Humanities Press, University Michigan, MPublishing

Draude, Claude and Döring, Daniela (2012): Körper nach Zahlen. Vom Maßnehmen und der Simulation von Menschlichkeit, in: Bulletin Texte 38, pages $61-87$

Ertel, Wolfang (2011): Introduction to Artificial Intelligence, Springer, London

Ethington, Philip J. (2011): Sociovisual Perspective. Vision and the Forms of the Human Past, in: Stafford, Barbara Maria (ed.): A Field-Guide to a New Meta-Field. Bridging the Humanities-Neuroscience Divide, The University of Chicago Press, pages 123-152

Federici, Silvia (2012): Aufstand aus der Küche. Reproduktionsarbeit im globalen Kapitalismus und die unvollendete feministische Revolution, edition assemblage, Münster

Forsythe, Diane E. (2002): Studying Those Who Study Us. An Anthropologist in the World of Artificial Intelligence, Stanford University Press

Franchi, Stefano (2011): Life, Death, and Resurrection of the Homeostat, in: idem/Bianchini, Francesco (eds.): The Search for a Theory of Cognition. Early Mechanisms and New Ideas, Springer, pages 3 52, http:// cleinias.org/node/ 4

- and Güzeldere, Guven (2005): Machinations of the Mind. Cybernetics and Artificial Intelligence from Automata to Cyborgs, in: idem (eds.): Mechanical Bodies, Computational Minds. Artificial Intelligence from Automata to Cyborgs, MIT Press, Cambridge

Franklin, Sarah and Lury, Celia and Stacey, Jackie (eds.) (2000): Introduction, in: idem: Global Nature, Gobal Culture, Sage, London 
Fraser, Mariam (2006): The Ethics of Reality and Virtual Reality. Latour, facts and values, in: History of the Human Sciences, Vol. 19, No. 2, pages $45-72$

Gehrig, Dirk and Thorsten Stein and Andreas Fischer and Hermann Schwameder and Tanja Schultz (2010): Towards Semantic Segmentation of Human Motion Sequences, pages 1 - 8, http: / / csl.anthropomatik.kit.edu/downloads/gehrig_ki2010.pdf

Gehrig, Dirk and Krauthausen, Peter and Rybok, Lukas and Kuehne, Hildegard and Hanebeck, Uwe D. and Schultz, Tanja and Stiefelhagen, Rainer(2011): Combined Intention, Activity, and Motion Recognition for a Humanoid Household Robot, in: 2011 IEEE/RSJ International Conference on Intelligent Robots and Systems, September 25-30, San Francisco, USA, pages 4819 - 4825

Gieryn, Thomas F. (1983): Boundary-Work and the Demarcation of Science from Non-Science: Strains and Interests in Professional Ideologies of Scientists American Sociological Review, Vol. 48, No. 6, pages $781-795$

Giffney, Noreen and Hird, Myra J. (2008): Introduction. Queering the Non/Human, in: idem (eds.): Queering the Non/Human, Ashgate Hampshire, pages 1 - 16

Görz, Günter and Nebel, Bernhard (2003): Künstliche Intelligenz, S. Fischer, Frankfurt am Main

Gregg, Melissa and Seighworth, Gregory J. (eds.) (2010): The Affect Theory Reader, Duke University Press, Durham

Halberstam, Judith and Livinston, Ira (1995): Introduction: Posthuman Bodies, in: idem (eds.): Posthuman Bodies, Indiana University Press, Bloomington, pages 1 - 19

Hagner, Michael and Hörl, Erich (2008): Die Transformation des Humanen. Beiträge zur Kulturgeschichte der Kybernetik, Suhrkamp, Frankfurt

Haraway, Donna J. (1991): Simians, Cyborgs, and Women. The Reinvention of Nature, Routledge, New York

- (1992): The Promises of Monsters. A Regenerative Politics for Inappropriate/d Others, in: Grossberg, Lawrence and Nelson, 
Cary and Treichler, Paula A. (eds.): Cultural Studies, Routledge, New York, pages $295-337$

(1994): A Game of Cat's Cradle: Science Studies, Feminist Theory,

Cultural Studies, in: Configurations, Vol. 2, No. 1, pages $59-71$ (1997): Modest_witness@second_millennium. Femaleman@_meets_ oncomouse TM. Feminism and Technoscience, Routledge, New York and Goodeve, Thyrza Nichols (2000): How Like a Leaf. An Interview with Donna Haraway, Routlegde, New York

. (2003a): The Companion Species Manifesto. Dogs, People, and Significant Otherness, Prickly Paradigm Press, Chicago . (2003b): Cyborgs to Companion Species. Reconfiguring Kinship in Technoscience, in: Ihde, Don and Selinger, Evan (eds.): Chasing Technoscience. Matrix for Materiality, Indiana University Press, Bloomington

(2008): Foreword. Companion Species, Mis-Recognition, and Queer Worlding, in: Giffney, Noreen/Hird, Myra J. (eds.): Queering the Non/Human, Ashgate Hampshire, pages xxiiv - xxvi

Hark, Sabine (2004): Queering oder Passing: Queer Theory eine normale Disziplin?, in: Steffen, Therese Frey/Rosenthal, Caroline/Väth, Anke (eds.): Gender Studies. Wissenschaftstheorien und Gesellschaftskritik, Königshausen \& Neumann, Würzburg, pages $67-82$

(2007): Transformationen von Wissen, Mensch und Geschlecht.

Geschlechterforschung als kritische Ontologie der Gegenwart, in: idem and Dölling, Irene and Dornhof, Dorothea and Esders, Karin and Genschel, Corinna (eds.): Transformationen von Wissen, Mensch und Geschlecht. Transdisziplinäre Interventionen, Ulrike Helmer Verlag, Königstein/Taunus, pages $9-24$

. (2009): Was ist und wozu Kritik? Über Möglichkeiten und Grenzen feministischer Kritik heute, in: Feministische Studien 27/1, pages $22-35$

. and Laufenberg, Mike (2013): Sexualität in der Krise. Heteronormativität im Neoliberalismus, in: Appelt, Erna and 
Aulenbacher, Brigitte and Wetterer, Angelika (eds.): Gesellschaft.

Feministische Krisendiagnosen, Westfälisches Dampfboot, Münster, pages 227 - 245

Hartsock, Nancy C. M. (1987): The Feminist Standpoint: Developing the Ground for a Specifically Feminist Historical Materialism, in: Harding, Sandra (ed.): Feminism and Methodology, Indiana University Press, Bloomington, pages 157 - 180

Hayles, Katherine N. (1994): Boundary Disputes. Homeostasis, Reflexivity, and the Foundations of Cybernetics, in: Configurations 2.3, pages $441-467$

. (1999): How We Became Posthuman. University of Chicago Press, Chicago

Hemmings, Clare (2005): Invoking Affect. Cultural Theory and the Ontological Turn, in: Cultural Studies, Vol. 19, No. 5, pages $548-$ 567

Hinton, Peta (2013): The Quantum Dance and the World's 'Extraordinary Liveliness'. Refiguring Corporeal Ethics in Karen Barad's Agential Realism, in: Somatechnics, Vol. 3, No. 1, pages 169 - 189 (2014): 'Situated Knowledges' and New Materialism(s). Rethinking a

Politics of Location, in: Women. A Cultural Review, Vol. 25, No. 1, pages $99-113$

Hinton, Peta and Treusch, Pat (2015): Teaching with Feminist Materialisms, AtGender book series, De Lekstroom Griffioen, Nieuwegein

Hird, Myra J. (2009): Feminist Engagements with Matter, in: Feminist Studies, Vol. 35, No. 2, pages $329-346$ and Roberts, Celia (2011): Feminism theorises the nonhuman, in: Feminist Theory, Vol. 12, No. 2, pages $109-117$

Hochschild, Arlie Russell (2000): Global Care Chains and Emotional Surplus Value, in: Hutton, W. and Giddens, A. (eds.): On the Edge. Living with Global Capitalism, Jonathan Cape, London, pages 130 - 146

Hoel, Aud Sissel and Van der Tuin, Iris (2012): The Ontological Force of Technicity. Reading Cassirer and Simondon Diffractively, in: Philosophy \& Technology, Vol. 26, No. 2, pages 187 - 202

Honegger, Claudia (2011): Die kognitiven Prinzipien der neuen Wissenschaften vom Menschen und die Genese einer weiblichen 
Sonderanthropologie in Frankreich, in: Theresa Wobbe and Isabelle Berrebi-Hoffmann and Michel Lallemeent (eds.): Die gesellschaftliche Verortung des Geschlechts. Diskurse der Differenzen in der deutschen und französischen Soziologie um 1900, Campus, Frankfurt am Main, pages 93 - 113

Howe, David P. (2011): Cyborg and Supercrip: The Paralympics Technology and the (Dis)empowerment of Disabled Athletes, in: Sociology, Vol. 45, No. 5, pages $868-882$

Ichbiah, Daniel (2005): Roboter. Geschichte - Technik - Entwicklung, Knesebeck, München

Jasanoff, Sheila (2015): Future Imperfect: Science, Technology, and the Imaginations of Modernity, in: idem and Kim, Sang-Hyun: Dreamscapes of Modernity. Sociotechnical Imaginaries and the Fabrication of Power, University of Chicago Press, http: / / www.harvardiglp.org/wp-content/ uploads/2014/10/ Jasanoff-Ch-1.pdf and Kim, Sang-Hyun (2009): Containing the Atom: Sociotechnical Imaginaries and Nuclear Power in the United States and South Korea, in: Minerva, Vol. 47, No. 2, pages 119 - 146

Johnston, John (2008): The Allure of Machinic Life. Cybernetics, Artificial Life, and the New AI, The MIT Press, Cambridge

Keller, Evelyn Fox (2002): Marrying the Premodern to the Postmodern. Computers and Organisms after WWII, in: Tofts, Darren and Jonson, Annemarie and Cavallaro, Alessio (eds.): Prefiguring Cyberculture. An Intellectual History, The MIT Press, Cambridge, pages $52-65$

Kember, Sarah (2003): Cyberfeminism and Artificial Life, Routledge, New York

Kirby, Vicky (2011): Quantum Anthropologies. Life at Large, Duke University Press, Durham . and Wilson, Elizabeth A. (2011): Feminist conversations with Vicki Kirby and Elizabeth A. Wilson, in: Feminist Theory, Vol. 12, No. 2, pages $227-234$ 
Kirkup, Gil (2000): Introduction to Part One, in: idem and Janes, Linda and Woodward, Kathryn and Hovenden, Fiona (eds.): The Gendered Cyborg, Routledge, New York, pages 3 - 10

Kling, Rob and Star, Susan Leigh (1998): Human Centered Systems in the

Perspective of Organizational and Social Informatics, in:

Computers and Society, Vol. 28, No. 1, pages $22-29$

Knorr-Cetina, Karin D. (1981): The Manufacture of Knowledge: An Essay on the Constructivist and Contextual Nature of Science, Oxford, Pergamon Press

(1995): How Superorganisms Change: Consensus Formation and the

Social Ontology of High-Energy Physics Experiments, Social Studies of Science, Vol. 25, No. 1, pages $119-47$

Latour, Bruno (1988): The Pasteurization of France. Harvard University Press (2004): Why Has Critique Run out of Steam? From Matters of Fact to

Matters of Concern, in: Critical Inquiry, No. 30, pages 225 - 248 and Woolgar, Steve (1979): Laboratory Life: The Construction of

Scientific Facts, Sage, London

Law, John (2003): Making a Mess with Method, published by the Centre for Science Studies, Lancaster LA14YN, UK, http:/ / www.comp.lancs.ac.uk/ sociology/ papers/Law-Makinga-Mess-with-Method.pdf (2004): After Method. Mess in Social Science Research, Routledge, London (2009): Actor Network Theory and Material Semiotics, in: Turner, Bryan S. (ed.): The New Blackwell Companion to Social Theory, Blackwell, Oxford, pages $141-156$

Licklider, J.C.R. (1960): Man-Computer Symbiosis, in: IRE Transactions on Human Factors in electronics, Vol. HFE-1, pages 4 - 11, http:/ / groups.csail.mit.edu/medg/ people/psz/Licklider.html

Lindström, Catharina (2007): Queering Feminist Technology Studies, in: Feminist Theory, Vol. 8, No. 7, pages $7-26$

Lutz, Helma (2002): In fremden Diensten. Die neue Dienstmädchenfrage in Europa als Herausforderung für die Migrations- und Geschlechterforschung, in: Gottschall, Karin and Pfau-Effinger, 
Birgit (eds.): Zukunft der Arbeit und Geschlecht, Leske und Budrich, Opladen, pages $161-182$

Lykke, Nina (2008): Feminist Cultural Studies of Technoscience. Portrait of an Implosion, in: Smelik, Anneke/idem (eds.): Bits of Life. Feminism at the Intersections of Media, Bioscience, and Technology, University of Washington Press, Seattle, pages 3-15

(2010): Feminist Studies. A Guide to Intersectional Theory, Methodology and Writing, Routledge, New York

Mac Kenzie, Daniel and Wajcman, Judy (1999): Introductory Essay. The Social Shaping of Technology, 2nd Ed, in: idem (eds.): The Social Shaping of Technology, Open University Press, Buckingham, pages $3-27$

MacLure, Maggie (2013): Researching without representation? Language and materiality in post-qualitative methodology,in: International Journal of Qualitative Studies in Education, Vol. 26, No. 6, pages $658-667$

Meißner, Hanna (2010): Jenseits des autonomen Subjekts. Zur gesellschaftlichen Konstitution von Handlungsfähigkeit im Anschluss an Butler, Foucault und Marx, Transcript, Bielefeld (2013): Feministische Gesellschaftskritik als onto-epistemo-logisches Projekt, in: Bath, Corinna and idem and Trinkaus, Stephan and Völker, Susanne: Geschlechter Interferenzen: Wissensformen Subjektivierungsweisen - Materialisierungen, LIT, Münster, pages 163 - 208

Meuser, Michael and Nagel, Ulrike (2004): ExpertInneninterview: zur Rekonstruktion spezialisierten Sonderwissens, in: Becker, Ruth and Kortendiek, Beate (eds.): Handbuch Frauen- und Geschlechterforschung: Theorie, Methoden, Empirie. VS Verlag, Wiesbaden, pages $326-329$

Mokyr, Joel (1998): The Second Industrial Revolution 1870-1914, in: Storia dell'economia Mondiale, pages 219 - 245, http: / / faculty.wcas.northwestern.edu/ jmokyr / castronovo.pdf

Nelkin, Dorothy (1995): Selling Science: How the Press Covers Science and Technology W.H.Freeman \& Co Ltd., Gordonsville, Virginia 
Orland, Barbara and Böttger, Barbara and Ketschau, Irmhild and Langguth, Frauke (1991): HaushaltstRäume, Langewiesche, Königstein

Pham-Huu, Tu-Mai (2011): Humanoide Roboter lernen, Komplexes zu meistern, in: In the Name of Man. Anthropomatics and Robotics, LOOKKIT, No. 2, page 16

Pickering, Andrew (1995): The Mangle of Practice: Time, Agency, and Science, University of Chicago Press (2002): Cybernetics and the Mangle. Ashby, Beer and Pask Social Studies of Science, Vol. 32, No. 3, pages 413 - 437

Pickering, Andrew (2010): The Cybernetic Brain, University of Chicago Press, Chicago

Puar, Jasbir (2011): "Ich wäre lieber eine Cyborg als eine Göttin." Intersektionalität, Assemblage und Affektpolitik, http: / / eipcp.net/transversal/0811/puar/ de

Puig de la Bellacasa, Maria (2009): Touching Technologies, Touching Visions. The Reclaiming of Sensorial Experience and the Politics of Speculative Thinking, in: Subjectivity, Vol. 28, No.1, pages 297 315

(2010): Matters of Care in Technoscience. Assembling Neglected Things, in: Social Studies of Science, Vol. 41, No. 1, pages $85-106$

(2012): 'Nothing comes without its world'. Thinking with Care, in: The Sociological Review, Vol. 60, No. 2, pages 197 - 216

Regenstein, Kristian (2010): Modulare, verteilte Hardware-SoftwareArchitektur für humanoide Roboter, KIT Scientific Publishing, Karlsruhe

Rich, Adrienne (1980): Compulsory Heterosexuality and Lesbian Existence, Onlywomen Press Ltd.

Riskin, Jessica (2007): Introduction: The Sistine Gap, in: idem (ed.): Genesis Redux. Essays in the History and Philosophy of Artificial Life, University of Chicago Press, Chicago, pages 1 - 34

Robertson, Jennifer (2010): Gendering Humanoid Robots: Robo-Sexism in Japan, in: Body \& Society, Vol. 16, No. 2, pages 1 - 36 
Sandelowski, Margarete (1999): Troubling Distinctions. A Semiotics of the Nursing/Technology Relationship, in: Nursing Inquiry, No. 6, pages $198-207$

Schaal, Stefan (2007): The New Robotics-towards human-centered machines, in: HFSP Journal, Vol. 1, No. 2, pages 115 - 126

Schiebinger, Londa ([1993] 2004): Nature's Body, Rutgers University Press Schwarz Cowan, Ruth (1983): More Work for Mother, Basic Books, New York Sedgwick, Eve Kosofsky and Frank, Adam (2003): Shame in the Cybernetic Fold. Reading Silvan Tomkins, in: Sedgwick, Eve Kosofsky: Touching Feeling. Affect, Pedagogy, Performativity, Duke University Press, Durham, pages 93 - 121

Shapin, Steven and Schaffer, Simon (1985): Leviathan and the Air-Pump. Hobbes, Boyle, and the Experimental Life, Princeton University Press

Shildrick, Margrit (2002): Embodying the Monster. Encounters with the Vulnerable Self, Sage, London

(2009): Dangerous Discourses of Disability, Subjectivity and Sexuality, Palgrave Macmillan, Hampshire

Simonidis, C. and Gärtner, Stefan and Do, Martin (2009): Spezifikationen zu den Ganzkörpermenschmodellen im SFB 588, https: / / his.anthropomatik.kit.edu/21_622.php

Smith, Wally (2009): Theatre of Use. A Frame Analysis of Information Technology Demonstrations, in: Social Studies of Science, Vol. 39, No. 3, pages $449-480$

Sofoulis, Zoë (2003): Cyberquake. Haraway's Manifesto, in: Tofts, Darren and Jonson, Annemarie and Cavallaro, Alessio (eds.): Prefiguring Cyberculture. An Intellectual History, The MIT Press, Cambridge, pages $84-103$

Stacey, Jackie and Suchman, Lucy (2012): Animation and Automation - The Liveliness and Labours of Bodies and Machines, Body \& Society, Vol. 18, No. 1, pages $1-46$

Star, Susan Leigh (1999): The Ethnography of Infrastructure, in: American Behavioral Scientist, Vol. 43, No. 3, pages 377 - 391 . and Griesemer, James R. (1989): Institutional Ecology, 'Translations' and Boundary Objects: Amateurs and Professionals in Berkeley's 
Museum of Vertebrate Zoology, Social Studies of Science, Vol. 19, No. 4, 1989, pages 387 - 420

and Ruhleder, Karen (1996): Steps Toward an Ecology of Infrastructure. Design and Access for Large Information Spaces, in: Information Systems Research, Vol. 7, No. 1, pages 11 - 134

Stengers, Isabelle (1997): Power and Invention. Situating Science, University of Minnesota Press . (2000): Invention of Modern Science, University of Minnesota Press

Stiefelhagen, Rainer and Ekenel, Hazim Kemal and Fügen, Christian and Giselmann, Petra and Holzapfel, Hartwig and Kraft, Florian and Nickel, Kai and Voit, Michael and Waibel, Alex (2007): Enabling Multimodal Human-Robot Interaction for the Karlsruhe Humanoid Robot, in: IEE Transactions on Robotics. Special Issue on Human-Robot Interaction, http:/ / www.projekt-w2.de/petra/TRO_A06402R_Stiefelhagen EtAl_InPress.pdf

Strassmann, Burkhard (2012): Die Roboter kommen. In der Fabrik, im Pflegeheim und auf der Straße drängen mobile Blechkollegen in unseren Alltag. Lassen die Helfer ihre Kraft spielen, kann das schmerzhaft enden. In: Die Zeit, No. 4, January 2012, http: / / www.zeit.de/2012/04/T-Roboter

Suchman, Lucy (2007): Human-Machine Reconfigurations. Plans and Situated Actions, 2nd Edition, Cambridge University Press, New York . (2008): Feminist STS and the Science of the Artificial, in: Hackett, Edward J. and Amsterdamska, Olga and Lynch, Michael and Wajcman, Judy (eds.): The Handbook of Science and Technology Studies, Third Edition, The MIT Press, Cambridge, pages 139 164

. (2011): Subject Objects, in: Feminist Theory, Vol. 12, No. 2, pages 119 $-145$

. and Randall Trigg and Jeanette Blomberg (2002): Working artefacts: ethnomethods of the prototype, in: British Journal of Sociology, Vol. 53, No. 2, pages $163-179$ 
Terry, Jennifer and Jaqueline Urla (eds.) (1995): Deviant Bodies. Critical Perspectives on Difference in Science and Popular Culture, Indiana University Press, Bloomington

Traweek, Sharon ([1988] 1992): Beamtimes and Lifetimes: The World of High Energy Physicists, paperback edition, Harvard University Press, Cambridge

Turkle, Sherry (2005): The Second Self. Computers and the Human Spirit, Twentieth Anniversary Edition, MIT Press, Cambridge

Van der Tuin, Iris (2011): Review Essay 'New Feminist Materialisms', in:

Women's Studies International Forum, Vol. 34, pages 271 - 277

Wajcman, Judy (2000): Reflections on Gender and Technology Studies. In

What State is the Art?, in: Social Studies of Science, Vol. 30, No.

3, pages $447-464$ (2004): TechnoFeminism, Polity Press, Cambridge

Warner, Michael (1991): Introduction: Fear of a Queer Planet, in: Social Text, No. 29, pages $3-17$

Warwick, Kevin (2008): Cybernetic Enhancements, in: Zonneveld, Leo and Dijstelbloem, Huub and Ringoir, Danielle (eds.): Reshaping the Human Condition. Exploring Human Nehancement, Rathenau Institute, The Hague, pages 123 - 131

Weber, Jutta (2014): Opacity versus Computational Reflection. Modelling Human-Robot Interaction in Personal Service Robotics, in: Science, Technology \& Innovation Studies, Vol. 10, No. 1, pages 187 - 199

and Bath, Corinna (2007): 'Social' Robots \& 'Emotional' Software Agents. Gendering Processes and De-Gendering Strategies for 'Technologies in the Making', in: Zorn, Isabel and Maass, Susanne and Schirmer, Carola and Rommes, Els and Schelhowe, Heidi (eds.): Gender Designs IT. Construction and Deconstruction of Information, Society Technology, VS Verlag, Wiesbaden, pages 53 $-63$

Welke, Kai and Tamim Asfour and Rüdiger Dillmann (2009): Active MultiView Object Search on a Humanoid Head, in: 2009 IEEE International Conference on Robotics and Automation, Kobe 
International Conference Center, Kobe, Japan, May 12-17, 2009, pages $417-423$

Werner, Tino and Kargov, Artem and Gaiser, Immanuel and Bierbaum,

Alexander and Schill, Julian and Schulz, Stefan (2010): Eine fluidisch angetriebene anthropomorphe Roboterhand, in: Automatisierungstechnik 01/2010, No. 58, pages $681-687$

Wilson, Elizabeth (2003): Imaginable Computers. Affects and Intelligence in Alan Turing, in: Tofts, Darren and Jonson, Annemarie and Cavallaro, Alessio (eds.): Prefiguring Cyberculture. An Intellectual History, The MIT Press, Cambridge, pages 38 - 51 . (2010): Affect and Artificial Intelligence, University of Washington Press, Seattle

WIRED, No. 1, January 2013, http: / / www.wired.com/

Wirtz, Mica (2012): Mein Bauch gehört mir? Zur politischen Regulierung des Körpergewichts, in: Sänger, Eva and Rödel, Malaika (eds.): Biopolitik und Geschlecht, Westfälisches Dampfboot, Münster, pages 176 - 199

Yeasin, Mohammed and Sharma, Rajeev (2005): Foveated Vision Sensor and Image Processing - A Review, in: Studies in Computational Intelligence, No. 7, pages $57-98$

Yeates, Nicola (2004): Global Care Chains, in: International Feminist Journal of Politics, Vol. 6, No. 3, pages $369-391$ 


\section{List of Figures}

\section{Chapter 3}

page 62: Screen-shot of the "Tagesthemen", a German news broadcast; http: / / www.ardmediathek.de/tv / Tagesthemen/Sendung?documentId=391; 27.11.2010 page 67: Armar in the Kitchen Laboratory, shot by PT, July 2011

\section{Chapter 4}

pages 116 - 136: Photos shot by PT in July 2011 and 2012; altered with the App “U-Sketch"; https: / /itunes.apple.com/de/app/ usketch/id499835615?mt=12 